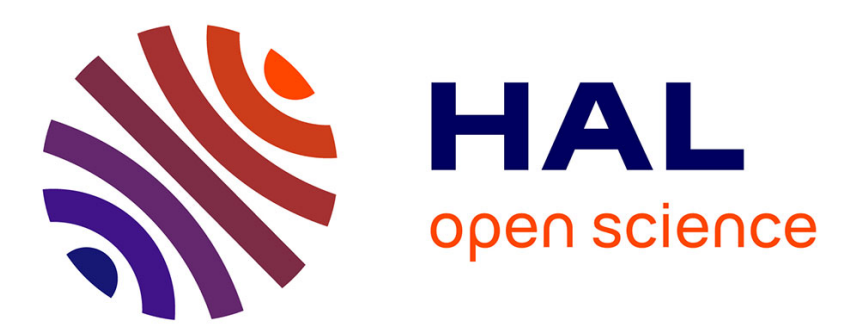

\title{
Opportunities and Challenges for Organic Electrodes in Electrochemical Energy Storage
}

Philippe Poizot, Joël Gaubicher, Stéven Renault, Lionel Dubois, Yanliang Liang, Yan Yao

\section{> To cite this version:}

Philippe Poizot, Joël Gaubicher, Stéven Renault, Lionel Dubois, Yanliang Liang, et al.. Opportunities and Challenges for Organic Electrodes in Electrochemical Energy Storage. Chemical Reviews, 2020, 120, pp.6490 - 6557. 10.1021/acs.chemrev.9b00482 . hal-02553542

HAL Id: hal-02553542

https://hal.science/hal-02553542

Submitted on 27 Nov 2020

HAL is a multi-disciplinary open access archive for the deposit and dissemination of scientific research documents, whether they are published or not. The documents may come from teaching and research institutions in France or abroad, or from public or private research centers.
L'archive ouverte pluridisciplinaire HAL, est destinée au dépôt et à la diffusion de documents scientifiques de niveau recherche, publiés ou non, émanant des établissements d'enseignement et de recherche français ou étrangers, des laboratoires publics ou privés. 


\title{
Opportunities and Challenges for Organic Electrodes in Electrochemical Energy Storage
}

\author{
3 Philippe Poizot,* Joël Gaubicher, Stéven Renault, Lionel Dubois, Yanliang Liang, and Yan Yao
}

Cite This: https://dx.doi.org/10.1021/acs.chemrev.9b00482

Read Online

4 ABSTRACT: As the world moves toward electromobility and a concomitant decarbon5 ization of its electrical supply, modern society is also entering a so-called fourth industrial 6 revolution marked by a boom of electronic devices and digital technologies. Consequently, 7 battery demand has exploded along with the need for ores and metals to fabricate them. 8 Starting from such a critical analysis and integrating robust structural data, this review aims 9 at pointing out there is room to promote organic-based electrochemical energy storage. 10 Combined with recycling solutions, redox-active organic species could decrease the pressure 11 on inorganic compounds and offer valid options in terms of environmental footprint and 12 possible disruptive chemistries to meet the energy storage needs of both today and tomorrow. 13 We review state-of-the-art developments in organic batteries, current challenges, and prospects, 14 and we discuss the fundamental principles that govern the reversible chemistry of organic 15 structures. We provide a comprehensive overview of all reported cell configurations that involve

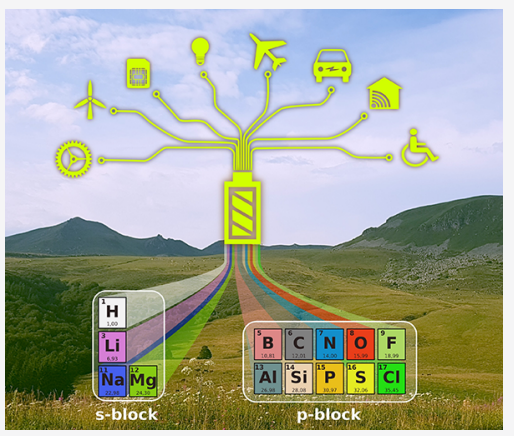
16 electroactive organic compounds working either in the solid state or in solution for aqueous or nonaqueous electrolytes. These 17 configurations include alkali $(\mathrm{Li} / \mathrm{Na} / \mathrm{K})$ and multivalent $(\mathrm{Mg}, \mathrm{Zn})$-based electrolytes for conventional "sealed" batteries and redox-flow 18 systems. We also highlight the most promising systems based on such various chemistries relying on appropriate metrics such as 19 operation voltage, specific capacity, specific energy, or cycle life to assess the performances of electrodes.

\section{CONTENTS}

22 1. Introduction

1.1. Current Status in Electrochemical Energy Storage in Short

1.2. Rise of Organics for Electrochemical Energy Storage

1.3. Goal, Scope, and Organization of This Review

2. Fourth Industrial Revolution: Batteries at the Crossroads

2.1. Background

2.2. Decarbonizing the Power Supply and Its Related Storage Challenges

2.3. Decarbonizing the Transportation Sector Through the Electrification Scheme

2.4. Digitalization and Growing Consumption of Electronic Devices

2.5. Summary

3. Material Supply for Electrochemical Storage: Resource Constraints Issues, Environmental Burden, and Opportunities Provided by Organic Electrode Materials

3.1. Resource Constraints Forecast in Conventional Material Supply

3.2. Sustainability and Environmental Aspects

3.3. Positioning Redox-Active Organic Species in the Battery Landscape
4. Fundamentals of Organic Electrode Compounds for Electrochemical Storage

4.1. Basics of Electrochemical Cells

4.2. Bridging the Gap between Inorganic and Organic Redox Chemistry

4.3. Reversible Organic Redox Chemistry and Cell Configurations

5. Performances of Nonaqueous Lithium-Organic Batteries

5.1. Positioning the Operation Voltage

5.2. Organic Electrode Materials with High Specific Capacity

5.3. Organic Electrode Materials with Long Cycle Life

6. Performances of Nonaqueous Sodium-Organic Batteries

6.1. High/Low Voltage Organic Electrode Materials and Hybrid/All-Organic High Output Voltage Na-lon Batteries

6.2. Organic Electrode Materials with High Specific Capacity

$\mathrm{H}$

Received: July 30, 2019 
118 Notes

119 Biographies

120 Acknowledgments
121 References

\section{INTRODUCTION}

\subsection{Current Status in Electrochemical Energy Storage in} 122 Short

123 The need to build innovative electrochemical energy storage 124 (EES) technologies and conversion solutions is now recog125 nized to be particularly critical not only by specialists in the 126 field but also by ordinary consumers eager to use different nomadic electronic devices which make their life easier, safer, 127 and more enjoyable. Representative devices of EES are 128 rechargeable (or secondary) batteries and (super)capacitors. 129 Chemists, electrochemists, and materials science researchers 130 helped by theoreticians (see for example the Materials Genome 131 Project launched by G. Ceder ${ }^{1}$ ) have already thoroughly 132 screened the periodic table of the elements in the quest to find 133 the best electrode associations essentially focused on increased 134 gravimetric and volumetric energy densities while improving 135 the safety, power, lifetime, and cost. Thus, decades of intensive 136 and innovative research have enabled us to develop and to 137 place on the market different kinds of primary and secondary 138 batteries able to power an increasingly diverse kind of appli- 139 cations from microchips to the emerging large-scale application 140 markets. ${ }^{2}$ Without describing them one by one, it must be 141 underlined that the pioneered lead-acid ( $\mathrm{PbA}$ ) battery devised 142 by G. Planté in 1859 is still in growing demand because it is 143 unrivalled for microhybrid and internal combustion vehicles 144 or large-scale power storage units (load-leveling applications, 145 uninterrupted power supply (UPS) for entire cities) at this 146 time; this technology is also robust, safe, and affordable 147 associated with efficient recycling and disposal management 148 programs notably to prevent lead emission. ${ }^{3}$ Regarding Li-ion 149 batteries (LIBs) - the current flagship technology to get high 150 energy densities-thanks to substantial improvements and 151 notably the discovery of new insertion positive electrode materials 152 (e.g., $\mathrm{LiFePO}_{4}, \mathrm{LFP} ; \mathrm{Li}\left(\mathrm{Ni}_{1 / 2-x} \mathrm{Mn}_{1 / 2-x} \mathrm{Co}_{2 x}\right) \mathrm{O}_{2}, \mathrm{NMC}$; Li-rich 153 layered oxides $\left.\mathrm{Li}\left(\mathrm{Li}_{x} \mathrm{M}_{1-x}\right) \mathrm{O}_{2}\right)$, they have become essential to 154 power the vast world of electronic equipment, robots, ongoing 155 electric transportation technologies, and some stationary 156 applications too. Consequently, nickel/metal hydride (Ni/ 157 $\mathrm{MH}$ ) rechargeable batteries, which have fully replaced nickel/ 158 cadmium $(\mathrm{Ni} / \mathrm{Cd})$ cells, are struggling to compete with LIBs 159 in the light of recent achieved progress including at the price 160 level. For the moment, Ni-MH batteries still power more than 161 10 million hybrid electric vehicles, and companies like BASF- 162 Ovonic maintain their R\&D activities. ${ }^{4}$ Redox flow batteries 163 (RFBs) represent another promising choice for stationary 164 energy storage because this particular cell configuration 165 operating basically with redox-active solutions is more durable 166 and scalable than conventional "sealed" battery systems 167 working with solid state electrode materials. The major plants 168 ever built to date are essentially based on the vanadium/ 169 vanadium redox flow battery technology $(\mathrm{VRFB})^{5}$ first 170 patented and developed by Skyllas-Kazacos in Australia in 171 the mid 80s. ${ }^{6-8}$ This rapid survey shows that all commercially 172 available electrochemical storage solutions deal with redox- 173 active inorganic systems, which poses now more than ever 174 certain problems in terms of metal resource constraints, pro- 175 duction cost, and environmental footprint in view of the ever 176 growing demand.

\subsection{Rise of Organics for Electrochemical Energy Storage}

For several reasons, which will be thoroughly explained later, it 178 is now recognized that searching for organic matter-based 179 electrodes could bring new chemical opportunities to further 180 improve existing EES technologies while opening new play- 181 grounds to create innovative cell configurations. Thus, over the 182 last ten years, tremendous progress has been made to promote 183 electroactive organic systems attracting much interest from 184 the broad electrochemical storage community. This occurs to 185 such an extent that today we are witnessing a considerable 186 increase in the literature on the subject, ranging from 187 
188 nonaqueous/aqueous RFBs to nonaqueous/aqueous "sealed" 189 batteries including both organic polymers and crystallized 190 organic compounds as will be developed in this article. In only 191 ten years, more than 45 review papers have been published for 192 which the scope was initially broad but in view of the booming 193 of primary research papers due to the versatility of the organic 194 synthesis and molecular engineering. The most recent reviews 195 are now focused on thematic research areas although it should 196 be recognized that some of them overlap. In the following list 197 sorted by year, the reader can find the series of review papers 198 on organic-based EES published since 2012 including notably 199 several remarkable contributions of both Chen's group at Nankai 200 University and Schubert's group at Friedrich Schiller University: $2012012,{ }^{9,10} 2013,{ }^{11,12} 2015,^{13-15} 2016,{ }^{16-27} 2017,^{28-35} 2018,^{36-46}$ 202 2019. ${ }^{47-58}$

203 Basically, before 2011 the literature on the topic was clearly 204 limited. The reference review article dealing with organic 205 electrodes in this period was published by Novák et al. in $2061997^{59}$ on the basis of the existing literature focused at that 207 time only on conducting polymers following the discovery 208 of polyacetylene (PAc) by Shirakawa in $1974^{60}$ and its 209 subsequent chemical "p- or n-doping" (see section 4.3) to give 210 a series of semiconductors and ultimately "organic metals" 211 thanks to overlap of adjacent $\pi$-orbitals. ${ }^{61-64} \mathrm{~A}$ few years later, 212 the possible use of PAc as electrode material to store electricity 213 was readily demonstrated by MacDiarmid taking advantage of 214 both p- or n-doping. ${ }^{65,66}$ Channels were opened to develop 215 other conjugated polymers such as polyaniline (PAni), polypyrrole 216 (PPy), or polythiophene (PT), which were particularly 217 explored in the 80 s as positive electrode materials in "dual218 ion cell configurations" (see section 4.3) using metals or alloys 219 as the negative electrode (e.g., lithium $(\mathrm{Li})$, sodium $(\mathrm{Na})$, or 220 the stoichiometric lithium-aluminum alloy (LiAl)), which led 221 to the first practical polymer batteries with the commercializa222 tion of two types of metal-organic dual-ion cells by Varta 223 Corp. (with PPy) and Bridgestone Corp. (with PAni). ${ }^{67-69}$ 224 Note that for the discovery and the development of conductive 225 polymers, Alan G. MacDiarmid, Alan J. Heeger, and Hideki 226 Shirakawa were awarded the 2000 Nobel Prize in Chemistry. 227 However, shorter cycle life ( $\sim 50$ cycles), higher self-discharge 228 values, and limited volumetric energy densities compared to the 229 newcomer LIB commercialized by Sony Corp. in 1991 were 230 some of the reasons for the abandonment at the end of the 20th 231 century of efforts to make organic batteries from conjugated 232 polymers. Note that in the 1990s organosulfur polymers were 233 also investigated in $\mathrm{Li}$ batteries but as "n-type" electrode 234 materials for which reversible $\mathrm{Li}^{+}$uptake/release reactions take 235 place. Indeed, among the myriad of possible molecular organic 236 arrangements, sulfur atoms can also be linked onto a carbon 237 backbone $(-\mathrm{C}-\mathrm{S}-\mathrm{S}-\mathrm{C}-$ ) allowing the use of the redox238 active disulfide bond; the charge transfer reaction involves 2 239 electrons together with the cleavage of the $S-S$ bond. Pioneering 240 research was performed by Visco and co-workers ${ }^{70-72}$ with a 241 survey of diverse groups of organodisulfide as positive electrode 242 materials essentially main-chain type organosulfur polymers. 243 For example, 2,5-dimercapto-1,3,4-thiadiazole (DMcT) with a 244 theoretical specific capacity as high as $362 \mathrm{mAh} \mathrm{g}^{-1}$ is one 245 of the best well-known organosulfur compounds. However, 246 such electrode materials are generally impeded by sluggish 247 kinetics along with a large polarization as well as solubility 248 issues stemming from the repeated scission/reconstruction of 249 disulfide bonds. Better results were obtained with side-chain 250 type organodisulfide polymer such as poly $\left(2,2^{\prime}\right.$-dithiodianiline $)$
(PDTDA) and other related derivatives, but long-lasting cyclings 251 were never attempted. ${ }^{73}$ Note that in the quest to develop 252 lithium-sulfur ( $\mathrm{Li}-\mathrm{S}$ ) batteries while limiting the polysulfide 253 shuttle, high sulfur content organic materials have been recently 254 investigated such as a new cross-linked disulfide material 255 $\mathrm{C}_{6}(\mathrm{SLi})_{6}$ developed by Wudl's group but the restored specific 256 capacity is still limited with $1 / 4$ of the theoretical value. ${ }^{74} \quad 257$

A new class of polymers (nonconjugated) able to store 258 electric energy and consisting of a stable organic polymeric 259 chain bearing stabilized nitroxyl radicals such as 2,2,6,6-260 tetramethylpiperidinyl- $N$-oxy (TEMPO) radicals emerged in 261 the early 2000s thanks to joint efforts of NEC Corp. and 262 Nishide's group in Japan. ${ }^{75-77}$ These studies have led to the 263 development of the so-called organic radical batteries (ORBs) 264 which are characterized by excellent rate performance, a 265 flexible design, but moderate energy density values due to the 266 adding of high amounts of conductive carbon in electrodes. 267 The achievement of robust $0.3 \mathrm{~mm}$-thick ORB prototypes 268 compatible with functional smart card and wearable devices 269 was, however, announced by NEC Corp. as early as $2012 .^{78} 270$ This innovative chemistry coupled with the emergence of 271 promising high-capacity organic compounds characterized by 272 multiple electroactive carbonyl $(\mathrm{C}=\mathrm{O})$ functional groups ${ }^{79-83} 273$ (a redox-active moiety encountered in the chemistry of life and 274 numerous natural substances) enabled the publication of a 275 broader review in 2011 focused this time on the perspectives of 276 organic batteries in addressing some eco-development issues 277 through the possibility of integrating the concept of "renew- 278 ability" in electrode material design and the prospect of 279 realizing greener and sustainable batteries. ${ }^{84}$ The use of 280 organics emerges also in RFBs with a first organic/inorganic 281 flow battery reported in 2009 by Xu et al. ${ }^{85}$ based on the Cd- 282 chloranil system operating in sulfuric acid aqueous medium. 283 Two years later, an all-organic redox flow battery (ORFB) 284 working in nonaqueous medium $\left(\mathrm{NaClO}_{4}\right.$ /acetonitrile) was 285 reported by $\mathrm{Li}$ et al. $^{86}$ employing 2,2,6,6-tetramethyl- 286 1-piperidinyloxy as the posolyte and $N$-methylphthalimide as 287 the negolyte, respectively. Many other examples were then 288 reported in the literature as developed later (section 9). The 289 interest taken over time by organics in the field of electro- 290 chemical storage can simply be assessed thanks to common 291 data analysis tools like Scopus with suitable query string 292 (Figure S1). The histogram shows that the number of 293 publications (including articles, conference papers, reviews, 294 book chapters, conference reviews) focused on organic-based 295 electrochemical storage devices and published by year from 296 1972 onward follows a clear increase over the past 10 years. 297 One can also observe two successive bumps ranging from 1980298 to 2000 due to the investigations of conducting polymers then 299 organodisulfide positive electrode materials followed by a 300 larger increase thanks to the impetus given by ORBs. 301

Although beyond the scope herein, it seems instructive to 302 briefly recall in this Introduction that the addition of elec- 303 troactive molecules has also been shown to benefit carbon- 304 based electrostatic double-layer capacitors (EDLCs) as well as 305 the merging field of Li-ion capacitors. ${ }^{87-102}$ As early as 1983, 306 Saga Sanyo was the first company to integrate highly conducting 307 organic material (tetracyanoquinodimethane, TCNQ) in 308 electrolytic capacitors. ${ }^{69}$ Electroactive molecules are used to 309 significantly improve storage performance by adding a reversible 310 faradaic contribution (pseudocapacitance) to the double-layer 311 capacitance at the carbon electrode surface; these devices, 312 referred to as supercapacitors or ultracapacitors, can work both 313 
314 in aqueous and nonaqueous electrolyte media. Different 315 chemistries such as the functionalization of the carbon surface 316 by self-assembly or grafting of the redox-active organic 317 molecule can be used. ${ }^{87-97}$ Although covalent anchoring of 318 the carbon substrate via the diazonium chemistry ${ }^{94}$ appears as 319 the main approach, some authors have also reported the direct 320 incorporation of the redox-active organic molecules into the 321 electrolyte formulation referred to as "redox electrolyte" to 322 improve the specific capacitance of carbon-based electro323 chemical capacitors. ${ }^{93,95,96}$ A relevant example of "organic" 324 electrochemical pseudocapacitor consisting of activated carbon 325 powder electrodes modified with naphthalimide and 2,2,6,6326 tetramethylpiperidine- $N$-oxyl (TEMPO) was reported by 327 Lebègue et al. ${ }^{97}$ It shows an increase in specific capacitance 328 up to $51 \%$, an extended operating voltage of $2.9 \mathrm{~V}$ in propylene 329 carbonate, compared to $1.9 \mathrm{~V}$ for the unmodified system, and a 330 power 2.5 times higher. Alternatively, redox-active polymer 331 electrodes can be employed including, for instance, PPy, PAni, 332 and PT derivatives which offer advantages for making light333 weight and flexible (micro)supercapacitors while being com334 patible with aqueous electrolytes. ${ }^{98-100}$ Note that electroactive 335 organic molecules have also recently been introduced as key 336 materials to improve the sought-after "prelithiation" step of $337 \mathrm{Li}$-ion capacitors as well as the sustainability while reducing the 338 cost and complexity. ${ }^{101,102}$

339 It should be underlined that the boundary between faradaic 340 organic-adding for supercapacitors and capacitive carbon-adding 341 for organic batteries is sometimes not so clear. For instance, 342 Wang's group ${ }^{103}$ have reported a home-made hierarchical 343 porous carbon nanotubes (HPCNTs) decorated with anthra344 quinone $(\mathrm{AQ})$ molecules exhibiting ultrahigh specific capacitance 345 of $710 \mathrm{~F} \mathrm{~g}^{-1}$ (measured at $1 \mathrm{~A} \mathrm{~g}^{-1}$ ) when tested in $1 \mathrm{M} \mathrm{H}_{2} \mathrm{SO}_{4}$ 346 aqueous solution with the optimized mass ratio 7:5 indicating a 347 larger specific organic loading. Otherwise, recent years have 348 seen the emergence of so-called carbon-supported organic 349 electrode materials for LIBs/SIBs, that actually mirrors a 350 strategy to counteract common physical limitations of most 351 low-weight (neutral) organic molecules: their high solubility in 352 organic electrolytes and poor electrical conductivity. By mixing 353 these small organic molecules with large amounts of carbon 354 (generally by impregnation), a better stability can be expected 355 on cycling especially at high rate thanks to the establishment of $356 \pi-\pi$ stacking bonds with the surface of carbon particles (typical 357 carbon loading: $>55$ wt \%); this phenomenon being reinforced 358 with extended aromatic cores. Note that biomolecules such as 359 flavine $^{104}$ or dopamine ${ }^{105}$ were reported. Chen and co-workers 360 have reviewed this peculiar topic in $2015^{13}$ by questioning 361 some relevant points for practical applications such as the 362 uniformity/reproducibility at large scale production of carbon363 supported organic electrodes or the poor as-obtained energy 364 density values (especially in volumetric metrics).

\subsection{Goal, Scope, and Organization of This Review}

365 Following these introductory elements, it is obvious that a 366 consequent and growing amount of literature is now easily 367 available on organic batteries after years of silence. However, it 368 must be noted that because a certain disciplinary boundary 369 naturally exists between inorganic and organic compounds and 370 because the redox chemistry of organics is sometimes subtle 371 (involving often reactive delocalized charges), reading research 372 articles dealing with organic batteries (whatever the considered 373 technology) could be somewhat challenging for nonspecialist 374 readers. Therefore, the authors have thought it would be timely to bridge the gap by providing a kind of “tutorial”-oriented 375 review for a broader audience to take smoothly in hands the 376 most relevant points and achievements dealing with this 377 peculiar field without being redundant with the multiple review 378 articles already published today. Based on the latest selected 379 and reliable input data from both general and specialized 380 scientific literature (typically reported after 2015), this contri- 381 bution aims also at providing the readers with a better critical 382 view of the current evolution trends in our technology-oriented 383 modern societies and the consecutive global demand for elec- 384 trical energy sources, materials, and batteries before reviewing 385 the main achievements obtained with organic-based electrode 386 materials.

In practice, the layout of the article is structured in such a 388 way as the reader will be able to select the parts that interest 389 him most. From a chemical point of view, the following 390 approach will be stepwise addressed in this review:

391

- basic working principles and fundamental properties of key 392 redox-active organic moieties and comparison with the 393 formalism commonly used for inorganic materials together 394 with corresponding cell configurations (section 4),

395

- a selection (with description) of original/promising organic- 396 based batteries to date working either in the solid state 397 ("sealed" batteries) or in solubilized state (ORFBs) for 398 designing better realistic organic batteries in the future 399 (sections 5-9). Note that the reader can find specific 400 reviews on polymer-based organic batteries including radical 401 polymers in refs 10 and 18.

402

But as a preliminary step of this overview, it is thought 403 particularly relevant for some readers to provide a snapshot of 404 the global context that justifies there is room for reversible elec- 405 troactive organic systems in the future electrochemical storage 406 landscape in view of the particular conjunction of several critical 407 factors facing mankind at the turn of the 21 st century. Such a 408 tricky exercise, which is seldom considered in other review 409 articles, will constitute the background of sections 2 and 3 of this 410 paper.

\section{FOURTH INDUSTRIAL REVOLUTION: BATTERIES AT THE CROSSROADS}

412

\subsection{Background}

Since the appearance on the market of LIBs 30 years ago 413 the world has drastically changed. We have now entered the 414 so-called Fourth Industrial Revolution! ${ }^{106}$ In short, the First 415 Industrial Revolution used water and steam power to mech- 416 anize production, the Second used electric power to create 417 mass production, and the Third, emerging in the 60 s with the 418 birth of computers, used electronics and information tech- 419 nologies to automate production. Starting at the end of the 420 20th century, the Fourth Industrial Revolution is built on the 421 Third and is characterized by $(i)$ a fusion of technologies that 422 is blurring the lines between the physical, digital, and biological 423 spheres, (ii) an exponential rather than a linear pace, and (iii) 424 probably no control over either technology or the disruption 425 that will come. Basically, the driving forces of this revolution 426 are nestled in the digital and information technologies with 427 more active roles for the artificial intelligence (AI) that enables 428 innovations in "physical assets" such as autonomous vehicles, 429 Internet of things (IoT), robotics, electric unmanned aerial 430 vehicles (UAVs) or drones, 3-D printing, ... as well as "digital" 431 innovations (e.g., blockchain ${ }^{107}$ ). It is worth noting that a 432 rapid analysis of these innovative steps relies on a common 433 
434 denominator which is the finer and finer control of the 435 electron.

436 If we ignore herein that such innovations are also raising 437 major ethical and spiritual questions, ${ }^{106}$ the corollary of all this 438 technology-oriented and more recently "connected" society is 439 the ever-growing demand for energy especially for electrical 440 power sources and related storage devices ranging from $\mathrm{mWh}$ 441 to MWh: an era sometimes named "the Power Revolution". 442 Unambiguously, it is well established that access to electricity 443 improves life in a tangible way. ${ }^{108}$ However, as previously 444 pointed out in a former Perspective article a few years ago, ${ }^{84}$ 445 two related crucial threats cannot be ignored:

446

447

448

449

450

451

452

453

454

455

456

457

458

459

460

461

462

463

464

465

466

467

468

469

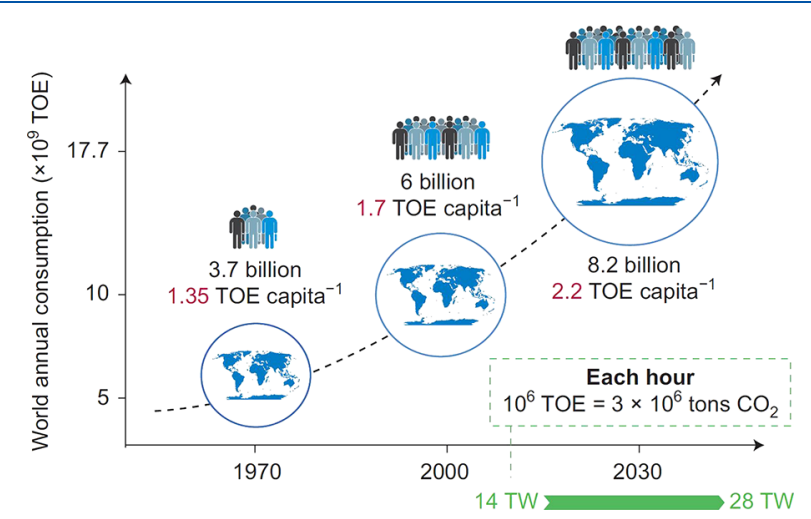

Figure 1. Forecast of the world's energy needs up to 2050. With the changing lifestyles of an increasing number of inhabitants, our energy rate demand will double from 14 TW (2010) to 28 TW (2050). $\mathrm{TOE}=$ ton of oil equivalent. Reproduced with permission from ref 112. Copyright 2015 Nature Publishing Group.

1. "Global warming" with its numerous and dangerous induced impacts (e.g., extreme and destructive climate events, rise in sea level with its aftermath, relocating industrial and farming areas, biodiversity alteration, new distribution of populations with conflicts over water and food, and so on). This major threat which seems to correlate to anthropogenic greenhouse gas (GHG) emissions represents not only ecological but also socioecological and economic issues. At the COP21/CMP11 (Conference of the Parties) meeting in Paris in 2015, 195 countries signed a legally binding agreement to keep global warming "well below $2^{\circ} \mathrm{C}$ above pre-industrial levels, and to pursue efforts to limit the temperature increase even further to $1.5^{\circ} \mathrm{C}$ " within this century. In practice, this means an $81 \%$ reduction of GHG intensity by 2050 , which is equivalent to $4.4 \%$ annual improvement. ${ }^{109}$ In 2018 almost all countries in the world have committed themselves to reduce their GHG emissions in their pledges to the Paris Agreement. Note that global warming is likely to reach $1.5^{\circ} \mathrm{C}$ between 2030 and 2052 if it continues to increase at the current rate as reported by the Intergovernmental Panel on Climate Change (IPCC) special report on January 2019. ${ }^{110}$

2. The constant increase in the world population which results in more and more energy consumers and therefore more GHG emissions as nicely shown in Figure 1.
112. Copyright 2015 Nature Publishing Group.

Predictions estimate around 9-10 billion the human load by the year 2050 (2.5 billion in Africa against 1.3 billion today) $66 \%$ of which will reside in urban areas in developing economies. ${ }^{111}$ For comparison, the population was 700 million at the beginning of the first 476 Industrial Revolution.

477

Although not yet fully accepted all over the world, such a 478 mankind development still falls short in terms of sustainability 479 and calls for a rapid and radical change in our current energy 480 engineering together with a responsible behavior in our 481 consuming fashion (pro-environmental behavior, "Nudge" 482 theory, ... $\left.{ }^{13,114}\right)$. It is interesting for example to read the 483 study of Dong et al. ${ }^{115}$ on the nexus among carbon dioxide 484 emissions, economic and population growth, and renewable 485 energy across regions. Their data allow us to underline that 486 economic growth is highly emission intensive, and economic 487 growth often means rising energy consumption and increasing 488 $\mathrm{CO}_{2}$ emissions with a proportional effect of the population 489 size. Hence our entering this Fourth Industrial Revolution can 490 be perceived as a threat but also as an opportunity to rethink 491 the development of mankind as a whole. Positive initiatives are 492 now under way, and some policy makers and important energy 493 stakeholders are making things happen probably also pushed 494 by the ostensibly large number of recent extreme weather 495 events $^{116}$ such as Category 5 Katerina hurricane in 2005. 496 Basically, new political goals and innovative/disruptive 497 economy models (like the "green growth" models, the circular 498 economy governed by 3Rs, namely Reduce, Reuse, and Recycle) 499 must also be formulated, notably in reference with $\mathrm{CO}_{2}$ emission 500 limits, in the quest for a long-term sustainability conjugating 501 Ecology/Economy/Society. [The reader who would be inter- 502 ested in this exciting field could find relevant and very informative 503 economic analyses in the specialized literature. $\left.{ }^{109,117-119}\right] \quad 504$

For a more technological point of view, generation of 505 decarbonized electricity and low-carbon transportation solutions 506 are the two main levers (in association with better energy 507 efficiency and conservation and the carbon capture utilization and 508 storage ${ }^{120}$ ) put traditionally forward to move toward a deep 509 decarbonization of the energy system. ${ }^{121}$ To better forecast the 510 future in this regard, we recap below the main observed trends 511 with supporting figures highlighting that rechargeable batteries 512 are expected at the crossroads of several paths in the global 513 demand pattern for electrical functionalities of today and 514 tomorrow, some applications being to mitigate GHG emissions 515 while others are probably less virtuous.

\subsection{Decarbonizing the Power Supply and Its Related Storage Challenges}

Regarding the future of electric grids, thanks to the efforts 518 of worldwide researchers, engineers, and policy makers, 519 remarkable progress has been made to connect renewable 520 energy sources (RESs) for electricity generation. ${ }^{122}$ For 521 instance, the European Directive 2009/28/EC ${ }^{123}$ aims at 522 promoting the use of RESs in the European Union (EU) with 523 a targeted value of $20 \%$ by 2020 with specific values regarding 524 each member state. The most exploited RESs are hydroelectric, 525 photovoltaic (PV), and wind. Other emerging renewable 526 technologies include wave and tidal energy conversion and 527 biomass energy conversion. Therefore, some predictions seem 528 to indicate that GHG emissions in the power sector could be 529 drastically reduced thus becoming a major contributor to 530 decarbonization (Figure 2). Although the total electricity 531 production is expected to more than double between 2010 and 532 2050 giving rise to the incredible value of more than 40000533 TWh of generated energy per year (notably to power the elec- 534 tromobility, see below), total emissions for the power sector 535 could be divided by more than four according the Deep 536 
a) Power generation mix at the worldwide scale

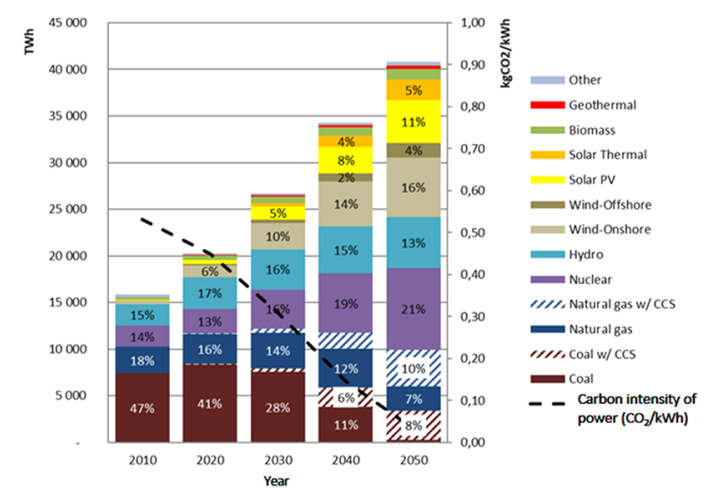

b) Power $\mathrm{CO}_{2}$ emissions at the worldwide scale

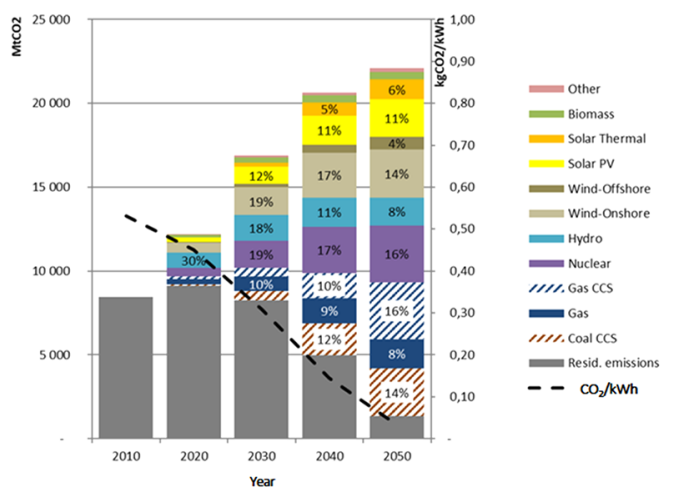

Figure 2. (a, b) Decarbonization Wedges in the power sector extracted from the ANCRE's report ${ }^{124}$ (with permission) elaborated in the DDPP and by considering the most ambitious scenario in each country; "worldwide scale" refers to only the 16 most emitting countries. These histograms show the emission trajectories for the electricity sector in the absence of any technological evolution and (in gray) the evolutions of the emissions within the framework of decarbonization scenarios; the difference between the two corresponds to reductions that allow different technologies (e.g., solar in yellow and orange, hydro in blue); CCS meaning carbon capture and sequestration. Further descriptions of the "Decarbonization Wedges" methodology can be found in ref 126.

537 Decarbonization Pathway Project (DDPP) ${ }^{124,125}$ by considering 538 the most ambitious scenario in the 16 largest GHG-emitting 539 countries representing $75 \%$ of current GHG emissions. According 540 to these scenarios, the electricity mix could be completely 541 modified with almost $90 \%$ of power generation from non- $\mathrm{CO}_{2}$ 542 emitting technologies, among which $54 \%$ is from renewable 543 sources (together with $21 \%$ from nuclear power plants); coal is 544 today responsible for $42 \%$ of $\mathrm{CO}_{2}$ emissions worldwide. The 545 electricity sector could be widely decarbonized by 2050 with a 546 reduction from the current $530 \mathrm{gCO}_{2} \mathrm{kWh}^{-1}$ to about $54733 \mathrm{gCO}_{2} \mathrm{kWh}^{-1}$ [the complete description of the "Decarbon548 ization Wedges" methodology as well as additional subscenar549 ios have been recently published by Mathy et al. $\left.{ }^{126}\right]$.

550 However, huge infrastructure investments will obviously be 551 needed to satisfy such perspectives in electricity generation. 552 For instance, some of these newly developed technologies 553 (e.g., PV, wind power) cannot serve as stable energy sources 554 alone because of their natural sensitivity to weather, landform, 555 or other environmental conditions (i.e., variability and high 556 ramping characteristics) requiring sophisticated planning and 557 operation scheduling to ensure the necessary and subtle balance between electricity production and consumption. New 558 technologies are currently being developed to upgrade existing 559 electricity grid infrastructures that will enable so-called "smart 560 grids", which are characterized by improved grid reliability and 561 utilization, the synergies between the power electronics, control, 562 and communication fields as well as the change from radial 563 networks to mesh networks with the possibility to reconfigure 564 and self-heal. ${ }^{127,128}$ Thus, the role of IoT will be eminent with a 565 significant reduction of costs associated with sensors, bandwidth, 566 processing, and memory/storage. ${ }^{129}$

Consequently, energy storage is increasingly seen as a 568 valuable asset for electricity grids and one of the important 569 tools of mitigation not only as a technical solution for network 570 management, ensuring real-time load leveling, but it is also a 571 means of better utilizing RESs by avoiding load shedding in 572 times of overproduction. For the moment, the worldwide 573 stationary electrical storage remains by far dominated by 574 pumped storage hydropower ( $98 \%$ of the installed power) but 575 the use of rechargeable batteries is emerging fast as underlined 576 in 2011 by Dunn et al. ${ }^{130}$ in a visionary paper; the wide use of 577 batteries is now clearly included in the roadmap storage 578 technologies. ${ }^{131,132}$ Already widely used for load-leveling 579 applications and UPS for entire cities (especially the PbA 580 technology), the reduction of costs in the electrochemical 581 storage technologies is attracting considerable interest for 582 short-term storage (for a period of seconds to a few days) 583 using "sealed" batteries and redox-flow batteries (RFBs) as 584 shown in Figure 3. Thus, LIBs in various chemistries are even 585

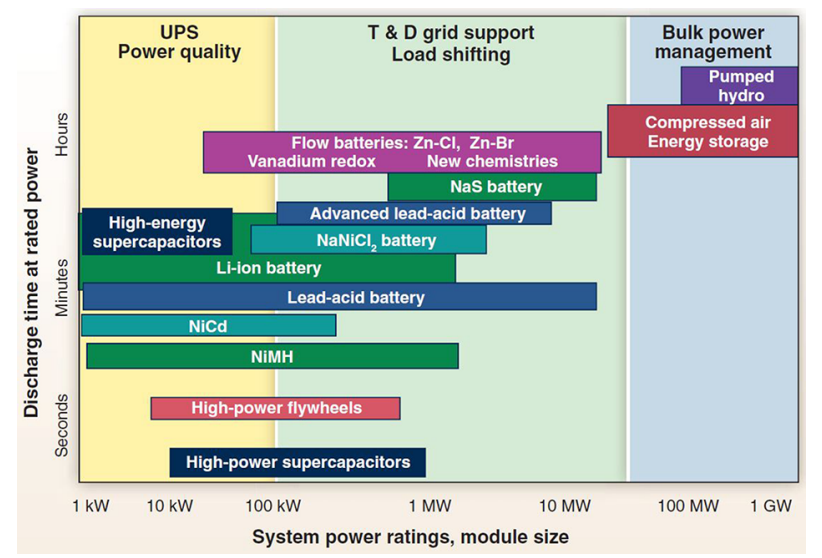

Figure 3. Comparison of discharge time and power rating for various electrical energy storage technologies highlighting the broad contribution of batteries with various chemistries; the latter being only based on inorganic electroactive materials, essentially metals. Reproduced with permission from ref 130. Copyright 2011 Science Publishing Group.

more seriously envisaged ${ }^{132}$ because the cost of battery storage 586 has declined fast in a few years with a drop of $73 \%$ between 587 2010 to 2016 to reach $\$ 273 \mathrm{kWh}^{-1}$ as market value while a 588 value of $\$ 73 \mathrm{kWh}^{-1}$ is forecast in $2030 .{ }^{133}$ Competing with gas- 589 fired peaking plants is made possible. For example, more than 590 18000 LIB packs (400-MW peak hour battery) would replace 591 a gas-fired power in California. ${ }^{134}$ Interestingly, the analysis of 592 3 years of real usage of LIBs (1 MW/250 kWh using 384593 modules connected in series) installed and in operation in 594 Hawaii has been recently reported by Dubarry et al. ${ }^{135} 595$

For such stationary applications, the capital invested and 596 operational costs (maintenance, energy lost during cycling, 597 
598 aging) are very important factors to consider for the entire life 599 of the system. The reader could find compared cost factors in 600 the literature including PbA, RFBs, LIBs, and so on. ${ }^{5,130,136}$ 601 The cost of storage can be calculated through the so-called 602 levelized cost of stored energy (LCOE) defined as the total 603 lifetime cost of the investment divided by the cumulated 604 generated energy by this investment. The LCOE values at 60525 years for an installed storage power of $1 \mathrm{MW}$ are estimated 606 at 0.338 and $€ 1.978 / \mathrm{kWh}$ for RFBs and LIBs, respectively 607 (against 3.072 for the PbA technology). ${ }^{137}$

\subsection{Decarbonizing the Transportation Sector Through the 608 Electrification Scheme}

609 Beyond the electric grid, the pressure on batteries is also 610 particularly intensive due to the deployment of decarbonized 611 transportation systems through the massive use of electric 612 motors (the so-called "electromobility" or "e-mobility") 613 although the use of biofuels, oil-based fuels, and liquefied 614 natural gas (LNG) has recently gained more attention. ${ }^{121,138}$ 615 [LNG consists mostly of $\mathrm{CH}_{4}$ and has the potential to reduce $616 \mathrm{SO}_{2}$-emissions over $90 \%$, $\mathrm{NOx}$-emissions with $80 \%$, and $\mathrm{CO}_{2}$ 617 emissions $20 \%$, which seems a competitive alternative in this 618 sector provided there is less than $2 \%$ leakage.] Indeed, the 619 transport sector's dependence on fossil fuels is another big part 620 of the necessary transition toward a climate-neutral and 621 sustainable society. Transport is a major source of total GHG 622 emissions (22\%), with road transport being the biggest 623 contributor and responsible for about $72 \%$ of $\mathrm{CO}_{2}$ emissions 624 worldwide according to IPCC analyses. ${ }^{139}$ Note that over 6251.2 billion vehicles were in service in 2015 according to the 626 International Organization of Motor Vehicle Manufacturers 627 (OICA). ${ }^{140}$ Moreover commercial air transportation still 628 represents about $11 \%$ of global fuel consumption across all 629 sectors, $2 \%$ of global $\mathrm{CO}_{2}$ emissions, and $13 \%$ of emissions in 630 the transport sector alone. ${ }^{141}$ Beyond the dangerous GHG 631 emissions when using Internal combustion engines (ICEs), the 632 electric motor intrinsically possesses several advantages that 633 have always been known such as better energy efficiencies 634 (>90\% because not subject to the Carnot cycle limitations of 635 heat engines). They are also quieter, easy to miniaturize, and 636 more importantly simpler in their design making the direct 637 motor and wheel coupling possible. Conversely, a conventional 638 ICE powered car typically has 10000 moving parts (essentially 639 within the drive train) against only 150 in battery electric 640 vehicles (BEVs) today and only one of which is in the drive 641 train as underlined by Parker. ${ }^{142}$ The gains in maintenance as 642 well as in energy efficiency are obvious.

643 Historically, the invention of ICE occurred in the middle of 644 the 19th century just like that of the electric motor but at a 645 time when oil and its derivatives were becoming cheap and 646 widely available whereas high energy batteries did not exist yet. 647 Gaston Planté had just invented the first rechargeable battery 648 with its $\mathrm{PbA}$ technology (then improved by Camille Faure in 649 1881), which enabled however the first automobile speed 650 record in 1899 ( $100 \mathrm{~km} \mathrm{~h}^{-1}$ but only on $2 \mathrm{~km}$ range) thanks to 651 the first BEV named "La jamais contente" powered by $750 \mathrm{~kg}$ of 652 Fulmen PbA batteries. In the early 1900s, 38\% of the US 653 automobile market was captured by electric vehicles. Even after 654 this feat, ICEs would increasingly supplant the electric car for 655 the next century especially thanks to Ford's innovations with 656 the consequences that we are now witnessing. Now vehicle 657 emission regulations have been forcing the automotive industry 658 worldwide to reduce its carbon footprint especially in the EU,
China, and India while governments around the world (like the 659 Electric Vehicles Initiative (EVI) $)^{143}$ are providing incentives 660 to the citizens for buying electrified vehicles (EVs). The 661 French government is to take the initiative to propose an 662 ambitious Euro 7 emission standard at European level and set 663 the goal of ending the sale of cars emitting greenhouse gases 664 in 2040! The Swedish automaker Volvo has announced 665 that from 2019 all its new models would be either hybrid or 666 $100 \%$ electric. Note that EVs include battery electric vehicles 667 (BEVs), plug-in hybrid electric vehicles (PHEVs), and fuel-cell 668 electric vehicles (FCEVs). As a reminder, the key difference 669 between BEVs and PHEVs is that FCEVs use a primary 670 electrochemical cell (i.e., fuel cell) to power the electric motor; 671 the recharging step of FCEVs needing hydrogen as a fuel 672 instead of electricity.

673

Based on the current roadmap reported by the International 674 Energy Agency (IEA) in the BLUE Map scenario ${ }^{144}$ (Figure 4a), 675 rechargeable batteries are likely to remain the better choice to 676 power light duty vehicles (LDV) in the next 2 decades whereas 677 FCEVs are considered as the future vision for the global 678 automotive industry beyond 2040-2050 because this technol- 679 ogy and related hydrogen supply infrastructures are still not at 680 the desirable level, ${ }^{121,145}$ with the production of low-carbon $\mathrm{H}_{2} 681$ being required too. For the present time progress made in 682 recent years to improve battery performance and reduce 683 $\operatorname{costs}^{133}$ has already enabled the use of LIBs in numerous 684 e-mobility applications such as two-wheelers, buses, taxis, 685 shared cars, ride-hailing services, and the upcoming self-driving 686 (or driverless) cars.

687

Thus, sales of new electric cars worldwide surpassed 1 million 688 units in 2017 (for 3 million EVs in circulation), a record volume 689 which represents a growth in new electric car sales of 54\% 690 compared with 2016 (more than half of global sales of electric 691 cars were in the People's Republic of China) whereas the 692 EV30@30 scenario makes as projection 228 million EVs 693 (excluding two- and three-wheelers) on the road by 2030 as 694 shown in Figure $4 \mathrm{~b} ;{ }^{143}$ the EV30@30 campaign redefining the 695 EVI ambition originally set at 20 million EVs on the road by 696 2020. More recently, Hache et al. ${ }^{146}$ have reported a bottom- 697 up analysis using the Times Integrated Assessment Model 698 (TIAM-IFPEN version) to forecast the diffusion of electrified 699 road transportation modes by integrating two climate scenarios 700 (4 and $2{ }^{\circ} \mathrm{C}$ ) and two shapes of mobility (high/low mobility). 701 The electric vehicles fleet could reach up to $1 / 3$ of global fleet 702 by 2050 in the $4{ }^{\circ} \mathrm{C}$ scenarios, while it could be up to $3 / 4$ in 703 the $2{ }^{\circ} \mathrm{C}$ scenarios both with high mobility, mostly located in 704 Asian countries (China, India, and other developing countries 705 in Asia) due to the large presence of 2- and 3-wheelers (Figure S2). 706 Consequently, electric transportation is integrated into the smart 707 grid/smart cities master plans ${ }^{147}$ first because the electricity needs 708 will boom but also as a means of flexibility since integrating BEVs/ 709 PHEVs into the electric utility grid facilitates both vehicle-to-grid 710 (V2G) and grid-to-vehicle applications owing to the bidirectional 711 nature of the power flows between the BEVs/PHEVs and the grid. 712

Last but not least, developing electric/hybrid aircraft is in 713 progress too because electric propulsion has the potential to 714 revolutionize aviation opening real opportunities for cleaner, 715 quieter travel to completely new types of transportation 716 models. In November 2017 Airbus announced the launching of 717 E-Fan X with its partners Siemens and Rolls-Royce which is an 718 ambitious technology demonstrator project: a hybrid civil 719 aircraft, another emerging sector calling for high-performance 720 batteries. Other equivalent projects exist such as the ZUNUM 721 

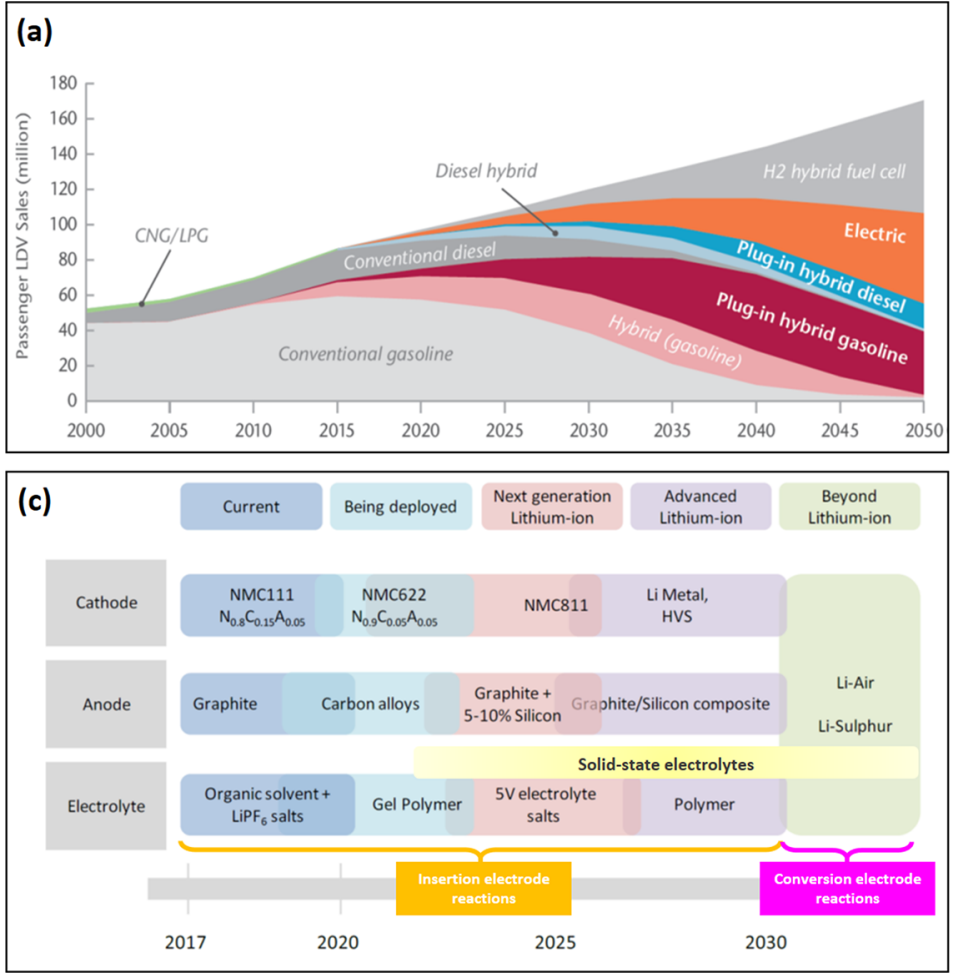
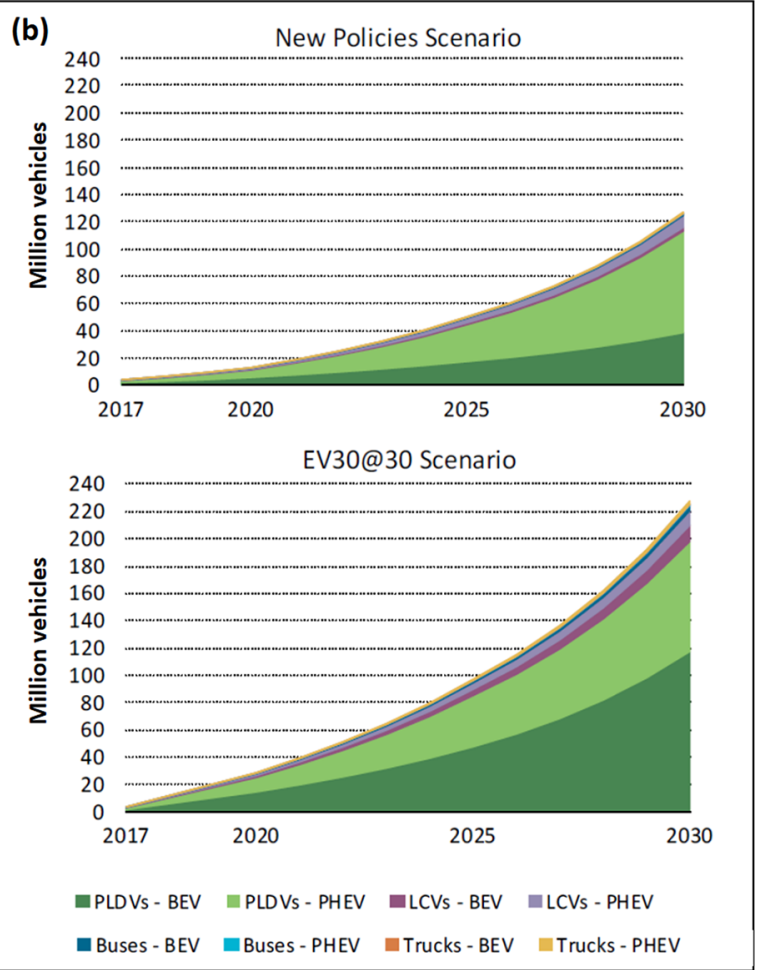

Figure 4. (a) Annual light-duty vehicle (LDV) sales according to the BLUE Map scenario, ${ }^{144} 2000-2050$ reported by IEA; combined EV/PHEV sales should share at least $50 \%$ of LDV sales worldwide by 2050. (b) Global EV stock for 2017-2030 excluding two- and three-wheelers by considering both New Policies Scenario and the EV30@30 Scenario reported by IEA ${ }^{143}$ (PLDVs = passenger light duty vehicles; LCVs = light commercial vehicles; BEVs = battery electric vehicles; PHEV = plug-in hybrid electric vehicles). (c) Battery technology roadmap adapted from IEA $^{143}$ (HVS = high voltage spinel). Adapted with permission, copyrights of IEA.

722 Aero airliner project supported by Boeing. Interesting inno723 vations can therefore be expected in the next decade even if 724 there is a long way to go for large-scale practical applications.

\subsection{Digitalization and Growing Consumption of Electronic} 725 Devices

726 The boom in electronic devices and digital technologies has 727 been going on for almost 30 years, and batteries are generally 728 needed to power them. The worldwide development of mobile 729 phones is probably the most vivid example. As underlined by 730 Galetovic et al. ${ }^{148}$ in a very interesting world mobile phone 731 industry study, the number of mobile phones sold rose 62-fold 732 between 1994 and 2013 whereas in June 2015 there were 733 around 7.5 billion subscriber connections, one for every person 734 on the planet. But all this has an energy cost but also an 735 environmental one. As an example, the entire mobile phone 736 system in a small country like Italy consumes approximately 7372200 GWh per year ( $0.7 \%$ of the national electricity consump738 tion) while producing potential e-waste from end-of-life 739 devices totaling over 11 thousand tons for the period from 7402007 to 2012 .

741 Today, consumer electronics (CE) mainly encompasses the 742 whole range of home electronic equipment, from audio systems, 743 home automation, home computing, and low-power electronics 744 to multimedia systems. In addition, IoT has nowadays gained 745 an incredible attraction ${ }^{149,150}$ imparting networked connectiv746 ity to everyday objects in the physical world with numerous 747 implications in logistics, manufacturing, retailing, environ748 mental monitoring, healthcare monitoring, industrial monitor749 ing, traffic monitoring, ... (as well as important monitoring in 750 the smart grid and EVs to relate to the previous paragraph).
In 2015, IBM predicted that 1 trillion devices would be connected 751 to the Internet and the IoT. In 2017, a Cisco-revised forecast 752 called for 50 billion devices to be connected by 2020 and, most 753 recently, the GSMA Association predicted 25 billion IoT devices 754 by 2025 ! Interesting data are reported by "The Shift Project" in 755 several reports. ${ }^{151}$ For example, the energy consumption of 756 Information and Communication Technologies (ICT) is 757 increasing by $9 \%$ every year while the share of ICT in GHG 758 emissions has increased by half since 2013, rising from $2.5 \%$ to 759 $3.7 \%$ in a few years.

760

Remarkable progress has also been made in many aspects of 761 robotics for which 10 grand challenges have recently been 762 pointed out in a Perspective article published in Science 763 Robotics ${ }^{152}$ including one related to power and energy sources 764 to make the deployment of mobile robotics possible. In par- 765 ticular, "service robots" which smartly mix IoT and AI to assist 766 human beings - typically by performing a job that is dirty, dull, 767 distant, dangerous or repetitive, including household chores- 768 are on the verge of equipping our homes and some public 769 places. Impressive statistics and forecast have been announced 770 by The International Federation of Robotics in the Executive 771 Summary World Robotics 2018 Service Robots reports. ${ }^{153}$ For 772 instance, it was estimated in 2017 that nearly 6.1 million robots 773 for domestic tasks, including vacuum cleaning, lawn-mowing, 774 window cleaning and other types, were sold which corresponds 775 to a $31 \%$ increase compared to 2016 . The market for elderly 776 and handicap assistance is also expected to increase substan- 777 tially within the next 20 years.

In the same vein of recent developments, benefiting of 779 electric propulsion $\mathrm{R} \& \mathrm{D}$, the market of drones (UAVs) is also 780 expected to rise at unprecedented rates due to growing interest 781 


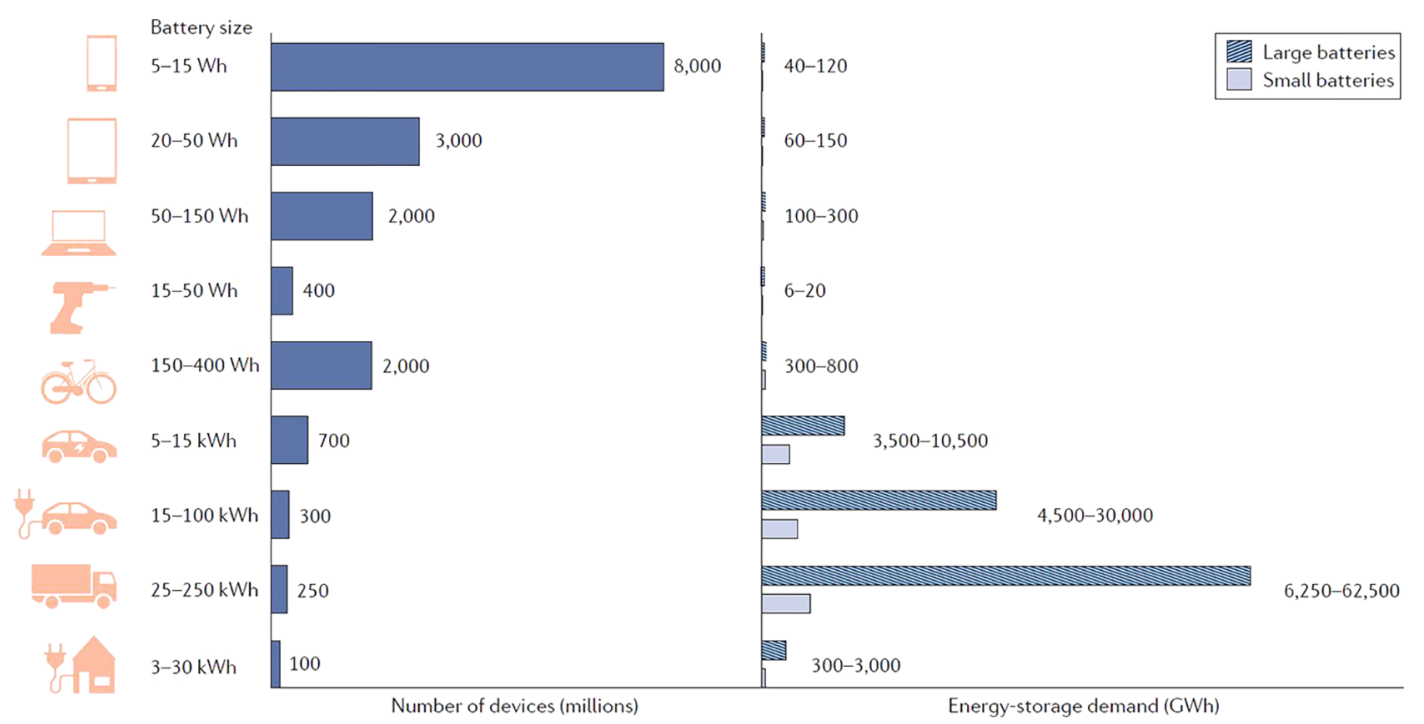

Figure 5. Estimated number of devices and related energy demand for 2016-2050. Note that all possible needs are not considered like the electric grid. Reproduced with permission from ref 154. Copyright 2019 Nature Publishing Group.

782 in monitoring applications by the military, researchers, farmers, 783 hobbyists, and investors in e-business since drones offer 784 superior abilities over their ground alternatives. It should be 785 pointed out that using drones for commercial deliveries was 786 something improbable ten years ago. Interestingly, Vaalma 787 et al. ${ }^{154}$ have very recently established a scenario-based supply 788 and demand analysis concerning LIBs for 2016-2050 con789 sidering some selected applications including portable elec790 tronic devices and tools as well as several electrified road trans791 portation modes and small stationary energy-storage devices 792 (Figure 5). Clearly, if portable electronics dominates in terms 793 of number of devices, they account for much less in terms of 794 the total energy-storage demand if electric vehicles and 795 residential energy-storage devices reach the high production 796 numbers estimated in their scenarios. ${ }^{154}$ However, several key 797 applications such as the powering of domestic robots, drones, 798 or IoT are not included in the scenario.

\subsection{Summary}

799 To sum up this overview, we are unambiguously facing a 800 tremendous need for EES for a double reason, first as a key 801 ingredient of the future energy engineering to fight global 802 warming and, second, as a central hub for the emergence of 803 disruptive technologies consecutive to the continuous moderni804 zation and development of mankind. The scale-up of industrial 805 facilities for the production of rechargeable batteries, especially 806 LIBs due to their high energy density values, is consequently 807 an opened and sensitive question. The production is currently 808 dominated by East-Asian competitors; with Panasonic (Japan) 809 and LG Chem (South Korea), these leading manufacturers on 810 the automotive market are closely followed by Samsung SDI 811 (South Korea), CATL (China), and SK Innovation (South 812 Korea). With its Gigafactory built in Nevada, Tesla (with 813 Panasonic as a partner) is now on the road too on US soil 814 whereas in the EU, things are moving forward to reduce its 815 dependence on the Asia and US suppliers. Sweden's Northvolt 816 has raised in June $2019 \$ 1$ billion in equity capital to complete 817 funding for its future Gigafactory while France and Germany 818 launched an Airbus-style $€ 6$ billion foray into the battery819 building business. Considering a typical battery capacity range 820 of $20-75 \mathrm{kWh}$, these factory capacities translate into a yearly production volume ranging between 6000 to 400000 packs. ${ }^{143} 821$ To better visualize the world LIB manufacturing capacity and 822 related international trade flows, Figures S3-4 report the 823 thorough mapping analysis performed by Mayyas et al. ${ }^{155} 824$ based on reliable collected data in 2016; the total LIB manu- 825 facturing capacity for this year was 189762 MWh including 826 $114484 \mathrm{MWh}$ for automobile LIBs. Finally, Bloomberg NEF 827 announced in November 2018 a need for 1800 GWh by 2030828 of LIBs including annual passenger EVs and E-buses, consumer 829 electronics, and stationary storage; roughly eight out of every 830 10 batteries sold annually will find their way into a passenger 831 electric vehicle; ${ }^{156}$ however, details regarding the modeling and 832 technical assumptions are not available. Anyway, the bottom 833 line is battery production will have to be strongly scaled up in 834 any scenario because a significant difference between supply 835 and demand could occur.

836

But departing from these capability considerations, it is 837 particularly important to avoid any pitfalls in this frenetic 838 endeavor and make sure that proposed technical solutions are 839 themselves sufficiently eco-friendly and sustainable. In other 840 words, such large-scale perspectives force us to consider the 841 environmental impact of rechargeable batteries (notably LIBs) 842 as well as dependencies on raw materials. This critical point 843 will be specifically discussed in the next section on the base of a 844 selection of relevant data again ranging from chemical element 845 abundance to potential environmental concerns related to their 846 production and disposal.

\section{MATERIAL SUPPLY FOR ELECTROCHEMICAL STORAGE: RESOURCE CONSTRAINTS ISSUES, ENVIRONMENTAL BURDEN, AND OPPORTUNITIES 849 PROVIDED BY ORGANIC ELECTRODE MATERIALS 850}

Even if some currents of thought advocate a negative or zero 851 growth as a solution, it is believed that technology and its 852 progressive developments should constitute the most important 853 pillars of energy saving and GHG reducing. Nevertheless, it 854 seems also established that with all decarbonization innovations 855 notably in the broad field of energy, new environmental and 856 resource issues are introduced with the growing need for ores 857 and refined metals; ${ }^{126,157}$ which partly offset the gains of 858 
859 innovative solutions; a phenomenon known in the economic 860 field as the "Jevons' paradox" or the Rebond effect. ${ }^{158,159}$ In a 861 very interesting paper published in 2011, Graedel wrote: ${ }^{160}$ 862 Assessors of technology no longer tend to ask, "What is being used?" 863 but rather, "What is not being used?" The answer to the last 864 question is, increasingly, "Almost nothing." In the last 20 years 865 (1994-2014), world mining production of indium, rare earth 866 elements (REEs), lithium, and cobalt increased from 149 to 867819 tons, 64.5 to 133 ktons, 6.0 to 36.0 ktons, and 18.5 to 868112.0 ktons, respectively, together with e-waste which is at the 869 world scale unfortunately poorly collected and recycled. ${ }^{161}$ 870 Hence the large quantities of waste electrical and electronic 871 equipment (WEEE) generated have raised a serious alarm on 872 their potential adverse health and environmental consequences 873 when incorrectly disposed of.

874 In 2012, Vesborg and Jaramillo ${ }^{162}$ very nicely studied the 875 tricky question about the scalability in the supply of chemical 876 elements (and the related cost in energy) to promote tech877 nologies for energy harvesting, conversion or storage at the 878 required TW-level for a sustainable future. Numerous relevant 879 data are provided in this article such as correlations between 880 crustal abundance and production of dozens of chemical elements 881 while underlining the significant energy costs associated with 882 providing the current flow of raw materials for energy tech883 nologies. Today's turbine blade alloys and coatings for wind 884 energy converter make use of as many as a dozen metals while 885 Electrical and Electronic Equipment (EEEs) incorporate some 88660 metals most of which are classified as "critical metals" 887 (CMs). ${ }^{160,163,164}$ In short, CM refers roughly to imbalances 888 between metal supply and demand (real or anticipated) at 889 national, regional, or very local level, which induces variable 890 appreciations, several definitions, and assessment method891 ologies. An extension to "critical raw materials" (CRMs) and 892 the "criticality" term have appeared in the literature too. ${ }^{146,164}$ 893 For instance, through the Raw Materials Initiative (RMI) 894 adopted in 2008, ${ }^{146,165}$ the European Commission ${ }^{166}$ has 895 defined CRM when it faces high supply risks (e.g., geological, 896 geopolitical, or production risk) or high environmental risks 897 and is of high economic importance; 14 CRMs were identified 898 in 2011, 20 in 2014, and 27 in 2017 as shown in Figure S5. 899 Interestingly, $\mathrm{Li}$ is not considered as $\mathrm{CM}$ for the European 900 Commission while the US has included it in its own list as 901 reported by the Department Of the Interior in 2018. ${ }^{167}$

902 Respective to the scope of this article, the relevant question 903 is therefore to establish if the current available and future 904 battery technologies depend on high material resource constraints 905 and at what cost in terms of environmental burden. A few 906 elements of an answer will be provided below.

\subsection{Resource Constraints Forecast in Conventional 907 Material Supply}

908 Based on the present state-of-the-art and whatever the con909 sidered technologies, electrode reactions involve redox-active 910 inorganic compounds especially metal-based electroactive com911 ponents, which is an historic heritage of the pioneered redox 912 chemistry (the voltaic pile followed by the PbA secondary cell) 913 as well as the material engineering that resulted (Figure 3). For 914 instance, if we consider the battery technology roadmap for 915 electrified vehicles (Figure 4c) it is expected that at least until 9162030 matured and advanced insertion inorganic positive 917 electrode materials will be essentially based on the 3d-metal 918 redox chemistry. However, it is also widely acknowledged that 919 traditional Li-ion batteries are starting to approach their limits especially for long-range EVs. Beyond 2030 other battery 920 chemistries are envisaged namely post-LIB systems. First, it is 921 commonly forecast that conversion-based cathode reactions 922 could be used (with $\mathrm{O}_{2}$ and $\mathrm{S}$ ) in Li-metal battery configuration 923 (Figure 4c), which supposes however the achievement of 924 consequent improvements. ${ }^{168}$ Recent R\&D trends also indicate 925 an expected switch from liquid (organic) electrolytes to ceramic 926 electrolytes (or solid state electrolytes, SEEs) notably following 927 the recent discovery of lithium superionic conductors at room 928 temperature by Kanno and co-workers $\left({\sigma_{\mathrm{Li}}}^{+}=25 \mathrm{mS} \mathrm{cm}{ }^{-1}\right.$ for 929 $\left.\mathrm{Li}_{9.54} \mathrm{Si}_{1.74} \mathrm{P}_{1.44} \mathrm{~S}_{11.7} \mathrm{Cl}_{0.3}\right){ }^{169,170}$ All-solid-state batteries operating 930 at moderate temperatures offer an attractive option for non- 931 flammable batteries while achieving both high power and high 932 energy densities because it is also a relevant option to reopen 933 the safe use of pure alkali metals especially $\mathrm{Li}$ as anode material 934 when paired with high-potential insertion materials (5 V spinel 935 materials, Figure 4c) or with conversion $\mathrm{S} / \mathrm{O}_{2}$-based cathodes. ${ }^{171} 936$ Nevertheless, this ceramic electrolyte option could require again 937 the consumption of more inorganic materials such as metal-based 938 sulfides, oxides, or phosphates. ${ }^{169,172}$ It is worth noting that the 939 emerging field of $\mathrm{Na}$ and $\mathrm{Na}$-ion batteries which are also 940 considered in the post-LIB field logically follows the same 941 trajectory in terms of materials choice and design as a sister 942 material chemistry of Li-based batteries. ${ }^{173,174}$ In addition, it 943 should be remembered that major built RFBs also draw their 944 chemical power from $3 \mathrm{~d}$-metals as well as already underlined 945 above.

While the number of publications and other reports has 947 greatly increased in recent years on the potential bottlenecks in 948 material supplies due to the ramping up of LIBs, ${ }^{146,155,154,175-177} 949$ the resource issue questionings in the field of energy storage 950 are not new especially for EV fleets since interesting estimates 951 were already reported by Andersson and Råde ${ }^{178}$ as early as 952 2001 by taking into account almost all cell chemistries at that 953 time: Li-metal polymer (LMP), LIBs, sodium nickel chloride 954 ( $\mathrm{NaNiCl}$ or ZEBRA batteries), Ni-metal hydrides ( $\mathrm{Ni}-\mathrm{MH}$ ), 955 and $\mathrm{PbA}$. Generally speaking, batteries that contain two or 956 more scarce metals may suffer from being limited by the 957 availability of any of them. With the pressure on LIBs and 958 future Li-based technologies, the main current concern is 959 about the potential risks surrounding the supply (and related 960 price volatility) of lithium and 3d-metals with battery-grade 961 quality (Co and Ni, essentially), which also raises the tricky 962 question of the mining interdependencies of elements; ${ }^{155}$ note 963 that natural graphite is commonly reported as CRM. Indeed, 964 the supply of cobalt is complicated by the fact that this element 965 is not typically the primary product of mining operations; 966 it is a coproduct of nickel (50\%) mining. ${ }^{179}$ Figure S6 shows a 967 mapping and quantified data regarding the world mining 968 industry production for materials used in LIBs. ${ }^{155}$ Taking 2016969 as the year of reference, the battery industry's demand for 970 lithium and cobalt is $46 \%$ and $50 \%$ of the world production, 971 respectively. ${ }^{154}$ It should also be underlined that 54\% of the 972 mining production of Co comes from the Democratic Republic 973 of Congo, a country characterized by socio-political instability, 974 a persistent economic stagnation, and no environmental policies; 975 the country could lose $40 \%$ of its forests by 2050 notably due to 976 mining activities. ${ }^{180}$

To ensure continuous flows of raw materials, new agreements 978 are set up between critical material suppliers and different 979 customers; for example, Apple Inc. seems interested in buying 980 long-term supplies of cobalt directly from miners. ${ }^{181}$ As previ- 981 ously stated by Andersson and Råde, ${ }^{178}$ closed loop recycling 982 
983 solutions and a high level of collection of spent batteries 984 are required to ensure that the stock of available metals for 985 batteries is not drained. The case of $\mathrm{PbA}$ batteries constitutes a 986 textbook example with a collection of spent batteries above $98799.9 \%$ thanks to environmental rules due to the lead toxicity 988 together with existing efficient recycling processes of this 989 simpler battery chemistry based essentially on $\mathrm{Pb}(\mathrm{Bi})$. In 2016, 990 almost all end-of-life LIB were batteries from consumer elec991 tronics and $95 \%$ of spent LIB were unfortunately landfilled. ${ }^{182}$ 992 Unlike recycling of $\mathrm{PbA}$ batteries, recycling of LIBs seems for 993 the moment not economically profitable albeit recycling LIBs 994 could save up to $51.3 \%$ of the natural resource required to 995 produce virgin materials (concept of Urban Mines). ${ }^{182}$ Today, 996 most recyclers focus on recovering expensive materials mainly 997 from positive electrode powders, but lithium is rarely recovered 998 (less than $1 \%$ of lithium is recycled). Stronger political incen999 tives seem required to promote recycling. In the EU, the 2006/ 1000 66/EC European directive ${ }^{183}$ imposes a minimum recycling 1001 efficiency of Li-batteries at $50 \%$ by average weight into materials 1002 for their original purpose or for other purposes and second, 1003 encourages technological developments that improve the envi1004 ronmental performance of batteries throughout their entire life. 1005 The reader can get precise and recent data regarding recycling 1006 end-of-life batteries, processing, and collections reported in refs 1007 146, 155, 182, and 184-187. Another hot point is that 1008 predictions underlined that all the material demand just for EV 1009 batteries will have to be supplied by resource extraction at least 1010 up to 2030 whatever the collection and recycling of spent 1011 battery electrode materials due to the eight-to-ten-year lifetime 1012 of EV batteries. ${ }^{143}$ Note that reuse of EV batteries can offset 1013 the production burden of new batteries by extending battery 1014 service life.

\subsection{Sustainability and Environmental Aspects}

1015 Beyond battery resource considerations which are getting all 1016 the attention today, let us also remember that mining opera1017 tions are destructive for the environment and energy-greedy 1018 and fall short of both the sustainability and $\mathrm{CO}_{2}$ footprint 1019 criteria. ${ }^{84,112}$ Moreover, the scarcity of most of these elements 1020 in the earth crust (Figure 6) could make their excavation more 1021 and more energy intensive and costly depending on the nature 1022 of the deposit because it must be kept in mind that elemental 1023 availability cannot be judged by crustal abundance alone (see 1024 ref 162 for more details). Moreover, after the extraction of 1025 ores, several refining steps are necessary to obtain the final 1026 reagents which will be engaged thereafter in high temperature 1027 synthesis reactions $\left(T \approx 600{ }^{\circ} \mathrm{C}\right)$ to produce the desired 1028 electrode material.

1029 At this stage, relevant data to evaluate potential environment 1030 concerns as well as the related energy cost for the production 1031 of batteries can be found in life cycle assessment (LCA) 1032 studies. Although LCA can be considered as a standardized 1033 methodology, it depends on the inventory database used and 1034 system boundaries. Consequently, LCA results in the literature 1035 differ significantly due to these uncertainties. Peters et al. ${ }^{192}$ 1036 have reported in 2017 an interesting review of LCA studies on 1037 LIBs. After a thorough review of 113 available publications 1038 on the topic, a total of 36 LCA studies were identified as very 1039 reliable because they provide detailed results for LIB produc1040 tion and sufficient information to recalculate the reported 1041 results. The conclusion is, on average, a cumulative energy 1042 demand (denoted "embodied energy") of $328 \mathrm{kWh}$ is needed across all chemistries to produce $1 \mathrm{kWh}$ of stored electro- 1043 chemical energy producing GHG emissions of $110 \mathrm{gCO}_{2}$ eq. 1044

Beyond LIBs, other similar values concerning $\mathrm{PbA}, \mathrm{Ni}-\mathrm{MH}, 1045$ or VRFBs can be found in the literature too. ${ }^{193,194}$ Note that 1046 the majority of existing studies are focused on GHG emissions 1047 or energy demand; however, other Eco indicators such as 1048 human toxicity (HTP) might be even more important. ${ }^{192,195} 1049$ More importantly, such LCA studies are restricted at the manu- 1050 facturing outlet ("cradle-to-gate analyses" and not "cradle-to- 1051 grave analyses"), so they do not take into account both 1052 collection and recycling steps. Yet the results obtained show 1053 that battery manufacturing is energy-intensive because of the 1054 involvement of quite high flows of exergy mainly due to the 1055 chemical nature of the commonly used materials (inorganic 1056 compounds). ${ }^{112,162}$

As a result, one common recommendation of current LCA 1058 analyses is the deployment of batteries with higher round-trip 1059 efficiency to extend the cycle life in operation but also the 1060 need for low-carbon innovations in future technologies while 1061 favoring the use of naturally abundant chemical elements of 1062 low toxicity. Within this background, one current trend in the 1063 post-LIB field is to reinvestigate $\mathrm{Na}$-ion batteries as candidates 1064 for medium and large-scale stationary energy storage in light 1065 of possible concerns in terms of cost and abundancy of 1066 lithium. ${ }^{174,196,197}$

1067

\subsection{Positioning Redox-Active Organic Species in the Battery Landscape}

1068

Within this background, which is particularly tense in many 1069 ways, the idea of taking advantage of organic chemistry for the 1070 electrochemical storage of energy can make sense. As stated in 1071 the Introduction, the idea to use organic electrode materials 1072 (OEMs) for rechargeable batteries is not new and goes back 1073 to the discovery of reversible redox-activity of conducting 1074 polymers in the late 70s following the discovery of PAc by 1075 Shirakawa ${ }^{61-64}$ and its subsequent electrochemical activity 1076 (doping) both in oxidation and in reduction. ${ }^{65,66}$ These findings 1077 led to the development of various conducting polymers as well 1078 as a first attempt to emerge in the marketplace before the boom 1079 of high-energy LIBs. ${ }^{59,69}$ Today the motivations are different and 1080 authors agree that organics can be notably seen as a pathway to 1081 stabilize the pressure on the CRM for energy storage while 1082 seeking to improve the environmental footprint as well as finding 1083 innovative storage solutions. ${ }^{42,84}$ Of course, OEMs have 1084 limitations especially when talking about volumetric energy 1085 density that can be achieved due to their intrinsic low 1086 volumetric mass densities $\left(<2 \mathrm{~g} \mathrm{~cm}^{-3}\right)$. Excluding ORFBs, this 1087 issue can be exacerbated by the need for large carbon addition 1088 when preparing composite electrodes. Moreover, their greater 1089 propensity to solubilize in liquids compared to inorganic com- 1090 pounds is an issue for solid electrodes but an asset for ORFBs. 1091 The development of organic batteries is clearly in its early 1092 stages compared to 150 years of intensive research and inno- 1093 vations dedicated to conventional inorganic-based electrochemical 1094 storage devices explaining why some room is expected to be given 1095 to redox-active organic species in the battery landscape. To be 1096 convinced, Figure 7 reports an interesting assessment for the 1097 electrochemical storage of OEMs classified by families. ${ }^{31}$ In fact, 1098 organics exhibit several interesting assets as recapped below. 1099

First, organics make potential access to low cost and greener 1100 chemistry possible because they are mainly composed of $\mathrm{C}, \mathrm{H}, 1101$ $\mathrm{O}, \mathrm{N}$, and $\mathrm{S}$, which are naturally abundant elements as well as 1102 the main constituents of biomass (Figure 6). ${ }^{191}$ This situation 1103 


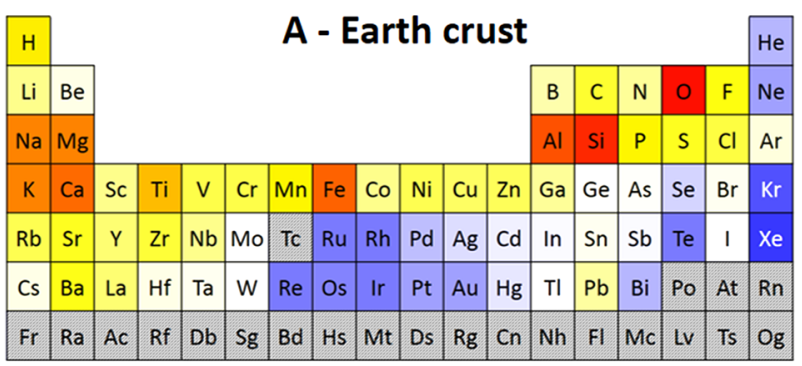

\begin{tabular}{|c|c|c|c|c|c|c|c|c|c|c|c|c|c|c|}
\hline \multirow{2}{*}{$\begin{array}{l}10^{3} \mathrm{ppm} \\
1 \mathrm{ppm} \\
10^{-3} \mathrm{ppm}\end{array}$} & $\mathrm{Ce}$ & $\mathrm{Pr}$ & $\mathrm{Nd}$ & $\mathrm{Pm}$ & Sm & Eu & $\mathrm{Gd}$ & $\mathrm{Tb}$ & Dy & $\mathrm{Ho}$ & $\mathrm{Er}$ & $\mathrm{Tm}$ & $\mathrm{Yb}$ & Lu \\
\hline & Th & $\mathrm{Pa}$ & U & $\mathrm{Np}$ & $\mathrm{Pu}$ & Am & $\mathrm{cm}$ & Bk & Cf & ES & $\mathrm{Fm}$ & $\mathrm{Md}$ & No & $\mathrm{Lr}$ \\
\hline
\end{tabular}
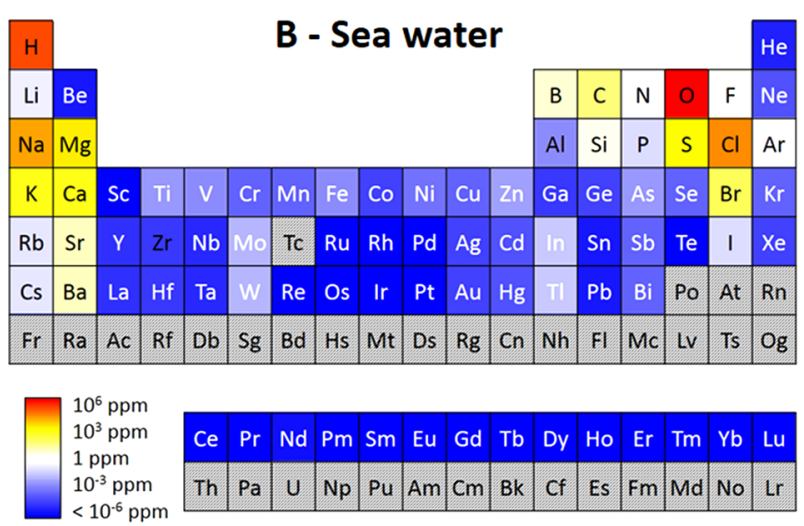

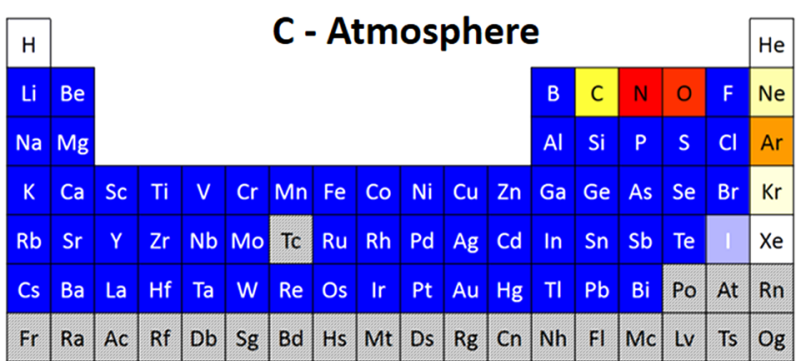

$10^{6} \mathrm{ppm}$ $10^{3} \mathrm{ppm}$ $1 \mathrm{ppm}$ $10^{-3} \mathrm{ppm}$ $<10^{-6} \mathrm{ppm}$
Ce $\operatorname{Pr}$ Nd Pm Sm Eu Gd Tb Dy Ho Er Tm Yb Lu

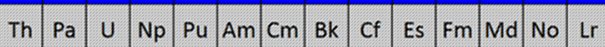

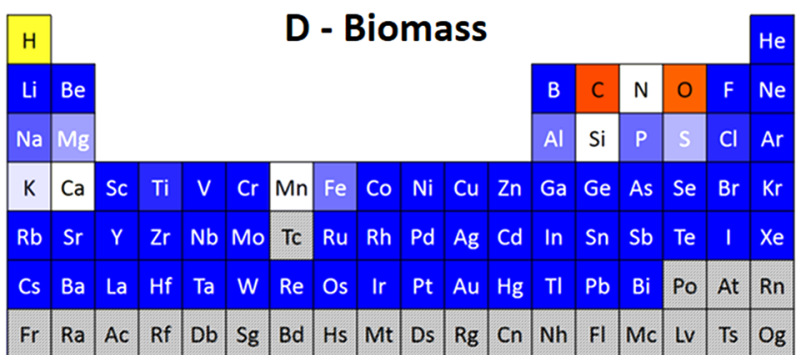

$10^{6} \mathrm{ppm}$ $10^{5} \mathrm{ppm}$ $10^{4} \mathrm{ppm}$

$10^{3} \mathrm{ppm}$

$<10^{2} \mathrm{ppm}$
Ce $\operatorname{Pr}$ Nd Pm Sm Eu Gd Tb Dy Ho Er Tm Yb Lu

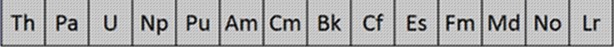

Figure 6. Periodic tables showing the abundance of elements in the Earth's crust (A), in the seawater (B), in the atmosphere (C), and in biomass (D); elements in gray indicate natural and/or radioactive elements. Courtesy of L. Simonin, CEA-Liten, adapted from ref 188 taking into account data from refs 189-191. This analysis highlights that among the naturally occurring elements only a few of them are abundant in each of these four compartments, which demonstrates the importance of developing recycling solutions too.

1104 offers opportunities to prepare electrodes (and other components 1105 in a cell like binders) ${ }^{198}$ from renewable resources benefiting from 1106 ongoing progress in the vast field of biorefineries too. ${ }^{199-201}$ 1107 Hydrolysis lignin features were even assessed in primary Li-cell ${ }^{202}$ 1108 or more interestingly in combination with PPy in an inter1109 penetrating lignosulfonate/PPy thin-film composite electrode 1110 tested in $0.1 \mathrm{M}$ aqueous $\mathrm{HClO}_{4}$ as electrolyte, with the 1111 catechol moiety in lignin being used for reversible electron and 1112 proton storage/uptake. ${ }^{203}$ Several naturally occurring poly1113 phenols (e.g., ellagic acid, ${ }^{204}$ purpurin, ${ }^{205}$ lawsone ${ }^{206}$ ) were 1114 electrochemically assessed in $\mathrm{Li} / \mathrm{Na}$ half cells; however, the 1115 proof of concept of making a "renewable" all-organic Li-ion 1116 battery was first demonstrated with oxocarbon derivatives as 1117 active electrode materials ten years ago. ${ }^{82-84}$ Esquivel and 1118 co-workers ${ }^{207}$ have also demonstrated opportunities for portable 1119 and disposable single-use applications to power small devices 1120 with the concept of PowerPAD (Power: Portable And Disposable), 1121 a fully organic and completely biodegradable battery designed 1122 to operate for relatively short periods of time (from minutes to $1123 \mathrm{l}-2 \mathrm{~h}$ ). The promising field of ORFBs (see section 9) has also 1124 demonstrated interest in the use of redox-active naturally 1125 occurring polyphenols/quinones for abundancy and cost 1126 reasons. $^{20,34}$ At this stage, it must be underlined that common 1127 routes to synthesize OEMs in this emerging field deal with 1128 petrochemicals. However, even if large scale production were 1129 used for high-performance OEMs in the future, petrochemicals 1130 are higher-value products than petroleum products for 1131 combustion (only a small fraction $(\approx 4 \%)$ of oil worldwide is used to make chemicals ${ }^{42}$ ). In terms of cost, it is difficult to 1132 make predictions for petrochemical reagents notably if in the 1133 future the demand for petroleum products used for combustion 1134 decreases; the access to new markets and applications can 1135 change the game. However, it is generally accepted that 1136 fluorinated derivatives are among the most expensive compounds. 1137

Second, simplified recycling managements of organic spent 1138 batteries (Figure S7) can be expected notably with solid 1139 electrodes since organic structures are typical fuels that can be 1140 consumed by combustion at medium temperatures producing 1141 heat (energy recovery). Interestingly, if spent organic batteries 1142 were inadvertently not collected (spread out in the wild), the 1143 loss of scarce and costly metallic chemical is notably reduced 1144 compared to the current battery technologies. Moreover, the 1145 use of biodegradable materials can be envisaged too. 1146

Last but not least, organic chemistry offers high structural 1147 designability providing great opportunities to find novel and 1148 innovative electrode materials with specific properties includ- 1149 ing the elaboration of multimodal systems such as electro- 1150 chemical/chemical or electrochemical/photochemical rechar- 1151 geability. ${ }^{208-210}$ More importantly, physicochemical properties 1152 can be rationally tuned using well-established principles of 1153 organic chemistry and molecular engineering giving access to 1154 redox-active species able to work:

- from dissolved to solid state (including polymers) in 1156 aqueous or nonaqueous electrolytes making them 1157 versatile in terms of electrochemical storage devices 1158 including access to flexible devices; 


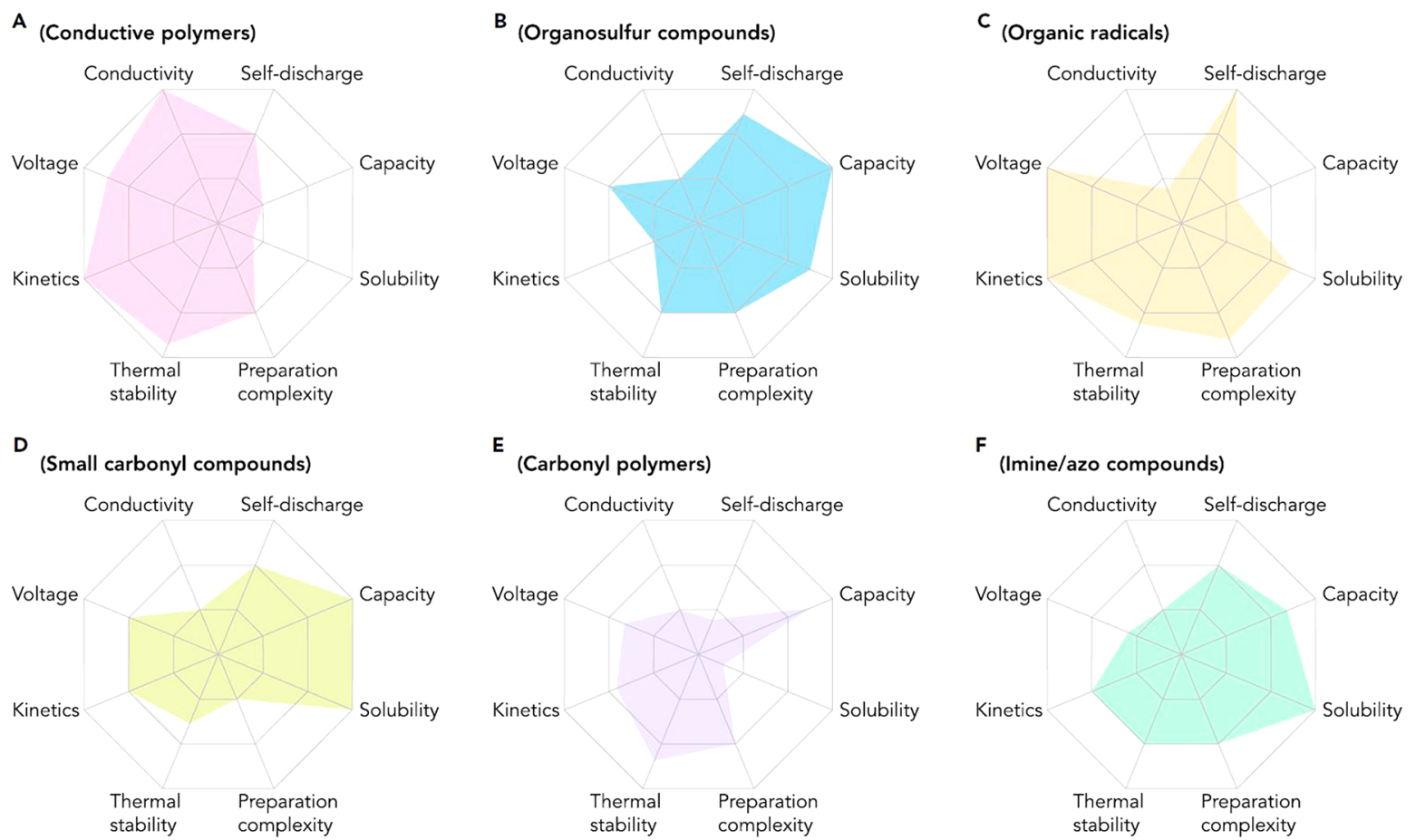

Figure 7. Overview of fundamental properties of different types of organic electrode materials. Reproduced with permission from ref 38 . Copyright 2018 Elsevier Ltd. 1182 nability through this multiplicity of chemical combinations at 1183 the molecular level, it could be somewhat challenging to grasp 1184 the electrochemical working principle of the reported OEMs in 1185 the literature for researchers more familiar with inorganic 1186 electrode materials. In the next section we will try to make under1187 standable all the redox functioning of organic molecular assemblies 1188 with the basics of electrochemical cells as a starting point.

\section{FUNDAMENTALS OF ORGANIC ELECTRODE 1189 COMPOUNDS FOR ELECTROCHEMICAL STORAGE}

\subsection{Basics of Electrochemical Cells}

1190 As reported in all undergraduate chemistry books, primary and 1191 secondary (rechargeable) cells (or batteries) produce discharge
DC current for an output voltage of a few volts by direct con- 1192 version of chemical energy by virtue of two opposite oxidation- 1193 reduction processes occurring at two separated electrodes 1194 (current collectors) maintained in ionic contact through an 1195 electrolytic medium (Figure 8) ${ }^{84}$ In such a situation, the two 1196 half redox reactions taking place at electrodes are called 1197 "electrochemical reactions". During discharge (spontaneous 1198 cell reaction or galvanic cell reaction), the electrochemical 1199 reduction reaction occurs at the positive electrode whereas the 1200 electrochemical oxidation reaction occurs at the negative 1201 electrode. For rechargeable cells, the terminology should be 1202 obviously reversed during charge (electrolysis cell reaction). 1203 Therefore, to avoid confusions, the terms "positive" electrode 1204 or "negative" electrode are preferred whatever the considered 1205 cell reaction (i.e., charging or discharging), with the positive 1206 electrode always displaying the highest potential value. Note 1207 that a cell is the basic electrochemical unit. A battery is com- 1208 posed, strictly speaking, of two or more such cells connected in $1209 \mathrm{~g}$ series or parallel. However, the term battery has evolved, 1210 especially in the language of the end user; therefore, the term 1211 "battery" will be used herein without this distinction for the 1212 sake of simplicity.

1213

The use of two antagonist redox couples is then required 1214 with (e.g., $O x_{1} / \operatorname{Red}_{1}$ and $O x_{2} / \operatorname{Red}_{2}$ characterized by standard 1215 potentials $\left.E^{\circ}\left(O x_{1} / \operatorname{Red}_{1}\right)>E^{\circ}\left(O x_{2} / \operatorname{Red}_{2}\right)\right)$ to reach high 1216 electromotive force $\left(e m f=E_{I=0}\right.$, in V) at the cell level under 1217 zero current since emf depends on the difference $E^{\circ}\left(O x_{1} / \operatorname{Red}_{1}\right) 1218$ $-E^{\circ}\left(\mathrm{Ox}_{2} / \mathrm{Red}_{2}\right)>0$ or more generally on the difference $E(+) 1219$ $-E(-)>0$. In short, it depends on the thermodynamics of the 1220 chosen electrode chemistries because $E_{I=0}$ is related to the 1221 Gibbs free energy change of the galvanic cell reaction, $\Delta_{\mathrm{r}} G$, as $1222 \mathrm{~g}$ follows: $\Delta_{\mathrm{r}} G=-n \cdot E_{\mathrm{I}=0} \cdot F$ ( $n$ being the number of electrons 1223 involved in the cell reaction and $F$ is the Faraday constant, 1224 equal to $96,485 \mathrm{C} \mathrm{mol}^{-1}$ ). Under discharge current (I, in $\mathrm{mA}$ ), 1225 for example, the operating voltage, $E_{I \neq 0}$, is lower than the $E_{I=0} 1226$ 


\section{a) Fully discharged state}

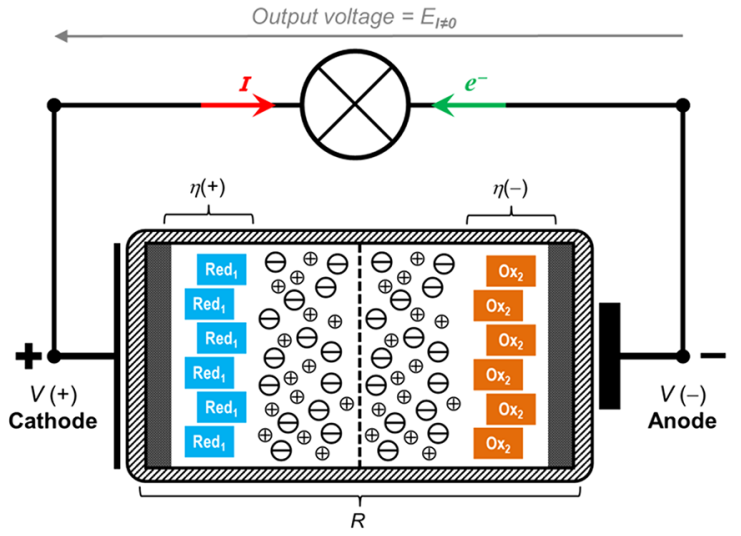

\section{b) Fully charged state}
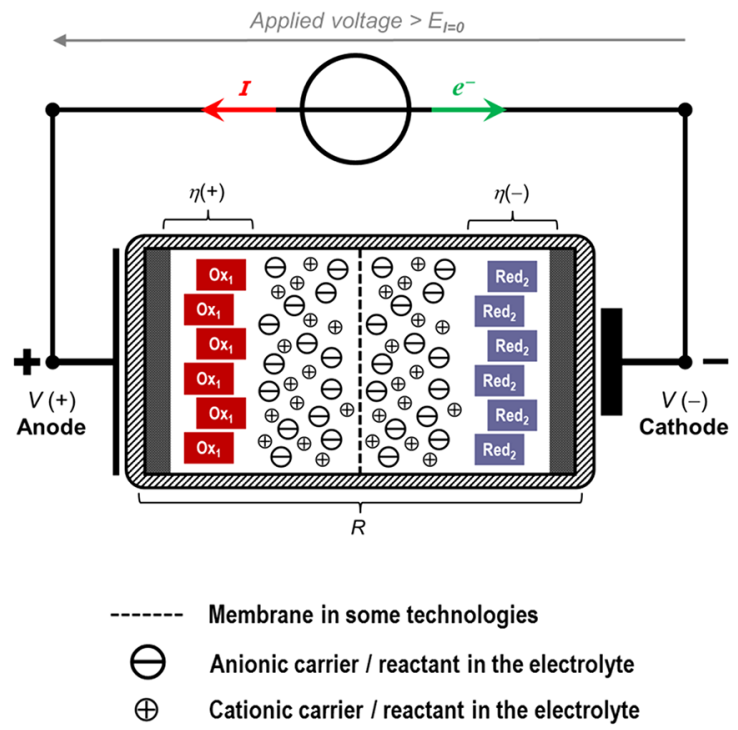

Figure 8. General architecture of an electrochemical cell for energy storage whatever the considered technology is. Note that additional electrolyte can be stored externally and then pumped through the cell in the particular case of a flow battery (see Section 9). (a) Cell under discharge (namely galvanic cell) at $100 \%$ depth-of-discharge (DOD). (b) Cell under charge (namely electrolysis cell) at 100\% state-of-charge (SOC); the electromotive force value $\left(e m f=E_{I=0}\right)$ is, in principle, at the maximum value. The measured capacity, $Q$ (in $m A h$ ), is experimentally obtained by integrating the operating time with current: $Q=\int_{0}^{t} I(t) \cdot d t=I \cdot \Delta t$ which gives rise to $Q=I \cdot \Delta t$ whereas the energy, $\varepsilon$ (in $\mathrm{mWh}$ ), is obtained by multiplying $Q$ with the voltage $E_{I \neq 0}$.

1227 value because of $(i)$ kinetic limitations at the electrodes 1228 (overpotentials or polarization losses, $\eta$ ) and (ii) ohmic drop 1229 (" $R \cdot I$ " term) due to the overall ohmic resistance $(R$, in $\Omega$ ) of 1230 electrodes and electrolytes as shown below:

$$
E_{\mathrm{I} \neq 0}=[E(+)-E(-)]-[\eta(+)+\eta(-)]-[R \cdot I]
$$

1231 Obviously, high $E_{I=0}$ values with minimum losses in 1232 operation are sought after together with high capacity values, ${ }_{1233} Q$ in $C$ (or Ah a unit more generally used in the field of 1234 electrochemical generators). By virtue of Faraday's law, the 1235 theoretical expected $Q$ value of a cell is proportional to $n$ and 1236 the amounts of the redox (electroactive) chemical species. 1237 Normalizations of $Q$ are often reported to make performance 1238 comparison easier giving rise for example to specific capacity $1239\left(Q_{m}\right)$ per gram of electroactive compound and volumetric 1240 capacity $\left(Q_{v}\right)$ per $\mathrm{cm}^{3}$ of electroactive compound ( $M$ being the 1241 molar mass and $\rho$ the specific density of the electroactive 1242 species, respectively):

$$
\begin{aligned}
& Q_{m}\left(\mathrm{C} \mathrm{g}^{-1}\right)=n \cdot F / M \text { or } Q_{m}\left(\mathrm{mAh} \mathrm{g}^{-1}\right)=n \cdot 26805 / M \\
& Q_{v}\left(\mathrm{C} \mathrm{cm}^{-3}\right)=n \cdot F \cdot \rho / M \text { or } Q_{v}\left(\mathrm{mAh} \mathrm{cm}^{-3}\right)=n \cdot 26805 \cdot \rho / M
\end{aligned}
$$

1243 Multiplying $Q$ with $E_{I \neq 0}$ at any time during the discharge makes 1244 the calculation of the as-obtained energy, $\varepsilon$ (in $\mathrm{mWh}$ ). Of course, 1245 high reversibility of the cell reaction (good cyclability), high 1246 Coulombic efficiency, and low self-discharge are notably required 1247 for long-lasting cycling of rechargeable batteries. More details can 1248 be found in specialized books (see for example, ref 2).

\subsection{Bridging the Gap between Inorganic and Organic} 1249 Redox Chemistry

1250 As previously recapped, oxidation-reduction reactions make elec1251 tricity production possible when properly used in a two-electrode 1252 cell design. Hence, redox-active chemical systems (especially reversible ones) constitute the workhorse of the electrochemist 1253 in the design of electrochemical generators. Beyond exploiting 1254 the potential values of redox couples (thermodynamics) to 1255 decide if the interest for a given system is related to positive or 1256 negative electrode application, the electrochemist follows with 1257 a great deal of interest variations of oxidation states (OS; or 1258 oxidation number, $O N$ ) of chemical elements constituting 1259 the considered redox couples because it allows us to readily 1260 understand and rationalize the formal involved redox center as 1261 well as subsequently determine the number of electrons involved 1262 in the half-reaction. Latimer appears to be the first to introduce 1263 this concept within the context of redox half-reactions. ${ }^{215} 1264$

According to the IUPAC definition, ${ }^{216}$ the OS of an atom is 1265 the charge of that atom after an ionic approximation of its 1266 heteroatomic bonds. The bonds between atoms of the same 1267 element are not replaced by ionic bonds; they are divided 1268 equally. In other words, to determine the $O S$ of a given atom, it 1269 is therefore considered that all heteroatomic bonds in which it 1270 participates are $100 \%$ ionic and the electrons of each of these 1271 bonds are assigned to the most electronegative atom (Allen's scale). 1272 Moreover, IUPAC recommends two closely related general algo- 1273 rithms for OS calculation in molecules, ions, and extended solids: ${ }^{216} 1274$

- Algorithm of assigning bonds. This algorithm works on 1275 structural Lewis formulas of molecules and ions which 1276 show all valence electrons.

1277

- Algorithm of summing bond orders. This algorithm 1278 works on structural Lewis formulas and bond graphs for 1279 an extended solid, especially iono-covalent structures. $\quad 1280$

However, as thoroughly explained above, because the used 1281 redox chemistry in battery applications is related to the OS 1282 change of the 3d-metallic redox centers (e.g., Ti, V, Mn, Fe, 1283 $\mathrm{Co}, \mathrm{Ni}$ ) or elemental/diatomic substances (e.g., $\mathrm{Li}, \mathrm{Na}, \mathrm{Mg}, \mathrm{C}, 1284$ $\left.\mathrm{O}_{2}, \mathrm{Si}, \mathrm{P}, \mathrm{S}, \mathrm{Sn}\right)$, ${ }^{11}$ a set of more general rules for determining 1285 $O S$ is more readily used (e.g., "the sum of OS for all atoms in the 1286 
1287 species is zero to ensure electroneutrality", "Fluorine: - 1", 1288 "Oxygen: - 2 unless combined with fluorine", and so on) as 1289 nicely recalled by Walsh et al. ${ }^{217}$ Although not recommended 1290 by IUPAC, this simplest method is quite sufficient to assign $O S$ 1291 of most (inorganic) ions and extended solids. Complications 1292 occur when two identical atoms have different $O S$ in the same 1293 compound like observed with several inorganic compounds 1294 based on chemical elements prone to catenation (e.g., C, N, S, $1295 \mathrm{Si}, \mathrm{I})$. This is precisely the situation encountered with organic 1296 compounds, which justifies the use of the algorithm of assigning 1297 bonds recommended by IUPAC based on Lewis formulas of 1298 molecules and ions to determine OS or organics. In practice, after 1299 assignment of electrons of each bond to the most electronegative 1300 element, the $O S$ of element " $i$ " is calculated as follows:

$$
\begin{aligned}
\text { OS }(i)= & \text { valence electrons of the element }{ }^{\prime \prime} i^{\prime \prime} \\
& -\sum \text { assigned electrons }
\end{aligned}
$$

1301 Two selected examples are shown below including the case of 1302 the inorganic thiosulfate anion $\left(\mathrm{S}_{2} \mathrm{O}_{3}{ }^{2-}\right)$ considering that the 1303 sulfur-sulfur bond is practically a single bond together with $1304 p$-benzoquinone as representative redox-active organic molecule. 1305 Note that only half of OS are reported due to the molecule 1306 symmetry whereas the green lines indicate the electrons 1307 assigned per atom. To briefly comment on the redox activity of 1308 -benzoquinone, each carbon atom bearing the oxygen (in 1309 bold) exhibits an $O S$ value of +2 that is decreased at +1 after 1310 the two-electron reduction to produce $p$-hydroquinone.
Thiosulfate anion

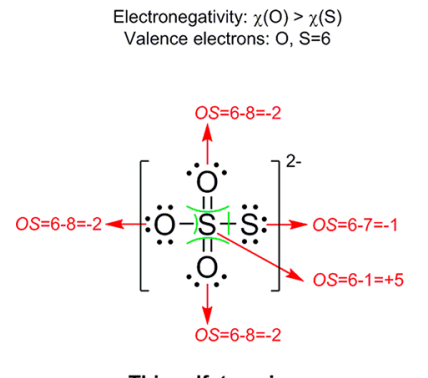

Electronegativity: $\chi(\mathrm{O})>\chi(\mathrm{C})>\chi(\mathrm{H})$ Valence electron(s): $\mathrm{H}=1 ; \mathrm{C}=4 ; \mathrm{O}=6$

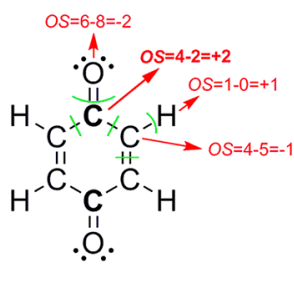

$p$-Benzoquinone

\subsection{Reversible Organic Redox Chemistry and Cell} 1311 Configurations

1312 Oxidation-reduction processes in organic chemistry, which 1313 commonly involve both $s$ and $p$ orbitals, can be classified in 1314 two different groups. In the first group, the electronic process 1315 is accompanied by atom transfer reaction (e.g., gain of oxygen 1316 for oxidation or hydrogen for reduction) including possible 1317 fragmentation or condensation subsequent reactions. ${ }^{218}$ However, 1318 such organic redox reactions are basically used for organic 1319 synthesis purpose as shown below in the case of the hydro1320 genation reaction of the most accessible double bond of 1321 limonene (reduction process of the $\mathrm{C}=\mathrm{C}$ double bond with 1322 decreasing of the $O S$ of the two carbon atoms whereas the two 1323 incorporated $\mathrm{H}$ atoms exhibiting an $\mathrm{OS}$ of +1 ).
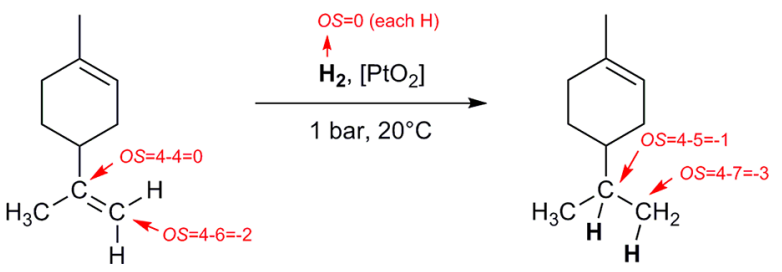

More interestingly for us are the redox processes for which 1324 no formation or rupture of electron-pair single bonds occurs 1325 after simple charge transfer reaction. In this latter case, 1326 stepwise transfer of single electrons must in principle be taken 1327 into account ${ }^{219}$ giving potentially access to reversible organic 1328 redox couples like conventional third-kind electrode reactions 1329 (e.g., $\left.\mathrm{Ce}^{4+}+e^{-} \rightleftharpoons \mathrm{Ce}^{3+}\right)$. However, caution should be 1330 exercised because one-electron oxidation or reduction of a 1331 neutral or ionic organic scaffold produces generally reactive ion 1332 radicals or radicals with possible subsequent reaction such as 1333 radical coupling. Consequently, some chemical tricks have to 1334 be used to ensure the production of stable (persistent) radical 1335 structures after charge transfer. ${ }^{220,221}$ Thus, simple $\pi$-extension 1336 and substituents of resonance electron donating or with- 1337 drawing groups (mesomerism) make delocalization of spin and 1338 charge density possible which deeply reduces the reactivity of 1339 the odd electron (e.g., galvinoxyl or tris(pentachlorophenyl)- 1340 methyl radicals). Aromatization after electron transfer and 1341 appropriate steric protection play also important role to protect 1342 a reactive radical center. Robust functional groups bearing an 1343 unpaired electron also exist such as nitroxide radicals $\left(>\mathrm{N}-\mathrm{O}^{\bullet}\right) .1344$ In this family, 2,2,6,6-tetramethylpiperidinyl- $N$-oxy (TEMPO) 1345 constitutes the most representative example. Beyond the reali- 1346 zation of magnetic organic materials, ${ }^{221}$ the nitroxide redox 1347 chemistry is at the origin of the rise of ORBs, ${ }^{10,75-77}$ a field 1348 particularly studied by Nishide, Oyaizu, and co-workers as 1349 previously underlined in the Introduction. Finally, the general 1350 structure principles that lead to multistage organic redox 1351 systems (expected reversible from a redox point of view) are 1352 owed to Deuchert and Hünig ${ }^{219}$ reported in a comprehensive 1353 article published in 1978 .

1354

Figure 9a recalls the three general key organic structures and 1355 their related charge transfer steps deriving from Hünig's 1356 classification together with representative examples of chemical 1357 compounds. Basically, two electrochemical storage mecha- 1358 nisms are accessible with organics characterized either by anion 1359 charge compensation (p-type system or System A) or by cation 1360 charge compensation (n-type system or System B); System C 1361 being a mixed assembly also named "bipolar" system. At other- 1362 wise constant conditions it is worth noting that redox-active 1363 p-type moiety exhibits as a rule higher formal potential values 1364 compared to n-type systems. ${ }^{219}$ Figure 9b shows the corre- 1365 sponding cell configurations. For instance, developing Li-ion 1366 organic batteries requires two n-type compounds (Figure 9b-1). 1367 The p-type redox reactivity is rarely encountered with inorganic 1368 electrode materials. Except carbonaceous materials which 1369 intercalate ions at relatively high potential (use as positive 1370 electrode), ${ }^{222-225}$ only a few conversion-type electrode 1371 materials have been reported to date (for F-ion batteries) 1372 exhibiting however poor electrochemical performances. ${ }^{226}$ On 1373 the other hand, p-type organic compounds enable, in principle, 1374 the development of anionic rocking-chair cells ${ }^{227,228}$ and 1375 potentially full "molecular" organic-ion batteries if the shuttling 1376 anion is metal free (Figure 9b-2). Nevertheless, the cell 1377 assembly most often encountered in the literature remains the 1378 dual-ion battery (Figure 9b-3) as recently review by Zhou 1379 et al. ${ }^{229}$ The use at the electrode level of advanced mixed 1380 $\mathrm{p} / \mathrm{n}$-type organic scaffolds that exchange simultaneously 1381 cations and anions can also be envisaged as recently shown 1382 in aqueous batteries with naphthalene diimide repeating units 1383 coupled to bipyridinium. ${ }^{230-232}$ The molecular engineering 1384 can even allow cation shuttling in the electrolyte while using 1385 p-type electrodes as reported by Nishide, Oyaizu, and co-workers 1386 
a) Electrochemical storage mechanisms using redox-active organic centers

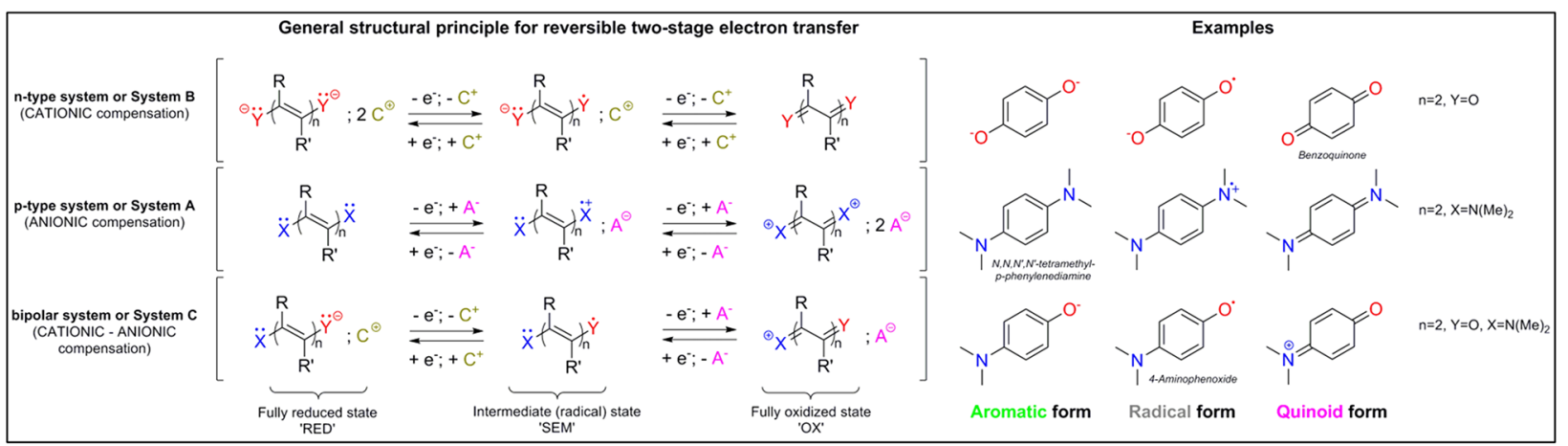

b) Related cell assemblies

(1): Cationic rocking-chair cell

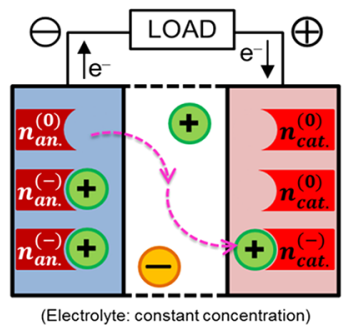

(2): Anionic rocking-chair cell

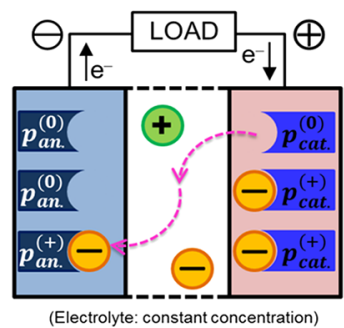

(3): Dual-ion cell

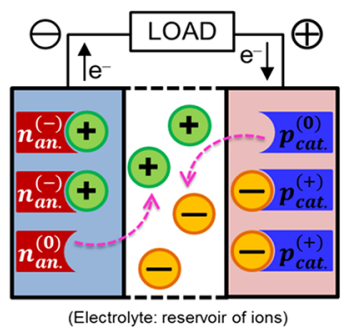

Figure 9. (a) Key reversible redox-active organic systems at the molecular level and their related charge transfer steps (adapted from refs 219 and 234) together with representative examples exhibiting the redox rocking from aromatic to quinoid form. $X / Y$ could be N, O, S, P, $\pi$-systems but also carboxylate, anhydride, or amide functional groups; $R, R^{\prime}$ being potentiality integrated within the same cyclic structure. Note that that $p$ - and $\mathrm{n}$-type structures correspond to system A and B, respectively, according to Hünig's classification. ${ }^{219}$ (b) Corresponding cell configurations obtained by playing with both $n$ - and p-type systems shown during the discharge process. Again, additional electrolyte can be stored externally and then pumped through the cell in the particular case of a flow battery (see Section 9). Adapted with permission from ref 36. Copyright 2018 Elsevier Ltd.

1387 with copolymer compositions of TEMPO-sulfonate anionic 1388 group. $^{233}$

1389 Finally, before reporting our selection (with description) of the 1390 best organic-based batteries to date, a summary of the organic 1391 families of interest for electrochemical storage is shown in Table 1 1392 demonstrating the richness in terms of formal redox center as well 1393 as the relevance of conjugated structures in general.

\section{PERFORMANCES OF NONAQUEOUS 1394 LITHIUM-ORGANIC BATTERIES}

1395 This section constitutes the first in a series of five (from section 13965 to 9) in which a personal selection of organic-based recharge1397 able cells will be described and commented on. Nonaqueous $1398 \mathrm{Li}$-organic batteries have by far the longest history among all 1399 branches of battery OEMs applications. The results from these 1400 pieces of research have also directly fueled or inspired the 1401 design of OEMs for other emerging organic batteries. Several 1402 comprehensive review articles have covered virtually every 1403 category of OEMs used in Li-organic batteries; ${ }^{9,39,43,47}$ hence, 1404 another comprehensive write-up on the topic is not intended 1405 herein. Instead, we will focus on the best performance ever 1406 achieved by OEMs in these batteries as well as the design 1407 rationale behind these successes. In particular, three key 1408 performance parameters will be reviewed: operating potential, 1409 specific capacity, and cycling stability. The properties and cell 1410 performance of these materials are summarized for compre1411 hensive comparison (Table 2).

\subsection{Positioning the Operation Voltage}

1412 A large variety of redox active functional groups have been 1413 explored for designing OEMs for Li-based batteries, and the voltages of cells based on these OEMs vary by a wide extent as 1414 a result. Depending on their operating potentials, OEMs may 1415 be used either as positive electrode $\left(>2.2 \mathrm{~V}\right.$ vs $\left.\mathrm{Li}^{+} / \mathrm{Li}\right)$ or 1416 negative electrode $\left(<1.5 \mathrm{~V}\right.$ vs $\left.\mathrm{Li}^{+} / \mathrm{Li}\right)$ active materials. Again, 1417 OEMs intrinsically showing the highest potentials, e.g. $>3.5 \mathrm{~V} 1418$ vs $\mathrm{Li}^{+} / \mathrm{Li}$, are p-type compounds which, upon charge, lose 1419 electrons and accept anions from the electrolytes (Figure 9). 1420 As previously mentioned, conductive polymers, which had 1421 been intensively studied as positive electrode materials to 1422 enable Li batteries (dual-ion cell configuration, Figure 9b-3), 1423 fall into this category too. Prime examples include the PAc ${ }^{292} 1424$ (Table 2, entry 1), PAni, PPy, PT, and poly( $p$-phenylene) 1425 families. ${ }^{59}$ Their operating potentials vary according to the 1426

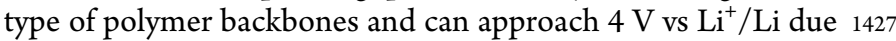
to the p-type redox activity. The charge storage mechanism 1428 of conductive polymers is based on multiple $\pi$-conjugated 1429 repeating units stabilizing one positive charge via charge 1430 delocalization. Unfortunately, as more charges are stored, fewer 1431 repeating units are available to stabilize the charges, and the 1432 polymers become less stable.

1433

More recent designs of high-potential p-type OEMs relied 1434 on dedicated redox centers for positive charge stabilization. 1435 These redox centers usually involve either carbon, oxygen, or 1436 nitrogen centers stabilized by aromatic structures and electron- 1437 donating functional groups. The polycyclic aromatic hydro- 1438 carbon coronene mimics mini graphene sheets and reversibly 1439 gives out 0.68 electrons per molecule upon charging (Table 2, 1440 entry 2). ${ }^{235}$ It delivers one of the highest average discharge 1441 potentials of $4.0 \mathrm{~V}$ vs $\mathrm{Li}^{+} / \mathrm{Li}$ among OEMs. 2,3,6,7,10,11- 1442 Hexamethoxytriphenylene (HMTP) undergoes a full one- 1443 electron redox reaction despite the smaller polycyclic aromatic 1444 
Table 1. A Few Electrochemical Storage Mechanisms in Redox-Active Organics Together with Examples ${ }^{a}$

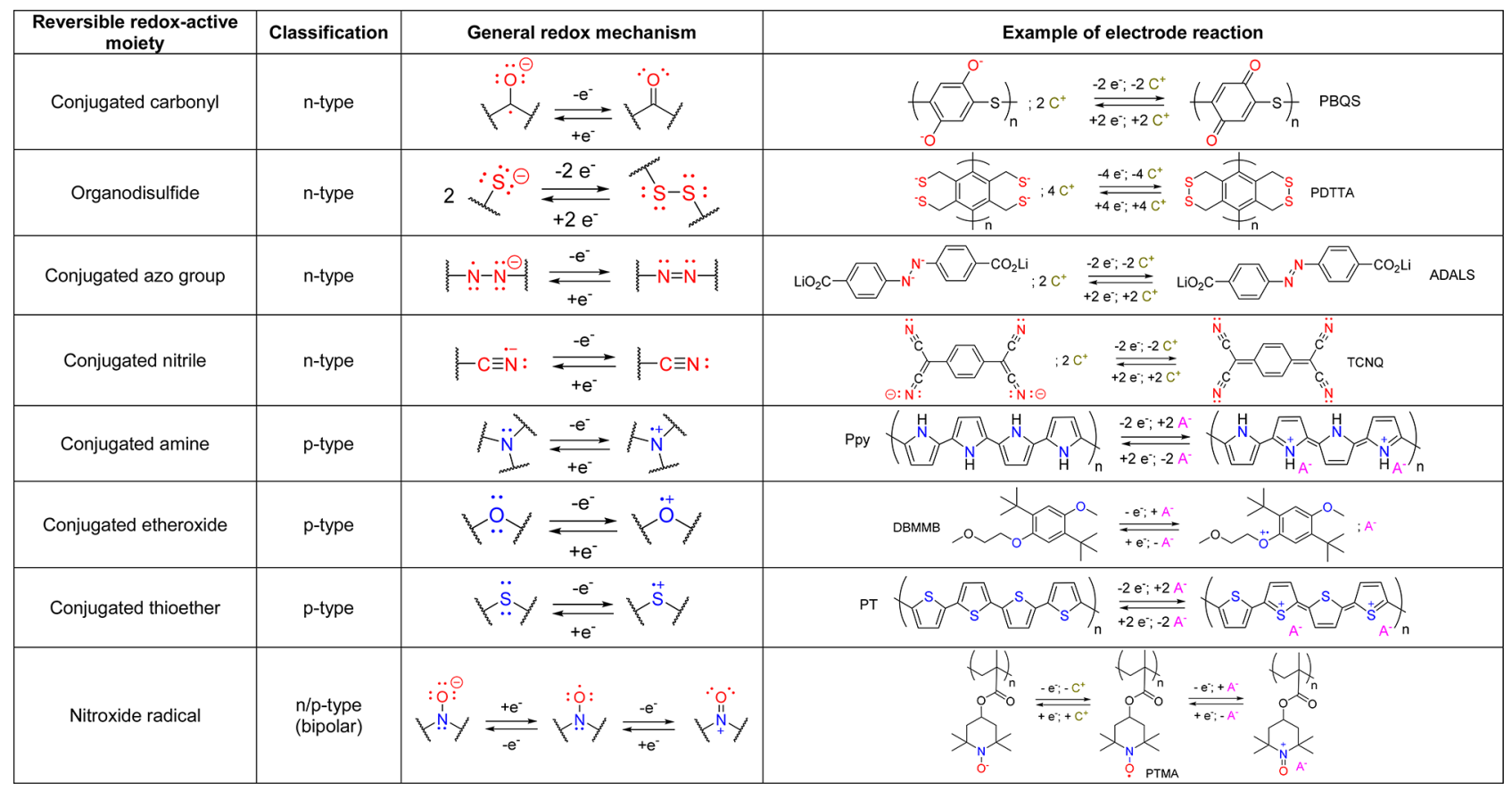

${ }^{a}$ PBQS: poly(benzoquinonyl sulfide); PDTTA: poly(5,8-dihydro- $1 H, 4 H-2,3,6,7$-tetrathia-anthracene; ADALS: azobenzene-4,4'-dicarboxylic acid lithium salt; TCNQ: tetracyanoquinodimethane; PPy: polypyrrole; DBMMB: 2,5-di-tert-butyl-1-methoxy-4-[2'-methoxyethoxy]benzene; PT: polythiophene; PTMA: poly(2,2,6,6-tetramethylpiperidinyloxy-4-yl methacrylate). Note the redox-active nitroxide radical is bipolar, in practice, good kinetics are only attempted with the p-type activity.

1445 hydrocarbon core than that found in coronene (Table 2, 1446 entry 3). ${ }^{236}$ The auxiliary electron-donating methoxy groups 1447 seem to have contributed to the higher p-doping level albeit 1448 with a lower discharge potential of $3.5 \mathrm{~V}$ vs $\mathrm{Li}^{+} / \mathrm{Li}$. 1449 Tetrathiafulvalene (TTF) is a $\pi$-conjugated molecule famous 1450 for its distinctive electronic properties in the highly stabilized 1451 oxidized form. OEMs incorporating the TTF structure, such as 1452 2,2' -bis [5-(1,3-dithiol-2-ylidene)-1,3,4,6-tetrathiapentanyli1453 dene] (TTPY, Table 2, entry 4) and pentakis-fused TTF 1454 (Table 2, entry 5), show almost full utilization of two electrons 1455 per TTF unit in the molecules thanks to the strong stabilizing 1456 power of the sulfur atoms. ${ }^{237}$ Pentakis-fused TTF shows a

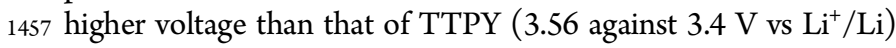
1458 due to the higher number of electrons involved in the reaction 1459 (Figure 10A). ${ }^{238}$

1460 Beyond conjugated hydrocarbon and thioether families, the 1461 one-electron oxidation reaction of nitroxide radical ${ }^{10,75-77}$ has 1462 spawned a large body of literature on radical polymer electrodes 1463 (Table 1). The poster-child building block of radical polymers 1464 is 2,2,6,6-tetramethyl-1-piperidinyloxy (TEMPO), where the 1465 nitroxide radical is sterically stabilized by the neighboring 1466 methyl groups. Polymers incorporating the TEMPO block, 1467 most notably poly(2,2,6,6-tetramethyl-1-piperidinyloxy-4-yl 1468 methacrylate) (PTMA) (Table 2, entry 6), deliver discharge 1469 potential of $\sim 3.55 \mathrm{~V}$ vs $\mathrm{Li}^{+} / \mathrm{Li}$ (Figure 10B). ${ }^{75,239}$ The 1470 potential can be tuned by using different nitroxide-containing 1471 cores. For example, poly(2,2,5,5-tetramethyl-3-oxiranyl-3-pyrro1472 lin-1-oxyl ethylene oxide) (PTEO, Table 2, entry 7), which 1473 contains the 2,2,5,5-tetramethyl-1-pyrrolidineoxy (PROXYL) 1474 core, shows a higher potential of $3.7 \mathrm{~V} \mathrm{vs} \mathrm{Li}^{+} / \mathrm{Li}^{240}$ Recently, 1475 a nonradical oxygen center was reported in the form of dibenzo1476 1,4-dioxin (DD) (Figure 10C, Table 2, entry 8). ${ }^{241}$ A remark-

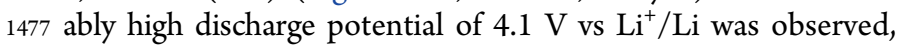

though only one out of the two oxygen atoms in the molecule 1478 contributed to charge storage. Nitrogen centers in aromatic 1479 amines may be easier to incorporate into a molecule from the 1480 organic synthesis point of view. Triphenylamine (TPA) is 1481 among the most studied building blocks in organic electronics. 1482 TPA-based OEMs, such as triphenylamine-based polymers 1483 (PTPA, Table 2, entry 9) show competitive discharge 1484 potentials of $\sim 3.6 \mathrm{~V} \mathrm{vs} \mathrm{Li}^{+} / \mathrm{Li}^{242}$ Many other aromatic amines 1485 have been studied as OEMs as well including small mole- 1486 cules $^{243,244}$ and organic salt forms such as dilithium 2,5- 1487 (dianilino)terephthalate $\left(\mathrm{Li}_{2} \mathrm{DAnT}\right)$, which are quite less soluble 1488 than non-salt molecules as further explained below (Table 2, 1489 entry 10). ${ }^{245}$

Compared with p-type OEMs, the n-type counterparts have 1491 attracted greater research interest because of giving access 1492 to the reversible storage of $\mathrm{Li}^{+}$and potentially to cationic 1493 "rocking-chair"-type batteries when n-type electrode materials 1494 are properly designed (Figure 9). $p$-Benzoquinone ( $p$-BQ) is 1495 one of the most studied n-type building blocks for OEMs 1496 (Table 1). The basic p-BQ molecule shows two discharge 1497 plateaus at 2.9 and $2.5 \mathrm{~V}$ vs $\mathrm{Li}^{+} / \mathrm{Li}$ with equal capacities, 1498

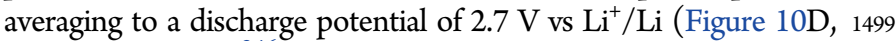
Table 2, entry 12). ${ }^{246}$ OEMs resembling the $p$-BQ structure show 1500 similar potentials as $p$-BQ. $\mathrm{BBQ}$ a dimer of $p-\mathrm{BQ}$ and $1,4,5,8-1501$ phenanthrenediquinone (PADQ), a three-ring molecule incorpo- 1502 rating two $p$-BQ units show discharge potentials at 2.9 and $2.77 \mathrm{~V} 1503$ vs $\mathrm{Li}^{+} / \mathrm{Li}$, respectively (Table 2 , entry 18,19$){ }^{247,248}$ The slightly 1504 higher potential than that of $p$-BQ may be related to the limited 1505 specific capacity (i.e., relatively small depth of discharge) rather 1506 than performance improvement by design, however. Polymers 1507 that incorporate the $p$-BQ structure without much modifica- 1508 tion to the building block preserve the discharge potential. 1509 PBQS and poly(2,5-dihydro-p-benzoquinonyl sulfide) (PDBS) 1510 
Chemical Reviews

pubs.acs.org/CR

Review

Table 2. Performances of Selected Nonaqueous Li-Organic Batteries

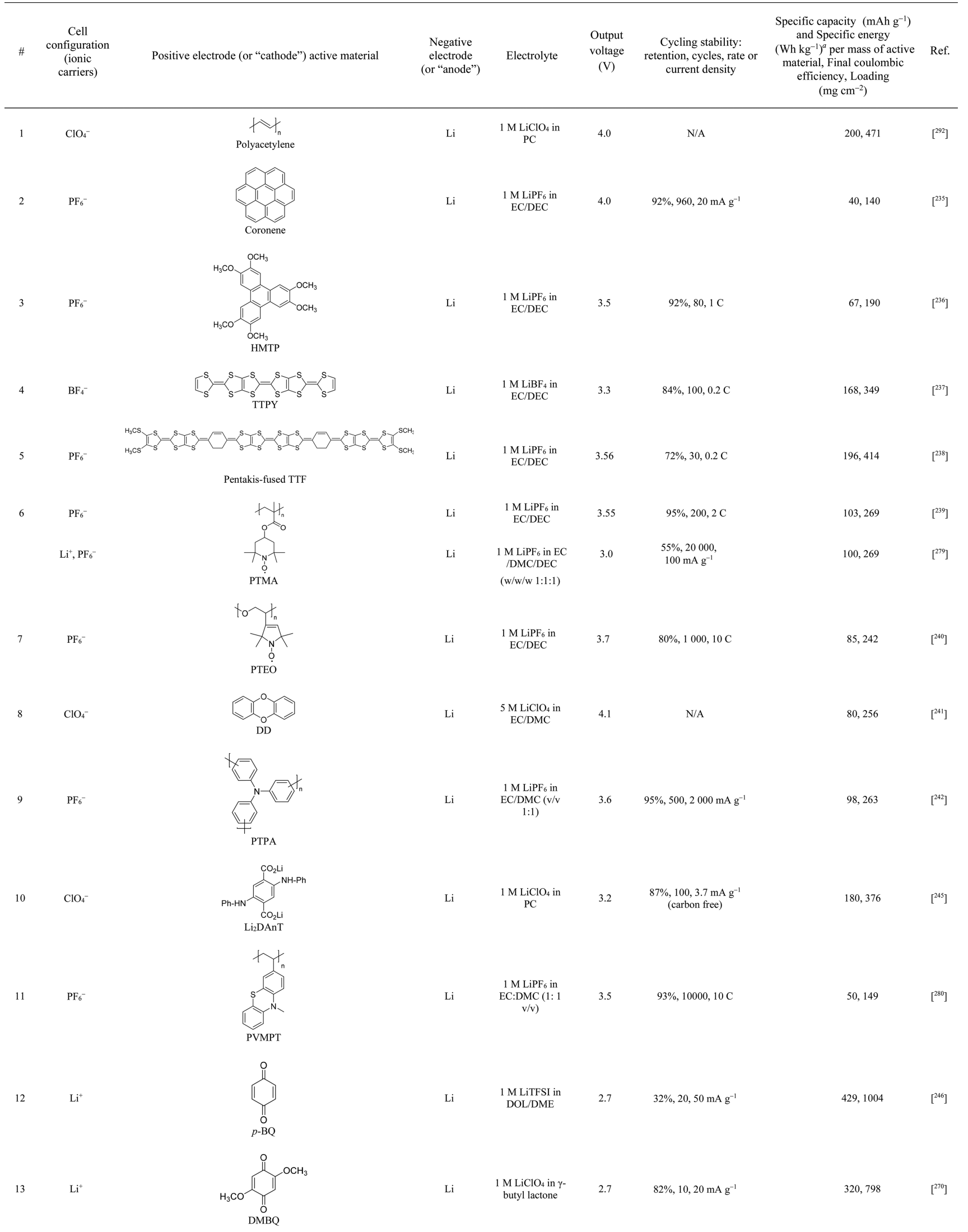

$\mathbf{R}$

https://dx.doi.org/10.1021/acs.chemrev.9b00482

Chem. Rev. XXXX, XXX, XXX -XXX 
Table 2. continued

\begin{tabular}{|c|c|c|c|c|c|c|c|c|}
\hline \# & $\begin{array}{c}\text { Cell } \\
\text { configuration } \\
\text { (ionic } \\
\text { carriers) }\end{array}$ & Positive electrode (or "cathode") active material & $\begin{array}{l}\text { Negative } \\
\text { electrode } \\
\text { (or "anode") }\end{array}$ & Electrolyte & $\begin{array}{l}\text { Output } \\
\text { voltage } \\
\text { (V) }\end{array}$ & $\begin{array}{l}\text { Cycling stability: } \\
\text { retention, cycles, rate or } \\
\text { current density }\end{array}$ & $\begin{array}{l}\text { Specific capacity }\left(\mathrm{mAh} \mathrm{g}^{-1}\right) \\
\text { and Specific energy } \\
\left(\mathrm{Wh} \mathrm{kg}^{-1}\right)^{a} \text { per mass of active } \\
\text { material, Final coulombic } \\
\text { efficiency, Loading } \\
\left.(\mathrm{mg} \mathrm{cm})^{-2}\right)\end{array}$ & Ref. \\
\hline 14 & $\mathrm{Li}^{+}$ & $\mathrm{CF}_{3}-\mathrm{BQ}$ & $\mathrm{Li}$ & $\begin{array}{c}1 \mathrm{M} \mathrm{LiPF}_{6} \text { in } \\
\mathrm{EC} / \mathrm{DEC}(\mathrm{v} / \mathrm{v} \\
3: 7)\end{array}$ & 3.0 & $37 \%, 20,0.1 \mathrm{~mA}$ & 162,466 & {$\left[{ }^{250}\right]$} \\
\hline 15 & $\mathrm{Li}^{+}$ & Rf4-BQ & $\mathrm{Li}$ & $\begin{array}{c}1 \mathrm{M} \mathrm{LiPF}_{6} \text { in } \\
\mathrm{EC} / \mathrm{DEC}(\mathrm{v} / \mathrm{v} \\
3: 7)\end{array}$ & 3.0 & $50 \%, 20,0.1 \mathrm{~mA}$ & 115,335 & {$\left[{ }^{250}\right]$} \\
\hline 16 & $\mathrm{Li}^{+}$ & Rf6-Cl-BQ & $\mathrm{Li}$ & $\begin{array}{c}1 \mathrm{M} \mathrm{LiPF}_{6} \text { in } \\
\mathrm{EC} / \mathrm{DEC}(\mathrm{v} / \mathrm{v} \\
3: 7)\end{array}$ & 3.1 & $55 \%, 20,0.1 \mathrm{~mA}$ & 177,525 & {$\left[{ }^{250}\right]$} \\
\hline 17 & $\mathrm{Li}^{+}$ & $\prod_{\mathrm{Mg}\left(\mathrm{Li}_{2}\right)}$ & $\mathrm{Li}$ & $\begin{array}{c}1 \mathrm{M} \mathrm{LiPF}_{6} \text { in } \\
\mathrm{EC} / \mathrm{DMC}(\mathrm{w} / \mathrm{w} \\
1: 1)\end{array}$ & 3.4 & $92 \%, 80,23 \mathrm{~mA} \mathrm{~g}^{-1}$ & 100,340 & {$\left[{ }^{252}\right]$} \\
\hline 18 & $\mathrm{Li}^{+}$ & BBQ & $\mathrm{Li}$ & $\begin{array}{l}2.75 \mathrm{M} \text { LiTFSI } \\
\text { in G4 }\end{array}$ & 2.8 & $67 \%, 20,40 \mathrm{~mA} \mathrm{~g}^{-1}$ & 358,917 & {$\left[{ }^{247}\right]$} \\
\hline 19 & $\mathrm{Li}^{+}$ & PADQ & $\mathrm{Li}$ & $\begin{array}{l}1 \mathrm{M} \mathrm{LiPF}_{6} \text { in } \\
\mathrm{DMC} / \mathrm{EMC} / \mathrm{EC} \\
(\mathrm{v} / \mathrm{v} / \mathrm{v} 1: 1: 1)\end{array}$ & 2.77 & $\mathrm{~N} / \mathrm{A}$ & 370,935 & {$\left[{ }^{248}\right]$} \\
\hline 20 & $\mathrm{Li}^{+}$ & $\mathrm{C} 4 \mathrm{Q}$ & $\mathrm{Li}$ & $\begin{array}{l}\text { PMA/PEG-based } \\
\text { gel polymer } \\
\text { electrolyte with } \\
\text { LiClO } / \text { DMSO } \\
\text { loading }\end{array}$ & 2.6 & $90 \%, 100,0.2 \mathrm{C}$ & 422,989 & {$\left[{ }^{272}\right]$} \\
\hline 21 & $\mathrm{Li}^{+}$ & $\mathrm{P} 5 \mathrm{Q}$ & $\mathrm{Li}$ & $\begin{array}{l}\mathrm{PMA}^{\mathrm{P}} \mathrm{PEG}- \\
\mathrm{LiClO}_{4}-\mathrm{SiO}_{2} \\
\text { composite }\end{array}$ & 2.6 & $89 \%, 50,0.2 \mathrm{C}$ & 409,964 & {$\left[{ }^{273}\right]$} \\
\hline 22 & $\mathrm{Li}^{+}$ & PBQS & $\mathrm{Li}$ & $\begin{array}{l}1 \mathrm{M} \text { LiTFSI in } \\
\text { DOL/DME }(\mathrm{v} / \mathrm{v} \\
1: 1)\end{array}$ & 2.7 & $\begin{array}{l}86 \%, 1000 \\
5000 \mathrm{~mA} \mathrm{~g}^{-1}\end{array}$ & 275,691 & {$\left[{ }^{246}\right]$} \\
\hline 23 & $\mathrm{Li}^{+}$ & & $\mathrm{Li}$ & $\begin{array}{c}1 \mathrm{M} \\
\mathrm{LiPF}_{6} / \mathrm{EC} / \mathrm{DMC} \\
(\mathrm{v} / \mathrm{v} 1 / 1)\end{array}$ & 2.0 & $53 \%, 100,15 \mathrm{~mA} \mathrm{~g}^{-1}$ & 250,470 & {$\left[{ }^{274}\right]$} \\
\hline 24 & $\mathrm{Li}^{+}$ & $\begin{array}{c}0 \\
\text { PDBS }\end{array}$ & $\mathrm{Li}$ & $\begin{array}{l}1 \mathrm{M} \mathrm{LiTFSI} \text { in } \\
\text { DOL/DME (v/v } \\
1: 1)\end{array}$ & 2.5 & $50 \%, 20,50 \mathrm{~mA} \mathrm{~g}^{-1}$ & 200,475 & {$\left[{ }^{249}\right]$} \\
\hline 25 & $\mathrm{Li}^{+}$ & LiO & $\mathrm{Li}$ & $\begin{array}{c}1 \mathrm{M} \mathrm{LiTFSI} \text { in } \\
\text { DOL/DME }(\mathrm{v} / \mathrm{v} \\
1: 1)\end{array}$ & 2.0 & $87 \%, 1500,500 \mathrm{~mA} \mathrm{~g}^{-1}$ & 247,464 & {$\left[{ }^{249}\right]$} \\
\hline
\end{tabular}


Table 2. continued

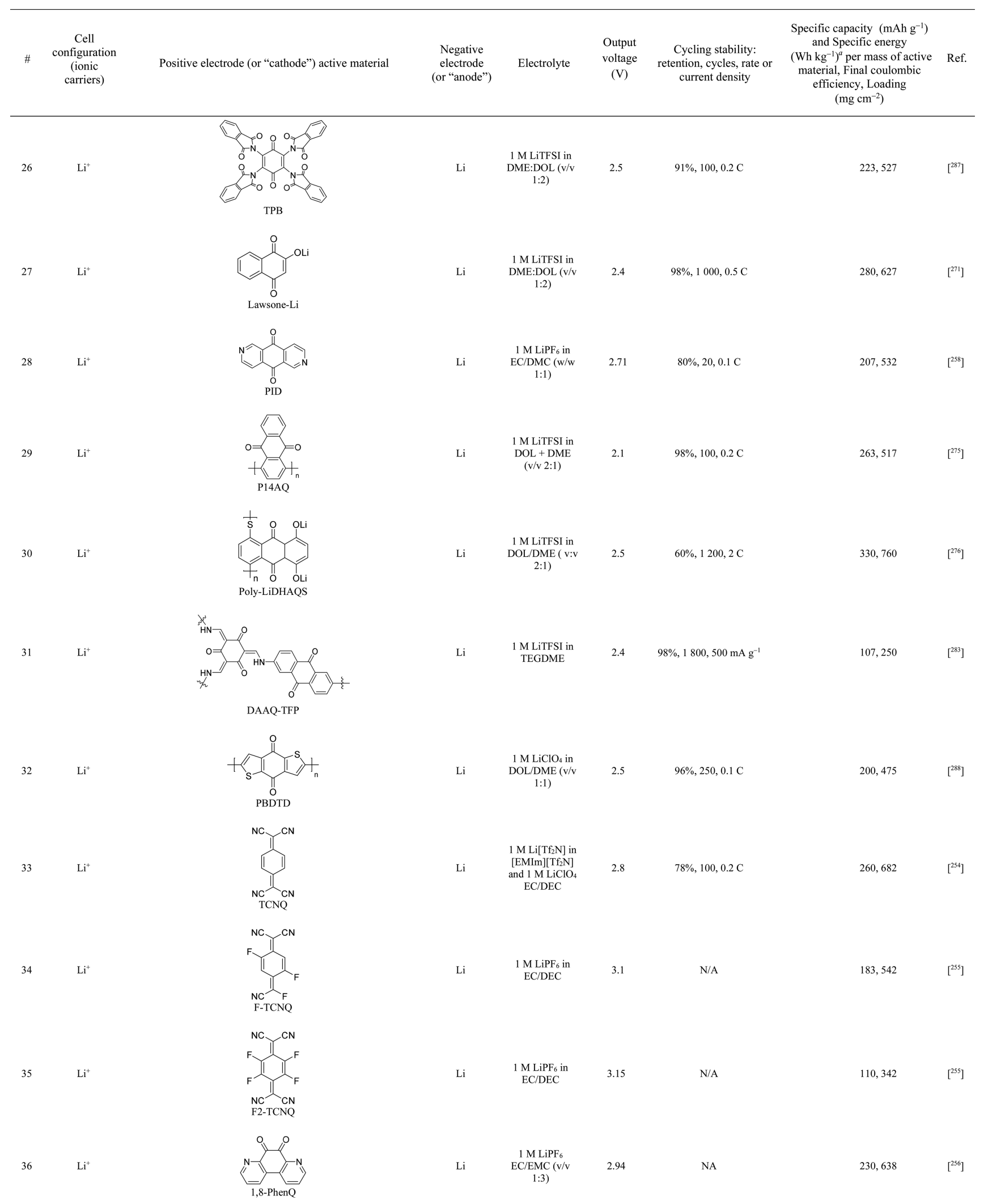


Table 2 . continued

\begin{tabular}{|c|c|c|c|c|c|c|c|c|}
\hline \# & $\begin{array}{c}\text { Cell } \\
\text { configuration } \\
\text { (ionic } \\
\text { carriers) }\end{array}$ & Positive electrode (or "cathode") active material & $\begin{array}{l}\text { Negative } \\
\text { electrode } \\
\text { (or "anode") }\end{array}$ & Electrolyte & $\begin{array}{l}\text { Output } \\
\text { voltage } \\
\text { (V) }\end{array}$ & $\begin{array}{l}\text { Cycling stability: } \\
\text { retention, cycles, rate or } \\
\text { current density }\end{array}$ & $\begin{array}{l}\left.\text { Specific capacity ( } \mathrm{mAh} \mathrm{g}^{-1}\right) \\
\text { and Specific energy } \\
\left(\mathrm{Wh} \mathrm{kg}^{-1}\right)^{a} \text { per mass of active } \\
\text { material, Final coulombic } \\
\text { efficiency, Loading } \\
\left.(\mathrm{mg} \mathrm{cm})^{-2}\right)\end{array}$ & Ref. \\
\hline 37 & $\mathrm{Li}^{+}$ & & $\mathrm{Li}$ & $\begin{array}{c}1 \mathrm{M} \mathrm{LiPF}_{6} \text { in } \\
\mathrm{EC} / \mathrm{DMC}^{2} \mathrm{w} / \mathrm{w} \\
1: 1)\end{array}$ & 2.74 & N/A & 231,597 & {$\left[{ }^{257}\right]$} \\
\hline 38 & $\mathrm{Li}^{+}$ & & $\mathrm{Li}$ & $\begin{array}{c}1 \mathrm{M} \mathrm{LiPF}_{6} \text { in } \\
\mathrm{EC} / \mathrm{DMC}(\mathrm{v} / \mathrm{v} \\
1: 1)\end{array}$ & 2.85 & $95 \%, 30,0.2-5 \mathrm{C}$ & 105,299 & {$\left[{ }^{234}\right]$} \\
\hline 39 & $\mathrm{Li}^{+}$ & & $\mathrm{Li}$ & $\begin{array}{l}1 \mathrm{M} \mathrm{LiPF}_{6} \text { in } \\
\mathrm{EC}-\mathrm{DMC}\end{array}$ & 2.59 & $27 \%, 50, \mathrm{~N} / \mathrm{A}$ & 360,853 & {$\left[{ }^{257}\right]$} \\
\hline 40 & $\mathrm{Li}^{+}$ & & $\mathrm{Li}$ & $\begin{array}{c}1 \mathrm{M} \mathrm{LiPF}_{6} \text { in } \\
\text { EC:DMC (v/v } \\
3: 7)\end{array}$ & 2.5 & $106 \%, 10000,0.1 \mathrm{~A} \mathrm{~g}^{-1}$ & 108,263 & {$\left[{ }^{105}\right]$} \\
\hline 41 & $\mathrm{Li}^{+}$ & Li ter & $\mathrm{Li}$ & $\begin{array}{c}1 \mathrm{M} \mathrm{LiPF}_{6} \text { in } \\
\mathrm{EC} / \mathrm{DMC}^{\mathrm{D}}(\mathrm{w} / \mathrm{w} \\
1: 1)\end{array}$ & 0.8 & $78 \%, 50,0.1 \mathrm{C}$ & $300, \mathrm{~N} / \mathrm{A}$ & {$\left[{ }^{261}\right]$} \\
\hline 42 & $\mathrm{Li}^{+}$ & $\mathrm{Li}_{2} \mathrm{BPDC}$ & $\mathrm{Li}$ & $\begin{array}{c}1 \mathrm{M} \mathrm{LiPF}_{6} \text { in } \\
\mathrm{EC} / \mathrm{DMC}(\mathrm{v} / \mathrm{v} \\
1: 1)\end{array}$ & 0.7 & $60 \%, 25,1 \mathrm{C}$ & $250, \mathrm{~N} / \mathrm{A}$ & {$\left[{ }^{264}\right]$} \\
\hline 43 & $\mathrm{Li}^{+}$ & Li 4,4- tolane-dicarboxylate & $\mathrm{Li}$ & $\begin{array}{c}1 \mathrm{M} \mathrm{LiPF}_{6} \text { in } \\
\mathrm{EC} / \mathrm{DMC}^{\mathrm{D}} \mathrm{( \textrm {v } / \mathrm { v }} \\
1: 1)\end{array}$ & 0.65 & $90 \%, 50,0.025 \mathrm{C}$ & $130, \mathrm{~N} / \mathrm{A}$ & {$\left[{ }^{265}\right]$} \\
\hline 44 & $\mathrm{Li}^{+}$ & & $\mathrm{Li}$ & $\begin{array}{l}0.38 \mathrm{M} \mathrm{LiTFSI} \\
0.31 \mathrm{M} \mathrm{LiNO}_{3} \text { in } \\
\mathrm{DOL} \mathrm{DME}\end{array}$ & 2.1 & $\begin{array}{c}82 \%, 100,167 \mathrm{~mA} \mathrm{~g}^{-1}, \\
0.1 \mathrm{C}\end{array}$ & 1000,1668 & {$\left[{ }^{266}\right]$} \\
\hline 45 & $\mathrm{Li}^{+}$ & & $\mathrm{Li}$ & $\begin{array}{l}1 \mathrm{M} \mathrm{LiPF}_{6} \text { in } \\
\mathrm{EC} / \mathrm{DEC}\end{array}$ & 1.8 & $73 \%, 1000,0.4 \mathrm{C}$ & 1200,1648 & {$\left[{ }^{268}\right]$} \\
\hline 46 & $\mathrm{Li}^{+}$ & & $\mathrm{Li}$ & $\begin{array}{l}1 \mathrm{M} \mathrm{LiPF}_{6} \text { in } \\
\mathrm{EC} / \mathrm{DEC}\end{array}$ & 2.1 & N/A & 580,1059 & {$\left[{ }^{82}\right]$} \\
\hline 47 & $\mathrm{Li}^{+}$ & $\mathrm{C}_{6} \mathrm{O}_{6}$ & $\mathrm{Li}$ & $\begin{array}{c}0.3 \mathrm{M} \text { LiTFSI- } \\
{[\text { PY13][TFSI] at }} \\
70^{\circ} \mathrm{C}\end{array}$ & 1.7 & $82 \%, 100,50 \mathrm{~mA} \mathrm{~g}^{-1}$ & 902,1243 & {$\left[{ }^{269}\right]$} \\
\hline 48 & $\mathrm{Li}^{+}$ & & $\mathrm{Li}$ & $\begin{array}{l}\text { 1.0 M LiTFSI in } \\
\mathrm{DOL} / \mathrm{DME}\end{array}$ & 2.0 & $70 \%, 10000,20 \mathrm{C}$ & 395,717 & {$\left[{ }^{277}\right]$} \\
\hline 49 & $\mathrm{Li}^{+}$ & & $\mathrm{Li}$ & $\begin{array}{l}1 \mathrm{M} \mathrm{LiClO}_{4} \text { in } \\
\mathrm{EC} / \mathrm{DEC}(\mathrm{v} / \mathrm{v} \\
1: 1)\end{array}$ & 2.4 & $83 \%, 30,0.2 \mathrm{C}$ & 300,668 & {$\left[{ }^{278}\right]$} \\
\hline
\end{tabular}


Table 2. continued

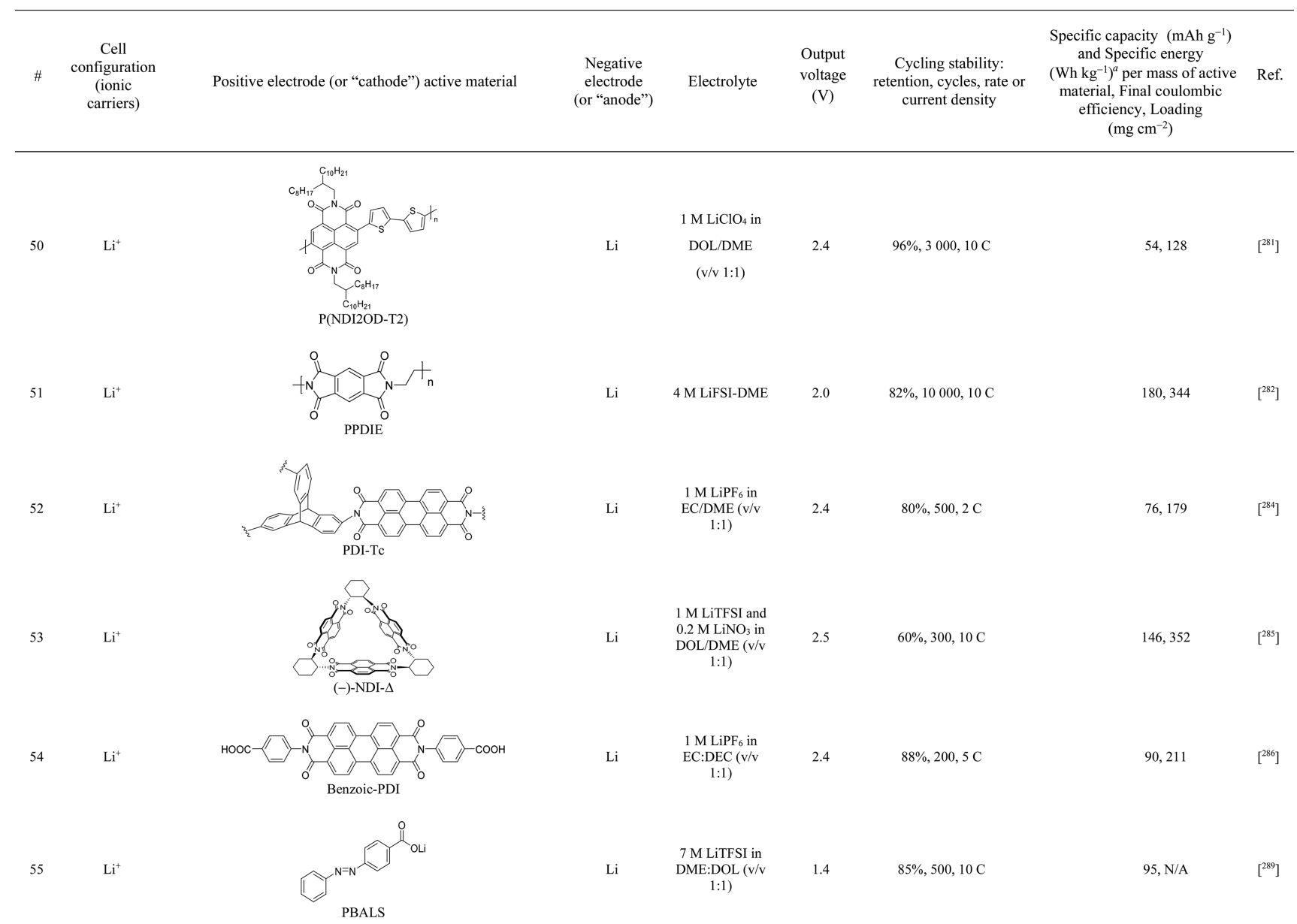

${ }^{a}$ Specific energy considers the weight of both the cathode and anode materials. For p-type OEMs, $\mathrm{LiBF}_{4}$ is considered as the Li salt due to its relatively light weight.

1511 show some of the highest discharge potentials for n-type 1512 polymer OEMs (Figure 10D, Table 2, entry 22, 23). ${ }^{246,249}$

1513 Since the discharge potentials of $p$-BQ-containing OEMs are 1514 noticeably lower than those of $p$-type OEMs as well as

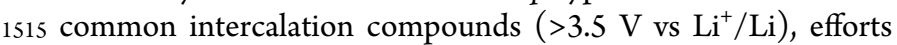
1516 have been made to obtain higher potentials. Installation of 1517 perfluoroalkyl groups and chlorine atoms at the carbon ring 1518 of $p$-BQ gives rise to $\mathrm{CF}_{3}$-BQ (Table 2, entry 14), Rf4-BQ 1519 (Table 2, entry 15), and Rf6-Cl-BQ (Table 2, entry 16), which 1520 show increased potentials of $3.0-3.1 \mathrm{~V}$ vs $\mathrm{Li}^{+} / \mathrm{Li}^{250}$ The 1521 introduction of these auxiliary groups, however, inevitably 1522 decreases the specific capacity and could be counterproductive 1523 when high specific energy is the goal. Dilithium (2,5-dilithium1524 oxy)-terephthalate $\left(\mathrm{Li}_{2}\left(\mathrm{Li}_{2}\right)\right.$-p-DHT or $\mathrm{Li}_{4}-p$-DHT) may be 1525 seen as a carboxylate-substituted $p$-BQ (crystallized "host" 1526 electrode material) synthesized at its discharged (lithiated) 1527 state; $^{208,251}$ with its polyanionic structure making this material 1528 highly insoluble. ${ }^{84}$ Since its life as an OEM starts from charging, 1529 like commercial positive electrode materials in LIBs do, it is one 1530 of the few n-type OEMs that can be paired with a Li-free anode, 1531 a great benefit for industrial cell production. However, this very 1532 interesting organic was hampered by a relatively low operating 1533 potential $\left(2.55 \mathrm{~V} \mathrm{vs} \mathrm{Li}^{+} / \mathrm{Li}\right)$. Replacing the $\mathrm{Li}^{+}$in the carboxylate 1534 groups with high-electronegativity cations such as $\mathrm{Mg}^{2+}$ and $1535 \mathrm{Ca}^{2+}$ amazingly increases the redox potential several hundreds 1536 of millivolts (Figure 10E). ${ }^{252}$ Thus the resulting magnesium (2,5-dilithium-oxy)-terephthalate $\left(\mathrm{Mg}\left(\mathrm{Li}_{2}\right)\right.$-p-DHT) shows the 1537 highest working potential $\left(3.45 \mathrm{~V}\right.$ vs $\left.\mathrm{Li}^{+} / \mathrm{Li}\right)$ among n-type 1538 OEMs approaching the well-known $\mathrm{LiFePO}_{4}$ electrode ma- 1539 terial (Table 2, entry 17). Note that an attempt to switch from 1540 the carboxylate functional groups present in $\mathrm{Li}_{4}-p$-DHT to the 1541 sulfonate substituent giving rise to the tetralithium salt of 2,5- 1542 dihydroxy-1,4-benzenedisulfonate ( $\mathrm{Li}_{4}-p$-DHBDS $)^{253}$ enables 1543 also a voltage gain $(+650 \mathrm{mV})$ but with inferior electrochemical 1544 performance upon cycling.

1545

A closely related structure to $p$-BQ is tetracyanoquinodi- 1546 methane (TCNQ), where the oxygen atoms in $p$-BQ are 1547 replaced by the even more electron-withdrawing dicyano- 1548 methylene groups (Table 2, entry 33). TCNQ itself is known 1549 as an electron acceptor for preparation of charge transfer salts, 1550 such as TTF-TCNQ. In a Li-battery, TCNQ discharges at 1551 $2.9 \mathrm{~V} \mathrm{vs} \mathrm{Li}^{+} / \mathrm{Li}$, a noticeable improvement over $p$-BQ. ${ }^{254}$ Further 1552 increase in potential was achieved by installing electron- 1553 withdrawing groups to the carbon ring. As the number of 1554 fluorine atoms installed to TCNQ increased from two (F-TCNQ) 1555 to four (F2-TCNQ), the average discharge potential increased 1556 from 3.1 to $3.15 \mathrm{~V} \mathrm{vs} \mathrm{Li}^{+} / \mathrm{Li}$ (Figure 10F, Table 2, entry 34, 35). ${ }^{255}{ }_{1557}$

The ortho-regioisomer of $p$-BQ gives rise to higher discharge 1558 potentials in general. The simplest molecule, ortho-benzoqui- 1559 none (o-BQ), has not been directly studied probably due 1560 to chemical stability issues, but $o$-BQ as a building block for 1561 OEMs is well documented. The pyridine rings-fused 1,8-diaza- 1562 

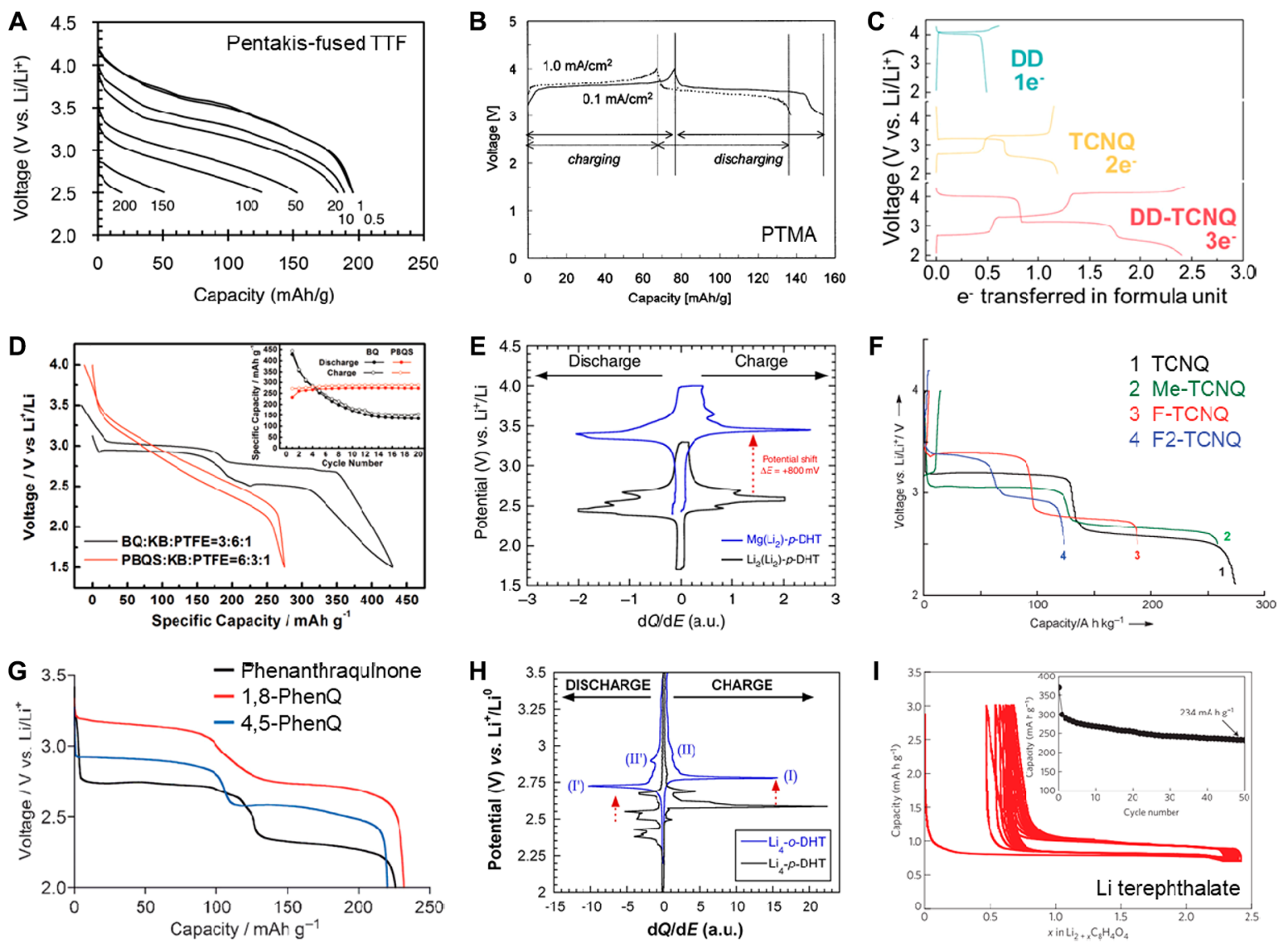

Figure 10. Voltage profiles of selected high-potential positive OEMs and low-potential negative OEMs measured vs Li including (A) pentakis-fused TTF (reproduced with permission from ref 238. Copyright 2014 The Royal Society of Chemistry), (B) PTMA (reproduced with permission from ref 75. Copyright 2002 Elsevier Ltd.), (C) DD (reproduced with permission from ref 241. Copyright 2019 Elsevier Ltd.), (D) BQ and PBQS (reproduced with permission from ref 246. Copyright $2015 \mathrm{John}$ Wiley \& Sons, Inc.), (E) $\mathrm{Li}_{2}\left(\mathrm{Li}_{2}\right)-p-\mathrm{DHT}$ and $\mathrm{Mg}\left(\mathrm{Li}_{2}\right)-p-\mathrm{DHT}$ (reproduced from ref 252), (F) TCNQ F-TCNQ and F2-TCNQ (reproduced with permission from ref 255. Copyright 2013 John Wiley \& Sons, Inc.), (G) 1,8PhenQ and 4,5-PhenQ (reproduced with permission from ref 257. Copyright 2013 The Royal Society of Chemistry, $(\mathrm{H}) \mathrm{Li}_{4}-\mathrm{o}-\mathrm{DHT}$ (reproduced with permission from ref 234. Copyright 2014 American Chemical Society), and (I) Li terephthalate (reproduced with permission from ref 261. Copyright 2009 Nature Publishing group).

1563 9,10-phenanthrenequinone (1,8-PhenQ, Table 2, entry 36) 1564 and 4,5-diaza-9,10-phenanthrenequinone (4,5-PhenQ, Table 2, 1565 entry 37) discharge at 2.94 and $2.74 \mathrm{~V} \mathrm{vs} \mathrm{Li}^{+} / \mathrm{Li}$ (Figure 10G), 1566 respectively, both higher than the $2.71 \mathrm{~V}$ for their $p$-BQ1567 containing isomer pyrido[3,4-g]isoquinoline-5,10-dione 1568 (PID). ${ }^{256-258}$ Interestingly, the position of nitrogen atoms in 1569 the fusing pyridine rings has a considerable impact on discharge 1570 potential: the pyridine nitrogen and the carbonyl oxygen being 1571 adjacent (as in the case of 1,8-PhenQ) promote favorable 1572 coordination of $\mathrm{Li}^{+}$, which leads to extra gain in potential. This 1573 explains the noticeably higher potential of 1,8-PhenQ than that 1574 of 4,5-PhenQ (+200 mV as gain). As previously attempted with $1575 p$-DHT redox-active ligand, attaching carboxylate functional 1576 groups to the carbon ring of the reduced form of $o$-BQ gives rise 1577 to another highly insoluble and lithiated electrode material 1578 namely (2,3-dilithium-oxy)-terephthalate ( $\mathrm{Li}_{4}-o$-DHT, Table 2, 1579 entry 38), which can be prepared from biomass too. ${ }^{234}$ Alike $1580 \mathrm{Li}_{4}-p$-DHT, this regioisomer is able to release/uptake $\mathrm{Li}$ ions 1581 over dozens of cycles but at higher operating potential $(2.85 \mathrm{~V}$ $\left.1582 \mathrm{vs}^{+} \mathrm{Li}^{+} / \mathrm{Li}\right)$ due to specific electronic effects ${ }^{211}$ occurring in 1583 orthoquinones (Figure $10 \mathrm{H}$ ). Since only one out of the two 1584 lithoxy groups in the carbon ring appears redox active, it may 1585 be reasonable to assume that upon possible full utilization, an 1586 even higher average potential could be achieved.
N-type OEMs with sufficiently low operating potential 1587 can be used as negative electrode materials as well. Many 1588

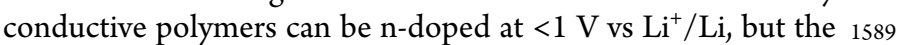
doped states usually lack stability, and the doping level is 1590 typically half of that for the p-doping of the same polymer. ${ }^{259}{ }_{1591}$ Two other mechanisms are currently being actively researched: 1592 lithiation of $\pi$-conjugated carboxylate and "superlithiation" 1593 (see section 7.3) of $\pi$-conjugated systems. ${ }^{260}$ A pioneering 1594 report on carboxylate negative electrodes concerned dilithium 1595 terephthalate ${ }^{261}$ which discharged at $0.8 \mathrm{~V} \mathrm{vs} \mathrm{Li}^{+} / \mathrm{Li}$ (Figure 10I, 1596 Table 2, entry 41). [Note: For a negative electrode material 1597 tested in a $\mathrm{Li}$ cell, the charging potential is more relevant, 1598 however, discharging potential is used here for consistency.] 1599 Since this work, the family of $\pi$-conjugated carboxylates has 1600 been widely extended, and it has been shown that the working 1601 potential can be slightly adjusted by playing with the electronic 1602 effects on the organic skeleton notably by Lakraychi et al. ${ }^{262,263} 1603$ Replacing the phenyl group in dilithium terephthalate with 1604 biphenyl gives the dilithium 4,4'-biphenyl dicarboxylate 1605 ( $\mathrm{Li}_{2} \mathrm{BPDC}$, Table 2, entry 42 ) with a discharge potential of 1606 $0.7 \mathrm{~V}$ vs $\mathrm{Li}^{+} / \mathrm{Li}^{264}$ The lower potential compared with $\mathrm{Li} 1607$ terephthalate was ascribed to the $\pi$-conjugation enhancement 1608 destabilizing the LUMO orbitals of the molecule. Further 1609 expansion of the $\pi$-conjugated system to diphenylacetylene 1610 

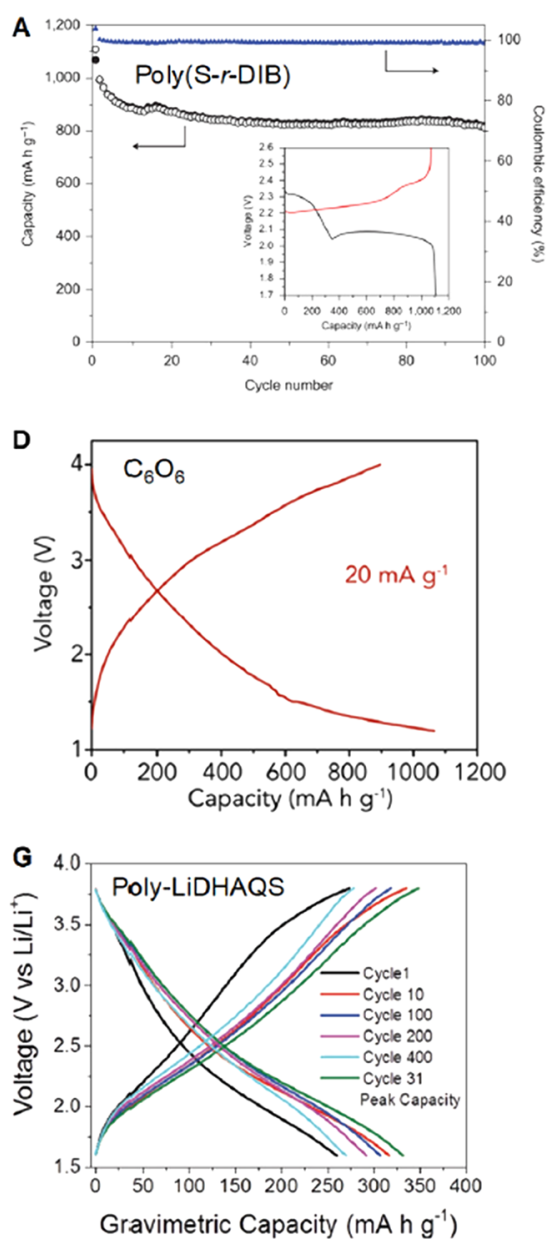
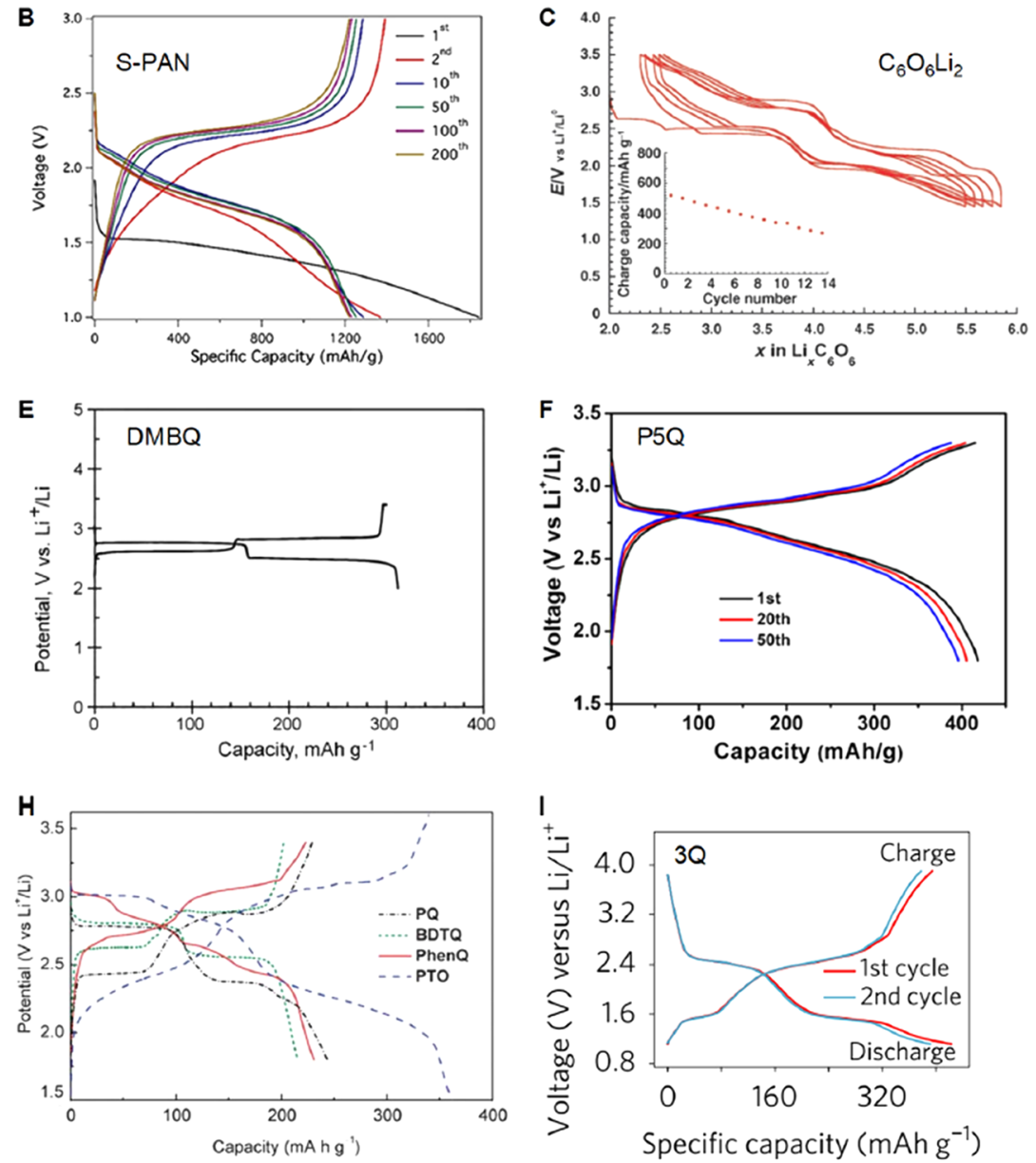

Figure 11. Voltage profiles of selected high-capacity OEMs measured vs Li including (A) poly(S-r-DIB) (reproduced with permission from ref 266. Copyright 2013 Nature Publishing group), (B) S-PAN (reproduced with permission from ref 268. Copyright 2015 American Chemical Society), (C) $\mathrm{Li}_{2} \mathrm{C}_{6} \mathrm{O}_{6}$ (reproduced with permission from ref 82. Copyright 2008 John Wiley \& Sons, Inc.), (D) $\mathrm{C}_{6} \mathrm{O}_{6}$ (reproduced with permission from ref 269. Copyright 2019 John Wiley \& Sons, Inc.), (E) DMBQ (reproduced with permission from ref 270. Copyright 2010 Elsevier Ltd.), (F) P5Q (reproduced with permission from ref 273. Copyright 2014 American Chemical Society), (G) poly-LiDHAQS (reproduced with permission from ref 276. Copyright 2017 John Wiley \& Sons, Inc.), (H) PTO (reproduced from ref 257. Copyright 2013 The Royal Society of Chemistry), and (I) 3Q (reproduced with permission from ref 277. Copyright 2013 Nature Publishing group).

1611 results in dilithium $4,4^{\prime}$-tolane-dicarboxylate, which discharges

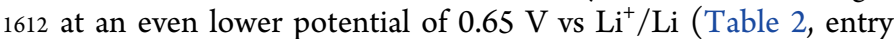
$161343) .{ }^{265}$ OEMs that undergo the peculiar "superlithiation" 1614 process (see section 7.3) exhibit sloping discharge profiles that 1615 start from $>1.5 \mathrm{~V}$ and eventually approach $0 \mathrm{~V}$ vs $\mathrm{Li}^{+} / \mathrm{Li}$ and 1616 then charge at $\geq 1 \mathrm{~V} \mathrm{vs} \mathrm{Li}^{+} / \mathrm{Li}$ on average. Due to the unique1617 ness of the reaction, these OEMs are to be separately covered 1618 in section 7.

\subsection{Organic Electrode Materials with High Specific} 1619 Capacity

1620 To gain high specific capacity, both formula weight and 1621 number of transferrable electrons are key considerations. 1622 Among the major classes of organic electrodes, organosulfur 1623 compounds offer the largest capacities. In particular, organo1624 sulfur polymers bearing polysulfide bonds not only exhibit high 1625 capacities but also stable cycling. Poly(sulfur-random-1,31626 diisopropenylbenzene) (poly(S-r-DIB)) is one such example, 1627 which was copolymerized between molten $S_{8}$ and 1,3-diisopro1628 penylbenzene (DIB) through inverse vulcanization. ${ }^{266}$ The 1629 DIB feed ratios can be varied between 10-50 wt \% during the 1630 synthesis. Galvanostatic voltage profiles of poly(S-r-DIB) with $163110 \mathrm{wt} \%$ DIB show distinct discharge plateaus at 2.3 and $2.1 \mathrm{~V}$ vs $\mathrm{Li}^{+} / \mathrm{Li}$ (Figure 11A, Table 2, entry 44). The initial discharge 1632 capacity is $1100 \mathrm{mAh} \mathrm{g}^{-1}$. Sulfur-polyacrylonitrile (S-PAN) is 1633 another organosulfur polymer attracting significant attention 1634 due to the ease of synthesis and high performance. ${ }^{267}$ S-PAN 1635 was formed by mixing and heating sulfur and polyacrylonitrile 1636 (PAN). It is interesting to note that S-PAN exhibits good 1637 capacity retention in a carbonate-based electrolyte, a behavior 1638 in sharp contrast with sulfur, which works well only in ethereal 1639 electrolytes. $^{268}$ S-PAN shows a single plateau at $2.1 \mathrm{~V}$ with a 1640 high specific capacity of $1200 \mathrm{mAh} \mathrm{g}^{-1}$ (Figure 11B, Table 2, 1641 entry 45).

Carbonyl group undergoes reversible one-electron reduction 1643 to form a radical anion. When multiple carbonyls are con- 1644 jugatedly connected as in quinones, the uncoupled electrons 1645 generated during reduction could combine intramolecularly to 1646 form multivalent anions. The theoretical capacity of carbonyl- 1647 based electrodes is typically lower than that of organosulfur 1648 polymers. Dilithium rhodizonate $\left(\mathrm{Li}_{2} \mathrm{C}_{6} \mathrm{O}_{6}\right)$ undergoes rever- 1649 sible four-electron reaction per $\mathrm{C}_{6} \mathrm{O}_{6}$ ring (Table 2, entry 46). 1650 The observed initial discharge capacity of $580 \mathrm{mAh} \mathrm{g}^{-1}$ set the 1651 record capacity among carbonyl-based OEMs since its 1652 discovery in 2008 (Figure $11 \mathrm{C}$ ). ${ }^{82}$ The fact that $\mathrm{Li}_{6} \mathrm{C}_{6} \mathrm{O}_{6}$ can 1653 be prepared from a renewable natural precursor opens up new 1654 
1655 pathways toward sustainable batteries for future clean energy 1656 economy. Recently, cyclohexanehexone $\left(\mathrm{C}_{6} \mathrm{O}_{6}\right)$ was claimed to 1657 be successively synthesized and surpass $\mathrm{Li}_{2} \mathrm{C}_{6} \mathrm{O}_{6}$ in terms of 1658 specific capacity (Table 2 , entry 47 ). ${ }^{269} \mathrm{C}_{6} \mathrm{O}_{6}$, a cyclic ketone 1659 composed of carbonyls without redundant mass, exhibits a 1660 higher capacity of $902 \mathrm{mAh} \mathrm{g}^{-1}$ (i.e., six-electron reaction per 1661 formula) (Figure 11D). Note that such an ultrahigh capacity 1662 was observed in an ionic liquid-based electrolyte measured at $166370{ }^{\circ} \mathrm{C}$. The compound exhibits sloping and polarized cycling 1664 curves, in contrast to the multiple plateaus observed for $1665 \mathrm{Li}_{2} \mathrm{C}_{6} \mathrm{O}_{6}{ }^{82}$

1666 After the $\mathrm{C}_{6} \mathrm{O}_{6}$ motif, $p$-BQ offers the highest theoretical 1667 specific capacity among common n-type OEM building blocks. $1668 \mathrm{p}$-BQ itself can deliver a specific capacity of $429 \mathrm{mAh} \mathrm{g}^{-1}$ 1669 during the initial discharge, but the capacity retention was only $167032 \%$ after 20 cycles due to its high solubility in organic 1671 solvents. ${ }^{246}$ Due to the ready dissolution of $p$-BQ into non1672 aqueous electrolyte solutions, many OEMs containing the 1673 -BQ unit have been developed to reduce dissolution while 1674 maintaining high capacity. They may be categorized into three 1675 types according to their molecular sizes. The first type includes 1676 molecules with one single $p$-BQ core modified with electron 1677 donating or withdrawing groups. Installation of methoxy 1678 functional groups on $p$-BQ results as DMBQ, which improves 1679 the stability compared to $p$-BQ albeit the discharge capacity is 1680 reduced to $320 \mathrm{mAh} \mathrm{g}^{-1}$ (Figure 11E, Table 2, entry 13). ${ }^{270}$ 1681 Lawsone-Li is another example showing modification of 1682 naphthoquinone (NQ) with lithoxy results in lawsone-Li salt. 1683 Lawsone (2-hydroxy-1,4-naphthoquinone) is a nature-derived 1684 red-orange dye. Lithium cells based on lawsone- $\mathrm{Li}$ as positive 1685 electrode material displayed a capacity of $280 \mathrm{mAh} \mathrm{g}^{-1}$ and a 1686 cycle life of 1000 cycles (Table 2, entry 27). ${ }^{271}$

1687 The second type includes molecules with multiple $p$-BQ 1688 units. 2,2'-Bis- $p$-benzoquinone (BBQ), calix[4] quinone (C4Q), 1689 and pillar[5]quinone (P5Q) contain two, four, and five $p$-BQ 1690 units, respectively (Table 2 , entries 18,20 , and 21 ). It seems 1691 that dissolution of oligomers could still be observed in liquid 1692 electrolytes; therefore, polymer electrolytes containing poly1693 (methacrylate) (PMA) and poly(ethylene glycol) (PEG) 1694 were used to increase capacity retention. Compared to BBQ $1695\left(358 \mathrm{mAh} \mathrm{g}^{-1}\right)$, P5Q and C4Q show higher specific capacity of 1696409 and $422 \mathrm{mAh} \mathrm{g}^{-1}$ (Figure 11F). ${ }^{247,272,273}$

1697 The third type includes polymers with (modified) $p$-BQ 1698 units. PBQS, PDBS, and $\mathrm{Li}_{2}$ PDBS present three examples of $1699 p$-BQ-based polymers when using sulfur as the linker (Table 2, 1700 entry 22-25). ${ }^{46,249,274}$ Among the three polymers, PBQS 1701 shows the highest specific capacity of $275 \mathrm{mAh} \mathrm{g}^{-1}$ for 1000 1702 cycles. Due to the addition of lithoxy and hydroxy groups on 1703 PBQS, $\mathrm{Li}_{2}$ PDHBQS and PDBS exhibit slightly lower specific 1704 capacity of $\sim 250 \mathrm{mAh} \mathrm{g}^{-1}$. Anthraquinone (AQ) can be 1705 considered as $p$-BQ with extended conjugation, which also has 1706 the solubility issue. Polymerization approach has been equally 1707 successful for AQ. P14AQ and poly-LiDHAQS are two 1708 polymers based on AQ. The specific capacities are 263 and $1709330 \mathrm{mAh} \mathrm{g}^{-1}$, respectively (Figure $11 \mathrm{G}$, Table 2, entries 29 1710 and 30$){ }^{27}$

1711 A closely related structure to $p$-BQ is pyrene-4,5,9,101712 tetraone (PTO) where two $o$-BQ units are connected with 1713 extended $\pi$-conjugated structure (Table 2 , entry 39 ). PTO 1714 undergoes a four-electron reduction with a specific capacity of $1715360 \mathrm{mAh} \mathrm{g}^{-1}$ in EC/DMC and an average discharge voltage 1716 of $2.59 \mathrm{~V}$ vs $\mathrm{Li}^{+} / \mathrm{Li}$ (Figure $11 \mathrm{H}$ ). ${ }^{257} \mathrm{TCNQ}$ can also be 1717 formed by replacing the oxygen atoms in $p$-BQ with more electron-withdrawing dicyanomethylene groups (Table 2, 1718 entry 33). The discharge capacity of TCNQ is lowered to 1719 $260 \mathrm{mAh} \mathrm{g}^{-1}$ albeit voltage is increased to $3.2 \mathrm{~V}^{254} \quad 1720$

$\pi$-Conjugated heteroaromatic molecules represent another 1721 class of OEMs with high specific capacity. Fused quinoxaline 1722 building blocks afford multiple redox-active sites centered on 1723 $\mathrm{N}$ atoms. Hexaazatrinaphthylene (3Q) enables six-electron 1724 reduction with a specific capacity of $395 \mathrm{mAh} \mathrm{g}^{-1}$ (Figure 11I, 1725 Table 2, entry 48). ${ }^{277}$ When hybridized with graphene, 3Q 1726 shows $70 \%$ capacity retention after 10000 cycles. Hexaaza- 1727 triphenylenehexacarbonitrile (6CN, Table 2, entry 49) shows 1728 higher redox voltage at $2.4 \mathrm{~V}$ vs $\mathrm{Li}^{+} / \mathrm{Li}$ by replacing the 1729 benzene groups in $3 \mathrm{Q}$ with electron-withdrawing cyanide 1730 groups. ${ }^{278}$ When the discharge potential cutoff is set at $1.5 \mathrm{~V}$ vs 1731 $\mathrm{Li}^{+} / \mathrm{Li}, 6 \mathrm{CN}$ shows a specific capacity of $300 \mathrm{mAh} \mathrm{g}$.

1732

\subsection{Organic Electrode Materials with Long Cycle Life}

Researchers have almost always attributed the capacity 1733 decay of OEMs to either chemical degradation or dissolution. 1734 In typical nonaqueous Li electrolytes, chemical degradation of 1735 OEMs is rarely observed; hence, material dissolution from the 1736 solid electrode into the electrolyte is the main degradation 1737 mechanism. For the most part, increasing the cycling stability 1738 of OEMs in nonaqueous $\mathrm{Li}$ batteries equals minimizing the 1739 solubility of OEMs in electrolytes. As long as material disso- 1740 lution is effectively suppressed, apparently most OEMs can 1741 deliver stable cycling performance. Even small-molecule OEMs 1742 that readily decay due to dissolution can be made stable when 1743 a sufficiently large amount of high-surface-area carbon adsor- 1744 bent is included in the positive composite electrode as previ- 1745 ously underlined in section $1.2 .^{13}$ Due to practical consid- 1746 erations, cycling performances enabled by intricate adsorbents 1747 are not a priority for this review.

1748

The most stable OEMs for nonaqueous $\mathrm{Li}$ batteries have 1749 been polymers. Polymer OEMs containing varying types of redox 1750 centers, from p-type to n-type, from nitroxides (e.g., PTMA) ${ }^{279}$ to 1751 aromatic amines (e.g., poly(3-vinyl- $N$-methylphenothiazine) or 1752 PVMPT) ${ }^{280}$ to quinones (e.g., polydopamine) ${ }^{105}$ to imides (e.g., 1753 poly $\left\{\left[N, N^{\prime}\right.\right.$-bis(2-octyldodecyl)-1,4,5,8-naphthalenedicarboxi- 1754 mide-2,6-diyl]-alt-5,5'-(2,2'-bithiophene) $\}$ or P(NDI2OD-T2), 1755 Table 2, entry 50 and poly(ethylene-pyromellitic diimide) or 1756 PPDIE, Table 2, entry 51), ${ }^{281,282}$ have all been reported to 1757 cycle for thousands to tens of thousands of cycles. It may be 1758 reasonable to extrapolate that, with proper polymerization, 1759 OEMs of all types can be made stable, even though synthetic 1760 difficulty may vary from type to type. With judicious selection 1761 of polymerization strategies, two- and three-dimensional 1762 polymer OEMs have been synthesized based on aromatic 1763 amines (e.g., polytriphenylamine or PTPA), ${ }^{242}$ quinones (e.g., 1764 2,6-diaminoanthraquinone-1,3,5-triformylphluroglucinol or 1765 DAAQ-TFP), ${ }^{283}$ and imides (e.g., perylene diimide- 1766 triptycene or PDI-Tc, Table 2, entry 52). ${ }^{284}$ These additional 1767 architectures are proposed to further improve cycling stability. 1768

The advantage of polymer OEMs in cyclability does not 1769 preclude molecular OEMs from being important. Molecular 1770 materials can still be preferred for their well-defined structures, 1771 high specific capacity, flexibility in processing, and so on. 1772 Therefore, approaches to improve the cyclability of small 1773 molecules are still being developed. Considering the success of 1774 polymer OEMs, a widely practiced strategy is to increase the 1775 molecular weight of molecules or simply oligomerization. Both 1776 3Q and coronene are big planar molecules which benefit from 1777 relatively strong van de Waals interaction and effective $\pi-\pi 1778$ 
1779 stacking. ${ }^{235,277}$ Even when the active cores are not as big, it is 1780 still convenient to connect multiple building blocks together 1781 to artificially increase the molecular weight. Some examples 1782 include a triangle molecule (-)-NDI- $\Delta^{285}$ (Table 2, entry 53) 1783 which incorporates three naphthalenediimide (NDI) units plus 1784 linkers, benzoic-PDI ${ }^{286}$ (Table 2, entry 54) which attaches 1785 more aryls to the already large molecule perylenediimide 1786 (PDI), and 2,3,5,6-tetraphthalimido-1,4-benzoquinone 1787 (TPB $)^{287}$ which incorporates two seemingly unrelated redox 1788 centers (tetraphthalimide and $p$-BQ) into one molecule. These 1789 molecules exhibit cycling stabilities that clearly set them apart 1790 from simple molecules without sacrificing most advantages of 1791 molecular OEMs. The large size of these molecules is blurring 1792 the boundary between molecules and polymers. In fact, some 1793 "polymer" OEMs such as poly(benzo[1,2-b:4,5-b']1794 dithiophene-4,8-dione-2,6-diyl) (PBDTD) ${ }^{288}$ contain few 1795 repeating units (e.g., $\leq 5)$ per polymer chain. They may as 1796 well be considered as molecular OEMs.

1797 Other strategies for stabilizing molecular OEMs include salt 1798 formation and grafting as previously mentioned. ${ }^{84}$ Salt 1799 formation has long been an established strategy to stabilize 1800 molecular OEMs: ionic groups introduced to OEMs increase 1801 their intermolecular interactions and decrease the similarity 1802 in polarity with nonaqueous electrolytes, thus decreasing 1803 solubility. ${ }^{82}$ Some recent excellent examples include $\mathrm{Mg}\left(\mathrm{Li}_{2}\right)$ $1804 p$-DHT, ${ }^{252}$ lawsone- $\mathrm{Li}^{271}$ and 4 -(phenylazo) benzoic acid 1805 lithium salt (PBALS, Table 2, entry 55) ${ }^{289}$; all show barely any 1806 capacity decay after hundreds of cycles. Grafting is also a 1807 known, if still exotic, method for enabling small-molecule 1808 OEMs. The key to successful grafting is rational functionaliza1809 tion of high-capacity OEM building blocks for covalent linking 1810 to high-surface-area substrates. Grafted naphthoquinone (n-type) 1811 and pyrene (p-type) derivatives can show no obvious capacity 1812 decay over a long cycling period. ${ }^{290-292}$

1813 We would like to note that although the cycle numbers for 1814 the examples discussed above vary from hundreds to tens of 1815 thousands, these numbers, in a lot of cases, seem to be limited 1816 by how fast the researchers felt comfortable to cycle their 1817 cells instead of the actual stability of the OEMs. Figure 12

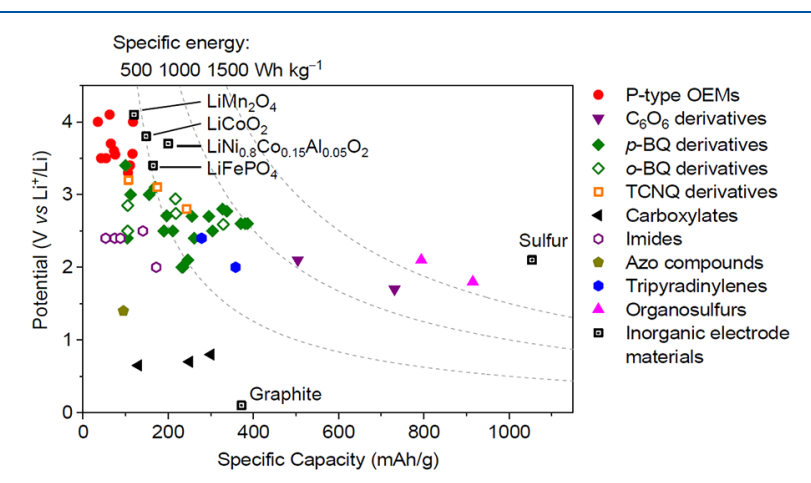

Figure 12. Comparison of the discharge potentials and specific capacities of state-of-the-art OEMs and inorganic electrode materials for Li batteries. Specific capacity calculation considers the weight of the lithiated form of positive electrode materials and delithiated form of negative electrode materials (e.g., azo compounds, carboxylates, and graphite). The highest observed reversible capacities are used instead of theoretical values.

1818 summarizes the discharge potentials and active material-level 1819 specific capacities of $\mathrm{Li}$-organic batteries discussed in this 1820 section and compares them with those of state-of-the-art inorganic electrode materials. Note that the specific capacities of 1821 batteries with p-type OEMs are impacted by the weight of the $\mathrm{Li} 1822$ salt in the electrolyte (dual-ion cell configuration, Figure 9b-3). 1823

For comparison convenience, the calculation of all batteries 1824 with p-type OEMs considers $\mathrm{LiBF}_{4}$ as the $\mathrm{Li}$ salt. Although 1825 p-type OEMs have comparable discharge potentials and 1826 specific capacities as those of inorganic electrode materials, 1827 batteries based on them fall short in specific energy where the 1828 weight of the electrolyte is included. Therefore, p-type OEMs 1829 are not yet contenders as high-energy battery cathode materials 1830 but may find applications in, for example, fast charging devices 1831 and wearables. Many quinone-based OEMs have surpassed 1832 inorganic electrode materials in terms of specific energy at the 1833 active material level (i.e., only the weight of active materials is 1834 included in calculation). In practice, however, most high- 1835 energy OEMs still require too much conductive agents in their 1836 electrode composites for decent performance, which decreases 1837 specific energies at the cell level. Another challenge for OEMs 1838 is to simultaneously achieve high specific energy and high 1839 cycling stability. Future development of OEMs for nonaqueous 1840 $\mathrm{Li}$ batteries demands deeper understandings of their electron 1841 and ion conduction mechanics as well as performance degra- 1842 dation mechanisms and strategies to address them.

1843

\section{PERFORMANCES OF NONAQUEOUS SODIUM-ORGANIC BATTERIES}

1844

For decades, nonaqueous organic sodium-ion batteries have 1845 been overshadowed by other electrochemical energy systems 1846 (such as inorganic lithium-ion batteries, inorganic sodium-ion 1847 batteries, and later organic lithium-ion batteries) and have only 1848 been sporadically investigated. ${ }^{293}$ However, in 2012, three 1849 different groups published their works on disodium tereph- 1850 thalate within a time frame of four months, marking then the 1851 beginning of the recent boom in this field. ${ }^{294-296}$ Since then, 1852 disodium terephthalate has been regularly investigated as a 1853 model compound for composite electrode formulation..$^{297-301} 1854$ In parallel, many other new materials were reported in the 1855 literature as already exhaustively covered in recent reviews. ${ }^{16,40,41,302} 1856$ Considering that strategies known to affect the potential with 1857 inductive effects (electron-withdrawing/donating groups) or 1858 appropriate aromatic ring design will have similar effects in 1859 organic LIBs and SIBs, the only distinctions to keep in mind 1860 are the differences in electrochemical potential for the refer- 1861 ence metal $\left(-3.04 \mathrm{~V}\right.$ vs $\mathrm{SHE}$ for the $\mathrm{Li}^{+} / \mathrm{Li}$ redox couple 1862 against $-2.71 \mathrm{~V}$ vs SHE for the $\mathrm{Na}^{+} / \mathrm{Na}$ redox couple) and 1863 atomic differences. For instance, a sodium carboxylate is expected 1864 to insert a sodium ion at an average potential slightly lower than 1865 the potential of lithium ion insertion for the corresponding 1866 lithium carboxylate with the same aromatic system $-0.33 \mathrm{~V}$ (e.g., 1867 $0.9 \mathrm{~V} \mathrm{vs} \mathrm{Li}^{+} / \mathrm{Li}$ average redox potential for dilithium terephthalate 1868 and $0.4 \mathrm{~V}$ vs $\mathrm{Na}^{+} / \mathrm{Na}$ for disodium terephthalate: $0.5 \mathrm{~V}$ difference 1869 instead of $0.33 \mathrm{~V}$ ). Similarly, the strategies for improving the 1870 specific capacity or reducing the dissolution phenomenon of 1871 active species within the electrolyte system such as polymer- 1872 ization work usually as well for organic SIBs as they do for 1873 organic LIBs and hence will not be repeated in this section. 1874 As a reminder, the use of sodium instead of lithium is also 1875 motivated by higher abundance and lower cost of the resource, 1876 with $\mathrm{Na}$ being widely distributed in the earth's crust and 1877 oceans (Figure 6) and nontoxic.

1878

As previously stated, only the materials delivering the best 1879 performances in specific capacity, operating potential, and 1880 
Table 3. Performances of Selected Nonaqueous Na-Organic Batteries

\begin{tabular}{|c|c|c|c|c|c|c|c|}
\hline \# & $\begin{array}{l}\text { Positive electrode (or } \\
\text { "cathode") active material }\end{array}$ & $\begin{array}{l}\text { Negative electrode (or "anode") active } \\
\text { material }\end{array}$ & Electrolyte & $\begin{array}{c}\text { Output } \\
\text { voltage }(\mathrm{V})\end{array}$ & $\begin{array}{l}\text { Cycling stability: } \\
\text { retention, cycles, } \\
\text { rate or current } \\
\text { density }\end{array}$ & $\begin{array}{c}\text { Specific capacity } \\
\left(\mathrm{mAh}^{-1}\right) \text { and Specific } \\
\text { energy }\left(\mathrm{Wh} \mathrm{kg}^{-1}\right) \text { per } \\
\text { mass of positive active } \\
\text { material if not specified } \\
\text { otherwise, Final } \\
\text { coulombic efficiency, } \\
\text { Loading }\left(\mathrm{mg} \mathrm{cm}^{-2}\right)\end{array}$ & Ref. \\
\hline
\end{tabular}

\section{Organic electrode materials with high/low voltage}<smiles>CC(C)(C)c1ccc(N(c2ccc(C(C)(C)C)cc2)c2ccc(C(C)(C)C)cc2)cc1</smiles><smiles>Cc1ccc(N(c2ccc(C(C)(C)C)cc2)c2ccc(C(C)(C)C)cc2)cc1</smiles>

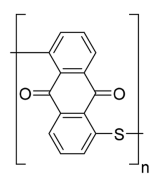

Na

$\mathrm{Na}$

$\mathrm{Na}$
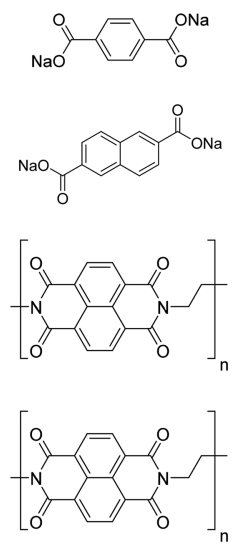

Na-predoped hard carbon

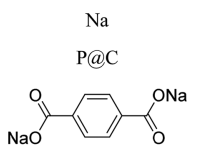

Disodium terephthalate

Saturated $\mathrm{NaPF}_{6}$ in DOL/DME (v/v $1: 1)$

3.6

$82 \%, 200,5 \mathrm{C}$
$\left(500 \mathrm{~mA} \mathrm{~g}^{-1}\right)$

$95,342,99$, n.d.

$\left[{ }^{307}\right]$

Saturated $\mathrm{NaPF}_{6}$ in DOLDME (v/v $1: 1)$

$\sim 1.8$

$85 \%, 500,8 \mathrm{C}$

180-155, ${ }^{a} 324$, a 99 , n.d.

$\left.{ }^{307}\right]$

$0.5 \mathrm{M} \mathrm{NaPF}_{6}$ in $\mathrm{EC}_{\mathrm{PCC}}$

$(\mathrm{v} / \mathrm{v} 1: 1)$

3.38

$68 \%, 1000,1 \mathrm{C}$

94-64, 318, n.d., $1.0-2.0$

[308]

$1 \mathrm{M} \mathrm{NaClO}_{4}$ in EC/PC (v/v

1:1)

$\sim 3.6$

$78 \%, 1200,1 \mathrm{C}$

$\left(300 \mathrm{~mA} \mathrm{~g}^{-1}\right)$

$98,353, \sim 100$, n.d.

$\left[{ }^{309}\right]$

$1 \mathrm{M} \mathrm{NaClO}_{4}$ in PC

$\sim 0.5$

$79 \%,{ }^{b} 1000$,

$\left(100 \mathrm{~mA} \mathrm{~g}^{-1}\right)$

$209,105, \sim 100$, n.d.

[317]

\section{Na-ion organic batteries}

$1 \mathrm{M} \mathrm{NaPF}_{6}$ in EC/EMC

$(\mathrm{v} / \mathrm{v} 3: 7)$

$1 \mathrm{M} \mathrm{NaClO}_{4}$ in $\mathrm{PC}$

$1 \mathrm{M} \mathrm{NaClO}_{4}$ in EC/DEC

$$
(\mathrm{v} / \mathrm{v} 1: 1)
$$

$1 \mathrm{M} \mathrm{NaClO}_{(\mathrm{in}}$ in EC/DEC

1.2

1.2

$73 \%, 100,1 \mathrm{C}$

$\left(140 \mathrm{~mA} \mathrm{~g}^{-1}\right)$

$158-102,{ }^{d} 190,{ }^{d} 95$, n.d.

[325]

$1 \mathrm{M} \mathrm{NaClO}_{4}$ in PC

$\sim 2.2$

$85 \%$, $40, \mathrm{C} / 10$
$\left(18 \mathrm{~mA} \mathrm{~g}^{-1}\right)$

$178-152,{ }^{\circ} 356,{ }^{\circ}$ n.d., 3.1

[226]

$0.6 \mathrm{NaPF}_{6}$ in DEGDME

1.5
1.3
1.25

$91 \%, 50,500 \mathrm{~mA} \mathrm{~g}^{-1}$

$83 \%, 50,500 \mathrm{~mA} \mathrm{~g}^{-1}$

$390,585, \sim 100,3-20$

$264,{ }^{a} 281,{ }^{a} \sim 100,3-20$

$137,{ }^{\mathrm{a}} 141,{ }^{\mathrm{a}} \sim 100,3-20$
[327] 
Table 3. continued

\begin{tabular}{|c|c|c|c|c|c|c|c|}
\hline \# & $\begin{array}{l}\text { Positive electrode (or } \\
\text { "cathode") active material }\end{array}$ & $\begin{array}{l}\text { Negative electrode (or "anode") active } \\
\text { material }\end{array}$ & Electrolyte & $\begin{array}{c}\text { Output } \\
\text { voltage (V) }\end{array}$ & $\begin{array}{l}\text { Cycling stability: } \\
\text { retention, cycles, } \\
\text { rate or current } \\
\text { density }\end{array}$ & $\begin{array}{c}\text { Specific capacity } \\
\left(\mathrm{mAh} \mathrm{g}^{-1}\right) \text { and Specific } \\
\text { energy }\left(\text { Wh } \mathrm{g}^{-1}\right) \text { per } \\
\text { mass of positive active } \\
\text { material if not specified } \\
\text { otherwise, Final } \\
\text { coulombic efficiency, } \\
\text { Loading }\left(\mathrm{mg} \mathrm{cm}^{-2}\right)\end{array}$ & Ref. \\
\hline 12 & & & $1 \mathrm{M} \mathrm{NaPF}_{6}$ in $\mathrm{PC}$ & $\sim 1.6$ & $70 \%, 20,50 \mathrm{~mA} \mathrm{~g}^{-1}$ & $73-51,{ }^{\mathrm{d}} 117,{ }^{\mathrm{d}}$ n.d., 1.4 & [328] \\
\hline 13 & & & $\underset{(\mathrm{v} / \mathrm{v} 1: 1)}{1 \mathrm{M} \mathrm{NaClO}_{4} \text { in EC/DMC }}$ & $\sim 2.0$ & $\begin{array}{l}76 \%, 100, \mathrm{C} / 10 \\
\left(19 \mathrm{~mA} \mathrm{~g}^{-1}\right)\end{array}$ & $204-155,{ }^{\mathrm{c}} 65, \mathrm{c} 99,1.0-1.8$ & {$\left[{ }^{329}\right]$} \\
\hline 14 & & $\mathrm{Na}$ & $1 \mathrm{M} \mathrm{NaPF}_{6}$ in EC/PC (v/v & 1.0 & $\begin{array}{l}100 \%,{ }^{\mathrm{b}} 1024, \\
50 \mathrm{~mA} \mathrm{~g}^{-1}\end{array}$ & $500,500, \sim 100,1.0$ & {$\left[{ }^{330}\right]$} \\
\hline 15 & & $\mathrm{Na}$ & $\begin{array}{l}1 \mathrm{M} \mathrm{NaClO}_{4} \text { in EC/DMC } \\
(\mathrm{v} / \mathrm{v} 1: 1)\end{array}$ & $\sim 1$ & $\begin{array}{c}95 \%, 500,100 \mathrm{~mA} \mathrm{~g}^{-1} \\
97 \%, 2600,1 \mathrm{~A} \mathrm{~g}^{-1}\end{array}$ & $\begin{array}{c}320,320, \sim 100,0.7 \\
218-258,250, \sim 100,0.7\end{array}$ & {$\left[{ }^{331}\right]$} \\
\hline 16 & & $\mathrm{Na}$ & $\begin{array}{c}1 \mathrm{M} \mathrm{NaClO}_{4} \text { in EC/DMC } \\
(\mathrm{v} / \mathrm{v} 1: 1)\end{array}$ & $\sim 0.9$ & $\begin{array}{c}82 \%, 100,100 \mathrm{~mA} \mathrm{~g}^{-1} \\
99 \%, 10000,5 \mathrm{~A} \mathrm{~g}^{-1}\end{array}$ & $\begin{array}{l}420,378, \sim 100 \text {, n.d. } \\
198,178, \sim 100 \text {, n.d. }\end{array}$ & [332] \\
\hline 17 & & $\mathrm{Na}$ & $\begin{array}{l}1 \mathrm{M} \mathrm{NaClO})_{4} \text { in } \\
\mathrm{EC} / \mathrm{DMC} / \mathrm{FEC}\end{array}$ & 1.3 & $66 \%, 250,500 \mathrm{~mA} \mathrm{~g}^{-1}$ & $567,737, \sim 100,1.0$ & {$\left[{ }^{333}\right]$} \\
\hline
\end{tabular}

Organic electrode materials with high stability

18

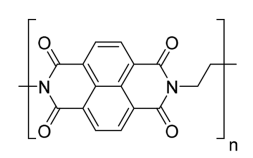

19

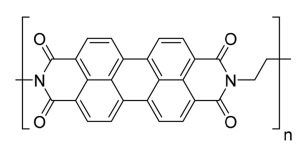

20

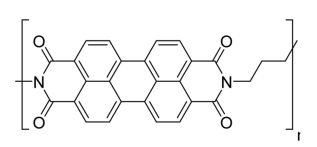

21

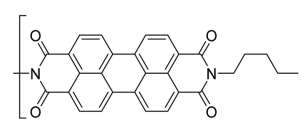

$\mathrm{Na}$

Na

$\mathrm{Na}$

Na

$$
\begin{gathered}
1 \mathrm{M} \mathrm{NaClO}_{4} \text { in } \\
\mathrm{EC} / \mathrm{PC} / \mathrm{FEC}
\end{gathered}
$$

$$
\begin{gathered}
1 \mathrm{M} \mathrm{NaPF} 6 \text { in EC/DMC } \\
(\mathrm{v} / \mathrm{v} 1: 1) \\
1 \mathrm{M} \mathrm{NaPF} 6 \text { in EC/DMC } \\
(\mathrm{v} / \mathrm{v} 1: 1)
\end{gathered}
$$

$1 \mathrm{M} \mathrm{NaPF}_{6}$ in $\mathrm{EC} / \mathrm{DMC}$

$$
\text { (v/v } 1: 1)
$$

$1 \mathrm{M} \mathrm{NaPF} 6$ in EC/DMC

$(\mathrm{v} / \mathrm{v} 1: 1)$

$\sim 2.1$

$93 \%, 1000,1 \mathrm{~A} \mathrm{~g}^{-1}$

$82,172, \sim 100,0.8$ $\left[{ }^{340}\right]$ 
Table 3. continued

\begin{tabular}{|c|c|c|c|c|c|c|c|}
\hline$\#$ & $\begin{array}{l}\text { Positive electrode (or } \\
\text { "cathode") active material }\end{array}$ & $\begin{array}{l}\text { Negative electrode (or "anode") active } \\
\text { material }\end{array}$ & Electrolyte & $\begin{array}{c}\text { Output } \\
\text { voltage (V) }\end{array}$ & $\begin{array}{l}\text { Cycling stability: } \\
\text { retention, cycles, } \\
\text { rate or current } \\
\text { density }\end{array}$ & $\begin{array}{c}\text { Specific capacity } \\
\left(\mathrm{mAh} \mathrm{g}^{-1}\right) \text { and Specific } \\
\text { energy }\left(\text { Wh } \mathrm{kg}^{-1}\right) \text { per } \\
\text { mass of positive active } \\
\text { material if not specified } \\
\text { otherwise, Final } \\
\text { coulombic efficiency, } \\
\text { Loading }\left(\mathrm{mg} \mathrm{cm}^{-2}\right)\end{array}$ & Ref. \\
\hline 22 & & $\mathrm{Na}$ & $\begin{array}{c}0.1 \mathrm{M} \mathrm{NaPF}_{6} \text { in } \\
\mathrm{DME} / \mathrm{DOL}(\mathrm{v} / \mathrm{v} 1: 1)\end{array}$ & 1.6 & $84 \%, 1000,0.5 \mathrm{C}$ & $157-132,251, \sim 100,2.0$ & [34] \\
\hline 23 & & $\mathrm{Na}$ & $1 \mathrm{M} \mathrm{NaPF}_{6}$ in $\mathrm{DME}$ & 1.8 & $90 \%, 1000,1 \mathrm{~A} \mathrm{~g}^{-1}$ & $104-94,187, \sim 100,1.8-2$ & {$\left[{ }^{342}\right]$} \\
\hline 24 & & $\mathrm{Na}$ & $1 \mathrm{M} \mathrm{NaPF}_{6}$ in DME & 1.6 & $\begin{array}{l}88 \%, 10000,514 \mathrm{C} \\
\quad\left(50 \mathrm{~A} \mathrm{~g}^{-1}\right)\end{array}$ & $110,176, \sim 100,1.0$ & {$\left[{ }^{334}\right]$} \\
\hline 25 & & $\mathrm{Na}$ & $1 \mathrm{M} \mathrm{NaPF} 6$ in DEGDME & 1.25 & $\begin{array}{l}81 \%, 1000,10 \mathrm{C} \\
85 \%, 2000,20 \mathrm{C}\end{array}$ & $\begin{array}{l}140-113,175, \sim 100,1.5 \\
115-98,144, \sim 100,1.5\end{array}$ & {$\left[{ }^{335}\right]$} \\
\hline 26 & & $\mathrm{Na}$ & $1 \mathrm{M} \mathrm{NaBF}_{4}$ in TEG/DME & $\sim 0.5$ & $75 \%, 1500,10 \mathrm{C}$ & $100,50, \sim 100,2.0-2.5$ & [36] \\
\hline 27 & & $\mathrm{Na}$ & $1 \mathrm{M} \mathrm{NaClO}_{4}$ in $\mathrm{PC}$ & $\sim 2.6$ & $80 \%, 7000,1 \mathrm{~A} \mathrm{~g}^{-1}$ & $\sim 90,234, \sim 100, \sim 1.5$ & {$[337]$} \\
\hline 28 & & $\mathrm{Na}$ & $1 \underset{(\mathrm{v} / \mathrm{v} 1: 1)}{\mathrm{M} \mathrm{NaClO} \text { in } \mathrm{EC} / \mathrm{DEC}}$ & $\sim 1.25$ & $\sim 100 \%,{ }^{\mathrm{e}}{ }_{1} 000,5 \mathrm{~A} \mathrm{~g}^{-1}$ & $107,134, \sim 100$, n.d. & {$\left[{ }^{343}\right]$} \\
\hline 29 & & $\mathrm{Na}$ & $\begin{array}{l}1 \mathrm{M} \mathrm{NaClO} \\
(\mathrm{v} / \mathrm{v} 1: 1)\end{array}$ & $\sim 1$ & $83 \%,{ }^{b} 1000,5 \mathrm{Ag} \mathrm{g}^{-1}$ & $89,89, \sim 100$, n.d. & {$\left[{ }^{343}\right]$} \\
\hline 30 & & $\mathrm{Na}$ & $1 \mathrm{M} \mathrm{NaPF}_{6}$ in DME & 1.65 & $\begin{array}{c}86 \%,{ }^{\mathrm{f}} 1000,0.56 \mathrm{C} \\
\left(100 \mathrm{~mA} \mathrm{~g}^{-1}\right) \\
95 \%,{ }^{\mathrm{f}} 1400,5.6 \mathrm{C} \\
\quad\left(1 \mathrm{~A} \mathrm{~g}^{-1}\right)\end{array}$ & $\begin{array}{l}177-145,292, \sim 100, \text { n.d. } \\
128-121,211, \sim 100 \text {, n.d. }\end{array}$ & {$\left[{ }^{344}\right]$} \\
\hline
\end{tabular}

${ }^{a}$ Based on cathode material weight. ${ }^{b}$ The first cycle is not taken into account. ${ }^{c}$ Based on anode material weight. ${ }^{d}$ Based on cathode and anode.

1881 cycling stability will be presented in the subsequent section 1882 (Table 3).

6.1. High/Low Voltage Organic Electrode Materials and 1883 Hybrid/All-Organic High Output Voltage Na-Ion Batteries

1884 The design of high and low voltage OEMs for SIBs has clearly 1885 taken inspiration from the lithium equivalents. "p-type" 1886 materials (i.e., anion insertion materials) are hence the most 1887 common compounds able to react at potential $>3.0 \mathrm{~V}$ vs $\mathrm{Na}^{+} /$ $1888 \mathrm{Na}$, while materials reacting at low potential $<1.5 \mathrm{~V}$ vs $\mathrm{Na}^{+} / \mathrm{Na}$ 1889 belong to "n-type" (i.e., cation insertion materials). Conductive 1890 polymers are an example of a type of material which could belong to any or both of these categories. Early research on 1891 conductive polymers for SIBs has been carried out by Yang's 1892 group, who used polyaniline derivatives (p-type), ${ }^{303}$ doped 1893 $\mathrm{PPy}^{304,305}$ (p-type), or $\mathrm{PT}^{306}$ (n-type) in some of the first 1894 articles in this field. Soon after, they reported the activity of 1895 polytriphenylamine (PTPAn, Table 3, entry 1) as p-type 1896 material with $\mathrm{PF}_{6}{ }^{-}$ingress. ${ }^{307}$ Each triphenylamine unit can 1897 lose one electron and intercalate one anion upon oxidation at 1898 an average redox potential of $3.6 \mathrm{~V}$ vs $\mathrm{Na}^{+} / \mathrm{Na}$ forming then 1899 quinoneimine units (Figure 13A). PTPAn displays stable 1900 reversible capacity even at high C-rate with $88 \mathrm{mAh} \mathrm{g}^{-1}$ at a 1901 
A

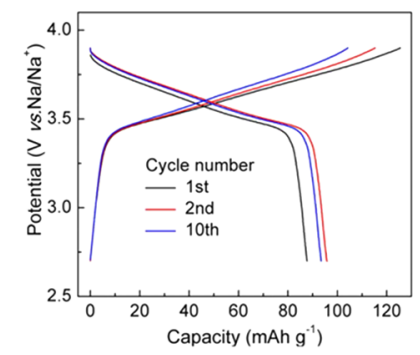

D

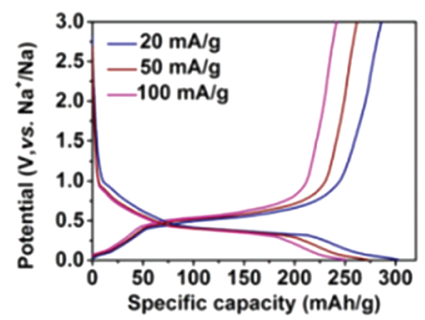

Specific capacity Iman gi

G

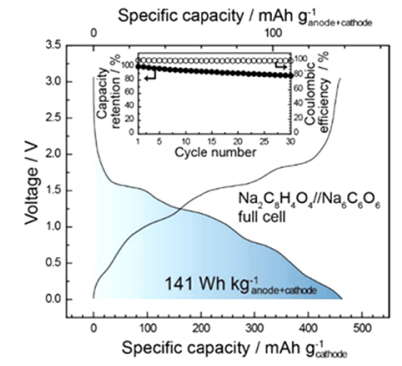

B

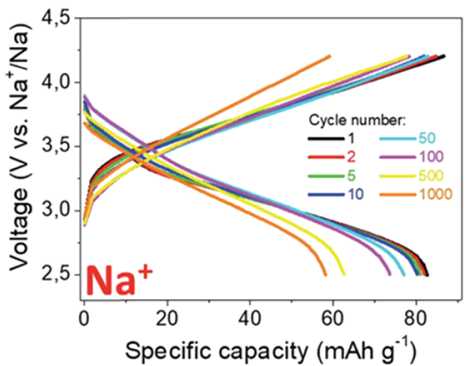

E

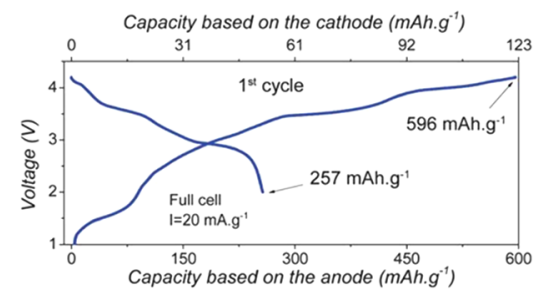

H

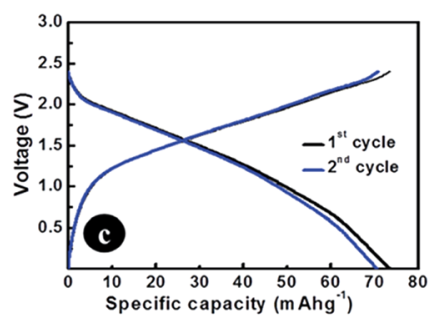

C

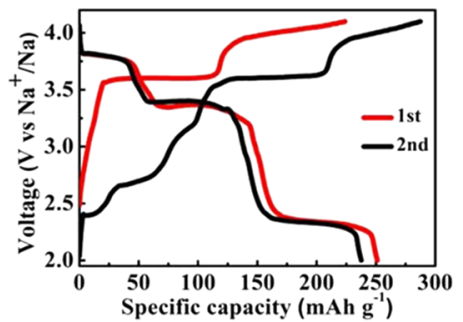

F

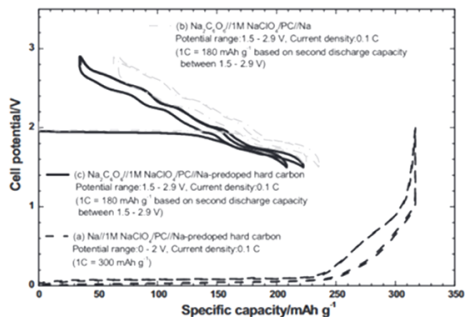

I

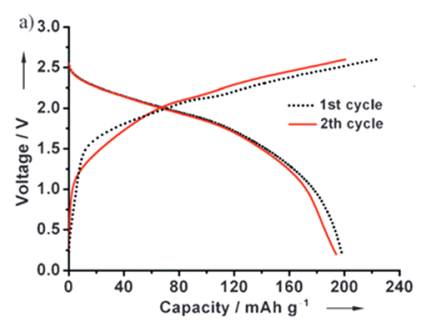

Figure 13. Voltage profiles of selected OEMs measured vs Na and all-organic Na-ion full cells including (A) PTPAn (reproduced from ref 307), (B) PDPPD (reproduced with permission from ref 308. Copyright 2019 The Royal Society of Chemistry), (C) CuTCNQ (reproduced with permission from ref 309. Copyright 2017 John Wiley \& Sons, Inc.), (D) Co-bpdc (reproduced with permission from ref 317. Copyright 2018 The Royal Society of Chemistry), (E) $\mathrm{Na}_{0.75} \mathrm{Mn}_{0.70} \mathrm{Ni}_{0.23} \mathrm{O}_{2} / / \mathrm{Na}_{2} \mathrm{C}_{8} \mathrm{H}_{4} \mathrm{O}_{4}$ (from ref 296. Copyright 2012 Royal Society of Chemistry), (F) $\mathrm{Na}_{2} \mathrm{C}_{6} \mathrm{O}_{6} / /$ $\mathrm{Na}$ predoped carbon (reproduced with permission from ref 326. Copyright 2013 Elsevier Ltd.), (G) $\mathrm{Na}_{2} \mathrm{C}_{6} \mathrm{O}_{6} / / \mathrm{Na}_{2} \mathrm{C}_{8} \mathrm{H}_{4} \mathrm{O}_{4}$ (reproduced with permission from ref 327. Copyright 2017 Nature Publishing Group), (H) PI// $\mathrm{Na}_{2} \mathrm{C}_{8} \mathrm{H}_{4} \mathrm{O}_{4}$ (reproduced with permission from ref 328. Copyright 2015 The Royal Society of Chemistry), and (I) $\mathrm{Na}_{4} \mathrm{C}_{8} \mathrm{H}_{2} \mathrm{O}_{6} / / \mathrm{Na}_{4} \mathrm{C}_{8} \mathrm{H}_{2} \mathrm{O}_{6}$ (reproduced with permission from ref 329. Copyright 2014 John Wiley \& Sons, Inc.).

1902 current of $20 \mathrm{C}$ and $97 \%$ capacity retention over 200 cycles 1903 when cycled at a current of $5 \mathrm{C}$. This material has also been 1904 cycled in dual-ion cell configuration paired with poly1905 (anthraquinoyl sulfide) (PAQS, Table 3, entry 2), an n-type 1906 material. This cell has an average voltage of $1.8 \mathrm{~V}$ and exhibits 1907 surprisingly high rate capability with $118 \mathrm{mAh} \mathrm{g}^{-1}$ reversible 1908 capacity (anode limitation design) at $32 \mathrm{C}$ rate. At a rate of $19098 \mathrm{C}$, the cell displays $85 \%$ capacity retention over 500 cycles. 1910 Poly $\left(N, N^{\prime}\right.$-diphenyl-p-phenylenediamine) (PDPPD, Table 3, 1911 entry 3) can be seen as another p-type derivative of polyaniline 1912 and can be used in lithium, sodium, or potassium batteries. ${ }^{308}$ 1913 At an average redox potential of $3.38 \mathrm{~V}$ vs $\mathrm{Na}^{+} / \mathrm{Na}$, its initial 1914 capacity is $94 \mathrm{mAh} \mathrm{g}^{-1}$ and sustains $76 \%$ of this value after 1915500 cycles at a $1 \mathrm{C}$ rate (Figure 13B). But the most striking 1916 performance of this polymer is certainly its ability to deliver 1917 capacity at current as high as $1000 \mathrm{C}$. At a current rate of 1,10 , 1918 50, or $100 \mathrm{C}$, the capacity losses are reasonable after 1000 1919 cycles. $^{308}$

1920 Metal organic compounds can also be used as positive 1921 electrode materials for SIBs. One such example is CuTCNQ 1922 (Table 3, entry 4). ${ }^{309,310}$ In its original redox state, CuTCNQ 1923 is a salt formed of cuprous ions $\left(\mathrm{Cu}^{+}\right)$and $\mathrm{TNCQ}^{-}$anion. Three 1924 redox stages could be obtained from this material at ca. 2.5, 3.4, 1925 and $3.9 \mathrm{~V}$ vs $\mathrm{Na}^{+} / \mathrm{Na}$, corresponding to $\mathrm{TNCQ}^{2-} / \mathrm{TNCQ}^{-}$, $1926 \mathrm{TNCQ}^{-} / \mathrm{TNCQ}^{0}$, and $\mathrm{Cu}^{+} / \mathrm{Cu}$, respectively (Figure $13 \mathrm{C}$ ). 1927 When nanostructured as flower-like nanorods anchored on 1-D carbon nanofibers (CNFs), CuTNCQ/CNFs composite 1928 displays reversible capacity of $137 \mathrm{mAh} \mathrm{g}^{-1}$ with $85 \%$ capacity 1929 retention after 300 cycles at a rate of $300 \mathrm{~mA} \mathrm{~g}^{-1}$ using the 1930 3 redox couples. If restricted to a cutoff voltage of $2.5-4.1 \mathrm{~V}$ vs 1931 $\mathrm{Na}^{+} / \mathrm{Na}$ which corresponds to $\mathrm{TNCQ}^{-} / \mathrm{TNCQ}^{0}$ and $\mathrm{Cu}^{+} / \mathrm{Cu}^{0}{ }_{1932}$ redox couples, the cell exhibits a capacity retention of $78 \% 1933$ after 1200 cycles for an average redox potential of $3.6 \mathrm{~V}$ vs 1934 $\mathrm{Na}^{+} / \mathrm{Na}$. But in this case, the high redox potential is shifted 1935 up due to the contribution of a metal center, unlike p-type 1936 OEMs.

For low potential OEMs for SIBs, carboxylates (e.g., 1938 disodium terephthalate, disodium naphthalene dicarboxy- 1939 late, ${ }^{311}$ disodium pyridine-2,5-dicarboxylate, ${ }^{312}$ disodium 4,4' 1940 biphenyldicarboxylate, ${ }^{313}$ and so on) or Schiff bases ${ }^{314-316} 1941$ have already been covered in recent reviews. ${ }^{16,40,41,302}$ The 1942 only recent example that will be covered here is the case of a 1943 metal organic framework (MOF) made of cobalt and 4,4'- 1944 biphenyldicarboxylate ligands (Co-bpdc, Table 3, entry 5). ${ }^{317} 1945$ According to the authors, the cobalt ions do not undergo 1946 reduction during the electrochemical process, leaving the redox 1947 activity to the sole organic moiety. The reversible sodium 1948 insertion/deinsertion occurs at an average potential of $0.5 \mathrm{~V}$ vs 1949 $\mathrm{Na}^{+} / \mathrm{Na}$ and exhibits stable capacity of ca. $300 \mathrm{mAh} \mathrm{g}^{-1}$ with $90 \% 1950$ capacity retention for 50 cycles at $20 \mathrm{~mA} \mathrm{~g}^{-1}$ or $264 \mathrm{mAh} \mathrm{g}^{-1} 1951$ and $79 \%$ capacity retention for 1000 cycles at $100 \mathrm{~mA} \mathrm{~g}^{-1} 1952$ (Figure 13D). 
1954 The interest for low potential OEMs for SIBs started to rise 1955 when poor long-term stability or safety issues were reported 1956 with classical inorganic materials or soft/hard carbons, while 1957 positive inorganic electrodes gave promising results. ${ }^{173,318-322}$ 1958 The larger ion diffusion pathways in OEMs are believed to be 1959 appropriate for the large sodium ions (as compared to lithium 1960 ions) while more constrained ion diffusion pathways in inor1961 ganic materials might be too restricted for sodium intercalation 1962 at low potentials. ${ }^{323}$ Ideally, a good compromise could be 1963 found with hybrid organic/inorganic sodium-ion batteries 1964 using inorganic materials as the positive electrode and OEMs 1965 as the negative electrode. One early example is the full sodium1966 ion cell made of disodium terephthalate as negative elec1967 trode and $\mathrm{Na}_{0.75} \mathrm{Mn}_{0.70} \mathrm{Ni}_{0.23} \mathrm{O}_{2}$ as positive electrode (Table 3, 1968 entry 6). ${ }^{296}$ With $3.6 \mathrm{~V}$ as output voltage, this cell delivers $1969257 \mathrm{mAh} \mathrm{g}^{-1}$ initial capacity (anode limitation design) with 1970 limited capacity loss after 50 cycles (93\% capacity retention, 1971 (Figure 13E). Interestingly, its stability is better for this full cell 1972 rather than the two half-cells using both electrodes and 1973 metallic sodium as counter electrode. However, this better 1974 stability for a hybrid organic/inorganic sodium-ion full cell is 1975 not systematic. In the case of a $\mathrm{Na}_{3} \mathrm{~V}_{2} \mathrm{O}_{2}\left(\mathrm{PO}_{4}\right)_{2} \mathrm{~F} / \mathrm{rGO} / /$ 1976 disodium naphthalene-2,6-dicarboxylate cell with an average 1977 redox potential of $3.3 \mathrm{~V}$ vs $\mathrm{Na}^{+} / \mathrm{Na}$, a severe capacity decay is 1978 noticeable after merely 20 cycles (Table 3, entry 7), while the 1979 half-cells display a better capacity retention. ${ }^{324}$ Other examples 1980 with acceptable stability include $\mathrm{Na}_{4} \mathrm{Fe}(\mathrm{CN})_{6} / /$ poly $1,4,5,8$ 1981 naphthalenetetracarboxylic dianhydride (PNTCD) and $\mathrm{Na}_{3} \mathrm{~V}$ $1982\left(\mathrm{PO}_{4}\right)_{3} / /$ PNTCD. ${ }^{325}$ However, like most diimide compounds, 1983 the average redox potential of PNTCD is $2.1 \mathrm{~V}$ vs $\mathrm{Na}^{+} / \mathrm{Na}$, 1984 which considerably restricts the average output voltage of the 1985 full cells to $1.2 \mathrm{~V}$ (Table 3, entry 8, 9).

1986 Examples of a hybrid organic/inorganic sodium-ion full cell 1987 using an OEM as the positive electrode are scarcer. One of the 1988 few cases is disodium rhodizonate which was cycled vs $\mathrm{Na}$ 1989 predoped hard carbon with improved cyclability as compared to 1990 cycling vs metallic sodium (Table 3, entry 10 and Figure 13F). ${ }^{326}$ 1991 Comparably to its lithium counterpart, disodium rhodizonate 1992 is able to reversibly intercalate four sodium ions (Table 3, 1993 entry 11). ${ }^{327}$ When nanosized, it delivers up to $484 \mathrm{mAh} \mathrm{g}^{-1}$ 1994 with several electrochemical features corresponding to the 1995 different sodium ion insertions. Disodium rhodizonate can also 1996 be cycled in a hybrid organic/inorganic full cell vs phosphorus 1997 encapsulated in a carbon scaffold (P@C) or in an all-organic 1998 configuration vs disodium terephthalate (Figure 13G).

1999 All-organic Na-ion batteries is an attractive concept without 2000 sensitive metals (price, rarity, geopolitics) such as cobalt, nickel, 2001 or lithium. But merely some examples have been reported in the 2002 literature. In addition to previously mentioned cases (Table 3, 2003 entries 2 and 11), a cell using $N, N^{\prime}$-diamino-3,4,9,102004 perylenetetracarboxylic polyimide (PI) as the positive elec2005 trode and disodium terephthalate as the negative electrode has 2006 been described (Table 3, entry 12, Figure $13 \mathrm{H}$ ). ${ }^{328}$ The 2007 limited output voltage of $1.6 \mathrm{~V}$ is here also connected to the 2008 choice of a polyimide whose average redox potential is $2.2 \mathrm{~V}$ vs $2009 \mathrm{Na}^{+} / \mathrm{Na}$.

2010 There is still to date only one example of an all-organic 2011 rocking chair sodium-ion battery published by Chen's group 2012 (Table 3, entry 13 and Figure 13I). ${ }^{329}$ The tetrasodium salt of 2013 2,5-dihydroxyterephthalic acid $\left(\mathrm{Na}_{4} \mathrm{DHTPA}\right.$ or $\mathrm{Na}_{4}-p$-DHT) is 2014 used in the same time as both positive and negative electrodes 2015 in a symmetrical cell as previously demonstrated in the case of 2016 the lithium chemistry. ${ }^{251}$ With $2 \mathrm{~V}$ as output voltage, this cell is hampered by the irreversible capacity of the negative electrode 2017 and displays reversible capacity of $198 \mathrm{mAh} \mathrm{g}^{-1}$ with $76 \% 2018$ capacity retention after 100 cycles at a rate of C/10.

\subsection{Organic Electrode Materials with High Specific} Capacity

All materials selected in this section are able to deliver more 2021 than $300 \mathrm{mAh} \mathrm{g}^{-1}$ over tens of cycles without conductive 2022 additive contribution. Interestingly, besides the previously 2023 mentioned disodium rhodizonate, many other high-capacity 2024 materials for SIBs involve the intercalation of sodium ions onto 2025 unsaturated carbons, as a sodium equivalent of the mechanism 2026 coined as "superlithiation" (see section 7.3), which will be 2027 thoroughly covered in the section 7.3. ${ }^{21,260}$ Consequently, their 2028 electrochemical features display similarities such as the 2029 requirement for large polarization values, sloping curves, and 2030 poor round trip efficiency. A first example is polydopamine 2031 (PDA, Table 3, entry 14) employed as both electrode and 2032 redox-active binder material, obtained as a mixture of ortho- 2033 catechol and ortho-quinone. ${ }^{330}$ After a first cycle with low 2034 Coulombic efficiency which could be explained by the solid 2035 electrolyte interface (SEI) formation and proton/sodium exchange 2036 in the catechol moieties, it shows an impressive stable capacity of 2037 $500 \mathrm{mAh} \mathrm{g}^{-1}$ with no obvious capacity loss over 1024 cycles. 2038

The group of Zhouguang $\mathrm{Lu}$ has investigated several 2039 derivatives of tri- $\beta$-ketoenamine linked compounds, either as a 2040 single molecule or as covalent organic frameworks (COF)..$^{331,332} 2041$ If cycled at low potential vs $\mathrm{Na}^{+} / \mathrm{Na}$, after the expected 2042 reduction of carbonyls from the anthraquinone moieties, the 2043 enolization of carbonyls of the tri- $\beta$-ketoenamine generates a 2044 triradical. The storage of three additional sodium ions is 2045 allowed by the reduction of the carbon backbone. Surprisingly, 2046 neither the triradical intermediate nor the organosodium 2047 species display major stability issues. In the case of TSAQ 2048 (Table 3, entry 15), the electrodes show a highly reversible 2049 capacity of $320 \mathrm{mAh} \mathrm{g}^{-1}$ with capacity retention higher than 2050 $95 \%$ after 50 cycles at a current density of $100 \mathrm{~mA} \mathrm{~g}^{-1} \cdot 3312051$ When cycled at a current 10 times higher, a capacity above 2052 $220 \mathrm{mAh} \mathrm{g}^{-1}$ is sustained for 2600 cycles (Figure 14A). For 2053 DAAQ-COF (Table 3, entry 16), which can be seen as a 2054 COF derivative of TSAQ the specific capacities are highly 2055 dependent on the particle size, even if this parameter does not 2056 seem to hamper the stability. The best performances are 2057 obtained with 4-12 nm particles that can sustain specific 2058 capacity above $400 \mathrm{mAh} \mathrm{g}^{-1}$ for 100 cycles. More impressively, 2059 when cycled at a current as high as $5 \mathrm{~A} \mathrm{~g}^{-1}$, ca. $200 \mathrm{mAh} \mathrm{g}^{-1} 2060$ are maintained for 10000 cycles (Figure 14B). 2061

As an alternative to carboxylates such as disodium tere- 2062 phthalate, their sulfur derivatives thiocarboxylates have been 2063 investigated, where either one or two of the oxygen atoms of 2064 the carboxylate function are replaced by sulfur atom in this 2065 series of analogues. ${ }^{333}$ The best performances are obtained 2066 with the compound Table 3, entry 17 with capacity as high as 2067 $567 \mathrm{mAh} \mathrm{g}^{-1}$ at a current density of $50 \mathrm{mAh} \mathrm{g}^{-1}$ and limited 2068 capacity loss after 250 cycles. Considering this compound has a 2069 larger molecular weight as compared to disodium tereph- 2070 thalate, its theoretical capacity per exchanged electron is lower 2071 (97.7 $\mathrm{mAh} \mathrm{g}^{-1}$ against $127.5 \mathrm{mAh} \mathrm{g}^{-1}$ ). However, while 2072 disodium terephthalate is limited to two electrons exchanged, 2073 compound 17 can accommodate up to 6 electrons with 2074 partial reversible reduction of its benzene ring through the 2075 "supersodiation" process (similar to "superlithiation", see 2076 section 7.3). 

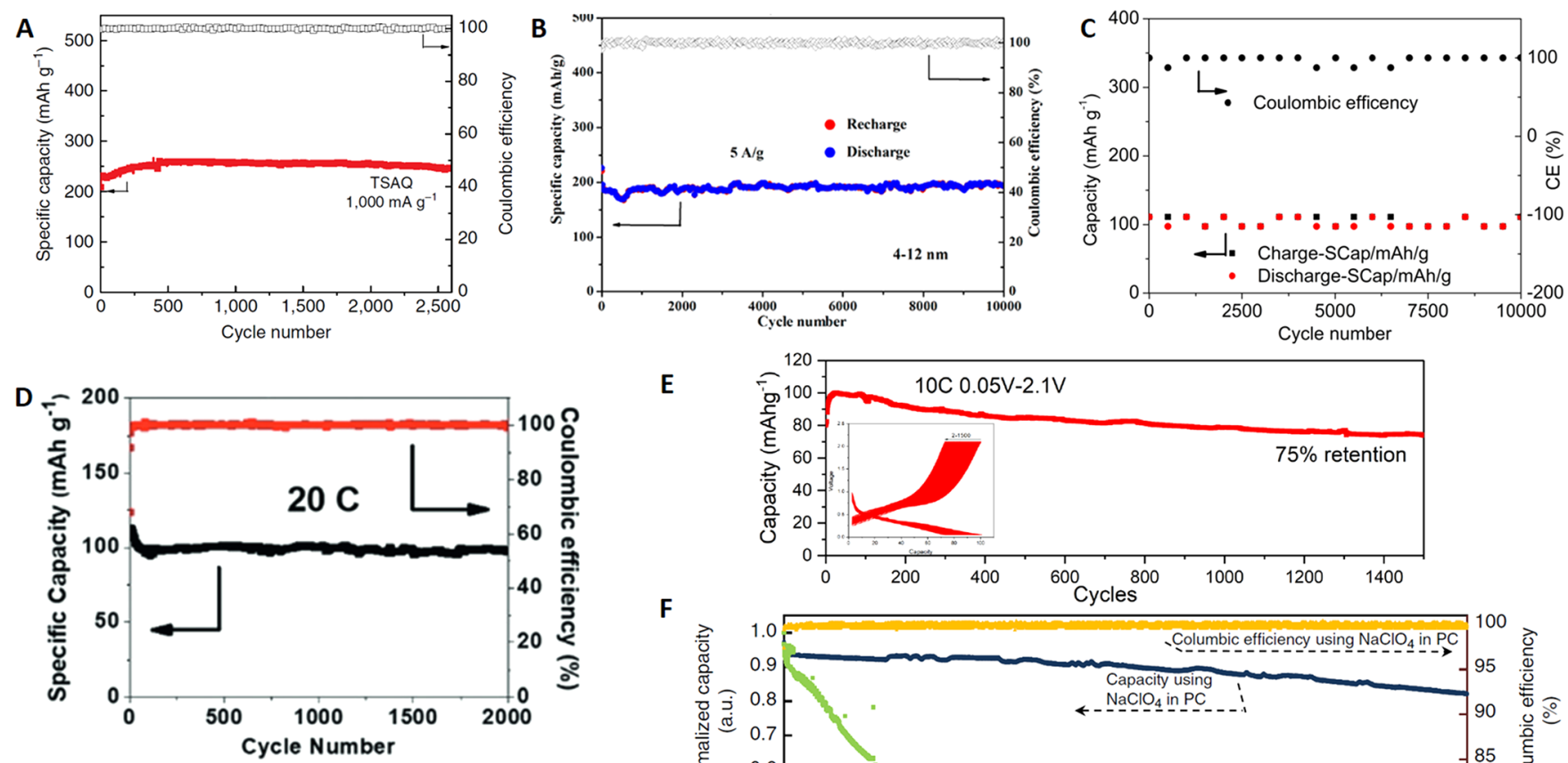

$\mathbf{E}$

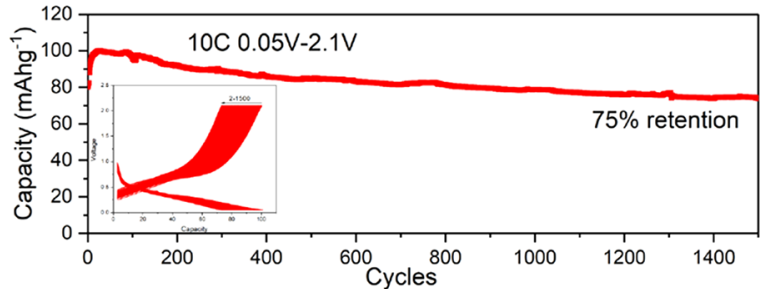

F

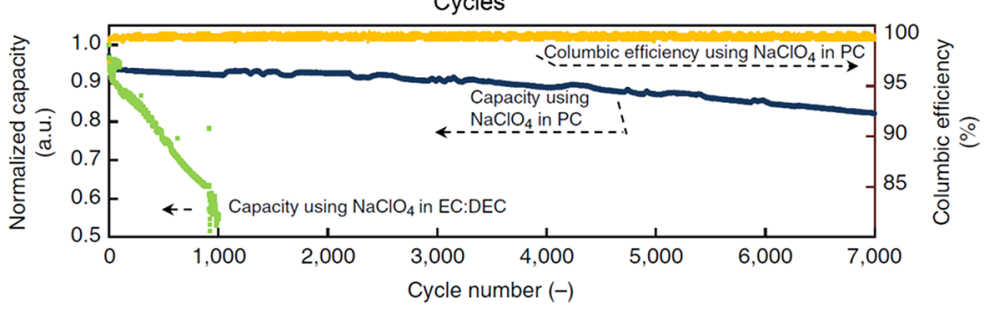

Figure 14. Capacity retention of selected OEMs measured vs Na including (A) TSAQ (reproduced from ref 331), (B) DAAQ-COF (reproduced with permission from ref 332. Copyright 2019 American Chemical Society), (C) PPTS (reproduced with permission from ref 334 . Copyright 2018 Elsevier Ltd.), (D) ADASS (reproduced with permission from ref 335. Copyright 2018 John Wiley \& Sons, Inc.), (E) $\mathrm{Na}_{3} \mathrm{C}_{9} \mathrm{H}_{3} \mathrm{O}_{6}$ (reproduced with permission from ref 336. Copyright 2018 John Wiley \& Sons, Inc.), and (F) BPOE (reproduced from ref 337).

\subsection{Organic Electrode Materials with Long Cycle Life}

2078 In general, poorer stabilities are observed for SIBs as compared 2079 to LIBs due to SEI layer compounds dissolution in the 2080 electrolyte system, to the very unstable metallic sodium for the 2081 half-cell configurations (dendrites formation), or to $\mathrm{Na}_{x} \mathrm{C}$ 2082 formed from sodium intercalation into the conductive additive 2083 at low potential. Achieving 1000 cycles or more for SIBs 2084 without severe capacity loss is hence a challenge. However, 2085 some OEMs are able to sustain high capacities for such long 2086 cycling. Some examples were previously commented (Table 3, 2087 entries 3, 4, 5, 14, 15, and 16).

2088 As already seen, the average redox potential of polyimides 2089 is usually in the $2.1-2.2 \mathrm{~V}$ vs $\mathrm{Na}^{+} / \mathrm{Na}$ potential range. 2090 Consequently, they suffer less long-term instability due to 2091 extreme potential windows. Polyethylenediamine 1,4,5,82092 naphthalenetetracarboxylic dianhydride (PEDA-NTCDA, 2093 Table 3, entry 18), ${ }^{338}$ polyethylenediamine 3,4,9,10-perylene2094 tetracarboxylic dianhydride (PEDA-PTCDA, Table 3, entry 2095 19), ${ }^{339,340}$ polypropylenediamine 3,4,9,10-perylenetetracarbox2096 ylic dianhydride (PPDA-PTCDA, Table 3, entry 20), ${ }^{340}$ and 2097 polyhexylenediamine 3,4,9,10-perylenetetracarboxylic dianhy2098 dride (PHDA-PTCDA, Table 3, entry 21) ${ }^{340}$ have all been 2099 cycled for at least 1000 cycles with negligible capacity loss. 2100 Especially, PEDA-PTCDA retained $87.5 \%$ of its initial 2101 capacity after 5000 cycles (Figure 14C). ${ }^{339}$

2102 Anthraquinones reversibly insert sodium at average redox 2103 potential slightly lower as compared to polyimides (i.e., 1.6$21041.8 \mathrm{~V}$ vs $\mathrm{Na}^{+} / \mathrm{Na}$ ), limiting also the risk of side reactions. 2105 Anthraquinones as polymers (PAQS, Table 3, entry 22$)^{341}$ or 2106 as salts (disodium 9,10-anthraquinone-2,6-disulfonate, $2107 \mathrm{Na}_{2} \mathrm{AQ} 26 \mathrm{DS}$, Table 3, entry 23) 342 have been success2108 fully cycled for 1000 cycles. An anthraquinone derivative, poly(pentacenetetrone sulfide) (PPTS, Table 3, entry 24) 2109 exhibits a remarkable stability at a very high rate of $50 \mathrm{~A} \mathrm{~g}^{-1} 2110$ corresponding to a full charge in $7 \mathrm{~s}$. After 10000 cycles, it still 2111 maintains $97 \mathrm{mAh} \mathrm{g}^{-1}$ (Figure 14C).

2112

Azobenzene-4, $4^{\prime}$-dicarboxylic acid sodium salt (ADASS, 2113 Table 3, entry 25) is a material that can reversibly insert two 2114 sodium ions on its azo $(-\mathrm{N}=\mathrm{N}-)$ function at an average 2115 redox potential of $1.25 \mathrm{~V}$ vs $\mathrm{Na}^{+} / \mathrm{Na}^{335}$ It can be cycled at 2116 a high current of 10 or $20 \mathrm{C}$ for 1000 and 2000 cycles, 2117 respectively, with moderate capacity losses (Figure 14D). The 2118 average redox potential of sodium carboxylates is rather low 2119 (usually in the $0.3-0.8 \mathrm{~V}$ range vs $\mathrm{Na}^{+} / \mathrm{Na}$ ) which makes side 2120 reaction likely to occur during long time cycling. Still, the 2121 group of Palani Balaya succeeded to cycle trisodium-1,3,5- 2122 benzene tricarboxylate (Table 3, entry 26) for 1500 cycles at a 2123 rate of $10 \mathrm{C}$ with $75 \%$ capacity retention with a lower cutoff 2124 potential of $50 \mathrm{mV}$ (Figure 14E)..$^{336} 2125$

Several covalent organic frameworks (COFs) have shown 2126 excellent cyclability. An early example from the literature is a 2127 p-type material (Table 3, entry 27) that reversibly inserts anion 2128 $\left(\mathrm{ClO}_{4}^{-}\right)$at an average potential of $2.6 \mathrm{~V}$ vs $\mathrm{Na}^{+} / \mathrm{Na}$ and 2129 sustains $80 \%$ of its capacity after 7000 cycles at a rate of 2130 $1 \mathrm{~A} \mathrm{~g}^{-1}$ (Figure 14F). ${ }^{337}$ Other triazine-based COFs have been 2131 used as n-type materials with the integration of carbonyl- 2132 containing moieties (Table 3, entry 28, 29). ${ }^{343}$ After a stabi- 2133 lization period corresponding to 30 cycles, they sustain most 2134 of their capacities over 1000 cycles at a high rate of $5 \mathrm{~A} \mathrm{~g}^{-1} .2135$ In addition to the previously mentioned tri- $\beta$-ketoenamine 2136 derivatives, which have already shown excellent stability (Table 3, 2137 entry 15,16$)$, the pentacenetetrone derivative 30 is able to maintain 2138 $95 \%$ of its capacity after 1400 cycles at a rate of $1 \mathrm{~A} \mathrm{~g}^{-1} \cdot{ }^{344} 2139$ 
Table 4. Performances of Selected Nonaqueous K-Organic Batteries

\begin{tabular}{|c|c|c|c|c|c|c|c|}
\hline \# & $\begin{array}{l}\text { Positive electrode (or "cathode") } \\
\text { active material }\end{array}$ & $\begin{array}{l}\text { Negative electrode (or "anode") } \\
\text { active material }\end{array}$ & Electrolyte & Output voltage (V) & $\begin{array}{l}\text { Cycling stability: } \\
\text { retention, cycles, rate } \\
\text { or current density }\end{array}$ & $\begin{array}{l}\left.\text { Specific capacity ( } \mathrm{mAh} \mathrm{g}^{-1}\right) \\
\text { and Specific energy } \\
\left(\mathrm{Wh} \mathrm{kg}^{-1}\right) \text { per mass of } \\
\text { positive active material if not } \\
\text { specified otherwise, Final } \\
\text { coulombic efficiency, } \\
\text { Loading }\left(\mathrm{mg} \mathrm{cm}^{-2}\right)\end{array}$ & Ref. \\
\hline 1 & & K & $1 \mathrm{M} \mathrm{KPF}_{6}$ in DME & 0.6 & $95 \%,{ }^{a} 500,1 \mathrm{~A} \mathrm{~g}^{-1}$ & $194,116, \sim 100,1.2-1.6$ & {$\left[{ }^{346}\right]$} \\
\hline 2 & & K & $1 \mathrm{M} \mathrm{KPF}_{6}$ in DME & 1.7 & $\begin{array}{l}74 \%, 3000,24 \mathrm{C} \\
\quad\left(5 \mathrm{~A} \mathrm{~g}^{-1}\right)\end{array}$ & $258,439,99,1.0-2.0$ & {$\left[{ }^{347}\right]$} \\
\hline 3 & & & $1 \mathrm{M} \mathrm{KPF}_{6}$ in DME & $\sim 1.1$ & $66 \%, 100,100 \mathrm{~mA} \mathrm{~g}^{-1}$ & $254,{ }^{\mathrm{b}} 122,{ }^{\mathrm{b}} 99,1.0-2.0$ & {$\left[{ }^{347}\right]$} \\
\hline 4 & & & $1.25 \mathrm{M} \mathrm{KPF}_{6}$ in $\mathrm{DME}$ & $\sim 1.25$ & n.d., $10,25 \mathrm{~mA} \mathrm{~g}^{-1}$ & $\sim 28,{ }^{\mathrm{b}} 35^{\mathrm{b}}$ n.d., $1.5-2.0$ & [348] \\
\hline 5 & & K & $\begin{array}{c}1 \mathrm{M} \mathrm{KPF}_{6} \text { in PC/FEC } \\
(\mathrm{v} / \mathrm{v} 98: 2)\end{array}$ & 4.05 & $\begin{array}{c}86 \%, 100,50 \mathrm{~mA} \mathrm{~g}^{-1} \\
55 \%, 500,2 \mathrm{~A} \mathrm{~g}^{-1}\end{array}$ & $\begin{array}{c}125,487,88,2.0 \\
85,351,88,2.0\end{array}$ & {$\left[{ }^{349}\right]$} \\
\hline 6 & & K & $\begin{array}{c}0.5 \mathrm{M} \mathrm{KPF}_{6} \text { in EC/DEC } \\
(\mathrm{v} / \mathrm{v} 1: 1)\end{array}$ & 3.52 & $63 \%, 1000,10 \mathrm{C}$ & $62-39,218$, n.d., $1.0-2.0$ & {$\left[{ }^{308}\right]$} \\
\hline 7 & & $\mathrm{~K}$ & $\begin{array}{c}\mathrm{PMMA}^{\mathrm{PM}} 0.8 \mathrm{M} \mathrm{KPF}_{6} \text { in } \\
\text { EC/DEC/FEC }(\mathrm{v} / \mathrm{v} / \mathrm{v} \\
45: 45: 10)\end{array}$ & 3.15 & $98 \%, 100,50 \mathrm{~mA} \mathrm{~g}^{-1}$ & 125,394, n.d., 3.0 & {$\left[{ }^{350}\right]$} \\
\hline
\end{tabular}

2140 To sum up, the development of organic SIBs has gained 2141 remarkably increased attention since 2012 and is considered as 2142 an interesting alternative to organic LIBs making the devel2143 opment of cationic rocking-chair batteries made of abundant 2144 elements possible. Although great achievements have been 2145 made, many challenges still remain to tackle problems such as 2146 capacity fading or low energy density. Polymerization, metal/ 2147 covalent organic frameworks, or insoluble salts are successful 2148 strategies to suppress the former, and very long cycling batte2149 ries have been reported without structural instability. As compared 2150 to their inorganic counterparts, promising results have been 2151 obtained for negative electrodes as an alternative to metallic 2152 sodium, graphite, or even hard/soft carbons. Improving the 2153 energy density is more complex and requires advanced elec2154 trode design in order to suppress as much conductive additive 2155 as possible. Nevertheless, the combination of renewable 2156 organic materials together with the high abundance of sodium 2157 raw materials provides an appealing concept, which is enough 2158 for encouraging continuous progress, and research in this field 2159 should certainly be esteemed.

\section{PERFORMANCES OF OTHER NONAQUEOUS 2160 ORGANIC BATTERIES}

\subsection{Performances of Nonaqueous Potassium-Organic} 2161 Batteries

2162 Surprisingly, despite the natural abundance of potassium, its 2163 relative low-cost, and the low electrochemical potential of $2164 \mathrm{~K}^{+} / \mathrm{K}(-2.94 \mathrm{~V}$ vs SHE), $\mathrm{K}$-ion batteries (KIBs) have not been 2165 thoroughly investigated until recently, ${ }^{345}$ with the motivation being related to its abundancy like $\mathrm{Na}$ compared to Li. One 2166 scientific reason is the large $1.38 \AA$ ionic radius of $\mathrm{K}^{+}(0.76 \AA 2167$ for $\mathrm{Li}^{+}, 1.02 \AA$ for $\mathrm{Na}^{+}$), which makes a challenge the design of 2168 inorganic materials able to reversibly insert such large ions into 2169 a rigid and constrained framework. Considering their larger 2170 interlayer spacing and flexible framework, OEMs for KIBs have 2171 then attracted the attention of researchers in parallel with the 2172 early development of their inorganic counterparts and not 2173 years or decades later unlike LIBs or SIBs. The research 2174 on OEMs for KIBs has clearly taken advantage of the years 2175 of development of OEMs for LIBs and SIBs and organic 2176 templates, which have been proven successful in these devices, 2177 have been adapted for KIBs, swapping from lithium or sodium 2178 salt to potassium salts when necessary. 2179

One such example is the dipotassium terephthalate (Table 4, 2180 entry 1) which intercalates/deintercalates potassium ion at 2181 an average potential of $0.6 \mathrm{~V}$ vs $\mathrm{K}^{+} / \mathrm{K}$ with a well-defined 2182 plateau after the first cycle. ${ }^{346}$ It exhibits reversible capacity up to 2183 $249 \mathrm{mAh} \mathrm{g}^{-1}$, and good capacity retention of $95 \%$ over 500 cycles 2184 is obtained when cycled at a rate of $1000 \mathrm{~mA} \mathrm{~g}^{-1}$ (Figure 15A). 2185 Quinone derivatives have already displayed their robustness 2186 in other EES devices. Poly(pentacenetetrone sulfide) (PPTS, 2187 Table 4, entry 2) can be cycled for 3000 cycles at a rate of 2188 $5 \mathrm{~A} \mathrm{~g}^{-1}$ with limited capacity decay (Figure 15B). ${ }^{347}$ Interestingly, 2189 at such a high rate, the Coulombic efficiency is much higher as 2190 compared to cycling at a rate of $0.1 \mathrm{~A} / \mathrm{g}$ ( 99\% against 90\%), 2191 which is due to the highly reactive metallic potassium counter 2192 electrode and dendrite formation according to the authors. 2193

These two materials have been cycled in an all-organic full cell 2194 (thereby without metallic potassium) which delivers $254 \mathrm{mAh} \mathrm{g}^{-1} 2195$ 
A

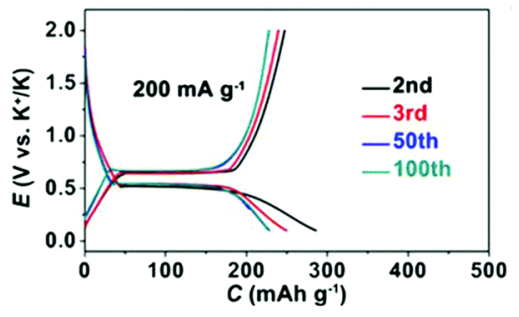

D

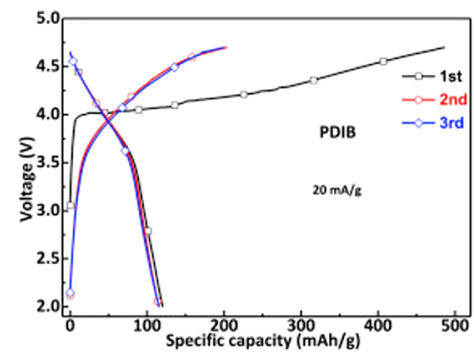

B

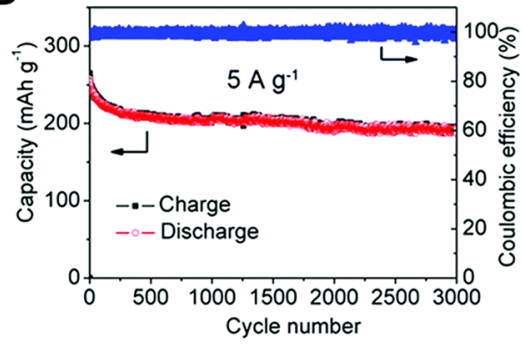

E

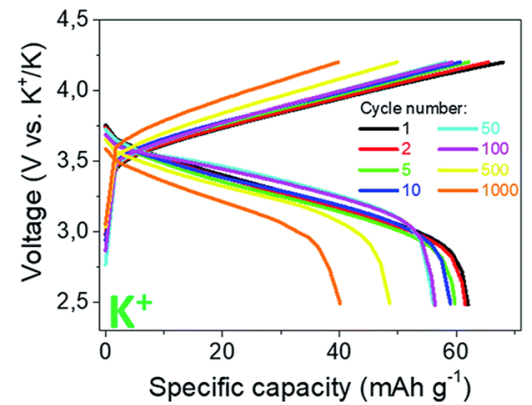

C

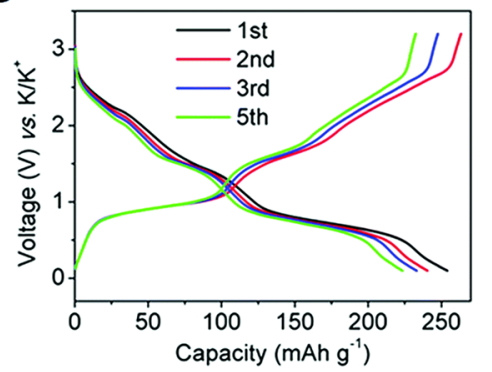

F

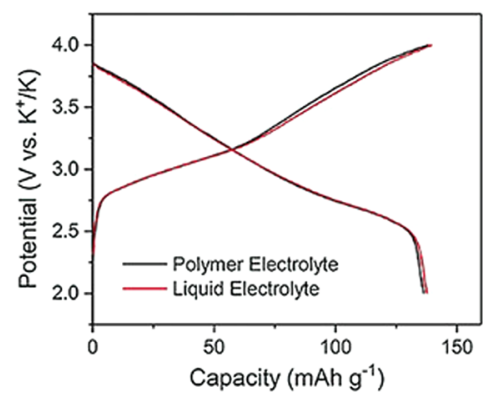

Figure 15. Voltage profiles or capacity retention of selected OEMs measured vs $\mathrm{K}$ including (A) $\mathrm{K}_{2} \mathrm{C}_{8} \mathrm{H}_{4} \mathrm{O}_{4}$ (reproduced with permission from ref 346. Copyright 2017 The Royal Society of Chemistry), (B) PPTS (reproduced with permission from ref 347 . Copyright 2019 The Royal Society of Chemistry), (C) PPTS// $\mathrm{K}_{2} \mathrm{C}_{8} \mathrm{H}_{4} \mathrm{O}_{4}$ (reproduced with permission from ref 347. Copyright 2019 The Royal Society of Chemistry), (D) PVK (reproduced with permission from ref 349. Copyright 2019 Elsevier Ltd.), (E) PDPPD (reproduced with permission from ref 308. Copyright 2019 The Royal Society of Chemistry), and (F) PAni (reproduced with permission from ref 350. Copyright 2018 John Wiley and Sons).

2196 initial capacity and $66 \%$ capacity retention after 100 cycles with 2197 an average Coulombic efficiency of 99\% (Table 4, entry 3, 2198 Figure $15 \mathrm{C}$ ). Another example of an all-organic full cell has 2199 been realized by Chen's group using dipotassium rhodizonate as 2200 the positive electrode of tetrapotassium salt of tetrahydroxyquinone 2201 as the negative electrode (Table 4, entry 4). ${ }^{348}$ Unfortunately, 2202 this cell displays very limited stability.

2203 Materials with an average redox potential above $3.0 \mathrm{~V}$ vs $2204 \mathrm{~K}^{+} / \mathrm{K}$ all belong to the p-type class and hence insert anions instead 2205 of potassium ions (dual-ion cell configuration, Figure 9b-3). 2206 The highest redox voltage for an organic KIB to date has been 2207 obtained using poly ( $N$-vinylcabazole) (PVK) which can insert $2208 \mathrm{PF}_{6}{ }^{-}$at an average redox potential of $4.05 \mathrm{~V} \mathrm{vs} \mathrm{K}^{+} / \mathrm{K}$ but with 2209 poor Coulombic efficiency (Figure 15D). ${ }^{349}$ Other remarkable 2210 performances have been obtained with PDPPD $(3.52 \mathrm{~V}$ vs $2211 \mathrm{~K}^{+} / \mathrm{K}$, Figure $\left.15 \mathrm{E}\right)^{308}$ and polyaniline (PAni, $3.15 \mathrm{~V}$ vs $\mathrm{K}^{+} / \mathrm{K}$, 2212 Figure $15 \mathrm{~F})$. $^{350}$

2213 In short, the research on KIBs is still in its infancy after starting 2214 to bloom in 2015 for inorganic electrode materials and 2016 for 2215 OEMs. One major challenge is the replacement of metallic potas2216 sium with a more stable negative electrode. But this has not pre2217 vented the development of long-term cycling batteries with more 2218 than 1000 cycles (Table 4, entries 2 and 6; see also refs 351-356).

\subsection{Nonaqueous Multivalent Metal-Organic Batteries} 2219 (Mg, Al, Zn)

2220 Among the investigated post-LIB systems, rechargeable batte2221 ries based on multivalent metal-ion shuttling (including $\mathrm{Mg}^{2+}$, $2222 \mathrm{Ca}^{2+}, \mathrm{Al}^{3+}, \mathrm{Zn}^{2+}$ ) are expected to offer significant improvement 2223 in volumetric energy density simply by using the corresponding 2224 metal as the negative electrode material (e.g., $\approx 3833 \mathrm{mAh} \mathrm{cm}^{-3}$ 2225 theoretical volumetric energy density for $\mathrm{Mg}$ compared to $2226 \sim 2046 \mathrm{mAh} \mathrm{cm}^{-3}$ for Li metal). In addition, the abundancy of 2227 such elements is not critical (2.5\% of the earth's crust for $\mathrm{Mg}$ against $0.0017 \%$ for $\mathrm{Li}){ }^{357,358}$ The current status is that few 2228 regular host inorganic electrode compounds, based on which 2229 Li-ion batteries are established, are able to deliver reasonable 2230 electrode performance for storing multivalent metal-ions. For 2231 $\mathrm{Mg}$ batteries, the flagship multivalent-metal batteries, Chevrel 2232 phase $\mathrm{Mo}_{6} \mathrm{X}_{8}(\mathrm{X}=\mathrm{S}, \mathrm{Se})$, continue to be the only reliable 2233 positive electrode materials despite the limited specific energy 2234 of the $\mathrm{Mo}_{6} \mathrm{X}_{8}-\mathrm{Mg}$ systems (up to $140 \mathrm{Wh} \mathrm{kg}^{-1}$ ). ${ }^{359,360}$ Recent 2235 discoveries of spinel $\mathrm{Ti}_{2} \mathrm{~S}_{4}$ and sulfur as $\mathrm{Mg}$ positive electrode 2236 materials in conjunction with the continuous development of 2237 non-nucleophilic chloride-free electrolytes greatly expanded 2238 the technology, but sluggish kinetics remain and stability issues 2239 are real. ${ }^{361,362}$ This is where OEMs start to look interesting: 2240 some OEMs have been reported to show adequate kinetics 2241 even at room temperature and deliver higher specific energies 2242 than those achieved by inorganic intercalation compounds at 2243 elevated temperatures. Due to these early successes, OEMs are 2244 now regarded by some as a wild card to enable multivalent- 2245 metal batteries. ${ }^{48,358,363}$ The properties and cell performance of 2246 these materials are summarized for comprehensive comparison 2247 (Table 5).

The promises aside, it is necessary to emphasize that 2249 multivalent chemistries are more complicated than monovalent 2250 ones, and the ion storage mechanism has not received enough 2251 scrutinization for many OEMs. For example, $\mathrm{Mg}^{2+}$ is noto- 2252 riously difficult to be dissociated from electrolyte solution 2253 species such as $\mathrm{Cl}^{-}$and ethereal solvent molecules. ${ }^{364,365} 2254$ While most studies on $\mathrm{Mg}$-organic batteries employed 2255 $\mathrm{Cl}^{-}$-containing electrolytes, a very recent study showed that 2256 probably all n-type OEMs store $\mathrm{MgCl}^{+}$instead of the presumed 2257 $\mathrm{Mg}^{2+}$ in these electrolytes. ${ }^{366}$ This unintended storage mechanism 2258 would effectively make most $\mathrm{Mg}$-organic batteries hybrid 2259 batteries, that is, the charge carrier ions at the positive and 2260 negative electrodes are different, and the electrolyte solution 2261 
Table 5. Performances of Selected Nonaqueous Multivalent Metal-Organic ${ }^{e}$

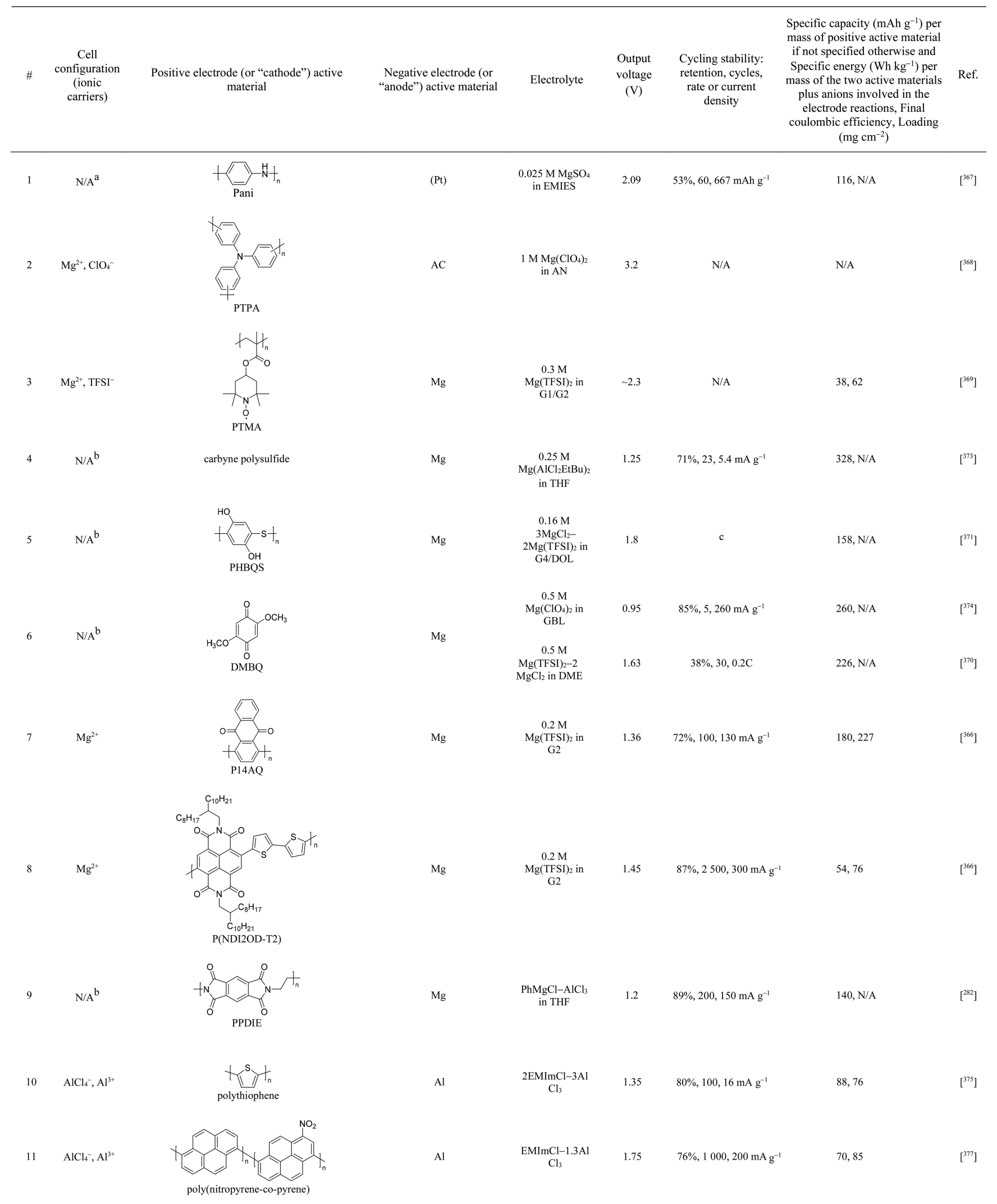


Table 5. continued

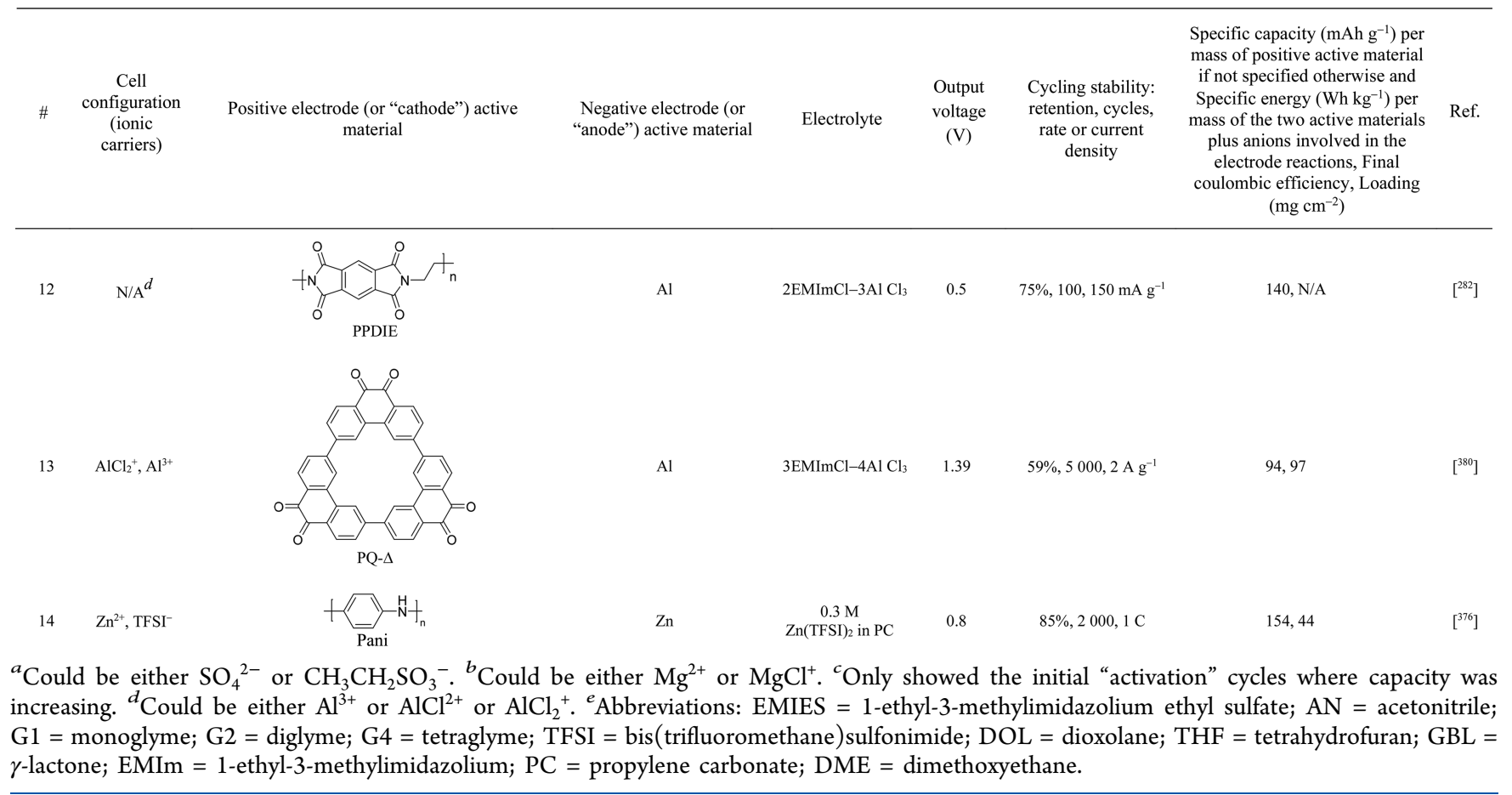

2262 must contain enough of the necessary ions to maintain charge 2263 balance. Cell specific capacity will be heavily limited by the 2264 weight of the electrolyte solution as a result. Since unambig2265 uous determination of the stored species in most previously 2266 reported $\mathrm{Mg}$-organic batteries has been overlooked, it would 2267 be difficult to estimate the actual specific capacity of those 2268 systems. In fact, such negligence is not specific to $\mathrm{Mg}$-organic 2269 batteries studies but Mg-ion storing positive electrode material 2270 research in general. In the future, this situation can be reverted 2271 by dedicated characterizations and rational selection of electro2272 lyte solutions. This section mainly concerns the apparent spe2273 cific capacity of OEMs and only discusses storage mechanism 2274 where sufficient experimental evidence of stored species is 2275 available.

2276 Similar to nonaqueous $\mathrm{Li}$-organic batteries, the highest 2277 discharge potentials for $\mathrm{Mg}$-organic batteries have been 2278 reported for p-type OEMs. Conductive polymer polyaniline 2279 (PAni), nitrogen-centered PTPA, and oxygen radical-centered 2280 PTMA all discharge at $>2 \mathrm{~V}$ vs $\mathrm{Mg}^{2+} / \mathrm{Mg}$, with PTPA showing 2281 the highest discharge potential at $3.2 \mathrm{~V}$ vs $\mathrm{Mg}^{2+} / \mathrm{Mg}^{367-369}$ 2282 Note that none of these materials were tested in electrolyte 2283 solutions where reversible $\mathrm{Mg}$ plating/stripping is possible. 2284 Among n-type OEMs, $p$-BQ-based molecule DMBQ and 2285 polymer poly(hydrobenzoquinonyl-benzoquinonyl sulfide) 2286 (PHBQS) show the highest discharge potentials of 1.63 and $22871.8 \mathrm{~V}$ vs $\mathrm{Mg}^{2+} / \mathrm{Mg}$, respectively (Figure 16B, C). ${ }^{370,371}$ Other 2288 carbonyl compounds based on anthraquinone and imides 2289 discharge at lower potentials, as they also do in Li batteries. ${ }^{372}$ 2290 As far as specific capacity is concerned, the organosulfur compound 2291 carbyne polysulfide shows the highest $328 \mathrm{mAh} \mathrm{g}^{-1}$ (Figure 16A), 2292 with carbonyl compounds DMBQ (up to $260 \mathrm{mAh} \mathrm{g}^{-1}$ ) and 2293 P14AQ (180 $\mathrm{mAh} \mathrm{g}^{-1}$ ) following (Figure 16C, D). ${ }^{366,373,374}$ The 2294 change of charge carrier ion from $\mathrm{Li}^{+}$to $\mathrm{Mg}^{2+}$ does not seem to 2295 alter the cycling stability generally observed for $\mathrm{Li}^{+}$-storing polymer 2296 OEMs. P(NDI2OD-T2) and PPDIE lose 13\% and $11 \%$ of their 2297 initial capacities after 2500 and 200 deep cycles, respectively, which 2298 stability is rarely seen from inorganic positive electrode materials
(Figure 16E). ${ }^{282,366}$ While these are quite some attractive numbers, 2299 there is no OEM that simultaneously shows high discharge 2300 potential, specific capacity, and cycling stability. There are also few 2301 OEMs that have been confirmed to store $\mathrm{Mg}^{2+}$ instead of complex 2302 ions. Therefore, there is a lot of opportunity lying ahead for 2303 developing better OEMs for Mg-organic batteries. 2304

OEMs for other nonaqueous multivalent metal-ions storage 2305 are quite rare. Most OEMs reported for multivalent-metal- 2306 organic batteries have been p-type materials where storage of 2307 anions rather than cations takes place (dual-ion cell configu- 2308 ration). Conductive polymers PT and PAni have been studied 2309 in $\mathrm{Al}$ and $\mathrm{Zn}$ batteries, respectively, showing decent to great 2310 cycling stability. ${ }^{375,376}$ Poly(nitropyrene-co-pyrene) shows the 2311 highest discharge potential for an Al-organic battery at $1.75 \mathrm{~V} 2312$ with great $75 \%$ capacity retention after 1000 cycles. ${ }^{377}$ Note 2313 that for $\mathrm{Al}$ batteries, only graphite, also a p-type material in this 2314 case, shows viable performances despite limited specific 2315 capacity. ${ }^{378,379}$ OEMs are thus welcomed additions to the 2316 technology. More interestingly, very recent studies show that 2317 efficient storage of $\mathrm{Al}$ in n-type OEMs is also possible. 2318 Phenanthraquinone triangle $\mathrm{PQ}-\Delta$ uniquely stores $\mathrm{AlCl}_{2}^{+}{ }_{2319}$ instead of $\mathrm{AlCl}_{4}^{-}$which basically every other decent cathode 2320 stores, hence opening up a brand new design space for $\mathrm{Al} 2321$ positive electrode materials (Figure 16F) ${ }^{380}$ PPDIE also seems 2322 to store cationic $\mathrm{Al}$ species considering it being an n-type 2323 material at the corresponding potential ( $\left.0.5 \mathrm{~V}_{\mathrm{vs}} \mathrm{Al}^{3+} / \mathrm{Al}\right), 2324$ though more characterization would be needed to reveal the 2325 nature of the stored ions. ${ }^{282}$

2326

Overall, OEMs indeed look promising as unique enablers for 2327 the otherwise quite problematic multivalent-metal batteries, 2328 even though detailed studies regarding the ion storage mech- 2329 anism and performance improvement have only just begun. 2330

\subsection{Comments on The Peculiar Multiple Cation Insertion} Phenomenon in Organics

The electrochemical process coined as "superlithiation" 2332 corresponds to a two-electron reduction of a carbon-carbon 2333 

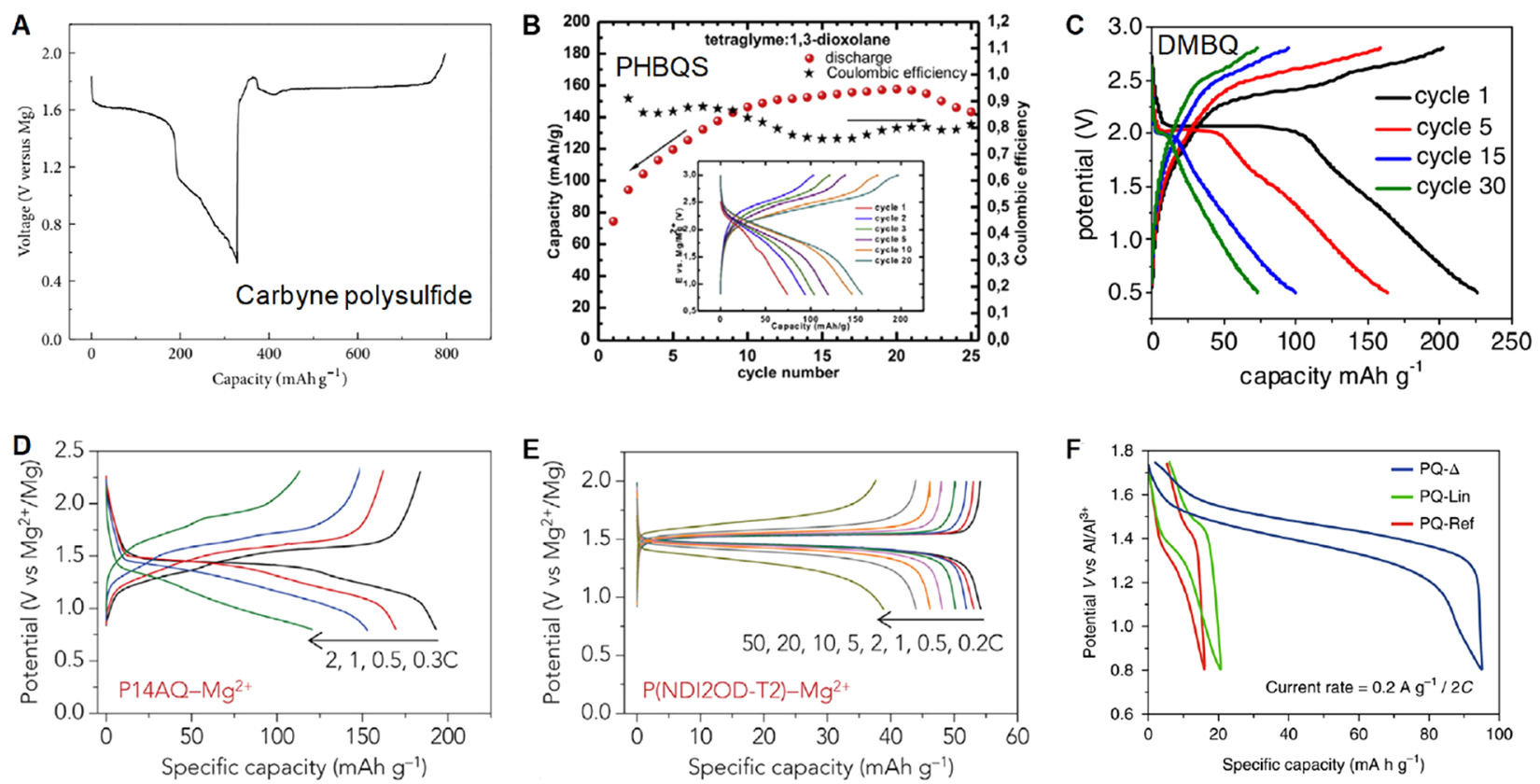

Figure 16. Voltage profiles of selected OEMs studied measured vs $\mathrm{Mg}(\mathrm{A}-\mathrm{E})$ and $\mathrm{Al}(\mathrm{F})$. (A) Carbyne polysulfide (reproduced from ref 373 ), (B) PHBQS (reproduced with permission from ref 371. Copyright 2016 Elsevier Ltd.), (C) DMBQ (reproduced with permission from ref 370. Copyright 2016 The Electrochemical Society), (D) P14AQ (reproduced with permission from ref 366. Copyright 2018 Elsevier Ltd.), (E) P(NDI2OD-T2) P14AQ (reproduced with permission from ref 366. Copyright 2018 Elsevier Ltd.), and (F) PQ- $\Delta$ (reproduced with permission from ref 380. Copyright 2016 Nature Publishing Group).

2334 double bond with a concomitant uptake of two lithium ions for 2335 charge compensation (Scheme 1A). Consequently, a material 2336 with solely $\mathrm{sp}^{2}$ hybridized carbons could in theory reach a $1 / 1$ $2337 \mathrm{Li} / \mathrm{C}$ ratio when fully reduced, allowing us to reach extremely 2338 high specific capacities. It was first established in 2012 in an 2339 article from Taolei Sun where 1,4,5,8-naphthalenetetracarboxylic 2340 dianhydride (NTCDA), a material with 4 carbonyls and $14 \mathrm{sp}^{2}$ 2341 hybridized carbons, could insert 18 lithium ions. ${ }^{381}$ This work 2342 was accompanied by an NMR study which displayed partic2343 ularly shielded ${ }^{1} \mathrm{H}$ peaks for the "superlithiated" NTCDA, 2344 matching their proposed mechanism.

2345 Remarkably, some template molecules seem to be subjected 2346 to diverse multiple alkali metal ions insertions; the process is 2347 hence not limited to lithium ion uptake. For instance, 3,4,9,102348 perylene-tetracarboxylicacid-dianhydride (PTCDA) is able 2349 to uptake up to 28 lithium ions, ${ }^{381} 15$ sodium ions ${ }^{382}$ or 11 2350 potassium ions (Scheme 1B). ${ }^{383}$ It is interesting to note that 2351 the larger the radius of the concerned cation, the fewer could 2352 be inserted onto PTCDA, possibly due to steric hindrance. 2353 However, in the case of PTCDA, the mere reduction of the 2354 first two carbonyls is a reversible process, while the reduction 2355 of the last two and the "superlithiation/sodation/potation" is 2356 not. Nonetheless, over the course of the last years, many 2357 materials have been described reacting according to reversible 2358 "superlithiation" and are able to deliver specific capacities 2359 sometimes exceeding $1000 \mathrm{mAh} \mathrm{g}^{-1}$ for hundreds of cycles.

2360 The typical electrochemical feature of the "superlithiation" 2361 process is a sloping curve without obvious plateau requiring a 2362 large potential window to achieve high Coulombic efficiency 2363 (typically $0.05-3 \mathrm{~V}$ ) and exhibiting a large hysteresis 2364 (polarization) sometimes exceeding $1 \mathrm{~V}$ (Figure 17A). Despite 2365 the attractive specific capacities obtained with these materials 2366 and the intriguing science (but still poorly understood) behind 2367 it, these electrochemical features make them of no practical 2368 use. Nevertheless, while initially believed to be connected with fused aromatic rings or to be kinetically limited, numerous 2369 examples have been described with a single ${ }^{260}$ or no aromatic 2370 ring $^{384}$ and with excellent capacity at a high current rate, and 2371 there is still hope for further developments of this redox 2372 process. By nature, "superlithiated" materials are typically inves- 2373 tigated as negative electrode (starting with a cation uptake). 2374 The only case of a "superlithiated" positive electrode (starting 2375 with a cation release) is lithium carbide $\mathrm{Li}_{2} \mathrm{C}_{2}$, where up to one 2376 lithium ion can be released from the structure. ${ }^{385,386}$ As previ- 2377 ously mentioned, this review does not try to be exhaustive, and 2378 just a few examples will be presented here. The total amount 2379 of articles on materials which could be related to a "super- 2380 lithiation" process has exceeded 100. For the sake of 2381 clarification, OEMs containing a transition metal such as 2382 metal-organic frameworks, coordination polymers, or organo- 2383 metallic compounds have been excluded, considering that their 2384 specific capacity has a contribution from the transition metal in 2385 addition to the "superlithiation" corresponding to the organic 2386 moiety.

2387

Polyanthraquinone-triazine (PAT) is a COF using repeating 2388 units similar to COFs previously mentioned. However, unlike 2389 the other triazine-based and anthraquinone-based COFs, PAT 2390 undergoes a 17-electron reduction per repeating unit, corre- 2391 sponding to the reduction of 2 carbonyls (2 electrons), the 2392 triazine unit ( 3 electrons) and the 2 benzene rings of the 2393 anthraquinone moiety ( 12 electrons), leading to a maximum 2394 reversible capacity of $770 \mathrm{mAh} \mathrm{g}^{-1}$ (Table 6, entry 1, and 2395 Figure 17B) ${ }^{387}$ Interestingly, the capacity decreases in the first 2396 30 cycles before slowly increasing with time over 400 cycles, 2397 which has been assigned to a slow activation process. This 2398 behavior has been observed for several "superlithiated" 2399 materials, such as F-PDI-3-TC (Table 6, entry 2). ${ }^{388}$ Its initial 2400 capacity is merely $95.7 \mathrm{mAh} \mathrm{g}^{-1}$ but reaches $783 \mathrm{mAh} \mathrm{g}^{-1}$ after 2401 1000 cycles (Figure 17C). Other examples include poly- 2402 (benzobisimidazobenzophenanthroline) (BBL) and poly(1,6- 2403 
Scheme 1. (A) Electrochemical Storage Mechanism of the "Superlithiation"; (B) Multiple Cation Insertion for PTCDA
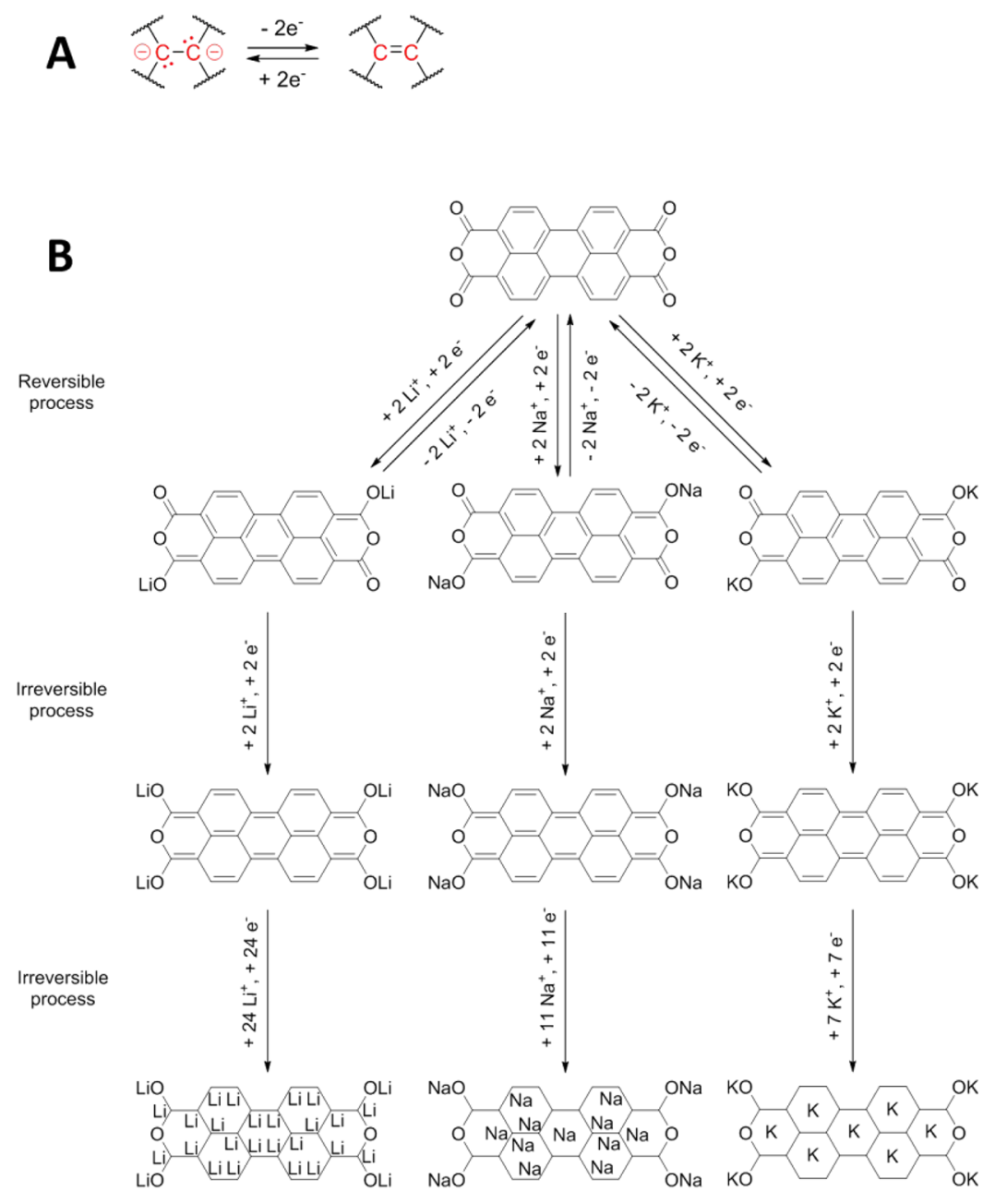

2404 dihydropyrazino[2,3g] quinoxaline-2,3,8-triyl-7- $(2 \mathrm{H})$-ylidene2405 7,8-dimethylidene) (PQL) that can reach up to $1285 \mathrm{mAh} \mathrm{g}^{-1}$ and $24061550 \mathrm{mAh} \mathrm{g}^{-1}$ of reversible capacity, respectively (Figure 17D, 2407 E). ${ }^{389,390}$ For these last two materials, the capacity and kinetics 2408 are improved when cycled at $50{ }^{\circ} \mathrm{C}$ instead of room temperature. $2409 \mathrm{BBL}$ and PQL display discharge capacities of $496 \mathrm{mAh} \mathrm{g}^{-1}$ and $2410 \mathrm{ca} .500 \mathrm{mAh} \mathrm{g}^{-1}$ at the 1000 th cycle at a rate of 3 and $2.5 \mathrm{C}$, 2411 respectively.

2412 Briefly, "superlithiation" is a peculiar but fascinating elec2413 trochemical process giving access to extremely high reversible 2414 capacities. However, very little is understood about it such as 2415 why some specific structures are subjected to "superlithiation" 2416 and others structurally closely related are not. But the main 2417 limitation is clearly the poor round trip energy efficiency of 2418 devices using "superlithiated" materials which, if not solved, 2419 will restrain this process to a scientific curiosity with no prac2420 tical applications for the moment.

\section{SOLID ORGANIC ELECTRODES FOR AQUEOUS 2421 BATTERIES}

\subsection{Introductory Statement}

2422 Although there are fewer examples in the literature concerning 2423 the use of OEMs in aqueous electrolyte, this application is of 2424 interest for developing low cost and environmentally friendly 2425 electrochemical storage solutions. Aqueous rechargeable 2426 batteries featuring low-cost and nonflammable water-based electrolytes are intrinsically safe and do not rely heavily on 2427 battery management systems, thereby providing robustness 2428 and cost advantages over competing lithium-ion batteries that 2429 use volatile and toxic organic electrolytes. However, the state- 2430 of-the-art aqueous rechargeable batteries show short cycle 2431 life and fall short of meeting large-scale applications where 2432 frequent replacement of batteries is undesirable. This is typical 2433 of $\mathrm{PbA}$ batteries ( 200 cycles for deep cycling) where the lead 2434 electrode undergoes irreversible passivation of $\mathrm{PbSO}_{4}$. Similarly, 2435 the capacity retention of nickel-based alkaline batteries is altered 2436 by the volume variations of the electrodes on cycling. On the 2437 contrary, neutral aqueous ion rocking-chair batteries such as 2438 introduced by J. Dahn in $1994^{391}$ appear more attractive in 2439 terms of cycle life due to smoother ion intercalation mech- 2440 anisms, but again, the commonly investigated chemistry was 2441 based on inorganic electrode materials; albeit, Alt et al. ${ }^{392} 2442$ reported as soon as 1972 an organic based aqueous cell using 2443 the tetrachloro-1,4-benzoquinone (TCQB) in $4 \mathrm{M}$ sulfuric 2444 acid. Such a cell exhibited a redox potential of $0.67 \mathrm{~V}$ vs 2445 saturated calomel electrode (SCE) associated with the pro- 2446 tonation of the quinone structure.

2447

One of the intentions of the authors is to provide in this 2448 section a critical view on the latest advances and challenges 2449 in the exploration of organic based aqueous cell chemistries, 2450 including a quantified comparison of their properties against 2451 those of inorganic materials including the tricky question of 2452 the volumetric energy density. As part of this review, we feel 2453 
A

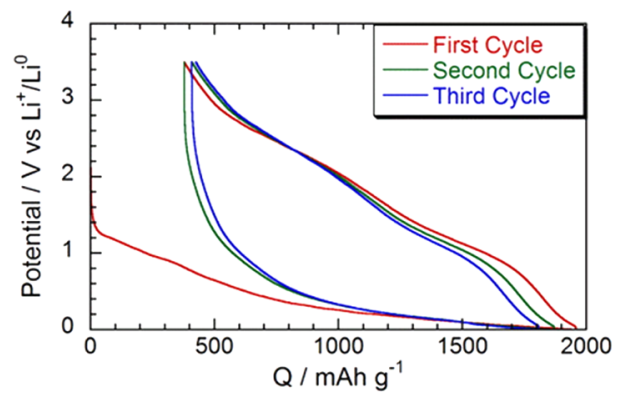

C

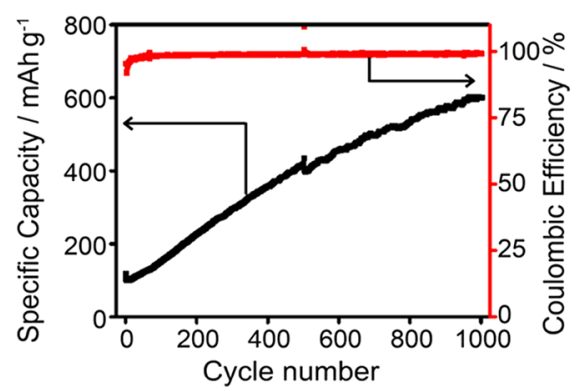

B

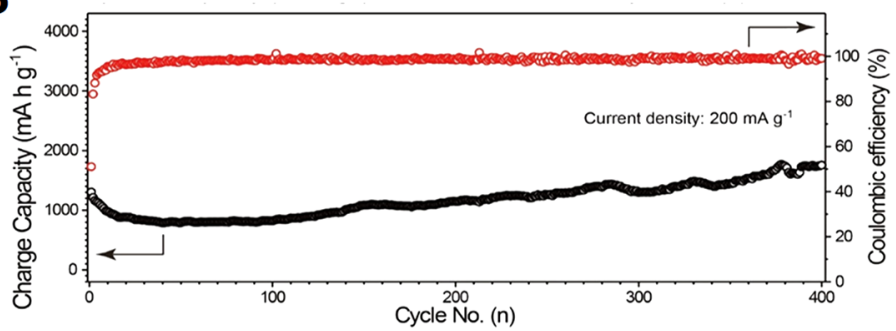

D

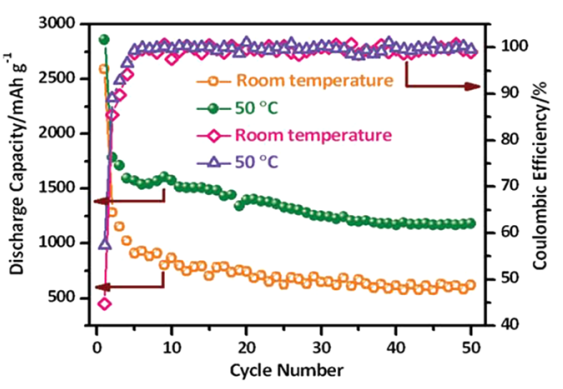

$E$

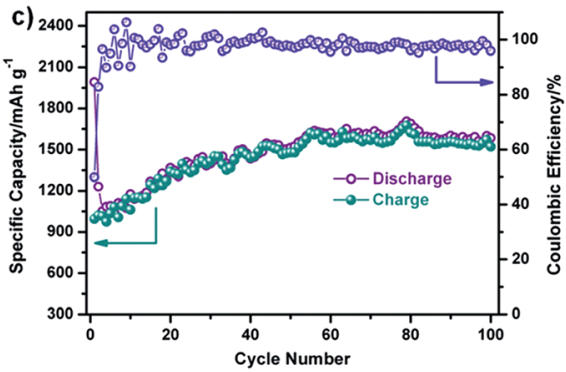

Figure 17. (A) Typical voltage profile of a "superlithiated" material: $\mathrm{Li}_{2} \mathrm{BDP}$ (reproduced with permission from ref 260. Copyright 2016 American Chemical Society). (B-E) Capacity retention of selected OEMs: (B) PAT (reproduced with permission from from ref 387. Copyright 2018 American Chemical Society), (C) F-PDI-3-TC (reproduced with permission from ref 388. Copyright 2019 American Chemical Society), (D) BBL (reproduced with permission from ref 389. Copyright 2015 John Wiley and Sons), and (E) PQL (reproduced with permission from ref 390. Copyright 2015 John Wiley and Sons).

\section{Table 6. Performances of Selected OEMs Exhibiting the "Superlithiation" Phenomenon}

\begin{tabular}{|c|c|c|c|c|c|c|c|}
\hline \# & $\begin{array}{l}\text { Positive electrode (or "cathode") active } \\
\text { material }\end{array}$ & Negative electrode (or "anode") & Electrolyte & Output voltage (V) & $\begin{array}{l}\text { Cycling stability: } \\
\text { retention, cycles, } \\
\text { rate or current } \\
\text { density }\end{array}$ & $\begin{array}{c}\text { Specific capacity } \\
\left(\mathrm{mAh}^{-1}\right) \text { and Specific } \\
\text { energy }\left(\mathrm{Wh} \mathrm{kg} \mathrm{kg}^{-1}\right) \text { per mass } \\
\text { of positive active material, } \\
\text { Final coulombic } \\
\text { efficiency, Loading } \\
\left(\mathrm{mg} \mathrm{cm}^{-2}\right)\end{array}$ & Ref. \\
\hline 1 & & $\mathrm{Li}$ & $1 \mathrm{M} \mathrm{LiPF}_{6}$ in $\mathrm{EC} / \mathrm{DMC}$ & $\sim 0.9$ & $\begin{array}{l}\text { n.d. }{ }^{a} 400 \\
200 \mathrm{mAh} \mathrm{g}^{-1}\end{array}$ & $1770,1593, \sim 99,1.1$ & {$\left[{ }^{387}\right]$} \\
\hline 2 & & $\mathrm{Li}$ & $1 \mathrm{M} \mathrm{LiPF}_{6}$ in $\mathrm{EC} / \mathrm{DEC}$ & $\sim 0.9$ & $\begin{array}{l}\text { n.d., }{ }^{a} 1000 \\
200 \mathrm{mAh} \mathrm{g}^{-1}\end{array}$ & $783,705, \sim 99$, n.d. & {$\left[{ }^{388}\right]$} \\
\hline 3 & & $\mathrm{Li}$ & $1 \mathrm{M} \mathrm{LiPF}_{6}$ in $\mathrm{EC} / \mathrm{DEC}$ & $\sim 0.9$ & $48 \%, 50,100 \mathrm{mAh} \mathrm{g}^{-1}$ & $1285,1156, \sim 99$, n.d. & {$\left[{ }^{389}\right]$} \\
\hline 4 & & $\mathrm{Li}$ & $1 \mathrm{M} \mathrm{LiPF}_{6}$ in EC/DEC & $\sim 0.9$ & $\begin{array}{l}\text { n.d., }{ }^{a} 100, \\
100 \mathrm{mAh} \mathrm{g}^{-1}\end{array}$ & $1550,1395, \sim 99$, n.d. & {$\left[{ }^{390}\right]$} \\
\hline
\end{tabular}

${ }^{a}$ Due to an activation process, the capacity increases with time.

2454 it is therefore interesting to evaluate the effective chances of 2455 organics to realize user/market-acceptable aqueous batteries. 2456 In addition, we believe that such a comparison would not be 2457 complete if another bottleneck of this technology that is the 2458 price of active materials is not compared. To address these 2459 points, the latest literature data associated with the most 2460 advanced and industry relevant inorganic material for molar 2461 range aqueous battery (as opposed to water-in-salt type ones 2462 that will be briefly discussed, vide infra) which is the carbon 2463 coated $\mathrm{Na}(\mathrm{Li}) \mathrm{Ti}_{2}\left(\mathrm{PO}_{4}\right)_{3}$ (referred to as C@NTP or C@LTP) 2464 is considered below.

\section{Volumetric Capacity Aspect}

On paper, this is not one of the most important factors for 2466 stationary energy storage although in practice, low energy 2467 density could also mean more layers in the stack (for a given 2468 electrode thickness) and therefore a higher price due to a 2469 larger amount of passive elements. The volumetric capacity of 2470 the $\mathrm{C} @ \mathrm{Na}(\mathrm{Li}) \mathrm{Ti}_{2}\left(\mathrm{PO}_{4}\right)_{3}\left(2.6 \mathrm{~g} / \mathrm{cm}^{3}\right)$ can reach up to $231^{393}-2471$ $300^{394} \mathrm{mAh} \mathrm{cm}^{-3}$ (93-118 $\mathrm{mAh} \mathrm{g}^{-1}$, respectively) taking into 2472 account the carbon coating $\left(2.0 \mathrm{~g} \cdot \mathrm{cm}^{-3}\right)$. Interestingly, such 2473 volumetric capacities are actually lower than that obtained for a 2474 
2475 quinone derivative also used on the negative side, the poly 2476 pyrene-4,5,9,10-tetraone (PPTO): $1.68 \mathrm{~g} \mathrm{~cm}^{-3}, 338 \mathrm{mAh} \mathrm{cm}^{-3}$, $2477201 \mathrm{mAh} \mathrm{g}^{-1}$ cycled in $\mathrm{Na}^{+}$-based aqueous electrolyte. ${ }^{395}$ 2478 Although the PPTO electrode contained 30 wt.\% of carbon 2479 additive its electrode volumetric capacity $\left(144 \mathrm{mAh} \mathrm{cm} \mathrm{cm}^{-3}\right.$ ) 2480 remains in the vicinity of that derived for the titanium 2481 phosphate ones: $121 \mathrm{mAh} \mathrm{cm}^{-3}$, ref 393 and $152 \mathrm{mAh} \mathrm{cm}^{-3}$, 2482 ref 394 . It is also important to point out that the previous 2483 results were obtained from relatively thin electrodes with areal 2484 capacity in the vicinity or below $1 \mathrm{mAh} \mathrm{cm}^{-2}$.

2485 For thicker ones (close to $2 \mathrm{mAh} \mathrm{cm}^{-2}$ ), Y. M. Chiang's

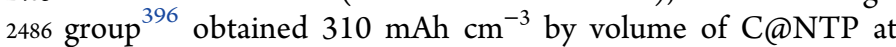
$24870.6 \mathrm{C}$, which turns into $161 \mathrm{mAh} \mathrm{cm}^{-3}$ by volume of composite 2488 electrode. Industrially relevant aqueous batteries were dem2489 onstrated by Whitacre with impressive electrode loadings 2490 (between 20 and $450 \mathrm{mg} \cdot \mathrm{cm}^{-2}$ ) using NTP derived from very 2491 cheap synthesis protocols. ${ }^{397}$ These good results pair, however, 2492 with a lower volumetric capacity of the C@NTP material $2493\left(182 \mathrm{mAh} \mathrm{cm}^{-3}\right.$ in approximately $20 \mathrm{mAh} \mathrm{cm}^{-2}$ pouch cells 2494 and $159 \mathrm{mAh} \mathrm{cm}^{-3}$ in approximately $1 \mathrm{mAh} \mathrm{cm}^{-2}$ coin cells ${ }^{397}$ ) 2495 which falls down to 83 and $77 \mathrm{mAh} \mathrm{cm}^{-3}$ in terms of electrode 2496 volume for pouch and coin cells, respectively, using the 2497 corresponding electrode chemistry. In comparison, the highest 2498 areal capacity demonstrated with organic materials lies in the

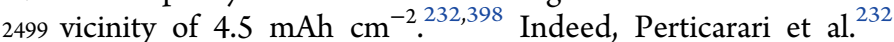
2500 achieved nearly $100 \mathrm{mAh} \mathrm{cm}{ }^{-3}$ of material and $66 \mathrm{mAh} \mathrm{cm}^{-3}$ 2501 of electrode using a diblock oligomer and 25 wt.\% of carbon 2502 additive for $4.5 \mathrm{mAh} \mathrm{cm} \mathrm{c}^{-2}$ while Nishide's group obtained $25033 \mathrm{mAh} \mathrm{cm}^{-2}$ using on a carbon nanotube hybridized poly 2504 (2,2,6,6-tetramethylpiperidin-4-yl) acrylamide (PTAm) polymer. ${ }^{398}$ 2505 To sum up, this short literature analysis of both inorganic 2506 and organic active materials for aqueous batteries near neutral $2507 \mathrm{pH}$ highlights that some of the proposed organic electroactive 2508 materials have already surpassed inorganic ones in term of 2509 volumetric capacity in the case of thin electrodes and are not 2510 too far behind in the case of thick ones.

\section{Cost Aspect}

2512 According to Whitacre, ${ }^{397}$ NTP can be produced with pre2513 cursor materials cost of $\$ 4$ per $\mathrm{kg}$ upon two synthesis steps, ball 2514 milling and calcination. Taking $\$ 5 / \mathrm{kg} / \mathrm{step}$, which is an average 2515 in the pigment industry, an estimate of the NTP price should 2516 be roughly $14 \$ / \mathrm{kg}$. In comparison, competitive organic 2517 materials (in terms of volumetric capacity) in neutral molar 2518 aqueous media such as PNDI and PPTO are approximately $2519 \$ 4-6 / \mathrm{kg}$ and $\$ 10-15 / \mathrm{kg}$, respectively, highlighting similar or 2520 even lower prices can indeed be achieved for organics.

2521 Lastly, it is noted that water-in-salt (WiSE) ${ }^{399}$ or hydrate2522 melt $^{400}$ electrolytes have emerged as interesting opportunities 2523 to significantly improve the energy density and the Coulombic 2524 efficiency and mitigate corrosion issues (materials, current 2525 collectors, ...) of these new classes of "water containing" 2526 batteries. A comprehensive and critical review of the scientific 2527 understanding as well as the electrochemical and physical 2528 properties of these new electrolytes has been recently 2529 published by Yamada et al. ${ }^{401}$ It is noted that the ability of 2530 WiSE electrolytes to extend the electrochemical window can 2531 be significantly improved by using an immiscible electrolyte 2532 additive, the 1,1,2,2-tetrafluoroethyl-2', $2^{\prime}, 2^{\prime}$-trifluoroethyl 2533 ether (HFE). The latter electrochemically decomposes at the 2534 surface of the materials and by virtue of its hydrophobicity 2535 expels water molecules from the inner-Helmholtz interface of 2536 the electrode thereby mitigating hydrogen formation at the expense of a more efficient SEI. ${ }^{402}$ Because, some articles 2537 commented in this review refer to these types of electrolytes, 2538 we feel that a few general comments should be recalled 2539 regarding this type of battery chemistry. First, such highly 2540 concentrated electrolytes have a volumetric density in the range 2541 of $1.6-1.9 \mathrm{~g} \mathrm{~cm}^{-3}$, which partially offsets the gain in energy 2542 density. For instance the mass of a $700 \mathrm{~cm}^{2}$ stack cell such as 2543 presented in ref 232 (taking $5 \mathrm{mAh} \mathrm{cm}{ }^{-2}$ electrodes of $580 \mu \mathrm{m}-2544$ thick and $40 \%$ porosity) increases by $14 \%$ considering a WiSE 2545 electrolyte of $1.7 \mathrm{~g} \mathrm{~cm}^{-3}$ compared to a "salt in water" $1 \mathrm{M}$ one. 2546 Second, the viscosity of these electrolytes is approximately ten 2547 times higher than molar range ones which considerably 2548 increases the wetting time of the electrodes and especially 2549 thick ones. ${ }^{401}$ Last but not least, the price of these electrolytes 2550 is obviously the most challenging issue to be overcome before 2551 commercialization can be considered. Indeed, recent results 2552 point to the fact that expensive imide based anions (as 2553 opposed for instance to acetate ones) would have a significant 2554 role in the widening of the electrochemical window on the 2555 negative electrode side. ${ }^{403}$

2556

Based on the previous comments, this section aims at providing 2557 the reader with a selection of relevant organic materials, that is to 2558 say those that allow performances approaching or higher than 2559 lead acid battery ones but with much extended cyclability. 2560 Accordingly, the lower limits were set to roughly $30 \mathrm{Wh} \mathrm{kg}^{-1} 2561$ per mass of the two materials and a capacity retention $>80 \% 2562$ after 500 cycles at $1 \mathrm{C}$ rate or equivalent. The intention of the 2563 authors is to give a critical view of the selected papers and also 2564 to highlight advantages and drawbacks vs those associated 2565 with inorganic materials. Key performances are reported in 2566 (Table 7) along with materials structures, aqueous electrolyte 2567 formulations, cycling conditions and electrode loading. Note 2568 that this critical review is focused on neutral $\mathrm{pH}$ batteries 2569 because they inherently offer reduced production costs and 2570 mitigated corrosion issues. Results are subcategorized into 2571 hybrid cells, where only one of the electrodes contains an 2572 organic electroactive material and all organic cells. 2573

\subsection{Hybrid Organic-Inorganic Batteries}

8.2.1. Aqueous Lithium-Ion Batteries (ALIBs). Some of 2574 the most attractive organic materials for aqueous battery to date 2575 are among the polyimide derivatives. These materials indeed 2576 combine both a high capacity (typically 130-160 mAh $\mathrm{g}^{-1}, 2577$ 208-256 $\mathrm{mAh} \mathrm{cm}^{-3}$ ) and a low price $\left(\$ 4-6 / \mathrm{kg}^{395}\right)$. To our 2578 knowledge such a dual advantage has not been reached by any 2579 inorganic materials used in the aqueous battery field. The 2580 electrochemical reduction/oxidation of a polyimide core is 2581 highly reversible in water at neutral $\mathrm{pH}$. The redox centers 2582 have been identified as involving the aromatic-carbonyl system 2583 of the imide functional moiety following two redox steps. The 2584 first one corresponds to the formation of a radical-anion upon 2585 enolization of a carbonyl group by one electron, followed by a 2586 second electron reduction into the dianion quinoid form. ${ }^{404} 2587$ Further reduction cannot be reached in molar range elec- 2588 trolyte at neutral $\mathrm{pH}$ before water hydrolysis is triggered. The 2589 delocalization of excess electron density in the reduced states 2590 has been studied by FTIR and UV-vis spectroscopy. ${ }^{405}$ Dong 2591 et al. $^{406}$ introduce a mixed liquid/solid cationic rocking chair 2592 aqueous battery using a $\mathrm{I}_{3}^{-} / \mathrm{I}^{-}$based posolyte and a polyimide 2593 derivative negative electrode (poly(1,4,5,8-naphthalenetetra- 2594 carboxylic)dianhydride-derived polyimide, PNTCDA) separated 2595 by a Nafion membrane allowing the $\mathrm{Li}^{+}$(or $\mathrm{Na}^{+}$) diffusion. This 2596 system delivers roughly 35000 deep cycles at a high current of 2597 
Table 7. Performances of Selected Aqueous Organic Batteries

\begin{tabular}{|c|c|c|c|c|c|c|c|c|}
\hline \# & $\begin{array}{c}\text { Cell } \\
\text { configuration } \\
\text { (ionic } \\
\text { carriers) }\end{array}$ & $\begin{array}{l}\text { Positive electrode (or } \\
\text { "cathode") active material }\end{array}$ & $\begin{array}{l}\text { Negative electrode (or "anode") active } \\
\text { material }\end{array}$ & Electrolyte & $\begin{array}{l}\text { Output } \\
\text { voltage } \\
\text { (V) }\end{array}$ & $\begin{array}{c}\text { Cycling } \\
\text { stability: } \\
\text { retention, } \\
\text { cycles, rate or } \\
\text { current density }\end{array}$ & $\begin{array}{l}\text { Specific capacity }\left(\mathrm{mAh} \mathrm{g}^{-1}\right) \\
\text { Specific energy }\left(\mathrm{Wh} \mathrm{kg}^{-1}\right)\end{array}$ & Ref. \\
\hline
\end{tabular}

Hybrid organic/inorganic aqueous systems

$\mathrm{Li}^{+}\left(\right.$or $\left.\mathrm{Na}^{+}\right)$

$\mathrm{I}^{-} / \mathrm{I}^{-}$

$\mathrm{LiMn}_{2} \mathrm{O}_{4}$

$2 \quad \mathrm{Li}^{+}-$ion

$\mathrm{K}_{x} \mathrm{Fe}_{y} \mathrm{Mn}_{1-y}\left[\mathrm{Fe}(\mathrm{CN})_{6}\right]_{w} \cdot z \mathrm{H}_{2} \mathrm{O}$

$3 \quad \mathrm{~K}^{+}$

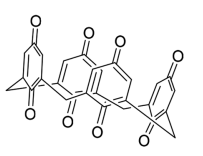

$\begin{array}{lcc}5 & \mathrm{Mg}^{2+} & \mathrm{Na}_{1.4} \mathrm{Ni}_{1.3} \mathrm{Fe}(\mathrm{CN})_{6} \cdot 5 \mathrm{H}_{2} \mathrm{O} \\ 6 & \mathrm{Mg}^{2+} & \mathrm{Li}_{3} \mathrm{~V}_{2}\left(\mathrm{PO}_{4}\right)_{3} @ \mathrm{C} \\ 7 & \mathrm{Ca}^{2+} & \mathrm{K} \\ 7.02 \mathrm{Cu}\left[\mathrm{Fe}(\mathrm{Cu})_{6}\right]_{0.66} \cdot 3.7 \mathrm{H}_{2} \mathrm{O}\end{array}$

$8 \mathrm{NH}_{4}{ }^{+}$- ion

$\left(\mathrm{NH}_{4}\right)_{1.47} \mathrm{Ni}\left[\mathrm{Fe}(\mathrm{CN})_{6}\right]_{0.88}$

$9 \quad \mathrm{Cl}^{-}$- ion

$10 \mathrm{BF}_{4}^{-}-$ion

11

Dual-ion
$\left(\mathrm{TFSI}^{-} / \mathrm{Li}^{+}\right)$
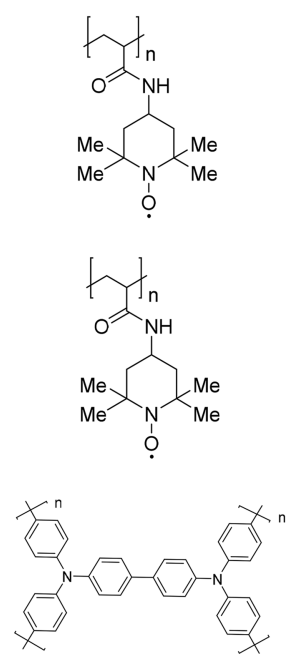

$\overbrace{\mathrm{NH}}$

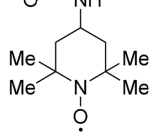

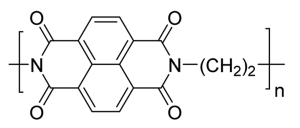

$\mathrm{LiNO}_{3} 1 \mathrm{M}$

$(\mathrm{pH} 7)$

$\sim 0.7-0.8$

$80 \%, 35000$,

$\sim 110, \stackrel{a}{\sim} \sim 88, \stackrel{a}{\sim} 100,1$

$\left[{ }^{406}\right]$<smiles>CC(C)(C)CCC(=O)Nc1cc2c3c(c1)c(=O)c(=O)c1cc(NC(C)(C)C)cc(c1-3)c(=O)c2=O</smiles>

$\begin{array}{ccc}\underset{\mathrm{Li}_{2} \mathrm{SO}_{4} 2.5 \mathrm{M}}{(\mathrm{pH} 7)} & 1.13 & 300 \%(3500 \mathrm{~h}), \\ & & 280 \mathrm{~mA} \mathrm{~g}^{-1}\end{array}$

$81,{ }^{b} 92,{ }^{b} 92 \%,-, 2$

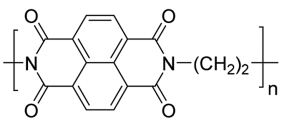

$\underset{22 \mathrm{M}}{\mathrm{KCF}_{3} \mathrm{SO}_{3},} \quad 1.27 \quad 73 \%, 2000,4 \mathrm{C}$

$63,{ }^{b} 80,{ }^{b} \sim 100,5-6$

all these values are at $0.5 \mathrm{C}$

Zn

$\frac{\mathrm{Zn}\left(\mathrm{CF}_{3} \mathrm{SO}_{3}\right)_{2}}{3 \mathrm{M}}$

$87 \%, 1000$,
$500 \mathrm{~mA} \mathrm{~g}^{-1}$

$197,{ }^{c} 80,{ }^{d} \sim 100,2.5-10$

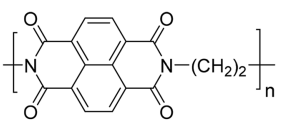

$\mathrm{MgSO}_{4} 1$

57,5000

$35,{ }^{b} 45^{b}, 100,2-3$, all these values

are at $0.5 \mathrm{~A} \mathrm{~g}^{-1}$

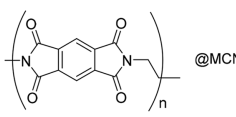

$\mathrm{Mg}(\mathrm{TFSI})_{2}$

$4 \mathrm{~m}$

$87 \%, 1000,2 \mathrm{C}$

$52,{ }^{b} 62.4, b \sim 100,2-3$, all these values are at $1 \mathrm{C}\left(0.1 \mathrm{~A} \mathrm{~g}^{-1}\right)$

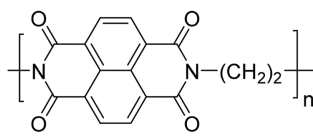

$\mathrm{Ca}\left(\mathrm{NO}_{3}\right)_{2}$ $2.5 \mathrm{M}$
$(\mathrm{pH} 5.1)$

$88,1000,10 \mathrm{C}$

$45,{ }^{b} 54, b_{\sim 100,}$, all these values

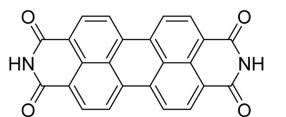

$\left(\mathrm{NH}_{4}\right)_{2} \mathrm{SO}_{4}$

$1 \mathrm{M}(\mathrm{pH} 6)$

$67 \%, 1000$

$0.120 \mathrm{~mA} \mathrm{~g}^{-1}$

$35,{ }^{b} 43,{ }^{b} 97.6 \%, 2-5$

\section{All-organic aqueous systems}

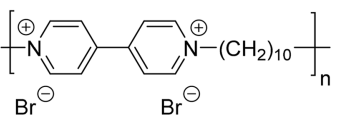

$\mathrm{NaBF}_{4} 0.1 \mathrm{M}$

$(\mathrm{pH} 7)$

1.2

$75-80 \%,>2000$,
$60 \mathrm{C}$
$\left(67 \mu \mathrm{A} \cdot \mathrm{cm}^{-2}\right)$

$104,{ }^{c} 108,{ }^{c} 95$

(100 $\mathrm{nm}$ thin films)

[ $\left.{ }^{419}\right]$

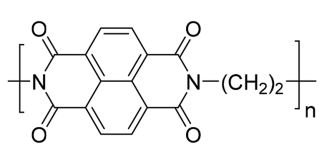

$85 \%, 700$,

$105,{ }^{c} 53,{ }^{c} \sim 100,1$

$\left[{ }^{418}\right]$ 


\section{Table 7. continued}

$\begin{gathered}\text { Cell } \\ \text { configuration } \\ \text { (ionic } \\ \text { carriers) }\end{gathered}$
"cathode") active material
Positive electrode (or

${ }^{a}$ Based on anode material weight. ${ }^{b}$ Based on cathode and anode materials weight. ${ }^{c}$ Based on cathode material weight. ${ }^{d}$ Based on the whole cell weight.

$259810 \mathrm{~A} \mathrm{~g}^{-1}$ (55 $\mathrm{C}$ nominal, that leads to a nominal ratio (number 2599 of cycles $/ \mathrm{C}$-rate $)=636$ ) before reaching $80 \%$ of the initial 2600 capacity $\left(Q_{0}=105 \mathrm{mAh} \mathrm{g}^{-1}\right)$ (Table 7 , entry 1 ).

2601 More recently, another negative electrode organic material 2602 was shown to stand out of the crowd, the quinone derivative 2603 PPTO. ${ }^{395}$ The latter exhibits storage properties rivaling those 2604 of any inorganic materials from mildly acidic to strongly basic 2605 media. In neutral $2.5 \mathrm{M} \mathrm{Li}_{2} \mathrm{SO}_{4}$ aqueous electrolyte, this 2606 material enables $92 \mathrm{Wh} \mathrm{kg}^{-1}$ materials $\left(208 \mathrm{Wh} \mathrm{L}^{-1}\right)$ when paired 2607 with $\mathrm{LiMn}_{2} \mathrm{O}_{4}$ at an average voltage of $1.13 \mathrm{~V}$ (Table 7, entry 2). 2608 This performance is in the same range as the competing system $2609 \mathrm{LiTi}_{2}\left(\mathrm{PO}_{4}\right)_{3}-\mathrm{LiMn}_{2} \mathrm{O}_{4}\left(90 \mathrm{Wh} \mathrm{kg}^{-1}\right.$ materials $\left(243 \mathrm{Wh} \mathrm{L}^{-1}, 1.5 \mathrm{~V}\right)$ 2610 thanks to the extremely high capacity of the PPTO electrode 2611 material ( $229 \mathrm{mAh} \mathrm{g}^{-1}, 366 \mathrm{mAh} \mathrm{cm}^{-3}$ at $1 \mathrm{C}$ rate). In addition, 2612 this PPTO-based cell shows quite a promising capacity retention 2613 of more than $3500 \mathrm{~h}$ (3000 cycles) (Figure 18). Among all 2614 aqueous systems that have been reviewed herein, PPTO/ $2615 \mathrm{LiMn}_{2} \mathrm{O}_{4}$ is by far the most promising one in the authors' 2616 opinion. In addition, as a quinone derivative, the fully reduced 2617 form of PPTO (PPTO- $\mathrm{Li}_{4}$ ) can support reversible oxidation by 2618 dissolved oxygen without impacting its charge-discharge 2619 properties. ${ }^{395}$ This is an important advantage over $\mathrm{LiTi}_{2}\left(\mathrm{PO}_{4}\right)_{3}$ 2620 for instance, which was shown to undergo rapid capacity fading 2621 in nondeaerated electrolyte. Indeed, PPTO based cell can 2622 therefore support the "oxygen cycle" (Figure 18), which is a 2623 built-in safety mechanism for aqueous battery at high charge 2624 states. Importantly, in such events the local $\mathrm{pH}$ at the negative 2625 electrode can be fairly alkaline ( $\mathrm{pH} 13)$. However, thanks to 2626 the combination of the chemical inertness of the quinone core, 2627 as well as the poor solubility, and robust amide linkage of the 2628 PPTO derivative, a capacity retention of $83 \%$ was demonstrated 2629 after $1200 \mathrm{~h}$ cycling in these $\mathrm{pH}$ conditions. ${ }^{395}$ Accordingly, this 2630 oxygen consumption capability of quinones enables in principle, 2631 to increase the state of charge of the positive electrode material 2632 (such as $\mathrm{LiMn}_{2} \mathrm{O}_{4}$ for instance) without significantly altering the 2633 mass balancing of the cell therefore paving the way toward the 2634 use of materials working at even higher potentials.

2635 8.2.2. Aqueous Sodium-Ion Batteries (ASIBs). As for 2636 Li-ion batteries, Na-based aqueous batteries must be 2637 investigated to counteract possible upcoming issues associated 2638 with geo-localized $\mathrm{Li}$ resources. One of the first instances of 2639 hybrid ASIBs bearing an organic electroactive material uses a polyimide derivative PNDI at the negative electrode and a 2640 $\mathrm{NaVPO}_{4} \mathrm{~F}$ based positive electrode in a $5 \mathrm{M} \mathrm{NaNO}_{3}$ aqueous 2641 electrolyte. ${ }^{404}$ This system shows, however, a very poor capacity 2642 retention ( $-25 \%$ in 20 cycles) that was mainly ascribed to 2643 $\mathrm{NaVPO}_{4} \mathrm{~F}$ ( $-30 \%$ loss of capacity in 20 cycles) compared to 2644 $-17 \%$ for PNDIE. ${ }^{404}$ Yao's group ${ }^{395}$ slightly improved these 2645 cyclability results to nearly $80 \%$ of capacity retention after 2646 80 cycles $(150 \mathrm{~h})$ by substituting $\mathrm{Na}_{3} \mathrm{~V}_{2}\left(\mathrm{PO}_{4}\right)_{3}$ for $\mathrm{NaVPO}_{4} \mathrm{~F} 2647$ and PPTO (208 $\mathrm{mAh} \mathrm{g}^{-1}$ ) for PNDIE $\left(160 \mathrm{mAh} \mathrm{g}^{-1}\right)$. To 2648 date, ASIB hybrid aqueous batteries are therefore not compet- 2649 itive with corresponding ALIB as reported above especially in 2650 terms of capacity retention. For this reason, ASIB related research 2651 has mainly focused on the use of inorganic compounds ${ }^{173}$ such as 2652 $\mathrm{NaFePO}_{4}{ }^{407}$ as well as fully inorganic systems based on 2653 Prussian (white)blue, ${ }^{408}$ carbon coated phosphates $\left(\mathrm{NTP}^{397}\right.$ and 2654 $\left.\mathrm{Na}_{3} \mathrm{MnTi}\left(\mathrm{PO}_{4}\right)_{3},{ }^{409}\right)$ and manganese oxides $\mathrm{Na}_{0.44} \mathrm{MnO}_{2}{ }^{396}$ and 2655 $\mathrm{Na}_{0.44}\left[\mathrm{Mn}_{1-x} \mathrm{Ti}_{x}\right] \mathrm{O}_{2}{ }^{410}$ We note however, that all these materials 2656 enable capacity values in the range of 40 to $60 \mathrm{mAh} \mathrm{g}^{-1}$ and 2657 energy density values in the range of $30-40 \mathrm{Wh} \mathrm{kg}^{-1}$ per mass of 2658 materials in molar range electrolyte which is the average value 2659 generally observed for most organic based aqueous cells. 2660

8.2.3. Aqueous Potassium-Ion Batteries (AKIBs). Full 2661 organic-inorganic hybrid AKIBs have not been reported until 2662 very recently owing to the scarcity of suitable electroactive 2663 materials and electrolytes. Hu's group ${ }^{411}$ demonstrated an 2664 AKIB cell based on an Fe-substituted Mn-rich Prussian blue 2665 $\mathrm{K}_{x} \mathrm{Fe}_{y} \mathrm{Mn}_{1-y}\left[\mathrm{Fe}(\mathrm{CN})_{6}\right]_{w} \cdot z \mathrm{H}_{2} \mathrm{O}$ (KFeMnHCF) as the positive 2666 electrode and the 3,4,9,10-perylenetetracarboxylic diimide 2667 derivative as the negative one in a $22 \mathrm{M} \mathrm{KCF}_{3} \mathrm{SO}_{3}$ water-in- 2668 salt electrolyte (Table 7, entry 3). The low water activity of the 2669 latter allowed not only to mitigate dissolution of both electrode 2670 materials but also to charge the positive electrode up to $1.2 \mathrm{~V} 2671$ vs $\mathrm{Ag} / \mathrm{AgCl}$ electrode, which allowed KFeMnHCF to 2672 reversibly reach $135 \mathrm{mAh} \mathrm{g}^{-1}$ at $0.5 \mathrm{C}$ above $0 \mathrm{~V}$ vs SCE. In 2673 addition, thanks to the mitigation of phase transitions by $\mathrm{Fe} 2674$ substitution, KFeMnHCF achieves 70\% capacity retention at 2675 $100 \mathrm{C}$ over 10000 cycles. This pioneering AKIB system shows 2676 a high energy density of $80 \mathrm{Wh} \mathrm{kg}^{-1}$ by mass of the two 2677 electrodes at a power density of $41 \mathrm{~W} \mathrm{~kg}^{-1}(0.5 \mathrm{C})$ and $73 \% 2678$ capacity retention over 2000 cycles at $4 \mathrm{C}$ (Figure 19A-C) 2679 which makes it one of the most attractive systems to date. 2680 Interestingly, authors have evaluated their system in pouch cell 2681 
A

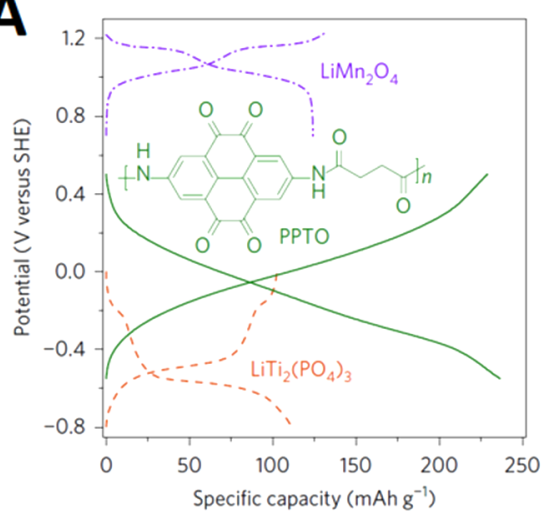

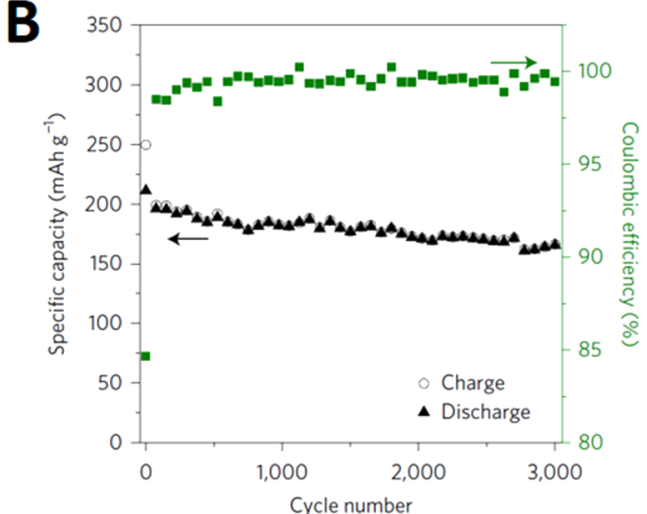

C

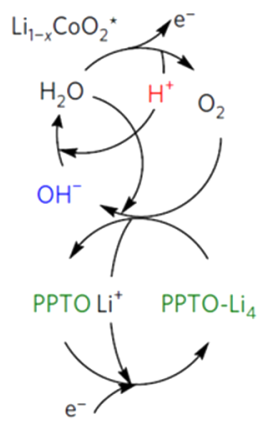

D

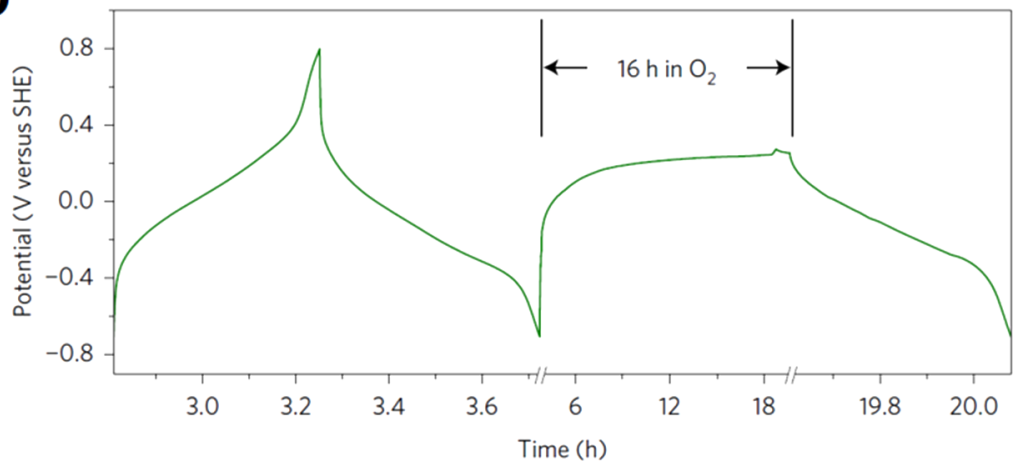

Figure 18. Characteristics of PPTO as an anode material for ALIBs. (A) Galvanostatic charge-discharge profiles for PPTO (280 $\mathrm{mA} \mathrm{g}^{-1}$ ), $\mathrm{LiTi}_{2}\left(\mathrm{PO}_{4}\right)_{3}\left(120 \mathrm{~mA} \mathrm{~g}^{-1}\right)$, and $\mathrm{LiMn}_{2} \mathrm{O}_{4}\left(140 \mathrm{~mA} \mathrm{~g}{ }^{-1}\right)$ in $2.5 \mathrm{M} \mathrm{Li}_{2} \mathrm{SO}_{4}\left(\mathrm{pH}\right.$ 7). (B) Capacity retention of a $\mathrm{LiMn}_{2} \mathrm{O}_{4}-\mathrm{PPTO}$ cell during galvanostatic cycling at $1 \mathrm{C}$ in $2.5 \mathrm{M} \mathrm{Li}_{2} \mathrm{SO}_{4}\left(\mathrm{pH}\right.$ 7). (C) Schematic explaining the oxygen cycle in ALIBs: $\mathrm{H}_{2} \mathrm{O}$ is oxidized at the catalytic sites (*) on the cathode (for example, $\mathrm{LiCoO}_{2}$ ) to generate $\mathrm{O}_{2}$ and $\mathrm{HC}$; the latter is then reduced by the charged anode (for example, PPTO-Li ${ }_{4}$ ) to afford $\mathrm{OH}^{-}$. (D) Oxygen consumption by charged PPTO: a PPTO electrode is first electrochemically discharged (oxidized) and charged (reduced) under $\mathrm{Ar}$ for one cycle, then left to rest under $\mathrm{O}_{2}$, and finally put under $\mathrm{Ar}$ and charged again. Reproduced from ref 395 . Copyright 2017 Nature Publishing Group.

2682 configuration and at several temperatures to better grasp the 2683 prospect of large-scale applications: an $11 \mathrm{mAh}$ pouch cell was 2684 shown to exert superior performance at low rates (i.e., $0.5 \mathrm{C} / 0.1 \mathrm{C}$ ) 2685 and low/high temperatures (i.e., $-20{ }^{\circ} \mathrm{C} /-10$ and $25^{\circ} \mathrm{C} / 60{ }^{\circ} \mathrm{C}$ ) 2686 and was able to operate from -20 to $60^{\circ} \mathrm{C}$ (Figure $19 \mathrm{D}, \mathrm{E}$ ). 2687 8.2.4. Aqueous Multivalent Metal-Ion Batteries (Mg, $\left.{ }_{2688} \mathrm{Ca}, \mathrm{Zn}\right) . \mathrm{Zn}^{2+}$. Chen's group demonstrated that high energy 2689 values could be obtained at the cell level (pouch cell) by 2690 pairing quinones (calix[4]quinone, referred to as $\mathrm{C} 4 \mathrm{Q}$ ) to a 2691 zinc negative electrode in a $3 \mathrm{M}\left(\mathrm{ZnCF}_{3} \mathrm{SO}_{3}\right)_{2}$ aqueous 2692 electrolyte (Table 7, entry 4). ${ }^{412}$ This system develops $1 \mathrm{~V}$ as 2693 output voltage and up to $337 \mathrm{mAh} \mathrm{g}^{-1}$ by mass of materials at 2694 low current density $\left(5 \mathrm{~mA} \mathrm{~g}^{-1}\right)$. The pouch cell achieved 220 $2695 \mathrm{Wh} \mathrm{kg}^{-1}$ at $500 \mathrm{~mA} \mathrm{~g}{ }^{-1}$ considering the electroactive mass 2696 fraction of the materials (which are $89 \%$ for the C4Q and $49 \%$ 2697 for $\mathrm{Zn}$ ) and $80 \mathrm{Wh} \mathrm{g}^{-1}$ by mass of the whole cell with an 2698 energy efficiency close to $80 \%$. However, due to the dissolution 2699 of the C4Q a Nafion membrane was required to stabilize the 2700 capacity retention at $87 \%$ after 1000 cycles $(-0.015 \% /$ cycle $)$. 2701 It is instructive to note that although the development of mild 2702 electrolyte based $\mathrm{Zn}$ batteries is still in its infancy, this kind of 2703 system clearly brings energy densities in the same order as 2704 those associated with the use of "water-in-salt" electrolytes. 2705 This point should therefore motivate more research in the near 2706 future to enhance the depth of discharge and cyclability and 2707 prevent the use of membranes.
$\mathrm{Mg}^{2+}$. Xia et al. ${ }^{413}$ recently developed a $33 \mathrm{Wh} \mathrm{kg}^{-1}(1 \mathrm{~V}$ as 2708 output voltage) per mass of active materials considering 2709 $\mathrm{Na}_{1.4} \mathrm{Ni}_{1.3} \mathrm{Fe}(\mathrm{CN})_{6.5} \mathrm{H}_{2} \mathrm{O}$ paired with poly $\left[N, N^{\prime}\right.$-(ethane-1,2- 2710 diyl)-1,4,5,8-naphthalene tetracarboximide (PNDIE) using $1 \mathrm{M} 2711$ $\mathrm{MgSO}_{4}$ aqueous electrolyte (Table 7, entry 4). This assembly 2712 allowed to achieve 1000 cycles at $2 \mathrm{C}$ rate while keeping 2713 approximately $88 \%$ of the initial capacity. Interestingly, Wang 2714 et al. $^{414}$ obtained nearly two times more energy density 2715 (62.4 $\mathrm{Wh} \mathrm{kg}^{-1}$ per mass of materials) using $\mathrm{Li}_{3} \mathrm{~V}_{2}\left(\mathrm{PO}_{4}\right)_{3}$, as the 2716 positive electrode and lighter diimide derivatives (polypyromel- 2717 litic dianhydride), as the negative electrode (Table 7, entry 6). 2718 Compared to the more often used naphthalene derivative, 2719 the smaller delocalization backbone of the polypyromellitic 2720 destabilizes the radical anion and dianions that form on reduc- 2721 tion and push the potential to lower values. The cell shows 2722 indeed a high voltage of $1.9 \mathrm{~V}$ which can be realized by using a 2723 relatively concentrated electrolyte $\left(4 \mathrm{M} \mathrm{Mg}(\mathrm{TFSI})_{2}\right){ }^{414}$ This 2724 resulted in a promising capacity retention of nearly $87 \%$ after 2725 1000 cycles at $2 \mathrm{C}$ rate. 2726

$\mathrm{Ca}^{2+} \cdot \mathrm{Ca}^{2+}$ is another interesting abundant ion to play with 2727 in aqueous media. Yao's group ${ }^{415}$ recently showed that the 2728 diffusion of $\mathrm{Ca}^{2+}$ is higher than that of $\mathrm{Mg}^{2+}$ both in the solid 2729 state and in the aqueous electrolyte media. These results were 2730 ascribed to smaller size of the hydrated $\mathrm{Ca}^{2+}$ complex and its 2731 more facile dehydration during the charge transfer process. 2732 This group assembled a battery with a copper hexacyanoferrate 2733 

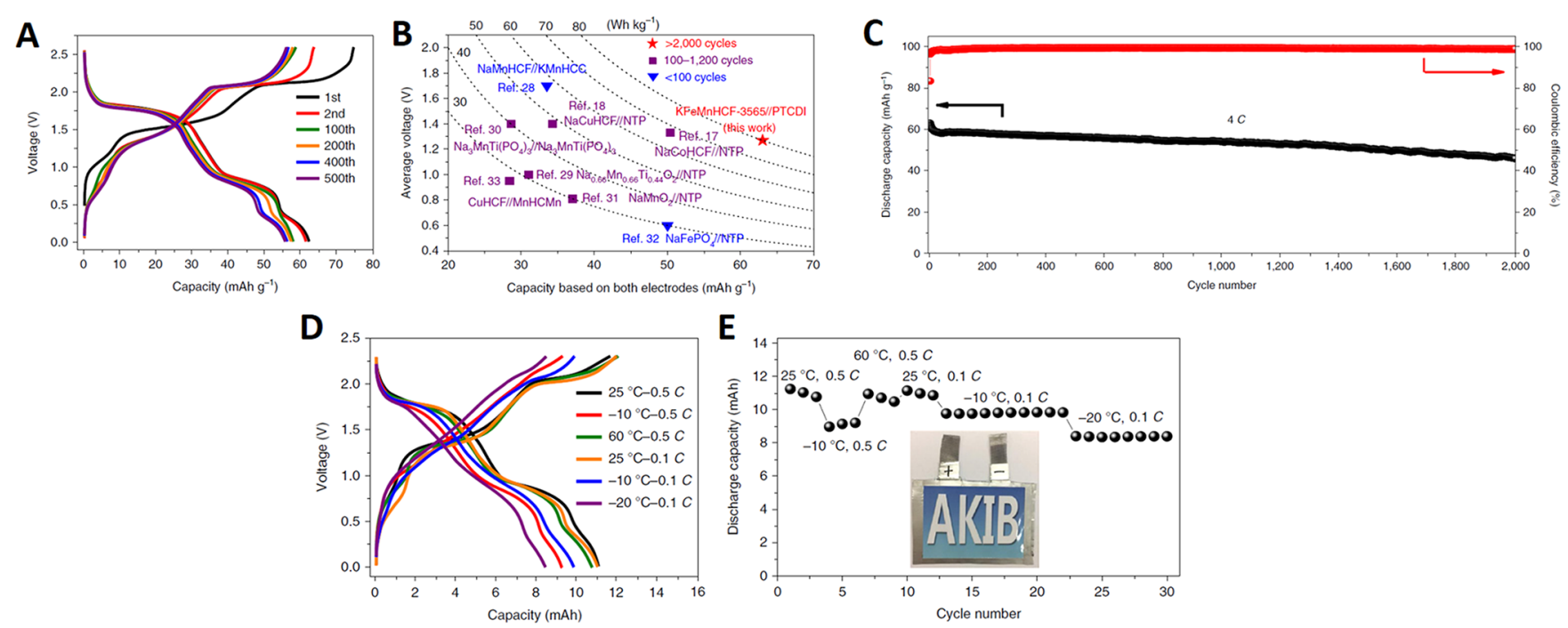

Figure 19. Performance of the $\mathrm{K}_{1.85} \mathrm{Fe}_{0.33} \mathrm{Mn}_{0.67}\left[\mathrm{Fe}(\mathrm{CN})_{6}\right]_{0.98} \cdot 0.77 \mathrm{H}_{2} \mathrm{Ol} 22 \mathrm{M} \mathrm{KCF}_{3} \mathrm{SO}_{3} \mid \mathrm{PTCDI}$ full battery. (A) Charge-discharge curves for coin cells at $4 \mathrm{C}$ from 0 to $2.6 \mathrm{~V}\left(1 \mathrm{C}=0.13 \mathrm{~A} \mathrm{~g}^{-1}\right)$. (B) Comparison of average voltage, capacity based on total mass of both electrodes, lifespan, and energy density for the full battery with reported aqueous Na-ion full batteries. (C) Long-term cycling performance of the coin cell at 4 C. (D, E) Corresponding electrochemical performance measured in pouch cell at different rates $(0.5 / 0.1 \mathrm{C})$ and temperatures $\left(-20 /-10 / 25 / 60{ }^{\circ} \mathrm{C}\right)$. Reproduced with permission from ref 411. Copyright 2019 Nature Publishing Group.

2734 compound of composition $\mathrm{K}_{0.02} \mathrm{Cu}\left[\mathrm{Fe}(\mathrm{Cu})_{6}\right]_{0.66} \cdot 3.7 \mathrm{H}_{2} \mathrm{O}$ 2735 ( $\mathrm{CuHCF}$ ) coupled to the PNDIE polyimide derivative in a $27362.5 \mathrm{M} \mathrm{Ca}\left(\mathrm{NO}_{3}\right)_{2}$ aqueous electrolyte (Table 7, entry 7). $2737 \mathrm{CuHCF}$ was found to proceed to insertion/deinsertion of 0.3 $2738 \mathrm{Ca}^{2+}$ ion at a $0.2 \mathrm{C}$ through a single-phase solid solution 2739 reaction rate at a potential of $0.72 \mathrm{~V}$ vs $\mathrm{Ag} / \mathrm{AgCl}$ electrode. 2740 This mechanism which is paired with the $\mathrm{Fe}^{3+} / \mathrm{Fe}^{2+}$ electroactivity 2741 leads to a specific capacity of $58 \mathrm{mAh} \mathrm{g}^{-1}$ (theoretical capacity $2742 Q_{\text {th }}=65 \mathrm{mAh} \mathrm{g}^{-1}$ ) that retains $88 \%$ of its initial capacity after 27432000 cycles at $5 \mathrm{C}$. On the other hand, PNDIE fully reacts with $2744 \mathrm{Ca}^{2+}$ at $-0.45 \mathrm{~V}$ vs $\mathrm{Ag} / \mathrm{AgCl}$ electrode with a reversible capacity 2745 of $160 \mathrm{mAh} \mathrm{g}^{-1}$ (theoretical capacity $Q_{\text {th. }}=183 \mathrm{mAh} \mathrm{g}^{-1}$ ). 2746 At $1 \mathrm{C}$ rate, the full cell delivered $54 \mathrm{Wh} \mathrm{kg}^{-1}$ of active materials 2747 for an output voltage of $1.2 \mathrm{~V}$. In addition, the battery still 2748 provides $88 \%$ capacity retention after 1000 cycles at $10 \mathrm{C}$.

2749 8.2.5. Aqueous Ammonium-Ion Battery. Little is 2750 reported with ammonium as shuttling ion. However, it must 2751 be mentioned that $\mathrm{Ji}$ and co-workers ${ }^{416}$ reported such an 2752 aqueous battery using Ni-based Prussian white at the positive 2753 electrode paired with 3,4,9,10-perylenetetracarboxylic diimide 2754 using $1 \mathrm{M}\left(\mathrm{NH}_{4}\right)_{2} \mathrm{SO}_{4}$ as electrolyte ( $\mathrm{pH} \mathrm{6)}$ (Table 7, entry 8). 2755 This cell enables up to $43 \mathrm{Wh} \mathrm{kg}^{-1}$ per mass of active materials 2756 with $1 \mathrm{~V}$ of voltage at $1.5 \mathrm{C}$ and achieves a capacity retention 2757 of $67 \%$ upon 1000 cycles at $3 \mathrm{C}$ rates $\left(120 \mathrm{~mA} \mathrm{~g}^{-1}\right)$ with an 2758 average Coulombic efficiency of $97.6 \%$.

\subsection{All-Organic Aqueous Batteries}

2759 Due to the lack of high potential n-type organic materials, ${ }^{417}$ 2760 cation-rocking chair cells have not been reported yet. Today, 2761 all-organic aqueous cell electrochemistry is indeed either related 2762 to counteranions or both countercation and anions (one at 2763 each electrode referred to as "dual mode" and the two at one 2764 electrode referred to as "intermixed mode"). First reports were 2765 released by Nishide, Oyaizu, and co-workers. ${ }^{418}$ They used a 2766 redox polymer resulting from the attachment of a $(2,2,6,6$ 2767 tetramethylpiperidin-1-yl)oxy known as “TEMPO” side groups 2768 to a polyalkane chain backbone, with poly $(2,2,6,6$ 2769 tetramethylpiperidin-4-yl) acrylamide (referred to as PTAm) 2770 as the positive electrode material. This material was paired to two different polyviologen derivatives, either the highly cross- 2771 linked polyviologen hydrogel (poly tripyridiniomesitylene) ${ }^{418} 2772$ which enabled $\sim 1.3 \mathrm{~V}$ as output voltage (Table 7, entry 9) or 2773 the poly $\left(N-4,4^{\prime}\right.$-bipyridinium- $N$-decamethylene dibromide) 2774 (Table 7, entry 10) leading to a cell average voltage of $1.2 \mathrm{~V}^{419} 2775$ Although both cells demonstrated more than 2000 cycles in $0.1 \mathrm{M} 2776$ Na-based aqueous electrolytes, electrodes were thin film deposits 2777 in the sub- to micron-thick range. Recently however, this group ${ }^{398} 2778$ has made decisive advances by demonstrating a thick composite 2779 electrode made of PTAm with a loading of $3 \mathrm{mAh} \mathrm{cm}^{-2}$. The 2780 latter was obtained by hybridizing PTAm with a 3-D self- 2781 assembled mesh of single-walled carbon nanotubes (SWNT). 2782 This thick electrode could still reach nearly $80 \mathrm{mAh} \mathrm{g}^{-1}$ of 2783 material at $10 \mathrm{C}$ rate. Although SWNT represents only $1 \%$ of 2784 the total electrode mass, it is noteworthy that authors demon- 2785 strated the importance of the contacts with the current 2786 collectors by showing such a high kinetics also stems from the 2787 optimization of the current collector/electrode contacts. ${ }^{398} 2788$

Dong et al. $^{420}$ cycled a p-type conjugated tertiary poly 2789 triphenylamine obtained by oxidative polymerization of the 2790 triphenylamine (PTPAn). The latter shows a sloppy discharge 2791 profile resulting from the superimposition of two pairs of broad 2792 peaks centered at 0.2 and $0.8 \mathrm{~V}$ vs SCE associated with the 2793 para and meta conformational isomers. Overall the discharge of 2794 this compound enables approximately $105 \mathrm{mAh} \mathrm{g}^{-1}$ PTPAn at 2795 $0.5 \mathrm{~A} \mathrm{~g}^{-1}$ (4.6 C-rate). However, the strong oxidative power of 2796 the $\mathrm{N}^{+}$species triggers the hydrolysis of water molecules that 2797 could be mitigated by the use of a "water-in-salt" electrolyte 2798 of $21 \mathrm{~m}$ LiTFSI. PTPAn was then coupled to 1,4,5,8- 2799 naphthalenetetracarboxylic dianhydride-derived polyimide 2800 (PNTCDA) as the negative electroactive material (Table 7, 2801 entry 11). During charge TFSI ${ }^{-}$and $\mathrm{Li}^{+}$react with the oxidized 2802 PTPAn and reduced PNTCDA, respectively (dual mode), 2803 enabling a maximum of $53 \mathrm{Wh} \mathrm{kg}^{-1}$ per mass of electroactive 2804 materials and a capacity retention of $85 \%$ after 700 cycles at 2805 $0.5 \mathrm{~A} \mathrm{~g}^{-1}$ (4.6 C-rate). ${ }^{420}$

2806

Some of us reported a possible new avenue to design 2807 aqueous batteries materials based on diblock-oligomers bearing 2808 

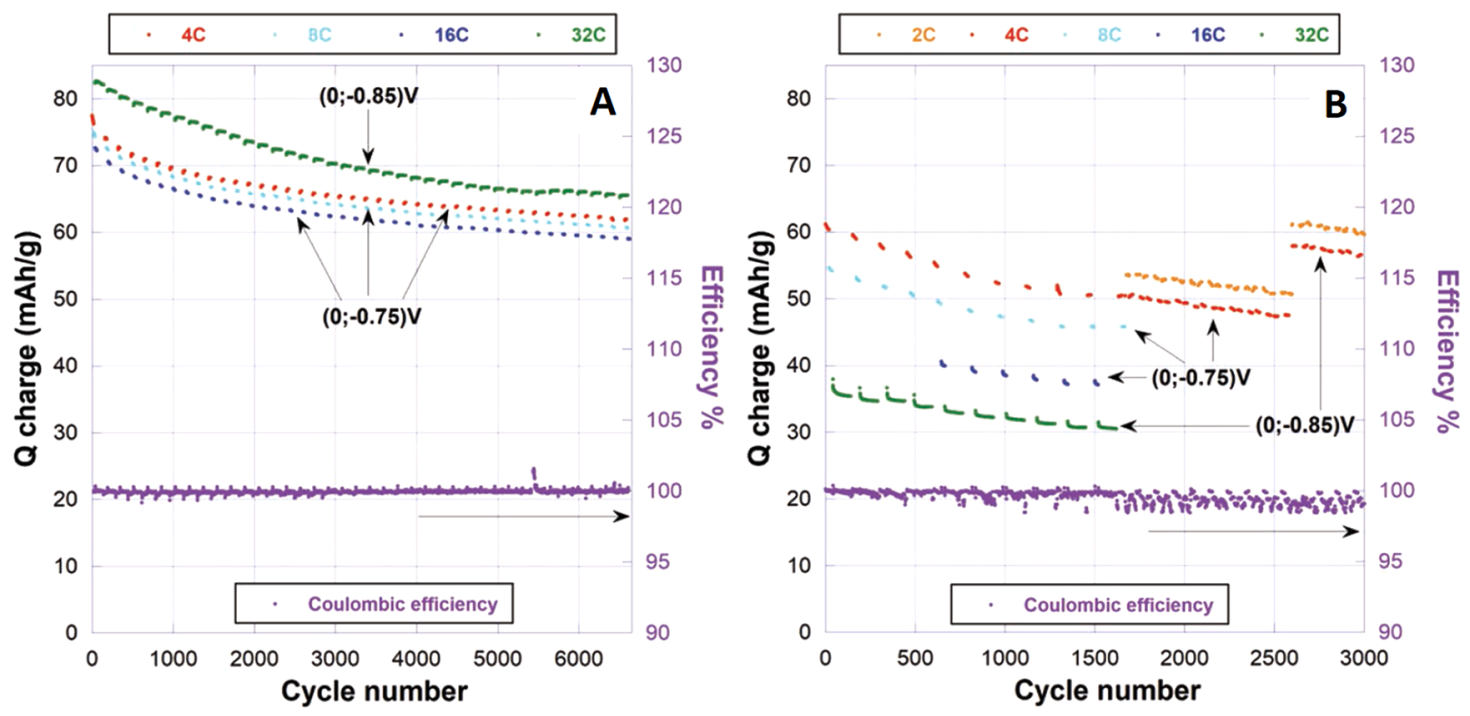

Figure 20. Capacity retention on charge (oxidation of the material) and corresponding Coulombic efficiency curves for diblock-oligomers bearing p-type viologen and n-type naphthalene diimide moieties composite electrodes in (A) $2.5 \mathrm{M} \mathrm{NaClO}_{4}$ aqueous electrolyte and (B) ocean water. Reproduced with permission from ref 231. Copyright 2019 John Wiley and Sons.

2809 p-type viologen and n-type naphthalene diimide moieties. These 2810 types of structures enable simultaneous release and uptake of 2811 anions $\left(\mathrm{ClO}_{4}^{-}, \mathrm{Cl}^{-}\right)$and cations $\left(\mathrm{Na}^{+}, \mathrm{Mg}^{2+}\right)$ respectively by a 2812 single electrode (intermixed mode) with the promise of mitigated 2813 volume variations on cycling. ${ }^{230}$ The best performances were 2814 obtained using an oligomer that can reach up to $105 \mathrm{mAh} \mathrm{g}^{-1}$ per 2815 mass of material and $80 \mathrm{mAh} \mathrm{g}^{-1}$ per mass of electrode. ${ }^{231}$ The 2816 extremely fast kinetics of longer diblock oligomer also allowed to 2817 reach an unmatched specific capacity of $60 \mathrm{mAh} \mathrm{g}^{-1}$ electrode $2818\left(0.7 \mathrm{mAh} \mathrm{cm}^{-2}\right)$ without any conducting additive while the 2819 optimum amount of carbon black additive was found to be $282010 \mathrm{wt} \%$ at $\mathrm{C}$-rate and below. Its capacity retention is remark2821 able for several thousand cycles ( 6500 cycles, $\approx 40$ days $)$ in $28222.5 \mathrm{M} \mathrm{NaClO}_{4}$ aqueous electrolyte as well as plain ocean water 2823 ( $\approx 3000$ cycles, $\approx 75$ days) (Figure 20 ). ${ }^{231}$ A $40 \mathrm{Wh} \mathrm{kg}^{-1}$ materials 2824 full cell demonstration was shown with more than 1600 cycles 2825 using the commercial 4-hydroxy TEMPO benzoate as the 2826 positive material and $0.7 \mathrm{mAh} \mathrm{cm}^{-2}$ as electrode loading 2827 (Table 7, entry 12). It is noted that a concentrated (but cheap) 2828 electrolyte $\left(8 \mathrm{M} \mathrm{NaClO}_{4}\right)$ was required to prevent dissolution 2829 of the TEMPO derivative. ${ }^{231,232}$ The same system was also evalu2830 ated using millimeter thick electrodes of $8 \mathrm{mAh} \mathrm{cm}^{-2}$ (nominal) 2831 leading to a stable areal capacity of nearly $4.5 \mathrm{mAh} \mathrm{cm}^{-2}$ for 2832500 cycles at $1 \mathrm{C}$ rate. To further demonstrate the practicability of 2833 the system, the same electrodes were evaluated in pouch cells. 2834 The output voltages were $0.78 \mathrm{~V}$ (C-rate) and $1.1 \mathrm{~V}$ (C/8-rate) 2835 leading to $22 \mathrm{Wh} \mathrm{kg}^{-1}$ (C-rate) and $36 \mathrm{Wh} \mathrm{kg}^{-1}$ (C/8-rate) 2836 per mass of materials with a $97 \%$ capacity retention over $500 \mathrm{~h}$ 2837 cycling at both $\mathrm{C}$ and $\mathrm{C} / 8$ rates (Table 7 , entry 13 ). ${ }^{232}$

\subsection{Summary and Outlooks}

2838 Neutral aqueous batteries based on organic electroactive mate2839 rials have been reviewed and discussed. New results point to 2840 the fact that some competitive organic materials have now 2841 surpassed inorganic ones even in terms of volumetric capacity 2842 while relatively large amounts of electrode carbon additive 2843 have been proved unnecessary for some derivatives. In addi2844 tion, we feel that this review highlights a decisive advantage of 2845 organic materials since most of them offer a highly versatile 2846 ionic compensation chemistry characterized by possible reactions with many different cations (monovalent and 2847 divalent), anions, and even both simultaneously. This aspect, 2848 that is encountered for the Prussian blue family for cations, 2849 opens up a large panel of possibilities regarding the cell chem- 2850 istry, with the additional advantage to be coupled to much 2851 larger storage capacity and, in some instance, with the possibility 2852 of supporting the oxygen cycle.

2853

Although it still remains far from that achieved with some 2854 inorganics, ${ }^{397}$ the technology readiness level (TRL) of organic 2855 based aqueous batteries has increased in the latest papers by 2856 the use of either highly loaded electrodes and/or pouch cell 2857 configurations. However, studies devoted to the impact of elec- 2858 trode formulation are scarce. As an example, the polytetra- 2859 fluoroethylene (PTFE) binder that is predominantly used so 2860 far because of its readiness is presumably not the most 2861 appropriate for the wettability of composite electrodes, for the 2862 volume variations on cycling, as well as from an industrial 2863 production point of view.

2864

Among the different cell chemistries that have been reviewed 2865 herein, three main topics attract research work: all organic 2866 systems, hybrid ones bearing an inorganic electroactive material, 2867 and water-in-salt electrolytes. Because of the prohibitive price 2868 incurred by the water-in-salt type electrolytes and although 2869 related energy densities can today approach that encountered 2870 for Li-ion batteries, we believe this strategy will remain 2871 confined to fundamental studies unless cheap salts are found to 2872 replace the capability of imide based ones to form stable SEI. 2873 On the other hand, both all organic and hybrid organic batte- 2874 ries using molar electrolytes now can show promising capacity 2875 retention at the cell level. However, this aspect still remains to 2876 be confirmed in large format batteries, at different temper- 2877 atures and by including self-discharge tests. Regarding energy 2878 density and except for a few examples of hybrid cells, most 2879 results are in the range of $40-60 \mathrm{Wh} \mathrm{kg}^{-1}$ per mass of mate- 2880 rials. However, as opposed to purely inorganic based aqueous 2881 batteries, the combination of attractive energy density, 80- 2882 $90 \mathrm{Wh} \mathrm{kg}^{-1}$ per mass of materials, with promising cyclability 2883 $(>3000 \mathrm{~h})$ can be reached thanks to the large capacity of 2884 organics. In addition, owing to its large voltage and low price, 2885 
a) Typical components in RFBs:

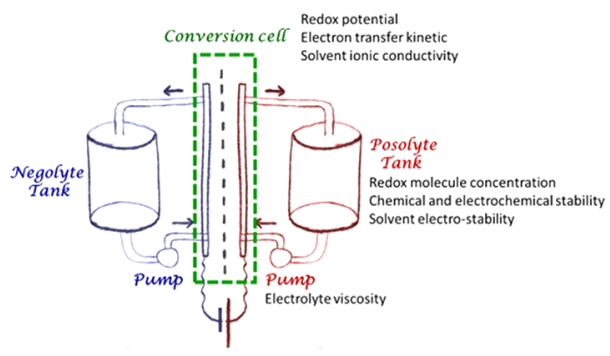

b) Various cell designs:

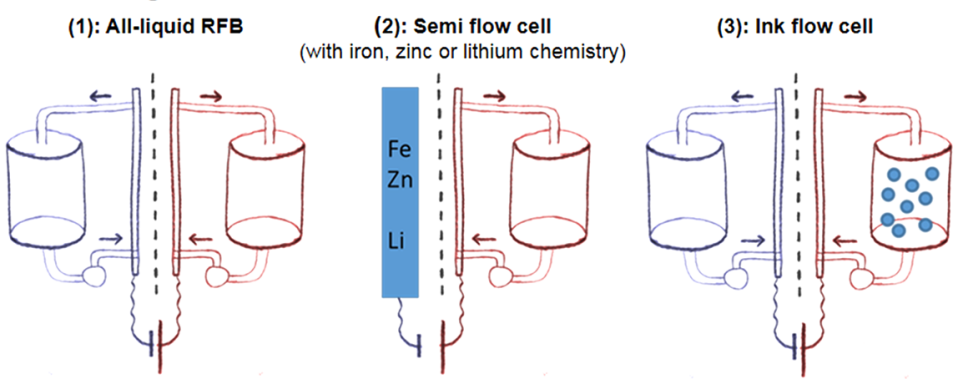

Figure 21. (a) Redox-flow battery schematic with main relevant parameters referred to redox-active compounds. (b) Possible cell configurations.

2886 the $\mathrm{Zn}$ system based on mild electrolyte is certainly an option 2887 to be considered more deeply in the future.

2888 Lastly, to close this section it appears interesting to recall 2889 that the ever decreasing price of Li batteries (and the increasing 2890 TRL of their novel high energy chemistries) turns them into a 2891 serious option for (off)in-grid application. ${ }^{421}$ In this context, 2892 the authors believe that the effective chances of organics to 2893 realize user/market-acceptable aqueous batteries (at least for 2894 complementary applications) stem from their low toxicity, 2895 their abundancy, as well as their recyclability which could turn 2896 out to be efficient and profitable.

\section{ORGANICS IN REDOX-FLOW BATTERIES}

\subsection{Specificities of Redox-Flow Batteries}

2897 Although we have already described the different cell 2898 assemblies using organics, some complementary details are 2899 required to better grasp the specificities of redox-flow cell for 2900 electrochemical storage (Figures 8,9). Basically, such a cell can 2901 be seen as a fuel cell where the fuel and oxidizer would be 2902 replaced by fluids with redox components in solution. As the 2903 associated electrochemical reactions are reversible, the device 2904 can be easily recharged. RFBs are energy storage devices with 2905 the advantage of dissociating power density (electrode surface 2906 area, number of cells in the conversion cell) and energy (tank 2907 volume). As currently energy densities remain low, these 2908 devices are more dedicated to stationary energy storage. The 2909 duration of storage (hour, day, week) depends mainly on the 2910 type of chemistry used.

2911 Many recent reviews related to ORFBs have been conducted 2912 in the literature. ${ }^{15,20,23,24,31,34,35,44,45,422}$ These reviews focus on 2913 describing the implemented redox molecules and the different 2914 strategies used to integrate them into a redox-flow device. This 2915 section will only focus on systems that are most advanced in 2916 terms of performance and that have been tested in systems as 2917 close to the application as possible and at least in a flow cell. 2918 In terms of concentration, there are many publications where 2919 tests are carried out in a very diluted medium, so we have decided to retain only studies on the most concentrated 2920 electrolytes. In solvent-based media, generally speaking, the 2921 performance is much weaker than in the case of aqueous 2922 electrolytes, so the selection we made was less drastic. 2923

A RFB consists of three main components: an electro- 2924 chemical conversion cell where electrochemical reactions take 2925 place, tanks to store redox-active fluids, and finally pumps to 2926 allow the circulation through the cell of the two electrolytes 2927 (posolyte/negolyte) containing the redox-actives species 2928 (Figure 21a). Behind this apparent simplicity lies a device 2929 that remains very difficult to optimize. Among the main 2930 parameters or components associated with the chemistry used, 2931 we can mention:

2932

- the nature of the solvent that composes the electrolyte, 2933 on which depends the accessible potential window, as 2934 well as the power density (ionic conduction) of the 2935 conversion cell;

2936

- the redox compounds solubility; it is important that the 2937 different redox states of each couple have the highest 2938 possible solubility. The number of electrons exchanged 2939 during the redox reaction must modulate this solubility; 2940 the important parameter is the quantity of electrons 2941 exchanged by the solution (mole electrons per liter); 2942

- the electron transfer kinetics with the electrode surface; 2943 electron transfers must be fast and perfectly reversible to 2944 avoid losses due to overvoltage problems. In general, for 2945 a redox-flow conversion cell, faradic efficiencies are very 2946 good; main losses come from overvoltage problems at 2947 the electrodes (different potentials between charge and 2948 discharge);

2949

- the chemistry itself which must obviously be stable 2950 enough without bringing corrosion problems that would 2951 shorten the battery life. RFBs must have a very long 2952 lifetime (>20 years) in order to make its components 2953 more cost-effective than in a regular "sealed" battery 2954 (membrane, pumps cost, etc, ...) since stationary storage 2955 applications are targeted as previously underlined; ${ }^{130,136} 2956$ 
2962 Flow Batteries. As already mentioned in the Introduction 2963 the most advanced and commercialized flow systems are based 2964 on inorganic materials with acidic aqueous electrolyte: vanadium, 2965 zinc-bromine, hydrogen-bromine, and so on. ${ }^{5,423-425}$ Each 2966 system has its own limitations: cost in the case of vanadium, 2967 formation of dendrites for zinc, need to use platinum in the 2968 case of $\mathrm{H}_{2}$, toxicity $\left(\mathrm{Br}_{2}\right)$. Energy efficiencies are between 65 to $296980 \%$ in the case of vanadium RFB for current densities of up to $2970100 \mathrm{~mA} \mathrm{~cm}^{-2}$ and an operating voltage of 1.25 to $1.4 \mathrm{~V}$. Energy 2971 densities of $55 \mathrm{Wh} \mathrm{L}^{-1}$ have been achieved. These values 2972 should be strongly tempered because at high vanadium con2973 centrations (2 M), electrolytes become very sensitive to tem2974 perature, they precipitate easily or become very viscous 2975 preventing their circulation, so the concentrations commonly 2976 used are rather in the order of 1.6 M. The shutdown system 2977 self-discharge would be in the order of $0.1 \%$ per week.

2978 From a practical point of view, many problems of matter 2979 transfer (solvent, ...) related to electro-osmosis through ion 2980 exchange membranes appear during operations. As a result, the 2981 volume of electrolytes in each tank changes according to the 2982 number of cycles and it is necessary to "redistribute" them by 2983 transferring a volume of electrolyte from one compartment 2984 to another, this approximately every 200 cycles. With this 2985 periodic rebalancing, life times of more than 2000 cycles and 298610 years can be achieved. This is independent of corrosion 2987 problems that require regular replacement of parts, involving 2988 high maintenance costs. In the case of chemistries other than 2989 vanadium, electrolyte "rebalancing" is not possible as each 2990 compartment has a different chemistry and the management of 2991 these solvent transfers becomes problematic. Despite these 2992 important limitations, at the moment no "alternative" chemistry 2993 can compete with inorganic flow batteries in terms of application. 2994 9.1.2. Possible Cell Configurations for Redox-Flow 2995 Batteries. Different types of ORFB have been described in the 2996 literature, with the most common being those where both 2997 electrolytes are liquid (Figure 21b). In the case where the only 2998 purpose is to evaluate a specific molecule, it is possible to use a 2999 symmetrical cell (same compounds in each compartment); 3000 however, this implies to have access to the two redox states of 3001 the molecule. There are also intermediate devices between a 3002 flow battery and a solid battery known as semisolid flow 3003 battery as proposed by Chiang's group. ${ }^{426}$ This latter approach, 3004 which generally has the disadvantage of using highly viscous 3005 dispersions that require oversized pumps, will not be discussed 3006 in this review.

\section{9.1.3. Redox-Active Organic Species and Solvents.} 3008 Redox-active organic moieties identified in the ORFB literature 3009 are the same as those found in solid batteries and also deduced 3010 from the general classification reported in Table 1 including 3011 the use of pure p- or n-type structures as well as mixed systems. 3012 They are however "functionalized" in order to increase solu3013 bility in the chosen solvent. These molecules can be combined 3014 in an undifferentiated way to form either a rocking chair cation 3015 ion or anion ion cell or a dual ion cell (Figure 9). It should be 3016 noted that in the latter case, unlike in the case of "sealed" 3017 batteries, since the volume of electrolyte is generally very large 3018 compared to the mass of active material, the dual-ion cell 3019 geometry does not create any problems (significant loss of conductivity of the electrolyte). The main redox-active moieties 3020 are nitroxide, viologen, perylene diimide, ferrocene, quinone, 3021 thio, amino, phenol, ... (Figure S8). In a general way, there is a 3022 strong lack of redox-active structures able to work at very low 3023 potential (as in the case of carboxylates in organic "sealed" 3024 batteries working with solid state compounds) in order to obtain 3025 higher voltage systems. The main problem to address with redox 3026 molecule is stability. Since redox-active compounds are 3027 solubilized in the electrolyte, they are more subject to decom- 3028 position than solid electrodes. Thus, upon cycling, molecules 3029 can react together with solvent or electrolyte giving rise to 3030 poor performances. This especially at high concentrations 3031 (>0.5 M) which enhance decomposition kinetics. 3032

The main role of the solvent is to dissolve the redox 3033 molecule in order to make it transportable between the tanks 3034 and the conversion cell. It must also ensure the ionic con- 3035 ductivity necessary to achieve electroneutrality at all points 3036 of the solution and avoid polarization phenomena in the 3037 conversion cell. For this purpose, the best solvent is water; its 3038 high polarity combined with its ability to dissociate elec- 3039 trolytes results from the fact that aqueous solutions have very 3040 high ionic conductivities. Moreover, in terms of cost, water is 3041 the cheapest solvent and presents the fewest safety problems 3042 (nonflammable, nontoxic). However, aqueous electrolytes 3043 display low electrochemical stability window (1.23 V from 3044 thermodynamics up to $1.5 \mathrm{~V}$ for kinetics reason). Organic 3045 solvents have the advantage of having larger electrochemical 3046 stability windows $(>4.5 \mathrm{~V}$ in the case of acetonitrile or carbon- 3047 ates), but electrolyte dissociation is less efficient, resulting in an 3048 ionic conductivity of about 100 times less than in aqueous 3049 solvent.

3050

Organic solvents are chemically unreactive, so they prevent 3051 degradation phenomena in solution and increase the lifetime 3052 of redox molecules. This also makes possible the stabilization 3053 of certain highly reactive redox molecules (e.g., radicals) and 3054 makes them relevant for redox-flow applications. The main 3055 solvents used are acetonitrile, carbonates, ethers, esters, and, 3056 more anecdotally, DMSO. Generally speaking, the solubility of 3057 organic molecules is not so different between aqueous and 3058 organic electrolytes, for two reasons: in organic media high 3059 concentrations of salts are used to increase the conductivity of 3060 solutions, with the consequence that the solubility of molecules 3061 decreases. An adapted functionalization renders the redox 3062 molecules highly soluble in water. The maximum concen- 3063 trations achievable in a complete electrolyte (salt + solvent) 3064 are in the order of 2-3 M. As the conversion cells have not yet 3065 been really optimized for organic solvents, at the moment the 3066 solvent strongly conditions the type of batteries: high power 3067 density $\left(0.1-0.3 \mathrm{~W} \mathrm{~cm}^{-2}\right)$ in aqueous solution (low voltage, 3068 high conductivity) and high energy density (>100 Wh $\left.\mathrm{L}^{-1}\right)$ in 3069 organic solvent (high voltage, low conductivity). It is of course 3070 possible to mix several solvents, even if this makes electrolyte 3071 development more complex. $^{427}$ This approach remains difficult 3072 to master because it is difficult to combine the advantages of 3073 solvents without also combining the disadvantages. 3074

One way to get around this is to use hydrotropes. A hydro- 3075 trope is a concentrated aqueous solution (several molars) of a 3076 small organic molecule such as urea, para-toluene sulfonic acid, 3077 nicotinic acid, and so on. Organic molecules are generally 3078 much more soluble in a hydrotrope than in water and the elec- 3079 trochemical properties are preserved or improved. The use of 3080 urea, for example, increases the solubility of benzoquinone by a 3081 factor of $7 .^{428}$ Other strategies have been used to make redox 3082 
3083 organic molecules "liquid". The use of ionic liquid was tested 3084 by following different paths: as a solvent, with an organic or 3085 aqueous cosolvent, and finally by making redox ionic liquids. 3086 The use of eutectics based on highly concentrated salts in a 3087 solvent has produced interesting results because they produce 3088 highly conductive solutions capable of dissolving highly polar 3089 redox organic molecules. ${ }^{429}$ Finally, some redox molecules 3090 developed to be highly soluble have been found to be liquid 3091 due to their low solid-state cohesion. However, the addition 3092 of salt is necessary to make the liquid ionically conductive, 3093 resulting in a significant increase in viscosity. While these 3094 alternative strategies have proved to be relevant, they have not 3095 yet made possible the development of large-scale devices 3096 capable of competing with inorganic flow cells in terms of power 3097 density, energy density, or stability (cycling and calendar aging). 3098 The use of ionized salt is necessary to enhance the solvent 3099 ionic conductivity and maintain electroneutrality during the 3100 electrochemical process. In aqueous media, acid $\left(\mathrm{H}_{2} \mathrm{SO}_{4}\right)$ or 3101 base $(\mathrm{KOH})$ could be used if the redox molecule does not 3102 react with them. Salts like sodium or lithium associated with 3103 nitrate, and chloride or sulfate could be used in neutral $\mathrm{pH}$. 3104 In organic medium, salts need to be highly soluble and dis3105 sociated, so lithium or tetra-alkylammonium cation associated 3106 with noncoordinating anion such as $\mathrm{PF}_{6}{ }^{-}, \mathrm{BF}_{4}{ }^{-}$, or $\mathrm{TFSI}^{-}$is 3107 mainly used, even if these salts are much more expensive than 3108 the ones used in aqueous solvents. Independently of the 3109 solvent, the choice of the supporting salt is very important on 3110 the electrochemical behavior of the redox molecule.

3111 One of the main problems remaining for RFB concerns the 3112 fact that the electrolyte in a highly concentrated solution tends 3113 to be very viscous (both in inorganic or organic RFB). In organic $3114 \mathrm{RFB}$, the problem is more important in the way that organic 3115 molecules possess a higher molecular weight compared to 3116 inorganic ones $\left(M(V)=50.9 \mathrm{~g} \mathrm{~mol}^{-1}\right)$. This means, for example, 3117 that an organic redox molecule with a molecular weight of $200 \mathrm{~g}$ $3118 \mathrm{~mol}^{-1}$, typically nonfunctionalized anthraquinonoid derivative, 3119 at a concentration of $1 \mathrm{M}$ corresponds to $200 \mathrm{~g}$ of molecule in $31201 \mathrm{~L}$ of solution. In some cases, the solution became as viscous 3121 as honey, precluding their use in flowing cells, apart from using 3122 a lot of energy to power the pump. A high viscosity also lowers 3123 the molecule diffusion in solution, with a direct effect on the 3124 apparent electron transfer kinetic and ionic conductivity. As a 3125 result, highly concentrated electrolytes suffer from higher cell 3126 overvoltage either in charge or in discharge.

3127 9.1.4. Favoring Highly Soluble Redox-Active Species. 3128 In order to make redox organic molecules highly soluble in 3129 the desired medium, it is necessary to functionalize them with 3130 appropriately selected groups. In aqueous media, ionic func3131 tions or functions with a large number of heteroelements (e.g., $3132 \mathrm{O}$ or $\mathrm{N}$ ) will be favored to increase the interactions between 3133 the redox compound and water molecules. The main ionic 3134 functions used are sulfonates, ${ }^{430}$ phosphates, ${ }^{431}$ carboxy3135 lates, ${ }^{432}$ ammonium, ${ }^{433}$ or hydroxo. ${ }^{434}$ These ionic functions 3136 have also the advantage of increasing the ionic conductivity of 3137 the solution, allowing in some cases to eliminate the use of 3138 supporting salts. Neutral substituents such as PEGs are also 3139 used regularly. However, it is necessary to remain attentive to 3140 the positions chosen to graft these solubilizing groups, because 3141 the functionalization of redox molecules can completely 3142 change the electrochemical response and make it irreversible. 3143 The solubility of nonfunctionalized organic molecules is gen3144 erally better in organic media. However, in most cases, func3145 tionalization is necessary to achieve the solubility necessary to develop an efficient flow battery. In organic media, neutral 3146 substituents are preferred, such as alkyl chains or PEGs. Alkyl 3147 chains are not necessarily the most efficient because of their 3148 low polarity, which is not optimal in polar solvents and which 3149 hinders the solubilization and dissociation of salts. PEG chains 3150 have the advantage of being more polar and their effect on 3151 solubility is more important. By choosing certain chain lengths, 3152 it is even possible to obtain liquid redox compounds. Finally, 3153 these PEG chains are capable of strongly complexing the alkaline 3154 cations contained in the supporting salt, thus improving its 3155 dissociation and increasing the conductivity of the solution. 3156

For the redox-flow system, the membrane is an important 3157 element; it allows the two compartments to be physically 3158 separated to avoid the mixing of species but must permit the 3159 passage of ions to ensure the electroneutrality of each of the 3160 compartments. In most cases, an ion exchange membrane is 3161 used, cationic in the case of a cationic rocking chair battery, 3162 anionic in the case of an anionic rocking chair battery, and one 3163 or the other in the case of a dual ion configuration. In aqueous 3164 environments, the most efficient membranes are mainly made 3165 of perfluoro sulfonated polymer. These membranes are very 3166 stable and have a high ionic conductivity. They have the dis- 3167 advantage of not being as stable in organic media or they tend 3168 to swell and become porous. Alternative organic membranes 3169 have been developed, but unfortunately for the moment they 3170 are not as stable as the perfluoro one. To counter this, ceramic 3171 membranes have been used, particularly in the case of mixed 3172 devices using a lithium electrode. As the cost of such membranes 3173 is important, different strategies have been deployed to try to 3174 replace them with simpler separators. Size based separators 3175 (dialysis membranes) combined with redox molecules in the 3176 form of poly/oligomer to block diffusion from one compart- 3177 ment to the other.

3178

\subsection{Aqueous Organic Redox-Flow Batteries}

9.2.1. Generality. In aqueous media, the most studied 3179 organic molecules are undoubtedly quinones and both methyl- 3180 viologen and TEMPO derivatives. Such electrolytes have the 3181 advantage of being highly dissociating for the supporting salts, 3182 forming solutions of high ionic conductivity allowing high 3183 power densities cycling. The highest conductivities are obtained 3184 in acidic environments since proton is the cation with the 3185 highest mobility (the Grotthuss mechanism). Similarly, the 3186 hydroxide ion is the most mobile anion, so many studies in 3187 aqueous media are also carried out in basic media. However, 3188 these two electrolytes have the disadvantage of being very 3189 reactive toward organic molecules: protons are responsible 3190 for degradation by acid catalysis (polymerization etc..), and 3191 hydroxide ions are good nucleophiles (hydroxylation). For 3192 example, it should be remembered that cleaning glassware in 3193 organic chemistry is often carried out in potash baths. 3194

In the case of quinones, these reactions are particularly 3195 troublesome (e.g., Michael reaction) and very effective in both 3196 acidic and basic media, so that after a few cycles, the initial 3197 molecule is completely transformed and in general the 3198 associated loss of capacity is significant. ${ }^{435}$ Similarly, quinones 3199 tend to dimerize, decreasing the capacity that can be addressed. ${ }^{436} 3200$ As far as methyl viologen derivatives are concerned, they are 3201 stable only in a neutral or acidic medium; in a basic medium an 3202 elimination reaction takes place resulting in the loss of redox 3203 properties. These compounds also tend to dimerize, resulting 3204 in one electron reactions instead of two. ${ }^{437}$ Similarly, in highly 3205 acidic environments, TEMPOs undergo degradation reactions. ${ }^{438} 3206$ 
3207 In all cases, it is necessary to develop sometimes complex 3208 strategies to avoid these adverse reactions for the battery 3209 operation and stability. In terms of solubility, by functionaliza3210 tion it is possible to achieve solubility values in about $2 \mathrm{M}$. 3211 In the case of quinones, the electrochemical and solubility 3212 properties are very strongly dependent on the number and 3213 substitution positions. ${ }^{430}$ Thus 9,10-anthraquinone-2,7-disul3214 fonic acid (AQDS) retains a high electrochemical reversibility 3215 while being highly soluble, which is not the case for other 3216 disulfonates. ${ }^{439}$ Generally speaking, aqueous ORFBs have 3217 many advantages: nontoxic, low solvent and salt costs, highly 3218 conductive solution. However, they pose two important and 3219 very difficult problems: the small window of potential 3220 associated with this solvent and its reactivity with organic 3221 molecules.

3222 9.2.2. Main Examples of Aqueous ORFB. Many works 3223 have been carried out over the last 5 years in the field of 3224 aqueous ORFBs, we have chosen a few didactic examples to 3225 show the diversity of approaches and the performances that 3226 can be obtained with this technology to date.

3227 Aziz's group (Harvard University) has conducted numerous 3228 studies on the use of quinone for ORFBs, or combined 3229 organic/inorganic batteries (quinone $-\mathrm{Br}_{2}$, quinone ferrocya3230 nide). ${ }^{434,440}$ Their studies focus mainly on the use of sulfonated 3231 (AQDS acid medium) or hydroxylated (DHAQ basic medium) 3232 quinones that can achieve electron concentrations $>1 \mathrm{M}$ 3233 (Figure 22a). The output cell voltage obtained with the full 3234 system $0.5 \mathrm{M}$ DHAQ/0.4 M ferrocyanide is about $1.2 \mathrm{~V}$. 3235 The battery was tested for 100 cycles at a current density of $3236100 \mathrm{~mA} \mathrm{~cm}^{-2}$ and showed an energy efficiency greater than $323780 \%$ and a capacity retention of $90 \%$. The maximum power 3238 density is $400 \mathrm{~mW} \cdot \mathrm{cm}^{-2}$. No significant degradation of the 3239 electrolyte seems to occur. With ADQS in sulfuric acid 3240 medium $(1 \mathrm{M})$ as negative electrolyte, associated with $3.5 \mathrm{M}$ 3241 hydrobromic acid and dibromine $(0.5$ or $2 \mathrm{M})$ the cell voltage 3242 is $0.8 \mathrm{~V}$. Different types of carbon felt and membranes have 3243 been tested to optimize battery performances. With a 212 3244 Nafion membrane and $2 \mathrm{M} \mathrm{Br}_{2}, 3 \mathrm{M} \mathrm{HBr}$, the battery reaches a 3245 power peak at $1 \mathrm{~W} \mathrm{~cm}^{-2}$ which is extremely high for a flow 3246 battery. It should be noted, however, that this was possible 3247 thanks to extremely high electrolyte flows $\left(400 \mathrm{~mL} \mathrm{~min}^{-1}\right)$ for 3248 an electrode surface area of $2 \mathrm{~cm}^{2}$, which is very demanding on 3249 the consumption of the pumps.

3250 Schubert's group (University of Jena) has developed an 3251 approach combining methyl viologen derivatives (low potential) 3252 and nitroxide (high potential). ${ }^{441,442}$ These organic compounds 3253 are reversible in electrochemistry and have very high electron 3254 transfer kinetics. The voltages of the cells reached are $1.4 \mathrm{~V}$ 3255 (Figure 22b). The TEMPTMA derivative has a solubility of $32562.3 \mathrm{M}$ in a solution of $\mathrm{NaCl} 1.5 \mathrm{M}$ which corresponds to a 3257 theoretical capacity of $61 \mathrm{Ah}$. The flow battery combining MV 3258 and TEMPTMA ( $2 \mathrm{M}$ each) addresses the maximum capacity 3259 of the electrolyte up to a current density of about $100 \mathrm{~mA} \mathrm{~cm}^{-2}$. 3260 The energy efficiency is greater than $70 \%$. At $80 \mathrm{~mA} \mathrm{~cm}^{-2}$ the 3261 battery is stable over 100 cycles without significant degradation 3262 of performance. To avoid using an ion exchange membrane, 3263 polymers have been developed from these molecular units. Due 3264 to the steric encumbrance of these polymers, a simple porous 3265 membrane is sufficient to prevent the two compartments from 3266 mixing. Ten $\mathrm{Ah} \mathrm{L}^{-1}$ electrolytes are made by dissolving these 3267 polymers in $2 \mathrm{M} \mathrm{NaCl}$ solution. The battery thus formed is 3268 capable of cycling up to current densities of $50 \mathrm{~mA} \mathrm{~cm}{ }^{-2}$ 3269 without significant loss of capacity. The properties are stable over 90 cycles with a loss of less than $10 \%$ in capacity. The 3270 energy density of redox fluids is in the order of $10 \mathrm{~W} \mathrm{~L}^{-1}$. $\quad 3271$

Liu's group (Utah State University) has developed several 3272 types of chemistry based mainly on viologen derivatives 3273 (negative) and either ferrocene derivatives or dibromine in 3274 positive compartment (Figure 22c). ${ }^{443,444}$ In particular, they 3275 used a sulfonate substituted viologen derivative to make a 3276 mixed organic/inorganic $\left(\mathrm{Br}_{2}\right) \mathrm{RFB}$. The output voltage of the 3277 cell is about $1.4 \mathrm{~V}$. The synthesized molecule has been tested 3278 in a neutral medium $\left(\mathrm{NH}_{4} \mathrm{Br}\right)$ at concentrations up to $1.5 \mathrm{M} 3279$ $(3 \mathrm{~N})$. The power densities obtained are as high as $227 \mathrm{~mW} \mathrm{~cm}^{-2} 3280$ for a current density of $300 \mathrm{~mA} \mathrm{~cm}{ }^{-2}$. The stability in charge and 3281 discharge over 50 cycles shows a loss of capacity per cycle of 3282 $0.11 \%$; the energy efficiency is $78 \%$ at $40 \mathrm{~mA} \mathrm{~cm}{ }^{-2}$. The energy 3283 density of these ORFBs is $30.3 \mathrm{Wh} \mathrm{L}^{-1}$. Tests have shown that 3284 the use of carbon nanotubes on current collectors improves 3285 battery performance, significantly reducing overpotential 3286 issues. This group has also developed ammonium-substituted 3287 ferrocene derivatives to improve solubility in aqueous media 3288 ( $>2 \mathrm{M}$ in $2 \mathrm{M} \mathrm{NaCl}$ ). The batteries produced have a cell 3289 voltage of $1 \mathrm{~V}$ and energy efficiencies that are highly dependent on 3290 current density ( $72 \%$ at $40 \mathrm{~mA} \mathrm{~cm}^{-2}$ and $43 \%$ at $100 \mathrm{~mA} \mathrm{~cm}^{-2}$ ). 3291 Aging studies carried out over 700 cycles have shown very high 3292 stability (about $0.00014 \%$ loss of capacity per cycle). 3293

Narayanan et al. ${ }^{445,446}$ from University of Southern California 3294 have developed an ORFB where posolyte and negolyte are 3295 quinone based: disulfonated anthraquinone (AQDS) or mono- 3296 sulfonated in negative compartment and disulfonated ortho- 3297 benzoquinone (BQDS or tiron) as positive electrolyte 3298 (Figure 22d). These two compounds have high solubility in 3299 acid electrolytes. The cell voltage is $0.8 \mathrm{~V}$ at a current density 3300 of $80 \mathrm{~mA} \mathrm{~cm}{ }^{-2}$. This voltage drops sharply as the current 3301 density increases. Several cell geometries and current collectors 3302 (carbon felts) have been tested to increase the performance of 3303 these batteries. The energy efficiency of a battery composed of 3304 BQDS and AQDS $1 \mathrm{M}$ is $70 \%$ over 100 cycles. In any case, due 3305 to the reactivity of these redox molecules, these batteries have 3306 low cycling stability.

Finally, Jin et al. ${ }^{432}$ from Nanjing University have modified a 3308 naphthoquinone by substituting it with a carboxylate group 3309 (HCNQ) to increase solubility in a neutral or basic medium 3310 (Figure 22e). The battery made with an alkaline electrolyte 3311 (KOH $1 \mathrm{M}$ ) and $0.5 \mathrm{M}$ HCNQ combined with ferrocyanide 3312 exhibits an output voltage of 1 V. Power densities of 3313 $250 \mathrm{~mW} \mathrm{~cm}{ }^{-2}$ were measured at a current density of about 3314 $400 \mathrm{~mA} \mathrm{~cm}{ }^{-2}$. The capacity loss measured over 50 cycles is 3315 $0.12 \%$ per cycle, probably resulting from the reactivity of the 3316 reduced form of HCNQ. To increase stability, it would be 3317 necessary to modify the structure of these quinones to block 3318 hydroxylation reactions.

Concerning ORFBs, the aqueous medium is undoubtedly 3320 the one with the best performance in terms of energy efficiency 3321 and current density. Contrary to what was anticipated, the 3322 solubility of redox molecules in aqueous medium is not much 3323 lower than what can be measured in organic medium. The 3324 power and energy densities are high and in some cases at 3325 the same level as those found in the case of inorganic BFRs 3326 (vanadium). Although different conversion cell geometries are 3327 being tested in some studies, it would now be useful to 3328 conduct systematic studies to try to minimize losses due to 3329 ohmic drops, or problems related to cross diffusion through 3330 the membrane. In general, many of these systems suffer from 3331 
a)<smiles>O=C1C(=O)c2ccc([AsH](=O)(O)O)cc2C(=O)c2ccc(O)cc21</smiles>

b)

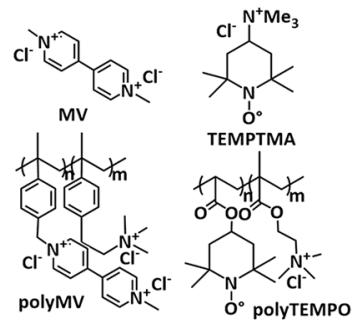

c)<smiles>O=S(=O)(O)CC[n+]1ccc(-c2cc[n+](CCS(=O)(=O)O)cc2)cc1</smiles>

d)

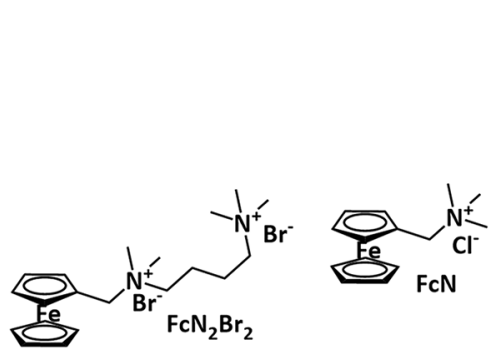
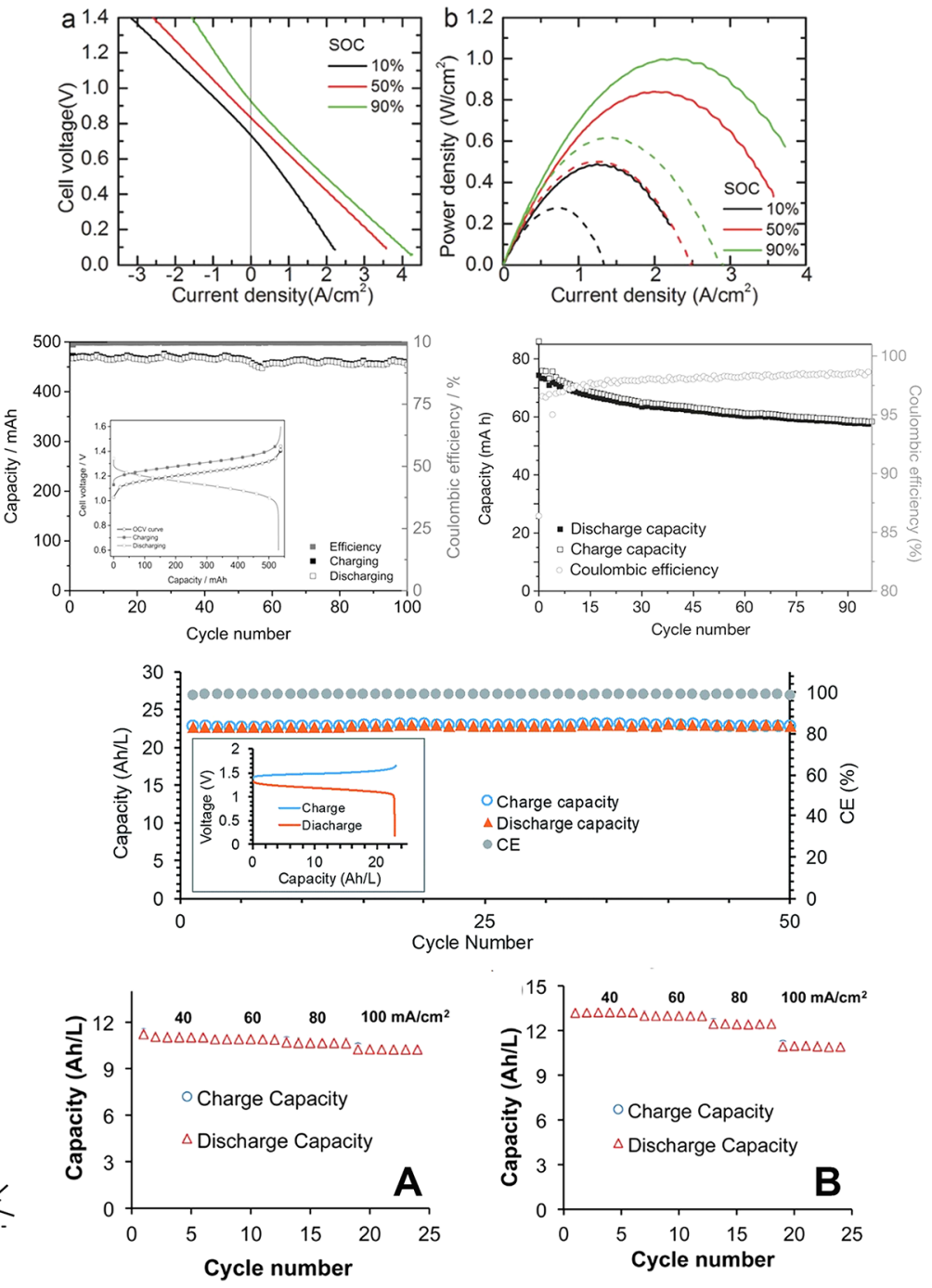

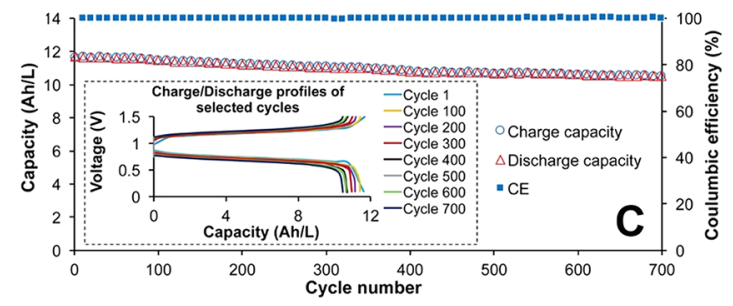

e)<smiles>O=CON=CC1=C(O)C(=O)c2ccccc2C1=O</smiles>

Figure 22. (a) Performance of ORFB composed of AQDS and $\mathrm{Br}_{2}$ showing both the cell voltage vs current density and the power density vs current density (reproduced with permission from ref 440. Copyright 2016 The Electrochemical Society). (b) Cycling capacity and efficiency of ORFB made of: MV and PEMPTMA (center); polymerized MV and TEMPO (left) (reproduced with permission from refs 441 and 442. Copyright 2015 John Wiley and Sons and Nature Publishing Group). (c) Cycling curve and aging behavior of the ORFB developed by Liu et coworkers. Concentration of redox molecule $1 \mathrm{M}$ in $\mathrm{NH}_{4} \mathrm{Br}$ (reproduced with permission from ref 443. Copyright 2019 The Royal Society of Chemistry). (d) Capacity vs cycle number at different current densities for (A) $\mathrm{FcNCl}$, (B) $\mathrm{FcN}_{2} \mathrm{Br}_{2}$ at $0.5 \mathrm{M}$, and (C) cycling stability of $\mathrm{FcNCl}$ / MV battery ( $0.5 \mathrm{M}$ electrolyte) over 700 cycles (reproduced with permission from ref 444. Copyright 2017 American Chemical Society). (e) Capacity vs cycle number at different current densities for an HCNQ cell $(0.5 \mathrm{M})$ in A. Corresponding voltage and power density vs current density in B (reproduced with permission from ref 432. Copyright 2018 American Chemical Society). 
3332 poor cyclability, particularly in concentrated conditions, due to 3333 the numerous possible decomposition reactions.

\subsection{All-Organic Redox-Flow Batteries}

3334 Redox batteries using an organic solvent have been strongly 3335 developed in the literature during the years 2000-2010, mainly 3336 with compounds from coordination chemistry with several stable 3337 redox states; more recently, the use of organic molecules has 3338 strongly increased. The main advantage of working with organic 3339 solvents is to have larger potential windows and therefore to 3340 increase the energy density. The voltages obtained with devices 3341 where both fluids circulate are at most in the order of $2.5 \mathrm{~V}$. This 3342 is mainly due to the fact that when the molecules are in solution 3343 no SEI can be formed. SEI layers are formed on the surface of 3344 particles inserting $\mathrm{Li}$ at very low potential and protect the 3345 solvents from decomposition. Due to main solvent stability 3346 window, it is necessary that the redox potential of the com3347 pound used in the negative electrolyte should be at the most in

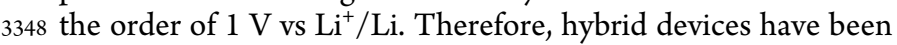
3349 developed combining a Li-based negative and an organic positive 3350 flow cell. Another difficulty comes from organic electrolytes: 3351 low ionic conductivity, about 100 times lower than aqueous 3352 electrolytes. This results in important ohmic drop and decreases 3353 the voltage efficiency. Thus, a complete optimization of the cell 3354 core would be necessary to counter this phenomenon.

3355 Various cells configurations are used to test new compounds 3356 by $(i)$ associating two organic redox couples, (ii) carrying test 3357 in symmetric cells, or (iii) Li/RFB hybrid cells. The latter, due 3358 to the low potential of $\mathrm{Li}$, have very high energy density, up to 3359 about $200 \mathrm{Wh} \mathrm{L}^{-1}$ but power density remains very low due to 3360 current limitation (less than $1 \mathrm{~mA} \mathrm{~cm}^{-2}$ ). However, to date, no 3361 redox solvent-based electrolyte battery has been able to achieve 3362 a true industrial scale demonstrator. Many questions remain to 3363 be answered, such as the associated costs, safety, and solubility, 3364 electrolyte viscosity, which is generally very high in concen3365 trated organic media, and calendar and cycling stability over 3366 very long periods. For example, there are few studies where 3367 highly concentrated electrolytes $(0.5-1 \mathrm{M})$ are tested in flux 3368 configuration mainly due to the high solutions viscosity. The 3369 few systems we have selected to discuss are the most advanced 3370 and representative of these devices.

3371 9.3.1. Main Results in Mix Configuration (Li/Organic 3372 RFB). The Pacific Northwest National Laboratory (PNNL) 3373 has particularly tested several types of strategies and redox 3374 molecules in mixed configuration. ${ }^{447-449}$ First, anthraquinone 3375 derivatives modified to increase their solubility were used, then 3376 TEMPO, and finally ferrocene derivatives. As the latter does 3377 not provide better properties than other approaches, it will not 3378 be discussed in this review, only the first two strategies are 3379 described below.

3380 Wang et al. ${ }^{447}$ proposed to modify anthraquinones with 3381 PEG groups (15D3GAQ) to promote the solubility of the 3382 molecule as well as the complexing effect toward $\mathrm{Li}$ ions. The 3383 electrolyte is composed of a solution of $\mathrm{LiPF}_{6} 1 \mathrm{M}$ in PC. This 3384 solvent forms a stable SEI with respect to $\mathrm{Li}$ metal. The static 3385 cell is composed of a $\mathrm{Li}$ sheet and a simple Celgard separator 3386 that confines the redox molecule to the positive compartment; 3387 the concentration of $15 \mathrm{G} 3 \mathrm{GAQ}$ being $0.25 \mathrm{M}$. An average 3388 voltage of $2.3 \mathrm{~V}$ is measured when the battery is cycled to $33890.1 \mathrm{~mA} \mathrm{~cm}^{-2}$ (Figure 23a). The battery properties are stable up 3390 to a cycling current of $0.5 \mathrm{~mA} \mathrm{~cm} \mathrm{~cm}^{-2}$ but collapse beyond that. 3391 Two plateaus corresponding to the two consecutive transfers 3392 of 1 electron are observed respectively at 2.15 and $2.40 \mathrm{~V}$ (during charging), respectively. An energy efficiency of $82 \%$ is 3393 measured; the cycling stability evaluated over 40 cycles shows a 3394 loss of about $0.8 \%$ in capacity per cycle. The measured energy 3395 density is about $25 \mathrm{Wh} \mathrm{L}^{-1}$, with the low concentration used to 3396 make the electrolyte ( $0.5 \mathrm{M}$ in electron) being compensated by 3397 the output cell voltage $(2.3 \mathrm{~V})$.

$\mathrm{Xu}$, Wang, and co-workers found that TEMPO was highly 3399 soluble in carbonate solvents. ${ }^{448}$ Thus in an EC/PC/EMC 3400 mixture $(4: 1: 5 \mathrm{w} / \mathrm{w}) 2.3 \mathrm{M} \mathrm{LiPF}_{6}$, TEMPO is soluble up to 3401 $2 \mathrm{M}$. However, it should be noted that the solutions obtained 3402 are very viscous and difficult to circulate $(67.1 \mathrm{cP}$ at $2 \mathrm{M}, 3403$ $4.02 \mathrm{cP}$ at $0.1 \mathrm{M}$ ). The flow cell consists of a Li/graphite mixed 3404 negative electrode, a porous physical separator, and a carbon 3405 felt through which the electrolyte circulates. The energy density 3406 was measured with the cell at $2 \mathrm{M}$ TEMPO and $126 \mathrm{Wh} \mathrm{L}^{-1}, 3407$ with an energy efficiency of $70 \%$. Stability in concentrated 3408 condition does not seem very high, in dilute solution (0.1 M), 3409 capacity losses are about $0.2 \%$ per cycle. As there is no ceramic 3410 membrane, the cycling currents are higher, up to $5 \mathrm{~mA} \mathrm{~cm}{ }^{-2}$. 3411

Finally, Lu et al. ${ }^{458}$ reported the use of 10-methylpheno- 3412 thiazine (MPT) melted, then mixed with carbon black 3413 (Ketjenblack EC-600JD), and finally ground when solidified. 3414 The electrolyte consists of a saturated solution of MPT (0.3 M) 3415 in an EC/DEC $1 \mathrm{M} \mathrm{LiPF}_{6}$ mixture to which the ground solid 3416 is added. The MPT in solution acts as a redox shuttle to 3417 electrochemically address the solid MPT. It should be noted 3418 that without carbon, solid MPT is not electroactive. Mixtures 3419 of $0 \%, 20 \%$, and $40 \%$ (in vol.) solid and electrolyte were tested. 3420 The electrolytes were tested in static and flow cells. The flow 3421 cell is composed of a Li sheet, a ceramic separator (LAGP) and 3422 of the electrolyte circulating on a carbon paper. On the cycling 3423 curves (Figure 23b), the electrolyte alone $(0 \%)$ has a plateau at 3424 $3.55 \mathrm{~V} \mathrm{vs} \mathrm{Li}^{+} / \mathrm{Li}$ and a capacity of $7 \mathrm{Ah} \mathrm{L}^{-1}$, which corresponds 3425 to $87 \%$ of the theoretical capacity. With $20 \%$ mixture, the 3426 cycling curves maintain the same behavior, but the capacity is 3427 increased to $27 \mathrm{Ah} \mathrm{L}^{-1}$. The $50 \%$ mixture allows to reach a 3428 capacity of $55 \mathrm{Ah} \mathrm{L}^{-1}$, which corresponds to an electron 3429 concentration of $2.23 \mathrm{M}$. The energy density of the $40 \% 3430$ electrolyte is $190 \mathrm{Wh} \mathrm{L}^{-1}$, one of the highest energy densities 3431 demonstrated to date. This is mainly due to the high cell 3432 voltage $(3.55 \mathrm{~V})$ even if the MPT/carbon Ketjenblack mixture 3433 significantly increases the capacity of the solution. 3434

The main problem with these mixed $\mathrm{Li}$ /organic molecules 3435 flow cell approaches comes from the very low current densities 3436 (often less than $1 \mathrm{~mA} \mathrm{~cm}^{-2}$ ) that can be passed through the 3437 device. This is particularly true if the separator between the 3438 two compartments is a ceramic membrane. When the separator 3439 is porous, it would appear that the SEI formed on the surface 3440 of the $\mathrm{Li}$ in the carbonates is beneficial. It would act as an ion 3441 exchange membrane while blocking electron transfers to the 3442 redox molecules. Thus, molecules in solution close to the 3443 negative electrode could not be reduced, which would explain 3444 the high Coulombic efficiency of these devices. On the other 3445 hand, at high concentration in redox molecules, the SEI is 3446 modified and/or no longer succeeds in blocking these electron 3447 transfers and the Coulombic efficiency falls strongly 3448 (Coulombic efficiency 99\% at $0.1 \mathrm{M}, 91 \%$ at $0.8 \mathrm{M}, 85 \%$ at 3449 $1.5 \mathrm{M}$, and $84 \%$ at $2 \mathrm{M}) .{ }^{448}$ Finally, these devices do not allow 3450 the power and energy density to be separated; they are 3451 therefore more limited in terms of application.

9.3.2. Main Results in Liquid All-Organic Cell 3453 Configuration. Argonne laboratory and their collaborators 3454 have optimized the structure of phenolic ethers used as 3455 
a)<smiles>CCOc1cccc2c1C(=O)c1cccc(OCCOC)c1C2=O</smiles>

b)<smiles>CN1c2ccccc2S(=[W])c2ccccc21</smiles>

c)

High potential redox molecule<smiles>COCCOc1cc(C(C)(C)C)c(OC)cc1C(C)(C)C</smiles>

Low potential redox molecule

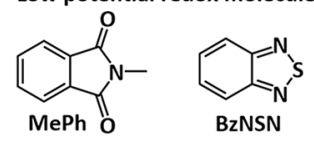

d)<smiles>CCN1c2ccccc2S(=[W])c2ccccc2N1CCOC</smiles>
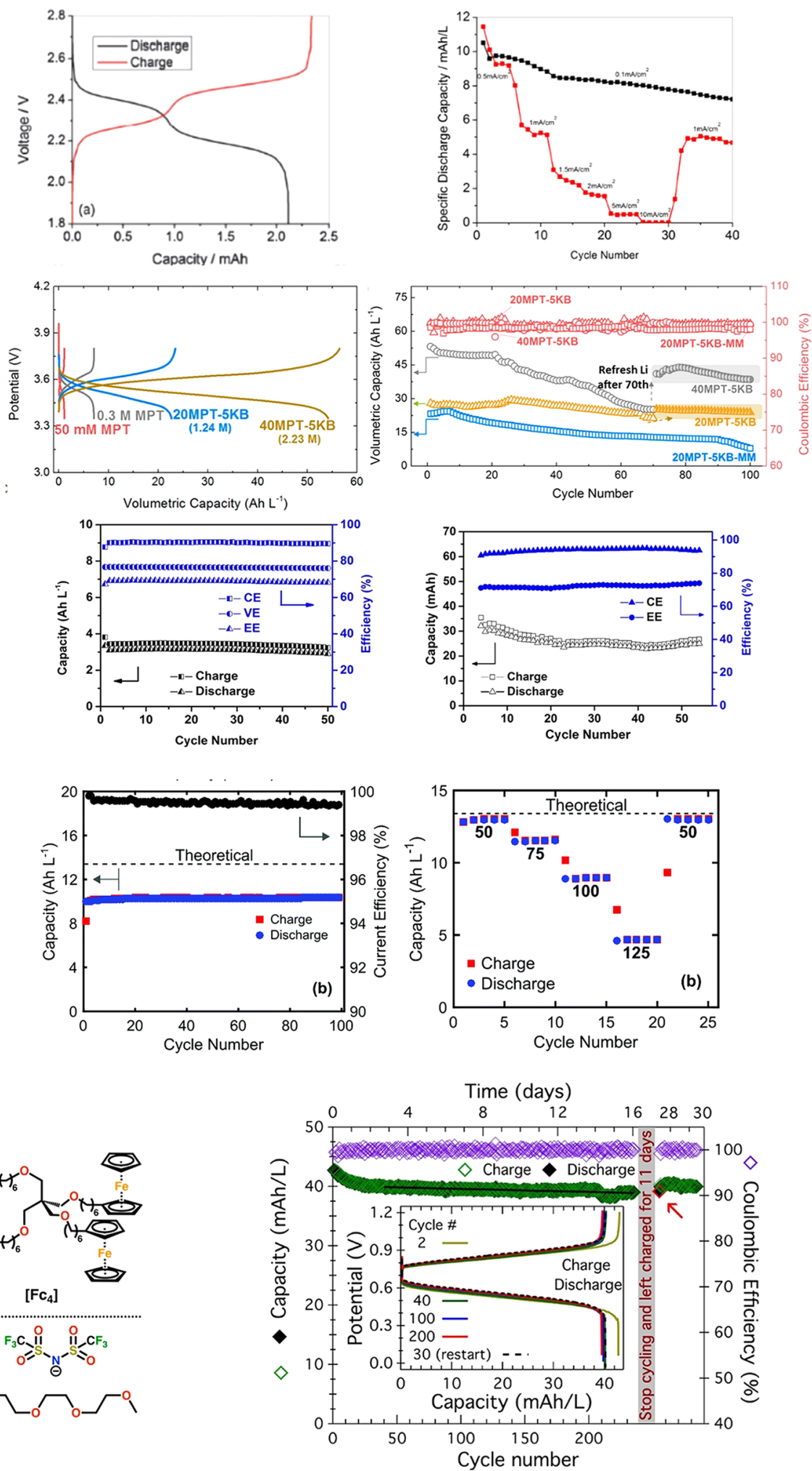

Figure 23. (a) Cycling performance and rate capability reported by Wang and co-workers of the cell with 0.25 M $15 \mathrm{D} 3 \mathrm{GAQ}$ as posolyte and lithium foil as anode (reproduced with permission from ref 447. Copyright 2012 The Royal Society of Chemistry). (b) Cycling performance of the $\mathrm{Li} / \mathrm{MPT}$ flow cell reported by $\mathrm{Lu}$ and co-workers (reproduced with permission from ref 450 . Copyright 2018 American Chemical Society). (c) Cycling performances of ORFBs based on MePh/DBMMB 0.3 M in DME- M LiTFSI (left) or BzNSN/DBMMB 0.5 M in ACN $1 \mathrm{M}$ LiTFSI (right) reported by Wei and co-workers (reproduced with permission from refs 452 and 453. Copyright 2016 and 2017 American Chemical Society). (d) Symmetric flow cell characterization of MEEPT $0.5 \mathrm{M}$ in ACN $0.5 \mathrm{M} \mathrm{TEABF}_{4}$ reported by Milshtein and co-workers (reproduced with permission from ref 454. Copyright 2016 The Royal Society of Chemistry). Constant current cycling at $100 \mathrm{~mA} \mathrm{~cm}{ }^{-2}$ (left), capacity vs cycle number at different current densities (right). (e) Molecule used by Sisto and co-workers to develop dialysis membrane-based ORFBs (left) together with the cycling performance (right), reproduced from ref 455. 
3456 high-potential molecules in order to increase their solubility, 3457 and stability. ${ }^{451}$ DBMMB offers the best compromise in terms 3458 of viscosity, stability and diffusion coefficient. Its redox 3459 potential is about $0.78 \mathrm{~V}$ vs $\mathrm{Ag}^{+} / \mathrm{Ag}$, so it has been retained 3460 and implemented against several low-potential and highly 3461 soluble molecules: BzNSN and $N$-methylphthalimide $3462(\mathrm{MePh}){ }^{452,453} \mathrm{MePh}$ has a reduction potential of about $3463-1.79 \mathrm{~V}$ vs $\mathrm{Ag}^{+} / \mathrm{Ag}$ in $1 \mathrm{M}$ LiTFSI DME electrolyte. A major 3464 effort has been made to choose a porous membrane of the 3465 Celgard or Daramic-type that is effective in preventing species 3466 mixing and does not generate a too high ohmic drop. 3467 A Daramic 175 membrane was selected to make a complete 3468 redox-flow cell using an equimolar mixture of DBMMB and $3469 \mathrm{MePh}$ at $0.3 \mathrm{M}$ in $1 \mathrm{M}$ LiTFSI DME electrolyte. Although 3470 tested only over about 50 cycles, the cell capacity is constant at 3471 about $3 \mathrm{Ah} \mathrm{L}^{-1}$ for an energy density of $9.3 \mathrm{Wh} \mathrm{L}^{-1}$. This cell is 3472 able to work at current densities close to those used in aqueous 3473 ones: $50 \mathrm{~mA} \cdot \mathrm{cm}^{-2}$ with no significant degradation of its perfor3474 mance. At this current level, the energy efficiency remains 3475 above $60 \%$. It is interesting to note that at low current the 3476 Coulombic efficiency is not very good due to the cross diffu3477 sion of species through the porous membrane while at high 3478 current density the voltage efficiency drops due to the ohmic 3479 drop. The redox potential of BzNSN is $-1.58 \mathrm{~V}$ vs $\mathrm{Ag}^{+} / \mathrm{Ag}$ in $34801 \mathrm{M}$ LiTFSI ACN electrolyte, with its solubility being $2.1 \mathrm{M}$ 3481 when considering 2.1 M LiTFSI ACN as the electrolyte.

3482 An electrolyte containing an equimolar mixture of BzNSN 3483 and DBMMB $(0.5 \mathrm{M})$ in $1 \mathrm{M}$ LiTFSI ACN as electrolyte was 3484 cycled in a redox-flow cell composed of two carbon felt elec3485 trodes and a Daramic type separator $(800 \mu \mathrm{m})$. Due to the 3486 viscosity of the solution and the problems of cross diffusion 3487 through the membrane, the current density applied is $348810 \mathrm{~mA} \cdot \mathrm{cm}^{-2}$. The energy yield is $72 \%$, mainly due to ohmic 3489 drops. The energy density is in the order of $6-8 \mathrm{Wh} \mathrm{L}^{-1}$. The 3490 stability of the cell is not very good ( 50 cycles) probably due to 3491 the reactivity at high concentration of the species that compose 3492 the electrolyte. These studies have shown that DBMMB derivatives 3493 are potentially relevant for the design of a fully organic redox-flow 3494 battery. They are extremely soluble in organic electrolytes (2-3 M) 3495 and the radicals resulting from their oxidation are stable in DME 3496 solvents. The two low-potential molecules tested, particularly $3497 \mathrm{BzNSN}$, are soluble up to $5 \mathrm{M}$, but their solutions are highly 3498 viscous precluding their use in flowing cell.

3499 Kentucky University has developed organically soluble 3500 phenothiazine derivatives. ${ }^{454}$ MEEPT has been selected as 3501 the most efficient compound: it is liquid at room temperature, 3502 and its solubility in $0.5 \mathrm{M} \mathrm{nBu}_{4} \mathrm{NBF}_{4} \mathrm{ACN}$ is greater than $2 \mathrm{M}$. 3503 It is electrochemically stable, and it is possible to prepare both 3504 forms, neutral and oxidized, easily by chemical methods. The 3505 core of the conversion cell has been optimized to reduce both 3506 ohmic drop and losses related to fluid flowing through the system 3507 (channel electrodes). The optimized cell has a resistance of about $35083.3 \Omega \mathrm{cm}^{-2}$. The assembly was tested in a symmetrical con3509 figuration with an electrolyte composed of $0.5 \mathrm{M}$ MEEPT at $50 \%$ 3510 state of charge with a theoretical capacity of $13.4 \mathrm{Ah} \mathrm{L}^{-1}$. 3511 In constant current cycling at 50 and $100 \mathrm{~mA} \cdot \mathrm{cm}^{-2}$, the measured 3512 capacity is respectively $97.3 \%$ and $60 \%$ of the theoretical capacity. 3513 Over 100 cycles $\left(80.6 \mathrm{~h}\right.$ in total) at $100 \mathrm{~mA} \mathrm{~cm}^{-2}$, the capacity is 3514 maintained, and no significant loss is observed.

3515 Columbia University, NY, has developed a flux battery based 3516 on perylene diimide derivatives (negative) and ferrocene tetramere 3517 (positive), both of which can achieve electron concentrations > $35181 \mathrm{M}^{455}$ The interest of this work is to demonstrate that cellulose dialysis membranes, combined with redox compounds 3519 with a large hydrodynamic radius, are very efficient to avoid 3520 mixing the two electrolytes. The authors also carried out studies 3521 on aging both in cycling and calendars (even if carried out in 3522 diluted solution). They were able to demonstrate that in 11 days 3523 in the charged state, no significant loss of capacity was noted. 3524 The cell could be cycled 450 times with an average capacity loss 3525 of $0.00614 \%$ per cycle.

3526

All organic redox-flow cell faces a lot of problems to develop 3527 a commercially viable system able to really compete with 3528 aqueous inorganic chemistries. This is mainly due to the fact 3529 that the molecular parameters are all interdependent. The fact 3530 of wanting high cell voltages implies the use of compounds 3531 where reduced (materials with very low potential) or oxidized 3532 (materials with very high potential) forms are poorly stabilized 3533 and therefore very reactive. From a solubility point of view, the 3534 use of highly concentrated solutions further increases decom- 3535 position phenomena. This often results in poor cycling stability 3536 and is in addition to the fact that calendar aging is almost never 3537 achieved or under very diluted conditions that are more 3538 favorable. ${ }^{456}$ Organic solutions that are highly concentrated 3539 generally become highly viscous, causing problems for flowing 3540 (pumps power consumption) and voltage efficiencies as these 3541 solutions become less conductive. The diffusion coefficients of 3542 redox species and ions decrease when viscosity increases with 3543 the result of lower apparent electron transfer kinetics. This 3544 results in high overvoltage values and low energy yields, often 3545 well below $60 \%$. This probably explains why there are no flow 3546 cell studies at concentrations above $2 \mathrm{M}$ in the literature, while 3547 several molecules have higher solubility values. The main 3548 interest of the studies in organic media is that due to the 3549 swelling of conventional ion exchange membranes and a high 3550 cross over, combined with low electrolyte conduction (high 3551 overvoltage), the community has been forced to develop 3552 membrane-free approaches, some of which have proven to be 3553 relevant.

3554

\subsection{Summary}

The use of organic molecules to make electrolytes for flow 3555 batteries is now well described in the literature. Dozens of dif- 3556 ferent molecules have been tested in various cell configurations. 3557 From a properties and behavior point of view, electrolytes based 3558 on organic molecules face the same problems as inorganic 3559 compounds: solubility, high viscosity of concentrated solutions 3560 with the result of a decrease in apparent electron transfer kinetics 3561 (overvoltage between charge and discharge), and a high power 3562 consumption by the pumps. Since the intrinsic stability of 3563 organic molecules in solution is lower than the stability of inor- 3564 ganic compounds, cycling and calendar stability are generally 3565 less good.

3566

This stability aspect remains the key point to go further. 3567 Many parameters must be taken into account to understand 3568 the degradation of ORFB performance: molecules in solutions 3569 are much more reactive than in the solid state, in addition they 3570 are in contact with different materials (plastic, stainless steel, 3571 and so on) which can act as catalysts. Most of these com- 3572 pounds are sensitive at least in one redox state to oxygen 3573 traces, which is difficult to prevent in the long term (leakage). 3574 Reactions are also possible, for example, with other com- 3575 ponents of the electrolyte, such as the solvent (substitution 3576 reactions, hydrolysis, ...), the supporting salts, or the molecule 3577 itself (dimerization or polymerization reaction). In addition, 3578 reactivity may change with molecules redox states, a reduced 3579 
3580 one will be more sensitive to reactions with an electrophile, 3581 while oxidized molecules will be more sensitive to reactions 3582 with nucleophiles. Therefore, it is necessary that all other 3583 components of the electrolytes be as unreactive as possible. 3584 It can be expected thanks to functionalizations to stabilize a 3585 molecule by blocking some degradation reactions. For 3586 example, the reduced state of dihydroxyanthraquinone tends 3587 to degrade through oxidative coupling. To avoid this side 3588 reaction, the functionalization of hydroxyl groups by PEG, 3589 alkyl carboxylate, or alkyl phosphate chains has been 3590 successfully proposed. However, these new molecules become 3591 sensitive to hydrolysis reactions and degradation reactions can 3592 occur. $^{431,457}$ This observation is general; attempting to stabilize 3593 a molecule in a given electrolyte may result in a change of its 3594 reactivity or redox property that makes the molecule less or no 3595 more relevant for the application.

3596 In most cases, crossover phenomena through the mem3597 branes are harmful. To compensate forthis, the development of 3598 stable molecules in at least three stable redox states, which can 3599 serve both as posolytes and as negolytes (such as vanadium), 3600 would greatly improve the stability of ORFBs. This would 3601 also allow the reservoirs to be rebalanced when the transfer 3602 of solvent by electro-osmosis becomes too high. All these 3603 constraints result in rather low overall energy yields (65\%) 3604 compared to other battery-based storage systems (90\%) but 3605 much better than the cycle associated with hydrogen: 3606 "electrolyzer, storage, fuel cell" whose total efficiency is around $360725 \%$. From the grid point of view, the real advantage of RFBs is 3608 that they decouple power and energy; they are the only storage 3609 systems that allow this.

3610 For the development and credibility of ORFBs, it is now 3611 necessary to rationalize the tests and studies carried out in the 3612 literature. Indeed, few tests are carried out under the same 3613 conditions and these are generally not representative of the 3614 final application. For example, it is important that systems 3615 should be tested at the highest possible concentrations. Systematic 3616 studies of cycling and calendar aging must be carried out. During 3617 cycling studies, it is important that the time of each cycle be 3618 representative of the RFB application (i.e., 4 to $12 \mathrm{~h}$ of energy 3619 storage). With regard to the flow rates used to carry out the 3620 measurements, very often they are disproportionately high to 3621 compensate for the high viscosity of the concentrated solu3622 tions. Moreover, depending on the cell geometry used, the flow 3623 rate does not have an important meaning. It would be more 3624 interesting to indicate the linear velocity of the fluid on the 3625 surface of the electrodes and to keep these values as low as 3626 possible to avoid that the pumps consume more energy than 3627 the energy stored in the battery.

\section{CONCLUDING REMARKS}

3628 Almost 170 years after the invention of the first operational 3629 rechargeable battery by G. Planté thanks to metal-based elec3630 trode materials, this tutorial review was intended to highlight 3631 several opportunities offered at the turn of the 21 st century by 3632 the reversible redox chemistry to promote innovative electro3633 chemical devices based on naturally abundant chemical 3634 elements (including biomass) while improving the environ3635 mental footprint. Indeed, we have shown in this article that the 3636 world has drastically changed since Plantés invention through 3637 the ongoing modernization of our societies but at the price of 3638 continuous consumption of both energy and nonrenewable 3639 materials at the expense of the environment. ${ }^{115}$ Changing the 3640 historic roadmap followed by our current energy engineering is nowadays mandatory in the general interest. In this context, 3641 global demand for batteries multiplies to store renewable energy, 3642 promote electromobility, and power the continued development 3643 of portable electronics and emerging technologies (mobile 3644 devices, IoT, AI, robotics, etc.). Seeking to develop innovative, 3645 efficient, and less polluting and energy consuming chemistries 3646 is therefore important today while jointly developing better 3647 recycling solutions (and second use).

3648

Depicted as a parallel and relatively recent research field in 3649 the history of rechargeable electrochemical storage systems, we 3650 have sequentially summarized the present state-of-the-art and 3651 highlighted important works that have contributed to the recent 3652 progress in organic-based rechargeable systems by covering all 3653 possible technologies and cell configurations to date. The 3654 as-obtained performance figures have been described without 3655 avoiding limitations. Some of the key performance metrics of 3656 organic electrode compounds such as specific energy, working 3657 potential, and cycling stability already look promising, and 3658 material design strategies specific to these metrics have been 3659 preliminarily established. Challenges remain for developing 3660 efficient storage solutions that simultaneously excel in all these 3661 metrics. It seems probable that the practical use of organics for 3662 the electrochemical storage in a near future could be through 3663 the development of ORFBs due to their attractive features of 3664 high power density and low cost for large-scale energy storage. 3665

In terms of solid electrode materials (for "sealed" batteries), 3666 electroactive molecules with simple structures such as simple 3667 quinones could offer the best balance between high discharge 3668 potential and high specific capacity, but stable cycling requires 3669 proper immobilization of these molecules which, until now, 3670 cannot be done without impacting potential and capacity. Two 3671 directions may directly counter this dilemma. The first is a 3672 chemical path revolving no-compromise immobilization. Rational 3673 connection of molecular building blocks complemented by 3674 suitable synthesis methods has been successful in preserving 3675 the full redox characteristics of active cores as seen in OEMs 3676 like PAQS and P(NDI2OD-T2). The second is to suit OEMs 3677 with solid electrolytes where dissolution is a nonissue. Solid- 3678 state batteries are emerging as an alternative to the traditional 3679 liquid electrolytes to enable safer and higher-energy batteries. 3680 The nondissolving nature of solid electrolytes is an additional 3681 perk specifically useful for organic batteries. In addition, p-type 3682 materials could offer access to molecular (metal-free) batteries 3683 as well as possible assemblies with n-type systems to promote 3684 dual-ion cells.

Continued evolution of organic batteries will inevitably 3686 involve a better understanding of involved electrochemical mecha- 3687 nisms (especially in the solid state) as well as the development of 3688 new OEMs, which is both a strong suit for organic compounds 3689 from the fundamental study point of view and a potential 3690 uncertainty for practical applications. Organic compounds are 3691 known to have good tuning knobs to manipulate the molecular 3692 structures and many subsequent properties, but complicated 3693 functionalization can drive up synthesis cost. Two currently 3694 practiced approaches could lead to a balance between per- 3695 formance and cost. One scours through structures that can be 3696 synthesized from cheap raw materials via simple, few-step, and 3697 high-yield reactions, the other prioritizes function and 3698 performance with no specific focus on minimizing cost. At an 3699 early stage of research and development, the former approach 3700 rarely affords high-performance candidates due to the limited 3701 options, while the latter could end up with prohibitive costs. 3702 Overtime, however, the building blocks found by the former and 3703 
3704 the design strategies established by the latter will merge the two 3705 approaches and strike the balance.

3706 Beyond the direct using of redox-active organics as the main 3707 active electrode compounds, other functionalities can be used 3708 in an electrochemical cell such as the hybridization of the 3709 conventional inorganic active materials with organic redox3710 active polymers giving rise to fast electrode kinetics. Thus let 3711 us recall that electrical properties of solid composite electrodes 3712 are critical to electrochemical performances, whatever the 3713 considered technology. This is especially the case for thick 3714 electrodes which are highly sought-after because they enable in 3715 principle simultaneous increase in volumetric and specific 3716 energy densities and decrease in price. It is estimated that 20 to $371780 \%$ of power losses in the case of a thick electrode originate 3718 from insufficient electronic conduction. ${ }^{458}$ The design of 3719 electronic conductivity at different scales is not easy, because it 3720 is currently based on the use of carbon-based conductive addi3721 tives that are difficult to disperse homogeneously on the one 3722 hand, and on the other hand, that renders difficult the manu3723 facturing of thick composite electrodes, because of the unstable 3724 nature of the electrode inks. In addition, the loss of intercluster 3725 and interparticle contacts due to volume variations of active 3726 materials is a major cause of the aging of battery electrodes. ${ }^{459}$ 3727 It is therefore mandatory to add polymeric binders (insulators), 3728 with the downside of a difficult compromise between electronic 3729 conductivity and mechanical properties of the composite 3730 electrode. ${ }^{40}$ The use of electron conducting binders or even 3731 redox binders ("smart binder") appears therefore quite 3732 attractive, since it would enable the design of electrodes with 3733 lower amount of carbon and binder additives. This objective 3734 was pursued in the particular case of $\mathrm{LiMPO}_{4}(\mathrm{M}=\mathrm{Fe}, \mathrm{Mn})$. 3735 As early as 2006, Goodenough and co-workers showed that 3736 carbon-coated $\mathrm{LiFePO}_{4}$ particles can be directly connected 3737 to the current collector using a matrix of p-doped PPy or 3738 PAni, ${ }^{461-463}$ while Gräetzel was actually the first to connect 3739 non-carbon-coated $\mathrm{LiMPO}_{4}(\mathrm{M}=\mathrm{Fe}, \mathrm{Mn})$ particles to the 3740 current collectors using molecular wires. ${ }^{464}$ In the latter, the 3741 Fermi levels of the organic matter and the active material need 3742 to be adjusted while the adsorbed wires should be percolated 3743 to allow for cross-surface charge. This approach was also recently 3744 investigated by Nishide and Oyaizu using nonconjugated radical 3745 polymers (radicals are densely introduced as the pendant groups) 3746 that were specifically designed for fast charging of $\mathrm{LiFePO}_{4}$ 3747 or $\mathrm{LiCoO}_{2}{ }^{465}$ Schougaard and co-workers also showed a 3748 poly(3,4-ethylenedioxythiophene) coating at the surface of bare $3749 \mathrm{LiFePO}_{4}$ particles advantageously replaced the carbon coating. ${ }^{466}$ 3750 Targeting the contemporary concerns of industry-relevant 3751 electrodes and especially thicker ones, Gaubicher and Blan3752 chard $^{467}$ used a short thiophene-based $\pi$-conjugated system as a 3753 molecular junction between uncoated $\mathrm{LiFePO}_{4}$ and multiwall 3754 carbon nanotubes within undensified $2 \mathrm{mAh} \mathrm{cm}^{-2}$ electrodes. 3755 Electrochemical and electrical properties of such electrodes 3756 demonstrate the key role of molecular junctions to reach power 3757 and cyclability performances comparable to those of carbon3758 coated $\mathrm{LiFePO}_{4}$ electrodes.

3759 To conclude, although this research activity is still in its 3760 infancy and much remains to be done to get attractive per3761 formances, redox-active organic compounds can be perceived 3762 today more than ever as an alternative chemical choice 3763 depending on the targeted application. We hope that this 3764 review will be a source of original and fresh ideas for our 3765 readers.

\section{ASSOCIATED CONTENT}

The Supporting Information is available free of charge at 3768 https://pubs.acs.org/doi/10.1021/acs.chemrev.9b00482.

3769

Evolution of the global EV stock by vehicle's category; 3770 estimated world LIB manufacturing capacity for 3771 automotive applications, International trade flows, and 3772 LIB cell manufacturing capacities in 2016; critical raw 3773 Materials in the EU, 2017; world mining industry 3774 production for materials used in LIBs in 2016; the 3775 concept of renewable organic battery; selection of redox- 3776 active units used in ORFBs. (PDF)

\section{AUTHOR INFORMATION}

\section{Corresponding Author}

Philippe Poizot - Université de Nantes, CNRS, Institut des Materiaux Jean Rouxel, IMN, F-44000 Nantes, France; ○ orcid.org/0000-0003-1865-4902; Email: philippe.poizot@3782 cnrs-imn.fr

Authors

Joël Gaubicher - Université de Nantes, CNRS, Institut des Materiaux Jean Rouxel, IMN, F-44000 Nantes, France; (1) orcid.org/0000-0001-6229-740X

Stéven Renault - Université de Nantes, CNRS, Institut des Materiaux Jean Rouxel, IMN, F-44000 Nantes, France

Lionel Dubois - Université Grenoble Alpes, CEA, 38000 Grenoble, France

$$
3783
$$

Yanliang Liang - Department of Electrical and Computer Engineering and Texas Center for Superconductivity, University 3793 of Houston, Houston, Texas 77204, United States; 3794 - orcid.org/0000-0001-6771-5172 3795

Yan Yao - Department of Electrical and Computer Engineering 3796 and Texas Center for Superconductivity, University of Houston, 3797 Houston, Texas 77204, United States; 이이.org/0000- 3798 0002-8785-5030

Complete contact information is available at: https://pubs.acs.org/10.1021/acs.chemrev.9b00482

\section{Notes}

The authors declare no competing financial interest.

Philippe Poizot was born in Crépy en Valois (France) in 1975. After a 3805 Master of Science in analytical chemistry and electrochemistry 3806 (University of Paris VI, 1998), he obtained his Ph.D. degree in 3807 Materials Science (2001) focused on "conversion reactions" under the 3808 guidance of J.-M. Tarascon at the University of Picardy Jules Verne 3809 (UPJV-LRCS) in Amiens, France. After a postdoctoral training with 3810 J. A. Switzer at the University of Missouri-Rolla (USA) to develop 3811 the electrodeposition of nanostructured materials, he came back to 3812 UPJV-LRCS as Associate Professor in 2002. In 2007, he proposed the 3813 concept of "renewable" batteries by promoting novel electrode 3814 materials based on redox-active organic compounds deriving from 3815 biomass. In 2012, he was appointed as full Professor at University of 3816 Nantes (Institut des Matériaux Jean Rouxel, IMN-CNRS, Nantes, 3817 France). His current research topics are mainly focused on 3818 rechargeable batteries, molecular electrochemistry, and the develop- 3819 ment of organic batteries in both aqueous and nonaqueous 3820 electrolytes. He is a recipient of the Bronze Medal of the French 3821 
3822 Society for Encouragement and Progress (2002) and was a Junior 3823 Fellow of the Institut Universitaire de France (2012-2017).

3824 Joël Gaubicher was born in Saint-Germain-en-Laye (France) in 1972. $3825 \mathrm{He}$ studied chemistry and materials engineering in Paris. After 3826 obtaining a Ph.D. from the P\&M Curie University of Paris, he joined 3827 the University of Waterloo, Canada, as a postdoctoral fellow with 3828 Prof. L. F. Nazar where he worked on phosphates and borates for $\mathrm{Li}$ 3829 ion battery. In 2001, he obtained a full CNRS researcher position at 3830 the Institut des Matériaux Jean Rouxel in Nantes and developed 3831 research programs dealing with $\mathrm{Li}$ metal polymer, Li-ion, $\mathrm{Na}$-ion, and $3832 \mathrm{Li} / \mathrm{S}$ batteries and supercapacitors. His main interests deal with solid 3833 state electrochemistry of inorganic and organic materials as well as 3834 synthesis and electrochemical mechanisms mainly through operando 3835 characterizations. He was the recipient of a CNRS award for his 3836 research in 2013. More recently, he has been developing aqueous 3837 battery and supercapacitor chemistries based on organic electroactive 3838 materials.

3839 Stéven Renault was born in Longjumeau (France) in 1980. He 3840 studied biochemistry and chemistry and obtained his Ph.D. in 3841 chemistry from Université de Rennes 1 in 2007 focused on drug 3842 design and medicinal chemistry. After working as a postdoctoral 3843 fellow in Amiens, he joined the group of Kristina Edström and Daniel 3844 Brandell in the Ångström Advanced Battery Center (Uppsala 3845 University, Sweden) as a researcher in 2011. Since 2018, he joined 3846 Universite de Nantes as an Associate Professor at the Institut des 3847 Matériaux Jean Rouxel. His research interests focus on $\mathrm{Li} / \mathrm{Na} / \mathrm{Mg}$ 3848 organic batteries and $\mathrm{Li}-$ air batteries.

3849 Lionel Dubois was born in Strasbourg (France) in 1973. He studied 3850 chemistry at "Ecole Nationale Superieure de Chimie de Paris". After 3851 obtaining a Ph.D in molecular chemistry from Grenoble Alps 3852 University he joined the University of Groningen (NL) as a 3853 postdoctoral fellow with Prof. B. L. Feringa where he worked on 3854 new iron based catalyst for alkane oxidation by molecular oxygen. 3855 Then he moved to the NMR laboratory of the French Atomic Energy 3856 Commission in Saclay under the direction of Dr. H. Desvaux on the 3857 development of laser polarized xenon NMR. In 2004, he obtained an 3858 assistant professor position at the University Institute of Technology 3859 of Castres (France), before being recruited as researcher at the French 3860 Atomic Energy Commission (CEA) in Grenoble in 2005. He 3861 developed a program related to the use of molecular chemistry for 3862 communication and information technologies and since 2011 has 3863 been working on the use of molecular compounds for energy storage. 3864 In 2017 he took the head of the "Molecular Architecture Conception 3865 and Electronic Process" laboratory of the CEA-Grenoble. His main 3866 interest deals with coordination chemistry, synthesis of new ligands, 3867 graphene chemistry, solution electrochemistry, and diverse spectros3868 copies (NMR, EPR) or operando experiments for energy applications, 3869 mainly organic batteries and supercapacitors.

3870 Yanliang Liang was born in Guangzhou (China) and studied materials 3871 physics and chemistry at Nankai University (China). He conducted 3872 his Ph.D. research on organic batteries and photovoltaics under the 3873 supervision of Prof. Jun Chen at Nankai University. After receiving his 3874 Ph.D. in 2012, he worked as a postdoctoral fellow with Prof. Yan Yao 3875 at University of Houston on low-cost safe battery technologies. He is 3876 now a Research Assistant Professor at University of Houston focusing 3877 on energy storage materials and next-generation battery develop3878 ments.

3879 Yan Yao was born in Nantong (China) and studied materials science 3880 in Fudan University (China). He conducted his Ph.D. research on 3881 organic photovoltaics under the supervision of Prof. Yang Yang at 3882 UCLA. He served as a senior scientist at Polyera Corporation from
2008 to 2010 and a postdoctoral fellow at Stanford University under 3883 the supervision of Prof. Yi Cui from 2010 to 2012. He joined the 3884 University of Houston as Assistant Professor of Electrical and 3885 Computer Engineering in 2012 and is now Associate Professor. His 3886 research interests focus on developing new materials for $\mathrm{Li}$ ion 3887 batteries and post-Li battery chemistries such as organic, $\mathrm{Na}, \mathrm{Mg}$, and 3888 solid-state batteries.

3889

\section{ACKNOWLEDGMENTS}

3890

The authors express their sincere gratitude to economist col- 3891 leagues E. Hache (IFP Énergies Nouvelles, Rueil-Malmaison, 3892 France) and P. Menanteau (GAEL, Grenoble, France) for 3893 helpful comments and discussions on this manuscript. The 3894 authors are also grateful to J. Zhang and X. Wang (UH, Texas, 3895 USA) for the help on Table 2 as well as to F. Dolhem (LG2A, 3896 Amiens, France) for insightful comments. The authors are 3897 thankful to P. Berrezig and C. Doutriaux for helpful assistance 3898 in editing the manuscript and the graphical abstract, 3899 respectively.

3900

\section{REFERENCES}

3901

(1) Jain, A.; Ong, S. P.; Hautier, G.; Chen, W.; Richards, W. D.; 3902 Dacek, S.; Cholia, S.; Gunter, D.; Skinner, D.; Ceder, G.; et al. 3903 Commentary: The Materials Project: A materials genome approach to 3904 accelerating materials innovation. APL Mater. 2013, 1, 011002.

(2) Linden's handbook of batteries, 4th ed.; Reddy, T. B., Linden, D., 3906 Eds.; McGraw-Hill: New York, NY, 2011; ISBN 978-0-07-162421-3. 3907

(3) Pavlov, D. D. Lead-acid batteries: science and technology: a 3908 handbook of lead-acid battery technology and its influence on the product; 3909 2017; ISBN 978-0-444-59552-2.

3910

(4) Young, K.-H. Research in Nickel/Metal Hydride Batteries 2016. 3911 Batteries 2016, 2, 31.

(5) Alotto, P.; Guarnieri, M.; Moro, F. Redox flow batteries for the 3913 storage of renewable energy: A review. Renewable Sustainable Energy 3914 Rev. 2014, 29, 325-335. 3915

(6) Sum, E.; Skyllas-Kazacos, M. A study of the V(II)/V(III) redox 3916 couple for redox flow cell applications. J. Power Sources 1985, 15, 3917 179-190.

3918

(7) Sum, E.; Rychcik, M.; Skyllas-kazacos, M. Investigation of the 3919 $\mathrm{V}(\mathrm{V}) / \mathrm{V}(\mathrm{IV})$ system for use in the positive half-cell of a redox battery. 3920 J. Power Sources 1985, 16, 85-95.

3921

(8) Rychcik, M.; Skyllas-Kazacos, M. Characteristics of a new all- 3922 vanadium redox flow battery. J. Power Sources 1988, 22, 59-67. 3923

(9) Liang, Y.; Tao, Z.; Chen, J. Organic Electrode Materials for 3924 Rechargeable Lithium Batteries. Adv. Energy Mater. 2012, 2, 742-769. 3925

(10) Janoschka, T.; Hager, M. D.; Schubert, U. S. Powering up the 3926 Future: Radical Polymers for Battery Applications. Adv. Mater. 2012, 3927 24, 6397-6409.

(11) Song, Z.; Zhou, H. Towards sustainable and versatile energy 3929 storage devices: an overview of organic electrode materials. Energy 3930 Environ. Sci. 2013, 6, 2280.

3931

(12) Gracia, R.; Mecerreyes, D. Polymers with redox properties: 3932 materials for batteries, biosensors and more. Polym. Chem. 2013, 4, 3933 2206.

3934

(13) Zhu, Z.; Chen, J. Review-Advanced Carbon-Supported 3935 Organic Electrode Materials for Lithium (Sodium)-Ion Batteries. J. 3936 Electrochem. Soc. 2015, 162, A2393-A2405.

3937

(14) Häupler, B.; Wild, A.; Schubert, U. S. Carbonyls: Powerful 3938 Organic Materials for Secondary Batteries. Adv. Energy Mater. 2015, 5, 3939 1402034.

3940

(15) Gong, K.; Fang, Q.; Gu, S.; Li, S. F. Y.; Yan, Y. Nonaqueous 3941 redox-flow batteries: organic solvents, supporting electrolytes, and 3942 redox pairs. Energy Environ. Sci. 2015, 8, 3515-3530.

(16) Oltean, V.-A.; Renault, S.; Valvo, M.; Brandell, D. Sustainable 3944 Materials for Sustainable Energy Storage: Organic Na Electrodes. 3945 Materials 2016, 9, 142. 
3947 (17) Casado, N.; Hernández, G.; Sardon, H.; Mecerreyes, D. 3948 Current trends in redox polymers for energy and medicine. Prog. 3949 Polym. Sci. 2016, 52, 107-135.

3950 (18) Muench, S.; Wild, A.; Friebe, C.; Häupler, B.; Janoschka, T.; 3951 Schubert, U. S. Polymer-Based Organic Batteries. Chem. Rev. 2016, 3952 116, 9438-9484.

3953 (19) Miroshnikov, M.; Divya, K. P.; Babu, G.; Meiyazhagan, A.; 3954 Reddy Arava, L. M.; Ajayan, P. M.; John, G. Power from nature: 3955 designing green battery materials from electroactive quinone 3956 derivatives and organic polymers. J. Mater. Chem. A 2016, 4, 3957 12370-12386.

3958 (20) Winsberg, J.; Hagemann, T.; Janoschka, T.; Hager, M. D.; 3959 Schubert, U. S. Redox-Flow Batteries: From Metals to Organic 3960 Redox-Active Materials. Angew. Chem., Int. Ed. 2017, 56, 686-711. 3961 (21) Schon, T. B.; McAllister, B. T.; Li, P.-F.; Seferos, D. S. The rise 3962 of organic electrode materials for energy storage. Chem. Soc. Rev. 3963 2016, 45, 6345-6404.

3964 (22) Xie, J.; Zhang, Q. Recent progress in rechargeable lithium 3965 batteries with organic materials as promising electrodes. J. Mater. 3966 Chem. A 2016, 4, 7091-7106.

3967 (23) Kowalski, J. A.; Su, L.; Milshtein, J. D.; Brushett, F. R. Recent 3968 advances in molecular engineering of redox active organic molecules 3969 for nonaqueous flow batteries. Curr. Opin. Chem. Eng. 2016, 13, 45397052.

3971 (24) Son, E. J.; Kim, J. H.; Kim, K.; Park, C. B. Quinone and its 3972 derivatives for energy harvesting and storage materials. J. Mater. Chem. 3973 A 2016, 4, 11179-11202.

3974 (25) Zhao, Q.; Guo, C.; Lu, Y.; Liu, L.; Liang, J.; Chen, J. 3975 Rechargeable Lithium Batteries with Electrodes of Small Organic 3976 Carbonyl Salts and Advanced Electrolytes. Ind. Eng. Chem. Res. 2016, 3977 55, 5795-5804.

3978 (26) Zhang, Y.; Wang, J.; Riduan, S. N. Strategies toward improving 3979 the performance of organic electrodes in rechargeable lithium 3980 (sodium) batteries. J. Mater. Chem. A 2016, 4, 14902-14914.

3981 (27) Yang, G.; Zhang, Y.; Huang, Y.; Shakir, M. I.; Xu, Y. 3982 Incorporating conjugated carbonyl compounds into carbon nanoma3983 terials as electrode materials for electrochemical energy storage. Phys. 3984 Chem. Chem. Phys. 2016, 18, 31361-31377.

3985 (28) Zhao, Q.; Lu, Y.; Chen, J. Advanced Organic Electrode 3986 Materials for Rechargeable Sodium-Ion Batteries. Adv. Energy Mater. 3987 2017, 7, 1601792.

3988 (29) Kim, K. C. Design Strategies for Promising Organic Positive 3989 Electrodes in Lithium-Ion Batteries: Quinones and Carbon Materials. 3990 Ind. Eng. Chem. Res. 2017, 56, 12009-12023.

3991 (30) Xie, J.; Gu, P.; Zhang, Q. Nanostructured Conjugated 3992 Polymers: Toward High-Performance Organic Electrodes for 3993 Rechargeable Batteries. ACS Energy Lett. 2017, 2, 1985-1996.

3994 (31) Zhao, Q.; Zhu, Z.; Chen, J. Molecular Engineering with 3995 Organic Carbonyl Electrode Materials for Advanced Stationary and 3996 Redox Flow Rechargeable Batteries. Adv. Mater. 2017, 29, 1607007. 3997 (32) Friebe, C.; Schubert, U. S. High-Power-Density Organic 3998 Radical Batteries. Top. Curr. Chem. 2017, 375, DOI: 10.1007/ 3999 s41061-017-0103-1

4000 (33) Wu, Y.; Zeng, R.; Nan, J.; Shu, D.; Qiu, Y.; Chou, S.-L. 4001 Quinone Electrode Materials for Rechargeable Lithium/Sodium Ion 4002 Batteries. Adv. Energy Mater. 2017, 7, 1700278.

4003 (34) Leung, P.; Shah, A. A.; Sanz, L.; Flox, C.; Morante, J. R.; Xu, 4004 Q.; Mohamed, M. R.; Ponce de León, C.; Walsh, F. C. Recent 4005 developments in organic redox flow batteries: A critical review. J. 4006 Power Sources 2017, 360, 243-283.

4007 (35) Wei, X.; Pan, W.; Duan, W.; Hollas, A.; Yang, Z.; Li, B.; Nie, Z.; 4008 Liu, J.; Reed, D.; Wang, W.; et al. Materials and Systems for Organic 4009 Redox Flow Batteries: Status and Challenges. ACS Energy Lett. 2017, 4010 2, 2187-2204.

4011 (36) Poizot, P.; Dolhem, F.; Gaubicher, J. Progress in all-organic 4012 rechargeable batteries using cationic and anionic configurations: 4013 Toward low-cost and greener storage solutions? Curr. Opin. 4014 Electrochem. 2018, 9, 70-80.
(37) Amin, K.; Mao, L.; Wei, Z. Recent Progress in Polymeric 4015 Carbonyl-Based Electrode Materials for Lithium and Sodium Ion 4016 Batteries. Macromol. Rapid Commun. 2019, 40, 1800565.

(38) Lu, Y.; Zhang, Q.; Li, L.; Niu, Z.; Chen, J. Design Strategies 4018 toward Enhancing the Performance of Organic Electrode Materials in 4019 Metal-Ion Batteries. Chem. 2018, 4, 2786-2813. 4020

(39) Lee, S.; Kwon, G.; Ku, K.; Yoon, K.; Jung, S.-K.; Lim, H.-D.; 4021 Kang, K. Recent Progress in Organic Electrodes for $\mathrm{Li}$ and $\mathrm{Na} 4022$ Rechargeable Batteries. Adv. Mater. 2018, 30, 1704682.

(40) Xu, Y.; Zhou, M.; Lei, Y. Organic materials for rechargeable 4024 sodium-ion batteries. Mater. Today 2018, 21, 60-78. 4025

(41) Wang, H.; Zhang, X. Organic Carbonyl Compounds for 4026 Sodium-Ion Batteries: Recent Progress and Future Perspectives. 4027 Chem. - Eur. J. 2018, 24, 18235-18245.

4028

(42) Liang, Y.; Yao, Y. Positioning Organic Electrode Materials in 4029 the Battery Landscape. Joule 2018, 2, 1690-1706. 4030

(43) Bhosale, M. E.; Chae, S.; Kim, J. M.; Choi, J.-Y. Organic small 4031 molecules and polymers as an electrode material for rechargeable 4032 lithium ion batteries. J. Mater. Chem. A 2018, 6, 19885-19911. 4033

(44) Armstrong, C. G.; Toghill, K. E. Stability of molecular radicals 4034 in organic non-aqueous redox flow batteries: A mini review. 4035 Electrochem. Commun. 2018, 91, 19-24.

(45) Ding, Y.; Zhang, C.; Zhang, L.; Zhou, Y.; Yu, G. Molecular 4037 engineering of organic electroactive materials for redox flow batteries. 4038 Chem. Soc. Rev. 2018, 47, 69-103.

(46) Zhao, Q.; Whittaker, A.; Zhao, X. Polymer Electrode Materials 4040 for Sodium-ion Batteries. Materials 2018, 11, 2567.

(47) Mauger, A.; Julien, C.; Paolella, A.; Armand, M.; Zaghib, K. 4042 Recent Progress on Organic Electrodes Materials for Rechargeable 4043 Batteries and Supercapacitors. Materials 2019, 12, 1770.

(48) Xie, J.; Zhang, Q. Recent Progress in Multivalent Metal (Mg, 4045 $\mathrm{Zn}, \mathrm{Ca}$, and Al) and Metal-Ion Rechargeable Batteries with Organic 4046 Materials as Promising Electrodes. Small 2019, 15, 1805061.

(49) Jia, X.; Ge, Y.; Shao, L.; Wang, C.; Wallace, G. G. Tunable 4048 Conducting Polymers: Toward Sustainable and Versatile Batteries. 4049 ACS Sustainable Chem. Eng. 2019, 7, 14321-14340. 4050

(50) Heiska, J.; Nisula, M.; Karppinen, M. Organic electrode 4051 materials with solid-state battery technology. J. Mater. Chem. A 2019, 4052 7, 18735-18758. 4053

(51) Friebe, C.; Lex-Balducci, A.; Schubert, U. S. Sustainable Energy 4054 Storage: Recent Trends and Developments toward Fully Organic 4055 Batteries. ChemSusChem 2019, 12, 4093-4115. 4056

(52) Wu, Z.; Xie, J.; Xu, Z. J.; Zhang, S.; Zhang, Q. Recent progress 4057 in metal-organic polymers as promising electrodes for lithium/ 4058 sodium rechargeable batteries. J. Mater. Chem. A 2019, 7, 4259-4290. 4059

(53) Oubaha, H.; Gohy, J.; Melinte, S. Carbonyl-Based $\pi$ - 4060 Conjugated Materials: From Synthesis to Applications in Lithium- 4061 Ion Batteries. ChemPlusChem 2019, 84, 1179-1214.

4062

(54) Han, C.; Li, H.; Shi, R.; Zhang, T.; Tong, J.; Li, J.; Li, B. 4063 Organic quinones towards advanced electrochemical energy storage: 4064 recent advances and challenges. J. Mater. Chem. A 2019, 7, 23378- 4065 23415 .

(55) Peng, H.; Yu, Q.; Wang, S.; Kim, J.; Rowan, A. E.; Nanjundan, 4067 A. K.; Yamauchi, Y.; Yu, J. Molecular Design Strategies for 4068 Electrochemical Behavior of Aromatic Carbonyl Compounds in 4069 Organic and Aqueous Electrolytes. Adv. Sci. 2019, 6, 1900431. 4070

(56) Luo, J.; Hu, B.; Hu, M.; Zhao, Y.; Liu, T. L. Status and 4071 Prospects of Organic Redox Flow Batteries toward Sustainable Energy 4072 Storage. ACS Energy Lett. 2019, 4, 2220-2240. 4073

(57) Cao, X.; Liu, J.; Zhu, L.; Xie, L. Polymer Electrode Materials for 4074 High-Performance Lithium/Sodium-Ion Batteries: A Review. Energy 4075 Technol. 2019, 7, 1800759.

(58) Zhu, L.; Ding, G.; Xie, L.; Cao, X.; Liu, J.; Lei, X.; Ma, J. 4077 Conjugated Carbonyl Compounds as High-Performance Cathode 4078 Materials for Rechargeable Batteries. Chem. Mater. 2019, 31, 85824079

(59) Novák, P.; Müller, K.; Santhanam, K. S. V.; Haas, O. 4080 Electrochemically Active Polymers for Rechargeable Batteries. Chem. 4081 Rev. 1997, 97, 207-282. 
4083 (60) Ito, T.; Shirakawa, H.; Ikeda, S. Simultaneous polymerization 4084 and formation of polyacetylene film on the surface of concentrated 4085 soluble Ziegler-type catalyst solution. J. Polym. Sci., Polym. Chem. Ed. 4086 1974, 12, 11-20.

4087 (61) Chiang, C. K.; Fincher, C. R.; Park, Y. W.; Heeger, A. J.; 4088 Shirakawa, H.; Louis, E. J.; Gau, S. C.; MacDiarmid, A. G. Electrical 4089 Conductivity in Doped Polyacetylene. Phys. Rev. Lett. 1977, 39, 4090 1098-1101.

4091 (62) Shirakawa, H.; Louis, E. J.; MacDiarmid, A. G.; Chiang, C. K.; 4092 Heeger, A. J. Synthesis of electrically conducting organic polymers: 4093 halogen derivatives of polyacetylene, $(\mathrm{CH})_{\mathrm{x}}$. J. Chem. Soc., Chem. 4094 Commun. 1977, 578

4095 (63) Chiang, C. K.; Gau, S. C.; Fincher, C. R.; Park, Y. W.; 4096 MacDiarmid, A. G.; Heeger, A. J. Polyacetylene, $(\mathrm{CH})_{x}: n$-type and 4097 -type doping and compensation. Appl. Phys. Lett. 1978, 33, 18-20. 4098 (64) Shirakawa, H. Synthesis and characterization of highly 4099 conducting polyacetylene. Synth. Met. 1995, 69, 3-8.

4100 (65) Nigrey, P. J.; MacInnes, D., Jr.; Nairns, D. P.; MacDiarmid, A. 4101 G.; Heeger, A. J. Lightweight Rechargeable Storage Batteries Using 4102 Polyacetylene, $(\mathrm{CH})_{\mathrm{x}}$ as the Cathode-Active. J. Electrochem. Soc. 1981, 4103128,1651

4104 (66) Ĉaja, J. A.; Kaner, R. B.; MacDiarmid, A. G. Rechargeable 4105 Battery Employing a Reduced Polyacetylene Anode and a Titanium 4106 Disulfide Cathode. J. Electrochem. Soc. 1984, 131, 2744.

4107 (67) Naegele, D.; Bittihn, R. Electrically conductive polymers as 4108 rechargeable battery electrodes. Solid State Ionics 1988, 28-30, 9834109989.

4110 (68) Matsunaga, T.; Daifuku, H.; Nakajima, T.; Kawagoe, T. 4111 Development of polyaniline-lithium secondary battery. Polym. Adv. 4112 Technol. 1990, 1, 33-39.

4113 (69) Miller, J. S. Conducting polymers-materials of commerce. Adv. 4114 Mater. 1993, 5, 671-676.

4115 (70) Liu, M. Electrochemical Properties of Organic Disulfide/ 4116 Thiolate Redox Couples. J. Electrochem. Soc. 1989, 136, 2570.

4117 (71) Liu, M. Novel Solid Redox Polymerization Electrodes - All4118 Solid-State, Thin-Film, Rechargeable Lithium Batteries. J. Electrochem. 4119 Soc. 1991, 138, 1891.

4120 (72) Liu, M. Novel Solid Redox Polymerization Electrodes 4121 Electrochemical Properties. J. Electrochem. Soc. 1991, 138, 1896.

4122 (73) Li, Y.; Zhan, H.; Kong, L.; Zhan, C.; Zhou, Y. Electrochemical 4123 properties of $\mathrm{PABTH}$ as cathode materials for rechargeable lithium 4124 battery. Electrochem. Commun. 2007, 9, 1217-1221.

4125 (74) Preefer, M. B.; Oschmann, B.; Hawker, C. J.; Seshadri, R.; 4126 Wudl, F. High Sulfur Content Material with Stable Cycling in 4127 Lithium-Sulfur Batteries. Angew. Chem., Int. Ed. 2017, 56, 15118412815122 .

4129 (75) Nakahara, K.; Iwasa, S.; Satoh, M.; Morioka, Y.; Iriyama, J.; 4130 Suguro, M.; Hasegawa, E. Rechargeable batteries with organic radical 4131 cathodes. Chem. Phys. Lett. 2002, 359, 351-354.

4132 (76) Anastas, P. T.; Zimmerman, J. B. Innovations in Green Chemistry 4133 and Green Engineering Selected Entries from the Encyclopedia of 4134 Sustainability Science and Technology; Springer: New York, NY, 4135 2013; ISBN 978-1-4614-5817-3.

4136 (77) Nakahara, K.; Oyaizu, K.; Nishide, H. Organic Radical Battery 4137 Approaching Practical Use. Chem. Lett. 2011, 40, 222-227.

4138 (78) Iwasa, S.; Yasui, M.; Nishi, T.; Nakano, K. Development of 4139 Organic Radical Battery. NEC Technol. J. 2012, 7, 102-106.

4140 (79) Ravet, N.; Michot, C.; Armand, M. Novel cathode materials 4141 based on organic couples for lithium batteries. Mater. Res. Soc. Symp. 4142 Proc. 1997, 496, 263-273.

4143 (80) Han, X.; Chang, C.; Yuan, L.; Sun, T.; Sun, J. Aromatic 4144 Carbonyl Derivative Polymers as High-Performance Li-Ion Storage 4145 Materials. Adv. Mater. 2007, 19, 1616-1621.

4146 (81) Xiang, J.; Chang, C.; Li, M.; Wu, S.; Yuan, L.; Sun, J. A Novel 4147 Coordination Polymer as Positive Electrode Material for Lithium Ion 4148 Battery. Cryst. Growth Des. 2008, 8, 280-282.

4149 (82) Chen, H.; Armand, M.; Demailly, G.; Dolhem, F.; Poizot, P.; 4150 Tarascon, J.-M. From Biomass to a Renewable $\mathrm{Li}_{\mathrm{x}} \mathrm{C}_{6} \mathrm{O}_{6}$ Organic
Electrode for Sustainable Li-Ion Batteries. ChemSusChem 2008, 1, 4151 348-355.

(83) Chen, H.; Armand, M.; Courty, M.; Jiang, M.; Grey, C. P.; 4153 Dolhem, F.; Tarascon, J.-M.; Poizot, P. Lithium Salt of Tetrahydrox- 4154 ybenzoquinone: Toward the Development of a Sustainable Li-Ion 4155 Battery. J. Am. Chem. Soc. 2009, 131, 8984-8988. 4156

(84) Poizot, P.; Dolhem, F. Clean energy new deal for a sustainable 4157 world: from non- $\mathrm{CO}_{2}$ generating energy sources to greener 4158 electrochemical storage devices. Energy Environ. Sci. 2011, 4, 2003.4159

(85) Xu, Y.; Wen, Y.; Cheng, J.; Cao, G.; Yang, Y. Study on a single 4160 flow acid Cd-chloranil battery. Electrochem. Commun. 2009, 11, 4161 $1422-1424$.

4162

(86) Li, Z.; Li, S.; Liu, S.; Huang, K.; Fang, D.; Wang, F.; Peng, S. 4163 Electrochemical Properties of an All-Organic Redox Flow Battery 4164 Using 2,2,6,6-Tetramethyl-1-Piperidinyloxy and N-Methylphthali- 4165 mide. Electrochem. Solid-State Lett. 2011, 14, A171.

4166

(87) Anjos, D. M.; McDonough, J. K.; Perre, E.; Brown, G. M.; 4167 Overbury, S. H.; Gogotsi, Y.; Presser, V. Pseudocapacitance and 4168 performance stability of quinone-coated carbon onions. Nano Energy 4169 2013, 2, 702-712.

4170

(88) Assresahegn, B. D.; Brousse, T.; Bélanger, D. Advances on the 4171 use of diazonium chemistry for functionalization of materials used in 4172 energy storage systems. Carbon 2015, 92, 362-381. 4173

(89) Brousse, T.; Cougnon, C.; Bélanger, D. Grafting of Quinones 4174 on Carbons as Active Electrode Materials in Electrochemical 4175 Capacitors. J. Braz. Chem. Soc. 2018, 29, 989997.

(90) Zeiger, M.; Weingarth, D.; Presser, V. Quinone-Decorated 4177 Onion-Like Carbon/Carbon Fiber Hybrid Electrodes for High-Rate 4178 Supercapacitor Applications. ChemElectroChem 2015, 2, 1117-1127. 4179

(91) Madec, L.; Humbert, B.; Lestriez, B.; Brousse, T.; Cougnon, C.; 4180 Guyomard, D.; Gaubicher, J. Covalent vs. non-covalent redox 4181 functionalization of $\mathrm{C}-\mathrm{LiFePO}_{4}$ based electrodes. J. Power Sources 4182 2013, 232, 246-253.

(92) Anothumakkool, B.; Taberna, P.-L.; Daffos, B.; Simon, P.; 4184 Sayed-Ahmad-Baraza, Y.; Ewels, C.; Brousse, T.; Gaubicher, J. 4185 Improved electro-grafting of nitropyrene onto onion-like carbon via 4186 in situ electrochemical reduction and polymerization: tailoring redox 4187 energy density of the supercapacitor positive electrode. J. Mater. 4188 Chem. A 2017, 5, 1488-1494.

4189

(93) Madec, L.; Bouvrée, A.; Blanchard, P.; Cougnon, C.; Brousse, 4190 T.; Lestriez, B.; Guyomard, D.; Gaubicher, J. In situ redox 4191 functionalization of composite electrodes for high power-high energy 4192 electrochemical storage systems via a non-covalent approach. Energy 4193 Environ. Sci. 2012, 5, 5379-5386.

4194

(94) Madec, L.; Robert, D.; Moreau, P.; Bayle-Guillemaud, P.; 4195 Guyomard, D.; Gaubicher, J. Synergistic Effect in Carbon Coated 4196 $\mathrm{LiFePO}_{4}$ for High Yield Spontaneous Grafting of Diazonium Salt. 4197 Structural Examination at the Grain Agglomerate Scale. J. Am. Chem. 4198 Soc. 2013, 135, 11614-11622.

4199

(95) Roldán, S.; Blanco, C.; Granda, M.; Menéndez, R.; Santamaría, 4200 R. Towards a Further Generation of High-Energy Carbon-Based 4201 Capacitors by Using Redox-Active Electrolytes. Angew. Chem., Int. Ed. 4202 2011, 50, 1699-1701.

(96) Gorska, B.; Frackowiak, E.; Beguin, F. Redox active electrolytes 4204 in carbon/carbon electrochemical capacitors. Curr. Opin. Electrochem. 4205 2018, 9, 95-105.

(97) Lebègue, E.; Brousse, T.; Gaubicher, J.; Retoux, R.; Cougnon, 4207 C. Toward fully organic rechargeable charge storage devices based on 4208 carbon electrodes grafted with redox molecules. J. Mater. Chem. A 4209 2014, 2, 8599-8602.

4210

(98) Naoi, K.; Morita, M. Advanced Polymers as Active Materials 4211 and Electrolytes for Electrochemical Capacitors and Hybrid Capacitor 4212 Systems. Electrochem. Soc. Interface 2008, 17, 44-48.

(99) Lang, A. W.; Ponder, J. F.; Österholm, A. M.; Kennard, N. J.; 4214 Bulloch, R. H.; Reynolds, J. R. Flexible, aqueous-electrolyte 4215 supercapacitors based on water-processable dioxythiophene poly- 4216 mer/carbon nanotube textile electrodes. J. Mater. Chem. A 2017, 5, 4217 23887-23897. 
4219 (100) Kurra, N.; Hota, M. K.; Alshareef, H. N. Conducting polymer 4220 micro-supercapacitors for flexible energy storage and Ac line-filtering. 4221 Nano Energy 2015, 13, 500-508.

4222 (101) Jeżowski, P.; Crosnier, O.; Deunf, E.; Poizot, P.; Béguin, F.; 4223 Brousse, T. Safe and recyclable lithium-ion capacitors using sacrificial 4224 organic lithium salt. Nat. Mater. 2018, 17, 167-173.

4225 (102) Anothumakkool, B.; Wiemers-Meyer, S.; Guyomard, D.; 4226 Winter, M.; Brousse, T.; Gaubicher, J. Cascade-Type Prelithiation 4227 Approach for Li-Ion Capacitors. Adv. Energy Mater. 2019, 9, 1900078. 4228 (103) Chen, X.; Wang, H.; Yi, H.; Wang, X.; Yan, X.; Guo, Z. 4229 Anthraquinone on Porous Carbon Nanotubes with Improved 4230 Supercapacitor Performance. J. Phys. Chem. C 2014, 118, 8262-8270. 4231 (104) Lee, M.; Hong, J.; Kim, H.; Lim, H.-D.; Cho, S. B.; Kang, K.; 4232 Park, C. B. Organic Nanohybrids for Fast and Sustainable Energy 4233 Storage. Adv. Mater. 2014, 26, 2558-2565.

4234 (105) Liu, T.; Kim, K. C.; Lee, B.; Chen, Z.; Noda, S.; Jang, S. S.; 4235 Lee, S. W. Self-polymerized dopamine as an organic cathode for Li4236 and Na-ion batteries. Energy Environ. Sci. 2017, 10, 205-215.

4237 (106) Schwab, K. The fourth industrial revolution, First U.S. ed.; 4238 Crown Business: New York, 2017; ISBN 978-1-944835-00-2.

4239 (107) Yli-Huumo, J.; Ko, D.; Choi, S.; Park, S.; Smolander, K. 4240 Where Is Current Research on Blockchain Technology?-A System4241 atic Review. PLoS One 2016, 11, e0163477.

4242 (108) Alam, M. S.; Roychowdhury, A.; Islam, K. K.; Huq, A. M. Z. A 4243 revisited model for the physical quality of life (PQL) as a function of 4244 electrical energy consumption. Energy 1998, 23, 791-801.

4245 (109) Antal, M.; Van Den Bergh, J. C. J. M. Green growth and 4246 climate change: conceptual and empirical considerations. Clim. Policy 4247 2016, 16, 165-177.

4248 (110) Global Warming $1.5^{\circ} \mathrm{C}$ - IPCC special report 2019, Available 4249 http://www.ipcc.ch/report/sr15/, last accessed June 2019.

4250 (111) World Population Prospects 2019, Available https:// 4251 population.un.org/wpp/, last accessed June 2019.

4252 (112) Larcher, D.; Tarascon, J.-M. Towards greener and more 4253 sustainable batteries for electrical energy storage. Nat. Chem. 2015, 7, $4254 \quad 19-29$.

4255 (113) Pichert, D.; Katsikopoulos, K. V. Green defaults: Information 4256 presentation and pro-environmental behaviour. J. Environ. Psychol. 4257 2008, 28, 63-73.

4258 (114) d'Adda, G.; Capraro, V.; Tavoni, M. Push, don't nudge: 4259 Behavioral spillovers and policy instruments. Econ. Lett. 2017, 154, $426092-95$

4261 (115) Dong, K.; Hochman, G.; Zhang, Y.; Sun, R.; Li, H.; Liao, H. $4262 \mathrm{CO}_{2}$ emissions, economic and population growth, and renewable 4263 energy: Empirical evidence across regions. Energy Econ 2018, 75, 4264 180-192.

4265 (116) Coumou, D.; Rahmstorf, S. A decade of weather extremes. 4266 Nat. Clim. Change 2012, 2, 491-496.

4267 (117) Geissdoerfer, M.; Savaget, P.; Bocken, N. M. P.; Hultink, E. J. 4268 The Circular Economy - A new sustainability paradigm? J. Cleaner 4269 Prod. 2017, 143, 757-768.

4270 (118) Carayannis, E. G.; Barth, T. D.; Campbell, D. F. The 4271 Quintuple Helix innovation model: global warming as a challenge and 4272 driver for innovation. J. Innov. Entrep. 2012, 1, 2.

4273 (119) Ghisellini, P.; Cialani, C.; Ulgiati, S. A review on circular 4274 economy: the expected transition to a balanced interplay of 4275 environmental and economic systems. J. Cleaner Prod. 2016, 114, 4276 11-32.

4277 (120) Norhasyima, R. S.; Mahlia, T. M. I. Advances in $\mathrm{CO}_{2}$ 4278 utilization technology: A patent landscape review. J. CO2 Util. 4279 2018, 26, 323-335.

4280 (121) Chu, S.; Majumdar, A. Opportunities and challenges for a 4281 sustainable energy future. Nature 2012, 488, 294-303.

4282 (122) Liserre, M.; Sauter, T.; Hung, J. Future Energy Systems: 4283 Integrating Renewable Energy Sources into the Smart Power Grid 4284 Through Industrial Electronics. IEEE Ind. Electron. Mag. 2010, 4, 18428537.
(123) European Directive 2009/28/EC - https://eur-lex.europa.eu/ 4286 legal-content/EN/ALL/?uri=celex\%3A32009L0028, last accessed 4287 June 2019.

(124) Decarbonization Wedges - ANCRE report 2015, Available 4289 https://www.allianceenergie.fr/wp-content/uploads/2017/06/ 4290 Decarbonization_Wedges_report_0.pdf, last accessed June 2019. 4291

(125) Deep Decarbonization Pathways Project (DDPP). Available 4292 http://deepdecarbonization.org/, last accessed June 2019.

(126) Mathy, S.; Menanteau, P.; Criqui, P. After the Paris 4294 Agreement: Measuring the Global Decarbonization Wedges From 4295 National Energy Scenarios. Ecol. Econ. 2018, 150, 273-289. 4296

(127) Aghaei, J.; Alizadeh, M.-I. Demand response in smart 4297 electricity grids equipped with renewable energy sources: A review. 4298 Renewable Sustainable Energy Rev. 2013, 18, 64-72.

4299

(128) Gelazanskas, L.; Gamage, K. A. A. Demand side management 4300 in smart grid: A review and proposals for future direction. Sustain. 4301 Cities Soc. 2014, 11, 22-30.

4302

(129) Bedi, G.; Venayagamoorthy, G. K.; Singh, R.; Brooks, R. R.; 4303 Wang, K.-C. Review of Internet of Things (IoT) in Electric Power 4304 and Energy Systems. IEEE Internet Things J. 2018, 5, 847-870. 4305

(130) Dunn, B.; Kamath, H.; Tarascon, J.-M. Electrical Energy 4306 Storage for the Grid: A Battery of Choices. Science 2011, 334, 928- 4307 935.

(131) Zhang, C.; Wei, Y.-L.; Cao, P.-F.; Lin, M.-C. Energy storage 4309 system: Current studies on batteries and power condition system. 4310 Renewable Sustainable Energy Rev. 2018, 82, 3091-3106. 4311

(132) Ceci, B. R.; Pinheiro Bernardon, D.; Canha, L. N.; Santana, T. 4312 Technology Roadmap Storage: Energy Storage Perspectives. In 4313 Proceedings of the 2018 53rd International Universities Power Engineer- 4314 ing Conference (UPEC); IEEE: Glasgow, 2018; pp 1-6. 4315

(133) Lithium-Ion Battery Costs and Market - Claire Curry for 4316 Bloomberg New Energy Finance, Available https://data.bloomberglp. 4317 com/bnef/sites/14/2017/07/BNEF-Lithium-ion-battery-costs-and- 4318 market.pdf, last accessed June 2019.

(134) Fialka, J. World's Largest Storage Battery Will Power Los 4320 Angeles; 2016.

4321

(135) Dubarry, M.; Devie, A.; Stein, K.; Tun, M.; Matsuura, M.; 4322 Rocheleau, R. Battery Energy Storage System battery durability and 4323 reliability under electric utility grid operations: Analysis of 3 years of 4324 real usage. J. Power Sources 2017, 338, 65-73.

4325

(136) Darling, R. M.; Gallagher, K. G.; Kowalski, J. A.; Ha, S.; 4326 Brushett, F. R. Pathways to low-cost electrochemical energy storage: a 4327 comparison of aqueous and nonaqueous flow batteries. Energy 4328 Environ. Sci. 2014, 7, 3459-3477.

4329

(137) Pawel, I. The Cost of Storage - How to Calculate the 4330 Levelized Cost of Stored Energy (LCOE) and Applications to 4331 Renewable Energy Generation. Energy Procedia 2014, 46, 68-77. 4332

(138) Liang, F.-Y.; Ryvak, M.; Sayeed, S.; Zhao, N. The role of 4333 natural gas as a primary fuel in the near future, including comparisons 4334 of acquisition, transmission and waste handling costs of as with 4335 competitive alternatives. Chem. Cent. J. 2012, 6, S4. 4336

(139) Sims, R.; Schaeffer, R.; Creutzig, F.; Cruz-Núñez, X.; 4337 D’Agosto, M.; Dimitriu, D.; Figueroa Meza, M. J.; Fulton, L.; 4338 Kobayashi, S.; Lah, O.; McKinnon, A.; Newman, P.; Ouyang, M.; 4339 Schauer, J. J.; Sperling, D.; Tiwari, G. Transport. In Climate Change 4340 2014: Mitigation of Climate Change. Contribution of Working Group III 4341 to the Fifth Assessment Report of the Intergovernmental Panel on Climate 4342 Change; Edenhofer, O., Pichs-Madruga, R., Sokona, Y., Farahani, E., 4343 Kadner, S., Seyboth, K., Adler, A., Baum, I., Brunner, S., Eickemeier, 4344 P., Kriemann, B., Savolainen, J., Schlömer, S., von Stechow, C., 4345 Zwickel, T., Minx, J. C., Eds.; Cambridge University Press: 4346 Cambridge, United Kingdom and New York, NY, USA, 2014.

(140) International Organization of Motor Vehicle Manufacturers. 4348 All Vehicles in Use (2005-2015). Available http://www.oica.net/wp- 4349 content/uploads//Total_in-use-All-Vehicles.pdf, last accessed June 4350 2019.

(141) Lo, P. L.; Martini, G.; Porta, F.; Scotti, D. The determinants of 4352 $\mathrm{CO}_{2}$ emissions of air transport passenger traffic: An analysis of 4353 
4354 Lombardy (Italy). Transp. Policy 2018, DOI: 10.1016/j.tran4355 pol.2018.11.010

4356 (142) Parker, D. The ascendency of electric motive power as a 4357 gradual replacement for the internal combustion engine (ICE), 4358 'Ockham's Electric Razor. Int. J. Environ. Stud. 2018, 75, 532-536. 4359 (143) IEA (2018), Global EV Outlook, Available https://www.iea. $4360 \mathrm{org} /$ gevo2018. All rights reserved. Last accessed June 2019.

4361 (144) IEA (2010), Electric and Plug-in Hybrid Vehicle Roadmap, 4362 Available https://www.iea.org/reports/technology-roadmap-electric4363 and-plug-in-hybrid-electric-vehicles. All rights reserved. Last accessed 4364 June 2019.

4365 (145) Saritas, O.; Meissner, D.; Sokolov, A. A Transition 4366 Management Roadmap for Fuel Cell Electric Vehicles (FCEVs). J. 4367 Knowl. Econ. 2019.101183

4368 (146) Hache, E.; Seck, G. S.; Simoen, M.; Bonnet, C.; Carcanague, $4369 \mathrm{~S}$. Critical raw materials and transportation sector electrification: A 4370 detailed bottom-up analysis in world transport. Appl. Energy 2019, $4371240,6-25$.

4372 (147) Zawieska, J.; Pieriegud, J. Smart city as a tool for sustainable 4373 mobility and transport decarbonisation. Transp. Policy 2018, 63, 39437450 .

4375 (148) Galetovic, A.; Haber, S.; Zaretzki, L. An estimate of the 4376 average cumulative royalty yield in the world mobile phone industry: 4377 Theory, measurement and results. Telecommun. Policy 2018, 42, 2634378276.

4379 (149) Madakam, S.; Ramaswamy, R.; Tripathi, S. Internet of Things 4380 (IoT): A Literature Review. J. Comput. Commun. 2015, 03, 164-173. 4381 (150) Xu, L. D.; He, W.; Li, S. Internet of Things in Industries: A 4382 Survey. IEEE Trans. Ind. Inform. 2014, 10, 2233-2243.

4383 (151) https://theshiftproject.org/en/article/lean-ict-our-new4384 report/, last accessed June 2019.

4385 (152) Yang, G.-Z.; Bellingham, J.; Dupont, P. E.; Fischer, P.; Floridi, 4386 L.; Full, R.; Jacobstein, N.; Kumar, V.; McNutt, M.; Merrifield, R.; 4387 et al. The grand challenges of Science Robotics. Sci. Robot. 2018, 3, 4388 eaar7650.

4389 (153) Executive Summary World Robotics 2018 Service 4390 Robots - https://ifr.org/downloads/press2018/ 4391 Executive\%20Summary\%20WR\%202019\%20Industrial\%20Robots. 4392 pdf, last accessed June 2019.

4393 (154) Vaalma, C.; Buchholz, D.; Weil, M.; Passerini, S. A cost and 4394 resource analysis of sodium-ion batteries. Nat. Rev. Mater. 2018, 3, 4395 DOI: $10.1038 /$ natrevmats.2018.13

4396 (155) Mayyas, A.; Steward, D.; Mann, M. The case for recycling: 4397 Overview and challenges in the material supply chain for automotive 4398 Li-ion batteries. Sustain. Mater. Technol. 2019, 19, e00087.

4399 (156) https://www.bloomberg.com/news/articles/2018-11-19/evs4400 set-to-become-the-biggest-battery-users, last accessed June 2019.

4401 (157) Some Geopolitical Issues of the Energy Transition, Available 4402 https://www.iris-france.org/notes/some-geopolitical-issues-of-the4403 energy-transition-2/, last accessed June 2019.

4404 (158) Missemer, A. William Stanley Jevons' The Coal Question 4405 (1865), beyond the rebound effect. Ecol. Econ. 2012, 82, 97-103.

4406 (159) Font Vivanco, D.; Kemp, R.; van der Voet, E. How to deal 4407 with the rebound effect? A policy-oriented approach. Energy Policy 4408 2016, 94, 114-125.

4409 (160) Graedel, T. E. On the Future Availability of the Energy 4410 Metals. Annu. Rev. Mater. Res. 2011, 41, 323-335.

4411 (161) Zhang, S.; Ding, Y.; Liu, B.; Chang, C. Supply and demand of 4412 some critical metals and present status of their recycling in WEEE. 4413 Waste Manage. 2017, 65, 113-127.

4414 (162) Vesborg, P. C. K.; Jaramillo, T. F. Addressing the terawatt 4415 challenge: scalability in the supply of chemical elements for renewable 4416 energy. RSC Adv. 2012, 2, 7933.

4417 (163) Chancerel, P.; Marwede, M.; Nissen, N. F.; Lang, K.-D. 4418 Estimating the quantities of critical metals embedded in ICT and 4419 consumer equipment. Resour. Conserv. Recycl. 2015, 98, 9-18.

4420 (164) Graedel, T. E.; Harper, E. M.; Nassar, N. T.; Nuss, P.; Reck, B. 4421 K. Criticality of metals and metalloids. Proc. Natl. Acad. Sci. U. S. A. 4422 2015, 112, 4257-4262.
(165) Løvik, A. N.; Hagelüken, C.; Wäger, P. Improving supply 4423 security of critical metals: Current developments and research in the 4424 EU. Sustain. Mater. Technol. 2018, 15, 9-18.

4425

(166) European Commission, Study on the Review of the List of 4426 Critical Raw Materials - https://publications.europa.eu/en/ 4427 publication-detail/-/publication/08fdab5f-9766-11e7-b92d- 4428 01aa75ed71a1/language-en, (2017), last accessed June 2019.

(167) Department Of The Interior of the USA, Federal Register 4430 /Vol. 83, No. 97/Friday, May 18, 2018, https://www.govinfo.gov/ 4431 app/details/FR-2018-05-18/2018-10667, last accessed November 4432 2019. 4433

(168) Choi, J. W.; Aurbach, D. Promise and reality of post-lithium- 4434 ion batteries with high energy densities. Nat. Rev. Mater. 2016, 1, 4435 DOI: $10.1038 /$ natrevmats.2016.13

4436

(169) Kamaya, N.; Homma, K.; Yamakawa, Y.; Hirayama, M.; 4437 Kanno, R.; Yonemura, M.; Kamiyama, T.; Kato, Y.; Hama, S.; 4438 Kawamoto, K.; et al. A lithium superionic conductor. Nat. Mater. 4439 2011, 10, 682-686.

4440

(170) Kato, Y.; Hori, S.; Saito, T.; Suzuki, K.; Hirayama, M.; Mitsui, 4441 A.; Yonemura, M.; Iba, H.; Kanno, R. High-power all-solid-state 4442 batteries using sulfide superionic conductors. Nat. Energy 2016, 1, 4443 DOI: $10.1038 /$ nenergy.2016.30

(171) Lei, D.; Shi, K.; Ye, H.; Wan, Z.; Wang, Y.; Shen, L.; Li, B.; 4445 Yang, Q.-H.; Kang, F.; He, Y.-B. Progress and Perspective of Solid- 4446 State Lithium-Sulfur Batteries. Adv. Funct. Mater. 2018, 28, 1707570. 4447

(172) Richards, W. D.; Miara, L. J.; Wang, Y.; Kim, J. C.; Ceder, G. 4448 Interface Stability in Solid-State Batteries. Chem. Mater. 2016, 28, 4449 266-273.

4450

(173) Muñoz-Márquez, M.Á.; Saurel, D.; Gómez-Cámer, J. L.; 4451 Casas-Cabanas, M.; Castillo-Martínez, E.; Rojo, T. Na-Ion Batteries 4452 for Large Scale Applications: A Review on Anode Materials and Solid 4453 Electrolyte Interphase Formation. Adv. Energy Mater. 2017, 7, 4454 1700463.

(174) Deng, J.; Luo, W.-B.; Chou, S.-L.; Liu, H.-K.; Dou, S.-X. 4456 Sodium-Ion Batteries: From Academic Research to Practical 4457 Commercialization. Adv. Energy Mater. 2018, 8, 1701428.

(175) Helbig, C.; Bradshaw, A. M.; Wietschel, L.; Thorenz, A.; 4459 Tuma, A. Supply risks associated with lithium-ion battery materials. J. 4460 Cleaner Prod. 2018, 172, 274-286. 4461

(176) Tarascon, J.-M. Is lithium the new gold? Nat. Chem. 2010, 2, 4462 510-511.

(177) Olivetti, E. A.; Ceder, G.; Gaustad, G. G.; Fu, X. Lithium-Ion 4464 Battery Supply Chain Considerations: Analysis of Potential Bottle- 4465 necks in Critical Metals. Joule 2017, 1, 229-243. 4466

(178) Andersson, B. A.; Råde, I. Metal resource constraints for 4467 electric-vehicle batteries. Transp. Res. Part Transp. Environ. 2001, 6, 4468 297-324.

(179) Nassar, N. T.; Graedel, T. E.; Harper, E. M. By-product metals 4470 are technologically essential but have problematic supply. Sci. Adv. 4471 2015, 1, e1400180.

(180) Butsic, V.; Baumann, M.; Shortland, A.; Walker, S.; 4473 Kuemmerle, T. Conservation and conflict in the Democratic Republic 4474 of Congo: The impacts of warfare, mining, and protected areas on 4475 deforestation. Biol. Conserv. 2015, 191, 266-273. 4476

(181) https://www.bloomberg.com/news/articles/2018-02-21/ 4477 apple-is-said-to-negotiate-buying-cobalt-direct-from-miners, last ac- 4478 cessed June 2019.

(182) Heelan, J.; Gratz, E.; Zheng, Z.; Wang, Q.; Chen, M.; Apelian, 4480 D.; Wang, Y. Current and Prospective Li-Ion Battery Recycling and 4481 Recovery Processes. JOM 2016, 68, 2632-2638.

(183) European Directive 2006/66/EC - https://eur-lex.europa.eu/ 4483 legal-content/FR/ALL/?uri=CELEX\%3A32006L0066, last accessed 4484 June 2019. 4485

(184) Lithium process chemistry: resources, extraction, batteries, and 4486 recycling; Chagnes, A., Swiatowska, J., Eds.; Elsevier: Amsterdam, 4487 Boston, Heidelberg, 2015; ISBN 978-0-12-801417-2.

(185) Zhang, X.; Li, L.; Fan, E.; Xue, Q.; Bian, Y.; Wu, F.; Chen, R. 4489 Toward sustainable and systematic recycling of spent rechargeable 4490 batteries. Chem. Soc. Rev. 2018, 47, 7239-7302. 
4492 (186) Chagnes, A.; Pospiech, B. A brief review on hydrometallurgical 4493 technologies for recycling spent lithium-ion batteries: Technologies 4494 for recycling spent lithium-ion batteries. J. Chem. Technol. Biotechnol. 4495 2013, 88, 1191-1199.

4496 (187) Zeng, X.; Li, J.; Singh, N. Recycling of Spent Lithium-Ion 4497 Battery: A Critical Review. Crit. Rev. Environ. Sci. Technol. 2014, 44, 4498 1129-1165.

4499 (188) Simonin, L.; Simone, V.; Martinet, S.; Monconduit, L. 4500 Accumulateurs Na-ion: doit-on/peut-on remplacer le lithium? In 4501 Batteries Li-ion Du présent au futur; EDP Sciences, 2019; pp 113-134, 4502 ISBN 978-2-7598-2392-5.

4503 (189) Haynes, W. M. Abundance of elements in the Earth's crust 4504 and in the sea. In CRC Handbook of Chemistry and Physics; 2026; Vol. $450514, \mathrm{p} 18$.

4506 (190) https://nssdc.gsfc.nasa.gov/planetary/factsheet/earthfact. $4507 \mathrm{html}$, last accessed June 2019.

4508 (191) Vassilev, S. V.; Baxter, D.; Andersen, L. K.; Vassileva, C. G. An 4509 overview of the chemical composition of biomass. Fuel 2010, 89, 4510 913-933.

4511 (192) Peters, J. F.; Baumann, M.; Zimmermann, B.; Braun, J.; Weil, $4512 \mathrm{M}$. The environmental impact of Li-Ion batteries and the role of key 4513 parameters - A review. Renewable Sustainable Energy Rev. 2017, 67, 4514 491-506.

4515 (193) Majeau-Bettez, G.; Hawkins, T. R.; Strømman, A. H. Life 4516 Cycle Environmental Assessment of Lithium-Ion and Nickel Metal 4517 Hydride Batteries for Plug-In Hybrid and Battery Electric Vehicles. 4518 Environ. Sci. Technol. 2011, 45, 4548-4554.

4519 (194) Hiremath, M.; Derendorf, K.; Vogt, T. Comparative Life 4520 Cycle Assessment of Battery Storage Systems for Stationary 4521 Applications. Environ. Sci. Technol. 2015, 49, 4825-4833.

4522 (195) Nordelöf, A.; Messagie, M.; Tillman, A.-M.; Ljunggren 4523 Söderman, M.; Van Mierlo, J. Environmental impacts of hybrid, 4524 plug-in hybrid, and battery electric vehicles-what can we learn from 4525 life cycle assessment? Int. J. Life Cycle Assess. 2014, 19, 1866-1890. 4526 (196) Ellis, B. L.; Nazar, L. F. Sodium and sodium-ion energy 4527 storage batteries. Curr. Opin. Solid State Mater. Sci. 2012, 16, 1684528177.

4529 (197) Muñoz-Márquez, M.Á.; Saurel, D.; Gómez-Cámer, J. L.; 4530 Casas-Cabanas, M.; Castillo-Martínez, E.; Rojo, T. Na-Ion Batteries 4531 for Large Scale Applications: A Review on Anode Materials and Solid 4532 Electrolyte Interphase Formation. Adv. Energy Mater. 2017, 7, 45331700463.

4534 (198) Zhang, L.; Liu, Z.; Cui, G.; Chen, L. Biomass-derived 4535 materials for electrochemical energy storages. Prog. Polym. Sci. 2015, 4536 43, 136-164.

4537 (199) Corma, A.; Iborra, S.; Velty, A. Chemical Routes for the 4538 Transformation of Biomass into Chemicals. Chem. Rev. 2007, 107, $45392411-2502$.

4540 (200) Bozell, J. J.; Petersen, G. R. Technology development for the 4541 production of biobased products from biorefinery carbohydrates- the 4542 US Department of Energy's “Top 10” revisited. Green Chem. 2010, 12, 4543539.

4544 (201) Gandini, A.; Lacerda, T. M.; Carvalho, A. J. F.; Trovatti, E. 4545 Progress of Polymers from Renewable Resources: Furans, Vegetable 4546 Oils, and Polysaccharides. Chem. Rev. 2016, 116, 1637-1669.

4547 (202) Gnedenkov, S. V.; Opra, D. P.; Sinebryukhov, S. L.; 4548 Tsvetnikov, A. K.; Ustinov, A. Y.; Sergienko, V. I. Hydrolysis lignin4549 based organic electrode material for primary lithium batteries. J. Solid 4550 State Electrochem. 2013, 17, 2611-2621.

4551 (203) Milczarek, G.; Inganas, O. Renewable Cathode Materials from 4552 Biopolymer/Conjugated Polymer Interpenetrating Networks. Science 4553 2012, 335, 1468-1471.

4554 (204) Goriparti, S.; Harish, M. N. K.; Sampath, S. Ellagic acid - a 4555 novel organic electrode material for high capacity lithium ion 4556 batteries. Chem. Commun. 2013, 49, 7234.

4557 (205) Reddy, A. L. M.; Nagarajan, S.; Chumyim, P.; Gowda, S. R.; 4558 Pradhan, P.; Jadhav, S. R.; Dubey, M.; John, G.; Ajayan, P. M. Lithium 4559 storage mechanisms in purpurin based organic lithium ion battery 4560 electrodes. Sci. Rep. 2012, 2, DOI: 10.1038/srep00960
(206) Miroshnikov, M.; Kato, K.; Babu, G.; Divya, K. P.; Reddy 4561 Arava, L. M.; Ajayan, P. M.; John, G. A common tattoo chemical for 4562 energy storage: henna plant-derived naphthoquinone dimer as a green 4563 and sustainable cathode material for Li-ion batteries. RSC Adv. 2018, 4564 $8,1576-1582$.

4565

(207) Esquivel, J. P.; Alday, P.; Ibrahim, O. A.; Fernández, B.; 4566 Kjeang, E.; Sabaté, N. A Metal-Free and Biotically Degradable Battery 4567 for Portable Single-Use Applications. Adv. Energy Mater. 2017, 7, 4568 1700275.

4569

(208) Renault, S.; Gottis, S.; Barrès, A.-L.; Courty, M.; Chauvet, O.; 4570 Dolhem, F.; Poizot, P. A green Li-organic battery working as a fuel 4571 cell in case of emergency. Energy Environ. Sci. 2013, 6, 2124.

(209) Godet-Bar, T.; Leprêtre, J.-C.; Poizot, P.; Massuyeau, F.; 4573 Faulques, E.; Christen, A.; Minassian, F.; Poisson, J.-F.; Loiseau, F.; 4574 Lafolet, F. Light assisted rechargeable batteries: a proof of concept 4575 with BODIPY derivatives acting as a combined photosensitizer and 4576 electrical storage unit. J. Mater. Chem. A 2017, 5, 1902-1905. 4577

(210) Li, W.; Kerr, E.; Goulet, M.; Fu, H.; Zhao, Y.; Yang, Y.; 4578 Veyssal, A.; He, J.; Gordon, R. G.; Aziz, M. J.; et al. A Long Lifetime 4579 Aqueous Organic Solar Flow Battery. Adv. Energy Mater. 2019, 9, 4580 1900918.

$$
4581
$$

(211) Zhu, X.-Q.; Wang, C.-H. Accurate Estimation of the One- 4582 Electron Reduction Potentials of Various Substituted Quinones in 4583 DMSO and $\mathrm{CH}_{3}$ CN. J. Org. Chem. 2010, 75, 5037-5047. 4584

(212) Suga, T.; Sugita, S.; Ohshiro, H.; Oyaizu, K.; Nishide, H. p- 4585 and n-Type Bipolar Redox-Active Radical Polymer: Toward Totally 4586 Organic Polymer-Based Rechargeable Devices with Variable Config- 4587 uration. Adv. Mater. 2011, 23, 751-754.

(213) Yao, M.; Sano, H.; Ando, H.; Kiyobayashi, T. Molecular ion 4589 battery: a rechargeable system without using any elemental ions as a 4590 charge carrier. Sci. Rep. 2015, 5, DOI: 10.1038/srep10962 4591

(214) Tong, L.; Jing, Y.; Gordon, R. G.; Aziz, M. J. Symmetric All- 4592 Quinone Aqueous Battery. ACS Appl. Energy Mater. 2019, 2, 4016- 4593 4021.

(215) Jensen, W. B. The Origin of the Oxidation-State Concept. J. 4595 Chem. Educ. 2007, 84, 1418.

(216) Karen, P.; McArdle, P.; Takats, J. Toward a comprehensive 4597 definition of oxidation state (IUPAC Technical Report). Pure Appl. 4598 Chem. 2014, 86, 1017-1081.

4599

(217) Walsh, A.; Sokol, A. A.; Buckeridge, J.; Scanlon, D. O.; 4600 Catlow, C. R. A. Oxidation states and ionicity. Nat. Mater. 2018, 17, 4601 958-964.

4602

(218) Klemm, L. H. A classification of organic redox reactions and 4603 writing balanced equations for them, with special attention to 4604 heteroatoms and heterocyclic compounds. J. Heterocycl. Chem. 1996, 4605 $33,569-574$

4606

(219) Deuchert, K.; Hünig, S. Multistage Organic Redox Systems- 4607 A General Structural Principle. Angew. Chem., Int. Ed. Engl. 1978, 17, 4608 $875-886$.

(220) Nishinaga, T.; Komatsu, K. Persistent ? radical cations: self- 4610 association and its steric control in the condensed phase. Org. Biomol. 4611 Chem. 2005, 3, 561.

(221) Stable radicals: fundamentals and applied aspects of odd-electron 4613 compounds; Hicks, R. G., Ed.; Wiley: Chichester, 2010; ISBN 978-0- 4614 470-77083-2.

(222) Brenner, A. Note on an Organic-Electrolyte Cell with a High 4616 Voltage. J. Electrochem. Soc. 1971, 118, 461.

(223) Besenhard, J. O.; Fritz, H. P. The Electrochemistry of Black 4618 Carbons. Angew. Chem., Int. Ed. Engl. 1983, 22, 950-975. 4619

(224) Guérard, D.; Fuzellier, H. The Graphite Intercalation 4620 Compounds and their Applications. In Condensed Systems of Low 4621 Dimensionality; Beeby, J. L., Bhattacharya, P. K., Gravelle, P.Ch., 4622 Koch, F., Lockwood, D. J., Eds.; Springer US: Boston, MA, 1991; Vol. 4623 253, pp 695-707, ISBN 978-1-4684-1350-2.

(225) Rothermel, S.; Meister, P.; Schmuelling, G.; Fromm, O.; 4625 Meyer, H.-W.; Nowak, S.; Winter, M.; Placke, T. Dual-graphite cells 4626 based on the reversible intercalation of bis(trifluoromethanesulfonyl)- 4627 imide anions from an ionic liquid electrolyte. Energy Environ. Sci. 4628 2014, 7, 3412-3423. 
4630 (226) Mohammad, I.; Witter, R.; Fichtner, M.; Anji Reddy, M. 4631 Room-Temperature, Rechargeable Solid-State Fluoride-Ion Batteries. 4632 ACS Appl. Energy Mater. 2018, 1, 4766-4775.

4633 (227) Yao, M.; Sano, H.; Ando, H.; Kiyobayashi, T. Molecular ion 4634 battery: a rechargeable system without using any elemental ions as a 4635 charge carrier. Sci. Rep. 2015, 5, 10962.

4636 (228) Jouhara, A.; Quarez, E.; Dolhem, F.; Armand, M.; Dupré, N.; 4637 Poizot, P. Tuning the Chemistry of Organonitrogen Compounds for 4638 Promoting All-Organic Anionic Rechargeable Batteries. Angew. Chem., 4639 Int. Ed. 2019, 58, 15680-15684.

4640 (229) Zhou, X.; Liu, Q.; Jiang, C.; Ji, B.; Ji, X.; Tang, Y.; Cheng, H.$4641 \mathrm{M}$. Beyond Conventional Batteries: Strategies towards Low-Cost 4642 Dual-Ion Batteries with High Performance. Angew. Chem., Int. Ed. 46432019.

4644 (230) Perticarari, S.; Sayed-Ahmad-Baraza, Y.; Ewels, C.; Moreau, 4645 P.; Guyomard, D.; Poizot, P.; Odobel, F.; Gaubicher, J. Dual Anion4646 Cation Reversible Insertion in a Bipyridinium-Diamide Triad as the 4647 Negative Electrode for Aqueous Batteries. Adv. Energy Mater. 2018, 8, 46481701988.

4649 (231) Perticarari, S.; Doizy, T.; Soudan, P.; Ewels, C.; Latouche, C.; 4650 Guyomard, D.; Odobel, F.; Poizot, P.; Gaubicher, J. Intermixed 4651 Cation-Anion Aqueous Battery Based on an Extremely Fast and 4652 Long-Cycling Di-Block Bipyridinium-Naphthalene Diimide 4653 Oligomer. Adv. Energy Mater. 2019, 9, 1803688.

4654 (232) Perticarari, S.; Grange, E.; Doizy, T.; Pellegrin, Y.; Quarez, E.; 4655 Oyaizu, K.; Fernandez-Ropero, A. J.; Guyomard, D.; Poizot, P.; 4656 Odobel, F.; et al. Full Organic Aqueous Battery Based on TEMPO 4657 Small Molecule with Millimeter-Thick Electrodes. Chem. Mater. 2019, $465831,1869-1880$.

4659 (233) Chae, I. S.; Koyano, M.; Oyaizu, K.; Nishide, H. Self-doping 4660 inspired zwitterionic pendant design of radical polymers toward a 4661 rocking-chair-type organic cathode-active material. J. Mater. Chem. A 4662 2013, 1, 1326-1333.

4663 (234) Gottis, S.; Barrès, A.-L.; Dolhem, F.; Poizot, P. Voltage Gain 4664 in Lithiated Enolate-Based Organic Cathode Materials by Isomeric 4665 Effect. ACS Appl. Mater. Interfaces 2014, 6, 10870-10876.

4666 (235) Rodríguez-Pérez, I. A.; Jian, Z.; Waldenmaier, P. K.; 4667 Palmisano, J. W.; Chandrabose, R. S.; Wang, X.; Lerner, M. M.; 4668 Carter, R. G.; Ji, X. A Hydrocarbon Cathode for Dual-Ion Batteries. 4669 ACS Energy Lett. 2016, 1, 719-723.

4670 (236) Kim, J.-K.; Thébault, F.; Heo, M.-Y.; Kim, D.-S.; Hansson, Ö.; 4671 Ahn, J.-H.; Johansson, P.; Öhrström, L.; Matic, A.; Jacobsson, P. 4672 2,3,6,7,10,11-Hexamethoxytriphenylene (HMTP): A new organic 4673 cathode material for lithium batteries. Electrochem. Commun. 2012, $467421,50-53$.

4675 (237) Inatomi, Y.; Hojo, N.; Yamamoto, T.; Watanabe, S.; Misaki, Y. 4676 Construction of Rechargeable Batteries Using Multifused Tetrathia4677 fulvalene Systems as Cathode Materials. ChemPlusChem 2012, 77, 4678 973-976.

4679 (238) Kato, M.; Senoo, K.; Yao, M.; Misaki, Y. A pentakis-fused 4680 tetrathiafulvalene system extended by cyclohexene-1,4-diylidenes: a 4681 new positive electrode material for rechargeable batteries utilizing ten 4682 electron redox. J. Mater. Chem. A 2014, 2, 6747.

4683 (239) Bugnon, L.; Morton, C. J. H.; Novak, P.; Vetter, J.; Nesvadba, 4684 P. Synthesis of Poly(4-methacryloyloxy-TEMPO) via Group-Transfer 4685 Polymerization and Its Evaluation in Organic Radical Battery. Chem. 4686 Mater. 2007, 19, 2910-2914.

4687 (240) Oyaizu, K.; Kawamoto, T.; Suga, T.; Nishide, H. Synthesis 4688 and Charge Transport Properties of Redox-Active Nitroxide 4689 Polyethers with Large Site Density. Macromolecules 2010, 43, 4690 10382-10389.

4691 (241) Lee, S.; Hong, J.; Jung, S.-K.; Ku, K.; Kwon, G.; Seong, W. M.; 4692 Kim, H.; Yoon, G.; Kang, I.; Hong, K.; et al. Charge-transfer 4693 complexes for high-power organic rechargeable batteries. Energy 4694 Storage Mater. 2019, 20, 462-469.

4695 (242) Zhang, C.; Yang, X.; Ren, W.; Wang, Y.; Su, F.; Jiang, J.-X. 4696 Microporous organic polymer-based lithium ion batteries with 4697 improved rate performance and energy density. J. Power Sources 4698 2016, 317, 49-56.
(243) Deunf, É.; Jiménez, P.; Guyomard, D.; Dolhem, F.; Poizot, P. 4699 A dual-ion battery using diamino-rubicene as anion-inserting 4700 positive electrode material. Electrochem. Commun. 2016, 72, 64-68. 4701

(244) Lee, M.; Hong, J.; Lee, B.; Ku, K.; Lee, S.; Park, C. B.; Kang, 4702 K. Multi-electron redox phenazine for ready-to-charge organic 4703 batteries. Green Chem. 2017, 19, 2980-2985.

(245) Deunf, É.; Moreau, P.; Quarez, É.; Guyomard, D.; Dolhem, F.; 4705 Poizot, P. Reversible anion intercalation in a layered aromatic amine: 4706 a high-voltage host structure for organic batteries. J. Mater. Chem. A 4707 2016, 4, 6131-6139.

4708

(246) Song, Z.; Qian, Y.; Zhang, T.; Otani, M.; Zhou, H. 4709 Poly(benzoquinonyl sulfide) as a High-Energy Organic Cathode for 4710 Rechargeable Li and Na Batteries. Adv. Sci. 2015, 2, $1500124 . \quad 4711$

(247) Yokoji, T.; Kameyama, Y.; Maruyama, N.; Matsubara, H. 4712 High-capacity organic cathode active materials of 2,2'-bis-p- 4713 benzoquinone derivatives for rechargeable batteries. J. Mater. Chem. 4714 A 2016, 4, 5457-5466.

4715

(248) Wu, D.; Xie, Z.; Zhou, Z.; Shen, P.; Chen, Z. Designing high- 4716 voltage carbonyl-containing polycyclic aromatic hydrocarbon cathode 4717 materials for Li-ion batteries guided by Clar's theory. J. Mater. Chem. 4718 A 2015, 3, 19137-19143.

4719

(249) Song, Z.; Qian, Y.; Liu, X.; Zhang, T.; Zhu, Y.; Yu, H.; Otani, 4720 M.; Zhou, H. A quinone-based oligomeric lithium salt for superior 4721 Li-organic batteries. Energy Environ. Sci. 2014, 7, 4077-4086. 4722

(250) Yokoji, T.; Matsubara, H.; Satoh, M. Rechargeable organic 4723 lithium-ion batteries using electron-deficient benzoquinones as 4724 positive-electrode materials with high discharge voltages. J. Mater. 4725 Chem. A 2014, 2, 19347-19354.

4726

(251) Wang, S.; Wang, L.; Zhang, K.; Zhu, Z.; Tao, Z.; Chen, J. 4727 Organic $\mathrm{Li}_{4} \mathrm{C}_{8} \mathrm{H}_{2} \mathrm{O}_{6}$ Nanosheets for Lithium-Ion Batteries. Nano Lett. 4728 2013, 13, 4404-4409.

4729

(252) Jouhara, A.; Dupré, N.; Gaillot, A.-C.; Guyomard, D.; 4730 Dolhem, F.; Poizot, P. Raising the redox potential in carboxypheno- 4731 late-based positive organic materials via cation substitution. Nat. 4732 Commun. 2018, 9, DOI: 10.1038/s41467-018-06708-x 4733

(253) Lakraychi, A. E.; Deunf, E.; Fahsi, K.; Jimenez, P.; Bonnet, J.- 4734 P.; Djedaini-Pilard, F.; Bécuwe, M.; Poizot, P.; Dolhem, F. An air- 4735 stable lithiated cathode material based on a 1,4-benzenedisulfonate 4736 backbone for organic Li-ion batteries. J. Mater. Chem. A 2018, 6, 4737 19182-19189.

4738

(254) Hanyu, Y.; Honma, I. Rechargeable quasi-solid state lithium 4739 battery with organic crystalline cathode. Sci. Rep. 2012, 2, 4740 DOI: $10.1038 /$ srep00453

(255) Nishida, S.; Yamamoto, Y.; Takui, T.; Morita, Y. Organic 4742 Rechargeable Batteries with Tailored Voltage and Cycle Performance. 4743 ChemSusChem 2013, 6, 794-797.

(256) Shimizu, A.; Tsujii, Y.; Kuramoto, H.; Nokami, T.; Inatomi, 4745 Y.; Hojo, N.; Yoshida, J. Nitrogen-Containing Polycyclic Quinones as 4746 Cathode Materials for Lithium-ion Batteries with Increased Voltage. 4747 Energy Technol. 2014, 2, 155-158.

4748

(257) Liang, Y.; Zhang, P.; Chen, J. Function-oriented design of 4749 conjugated carbonyl compound electrodes for high energy lithium 4750 batteries. Chem. Sci. 2013, 4, 1330.

(258) Liang, Y.; Zhang, P.; Yang, S.; Tao, Z.; Chen, J. Fused 4752 Heteroaromatic Organic Compounds for High-Power Electrodes of 4753 Rechargeable Lithium Batteries. Adv. Energy Mater. 2013, 3, 600-605. 4754 (259) Levi, M. D.; Aurbach, D. A short review on the strategy 4755 towards development of $\pi$-conjugated polymers with highly reversible 4756 p- and n-doping. J. Power Sources 2008, 180, 902-908. 4757

(260) Renault, S.; Oltean, V. A.; Araujo, C. M.; Grigoriev, A.; 4758 Edström, K.; Brandell, D. Superlithiation of Organic Electrode 4759 Materials: The Case of Dilithium Benzenedipropiolate. Chem. 4760 Mater. 2016, 28, 1920-1926.

4761

(261) Armand, M.; Grugeon, S.; Vezin, H.; Laruelle, S.; Ribière, P.; 4762 Poizot, P.; Tarascon, J.-M. Conjugated dicarboxylate anodes for Li-ion 4763 batteries. Nat. Mater. 2009, 8, 120-125.

4764

(262) Lakraychi, A. E.; Dolhem, F.; Djedaïni-Pilard, F.; Thiam, A.; 4765 Frayret, C.; Becuwe, M. Decreasing redox voltage of terephthalate- 4766 
4767 based electrode material for Li-ion battery using substituent effect. $J$. 4768 Power Sources 2017, 359, 198-204.

4769 (263) Lakraychi, A. E.; Dolhem, F.; Djedaïni-Pilard, F.; Becuwe, M. 4770 Substituent effect on redox potential of terephthalate-based electrode 4771 materials for lithium batteries. Electrochem. Commun. 2018, 93, 71477275.

4773 (264) Fédèle, L.; Sauvage, F.; Gottis, S.; Davoisne, C.; Salager, E.; 4774 Chotard, J.-N.; Becuwe, M. 2D-Layered Lithium Carboxylate Based 4775 on Biphenyl Core as Negative Electrode for Organic Lithium-Ion 4776 Batteries. Chem. Mater. 2017, 29, 546-554.

4777 (265) Walker, W.; Grugeon, S.; Vezin, H.; Laruelle, S.; Armand, M.; 4778 Wudl, F.; Tarascon, J.-M. Electrochemical characterization of lithium 4779 4,4'-tolane-dicarboxylate for use as a negative electrode in Li-ion 4780 batteries. J. Mater. Chem. 2011, 21, 1615-1620.

4781 (266) Chung, W. J.; Griebel, J. J.; Kim, E. T.; Yoon, H.; Simmonds, 4782 A. G.; Ji, H. J.; Dirlam, P. T.; Glass, R. S.; Wie, J. J.; Nguyen, N. A.; 4783 et al. The use of elemental sulfur as an alternative feedstock for 4784 polymeric materials. Nat. Chem. 2013, 5, 518-524.

4785 (267) Wang, J.; Yang, J.; Xie, J.; Xu, N. A Novel Conductive 4786 Polymer-Sulfur Composite Cathode Material for Rechargeable 4787 Lithium Batteries. Adv. Mater. 2002, 14, 963-965.

4788 (268) Wei, S.; Ma, L.; Hendrickson, K. E.; Tu, Z.; Archer, L. A. 4789 Metal-Sulfur Battery Cathodes Based on PAN-Sulfur Composites. J. 4790 Am. Chem. Soc. 2015, 137, 12143-12152.

4791 (269) Lu, Y.; Hou, X.; Miao, L.; Li, L.; Shi, R.; Liu, L.; Chen, J. 4792 Cyclohexanehexone with Ultrahigh Capacity as Cathode Materials for 4793 Lithium-Ion Batteries. Angew. Chem., Int. Ed. 2019, 58, 7020-7024. 4794 (270) Yao, M.; Senoh, H.; Yamazaki, S.; Siroma, Z.; Sakai, T.; 4795 Yasuda, K. High-capacity organic positive-electrode material based on 4796 a benzoquinone derivative for use in rechargeable lithium batteries. J. 4797 Power Sources 2010, 195, 8336-8340.

4798 (271) Lee, J.; Park, M. J. Tattooing Dye as a Green Electrode 4799 Material for Lithium Batteries. Adv. Energy Mater. 2017, 7, 1602279. 4800 (272) Huang, W.; Zhu, Z.; Wang, L.; Wang, S.; Li, H.; Tao, Z.; Shi, 4801 J.; Guan, L.; Chen, J. Quasi-Solid-State Rechargeable Lithium-Ion 4802 Batteries with a Calix[4]quinone Cathode and Gel Polymer 4803 Electrolyte. Angew. Chem., Int. Ed. 2013, 52, 9162-9166.

4804 (273) Zhu, Z.; Hong, M.; Guo, D.; Shi, J.; Tao, Z.; Chen, J. All4805 Solid-State Lithium Organic Battery with Composite Polymer 4806 Electrolyte and Pillar[5] quinone Cathode. J. Am. Chem. Soc. 2014, 4807 136, 16461-16464.

4808 (274) Liu, K.; Zheng, J.; Zhong, G.; Yang, Y. Poly(2,5-dihydroxy4809 1,4-benzoquinonyl sulfide) (PDBS) as a cathode material for lithium 4810 ion batteries. J. Mater. Chem. 2011, 21, 4125.

4811 (275) Song, Z.; Qian, Y.; Gordin, M. L.; Tang, D.; Xu, T.; Otani, M.; 4812 Zhan, H.; Zhou, H.; Wang, D. Polyanthraquinone as a Reliable 4813 Organic Electrode for Stable and Fast Lithium Storage. Angew. Chem., 4814 Int. Ed. 2015, 54, 13947-13951.

4815 (276) Petronico, A.; Bassett, K. L.; Nicolau, B. G.; Gewirth, A. A.; 4816 Nuzzo, R. G. Toward a Four-Electron Redox Quinone Polymer for 4817 High Capacity Lithium Ion Storage. Adv. Energy Mater. 2018, 8, 48181700960.

4819 (277) Peng, C.; Ning, G.-H.; Su, J.; Zhong, G.; Tang, W.; Tian, B.; $4820 \mathrm{Su}, \mathrm{C}$; $\mathrm{Yu}, \mathrm{D}$.; Zu, L.; Yang, J.; et al. Reversible multi-electron redox 4821 chemistry of $\pi$-conjugated $\mathrm{N}$-containing heteroaromatic molecule4822 based organic cathodes. Nat. Energy 2017, 2, DOI: 10.1038/ 4823 nenergy.2017.74

4824 (278) Hanyu, Y.; Sugimoto, T.; Ganbe, Y.; Masuda, A.; Honma, I. 4825 Multielectron Redox Compounds for Organic Cathode Quasi-Solid 4826 State Lithium Battery. J. Electrochem. Soc. 2014, 161, A6-A9.

4827 (279) Guo, W.; Yin, Y.-X.; Xin, S.; Guo, Y.-G.; Wan, L.-J. Superior 4828 radical polymer cathode material with a two-electron process redox 4829 reaction promoted by graphene. Energy Environ. Sci. 2012, 5, 522148305225 .

4831 (280) Kolek, M.; Otteny, F.; Schmidt, P.; Mück-Lichtenfeld, C.; 4832 Einholz, C.; Becking, J.; Schleicher, E.; Winter, M.; Bieker, P.; Esser, 4833 B. Ultra-high cycling stability of poly(vinylphenothiazine) as a battery 4834 cathode material resulting from $\pi-\pi$ interactions. Energy Environ. Sci. 4835 2017, 10, 2334-2341.
(281) Liang, Y.; Chen, Z.; Jing, Y.; Rong, Y.; Facchetti, A.; Yao, Y. 4836 Heavily n-Dopable $\pi$-Conjugated Redox Polymers with Ultrafast 4837 Energy Storage Capability. J. Am. Chem. Soc. 2015, 137, 4956-4959. 4838

(282) Fan, X.; Wang, F.; Ji, X.; Wang, R.; Gao, T.; Hou, S.; Chen, J.; 4839 Deng, T.; Li, X.; Chen, L.; et al. A Universal Organic Cathode for 4840 Ultrafast Lithium and Multivalent Metal Batteries. Angew. Chem., Int. 4841 Ed. 2018, 57, 7146-7150.

4842

(283) Wang, S.; Wang, Q.; Shao, P.; Han, Y.; Gao, X.; Ma, L.; Yuan, 4843 S.; Ma, X.; Zhou, J.; Feng, X.; et al. Exfoliation of Covalent Organic 4844 Frameworks into Few-Layer Redox-Active Nanosheets as Cathode 4845 Materials for Lithium-Ion Batteries. J. Am. Chem. Soc. 2017, 139, 4846 $4258-4261$

(284) Schon, T. B.; Tilley, A. J.; Kynaston, E. L.; Seferos, D. S. 4848 Three-Dimensional Arylene Diimide Frameworks for Highly Stable 4849 Lithium Ion Batteries. ACS Appl. Mater. Interfaces 2017, 9, 15631- 4850 15637. 4851

(285) Chen, D.; Avestro, A.-J.; Chen, Z.; Sun, J.; Wang, S.; Xiao, M.; 4852 Erno, Z.; Algaradah, M. M.; Nassar, M. S.; Amine, K.; et al. A Rigid 4853 Naphthalenediimide Triangle for Organic Rechargeable Lithium-Ion 4854 Batteries. Adv. Mater. 2015, 27, 2907-2912.

(286) Bhosale, M. E.; Krishnamoorthy, K. Chemically Reduced 4856 Organic Small-Molecule-Based Lithium Battery with Improved 4857 Efficiency. Chem. Mater. 2015, 27, 2121-2126.

(287) Luo, Z.; Liu, L.; Zhao, Q.; Li, F.; Chen, J. An Insoluble 4859 Benzoquinone-Based Organic Cathode for Use in Rechargeable 4860 Lithium-Ion Batteries. Angew. Chem., Int. Ed. 2017, 56, 12561-12565. 4861

(288) Jing, Y.; Liang, Y.; Gheytani, S.; Yao, Y. Cross-conjugated 4862 oligomeric quinones for high performance organic batteries. Nano 4863 Energy 2017, 37, 46-52.

(289) Luo, C.; Ji, X.; Hou, S.; Eidson, N.; Fan, X.; Liang, Y.; Deng, 4865 T.; Jiang, J.; Wang, C. Azo Compounds Derived from Electrochemical 4866 Reduction of Nitro Compounds for High Performance Li-Ion 4867 Batteries. Adv. Mater. 2018, 30, 1706498.

4868

(290) Lee, J.; Kim, H.; Park, M. J. Long-Life, High-Rate Lithium- 4869 Organic Batteries Based on Naphthoquinone Derivatives. Chem. 4870 Mater. 2016, 28, 2408-2416.

4871

(291) Bachman, J. C.; Kavian, R.; Graham, D. J.; Kim, D. Y.; Noda, 4872 S.; Nocera, D. G.; Shao-Horn, Y.; Lee, S. W. Electrochemical 4873 polymerization of pyrene derivatives on functionalized carbon 4874 nanotubes for pseudocapacitive electrodes. Nat. Commun. 2015, 6, 4875 DOI: $10.1038 /$ ncomms 8040

(292) Shinozaki, K.; Tomizuka, Y.; Nojiri, A. Performance of 4877 Lithium/Polyacetylene Cell. Jpn. J. Appl. Phys. 1984, 23, L892-L894. 4878

(293) Dai, Y.; Zhang, Y.; Gao, L.; Xu, G.; Xie, J. A Sodium Ion 4879 Based Organic Radical Battery. Electrochem. Solid-State Lett. 2010, 13, 4880 A22-A24.

4881

(294) Zhao, L.; Zhao, J.; Hu, Y.-S.; Li, H.; Zhou, Z.; Armand, M.; 4882 Chen, L. Disodium Terephthalate $\left(\mathrm{Na}_{2} \mathrm{C}_{8} \mathrm{H}_{4} \mathrm{O}_{4}\right)$ as High Perform- 4883 ance Anode Material for Low-Cost Room-Temperature Sodium-Ion 4884 Battery. Adv. Energy Mater. 2012, 2, 962-965.

(295) Park, Y.; Shin, D.-S.; Woo, S. H.; Choi, N. S.; Shin, K. H.; Oh, 4886 S. M.; Lee, K. T.; Hong, S. Y. Sodium Terephthalate as an Organic 4887 Anode Material for Sodium Ion Batteries. Adv. Mater. 2012, 24, 4888 $3562-3567$.

(296) Abouimrane, A.; Weng, W.; Eltayeb, H.; Cui, Y.; Niklas, J.; 4890 Poluektov, O.; Amine, K. Sodium insertion in carboxylate based 4891 materials and their application in $3.6 \mathrm{~V}$ full sodium cells. Energy 4892 Environ. Sci. 2012, 5, 9632-9638.

4893

(297) Wan, F.; Wu, X.-L.; Guo, J.-Z.; Li, J.-Y.; Zhang, J.-P.; Niu, L.; 4894 Wang, R.-S. Nanoeffects promote the electrochemical properties of 4895 organic $\mathrm{Na}_{2} \mathrm{C}_{8} \mathrm{H}_{4} \mathrm{O}_{4}$ as anode material for sodium-ion batteries. Nano 4896 Energy 2015, 13, 450-457.

(298) Wang, Y.; Kretschmer, K.; Zhang, J.; Mondal, A. K.; Guo, X.; 4898 Wang, G. Organic sodium terephthalate@graphene hybrid anode 4899 materials for sodium-ion batteries. RSC Adv. 2016, 6, 57098-57102. 4900

(299) Han, S.; Kim, Y.; Pyo, M. Reduced Graphene Oxide/ 4901 Disodium Terephthalate Composites via Ultrasonic-assisted Co- 4902 Precipitation for Sodium Ion Battery Anodes. Bull. Korean Chem. 4903 Soc. 2016, 37, 1838-1845. 
4905 (300) Deng, Q.; Wang, Y.; Zhao, Y.; Li, J. Disodium terephthalate/ 4906 multiwall-carbon nanotube nanocomposite as advanced anode 4907 material for Li-ion batteries. Ionics 2017, 23, 2613-2619.

4908 (301) Cao, T.; Lv, W.; Zhang, S.-W.; Zhang, J.; Lin, Q.; Chen, X.; 4909 He, Y.; Kang, F.-Y.; Yang, Q.-H. A Reduced Graphene Oxide/ 4910 Disodium Terephthalate Hybrid as a High-Performance Anode for 4911 Sodium-Ion Batteries. Chem. - Eur. J. 2017, 23, 16586-16592.

4912 (302) Zhao, Q.; Lu, Y.; Chen, J. Advanced Organic Electrode 4913 Materials for Rechargeable Sodium-Ion Batteries. Adv. Energy Mater. 4914 2017, 7, 1601792.

4915 (303) Zhao, R.; Zhu, L.; Cao, Y.; Ai, X.; Yang, H. X. An aniline4916 nitroaniline copolymer as a high capacity cathode for Na-ion batteries. 4917 Electrochem. Commun. 2012, 21, 36-38.

4918 (304) Zhou, M.; Zhu, L.; Cao, Y.; Zhao, R.; Qian, J.; Ai, X.; Yang, H. $4919 \mathrm{Fe}(\mathrm{CN})_{6}{ }^{-4}$-doped polypyrrole: a high-capacity and high-rate cathode 4920 material for sodium-ion batteries. RSC Adv. 2012, 2, 5495-5498.

4921 (305) Zhou, M.; Xiong, Y.; Cao, Y.; Ai, X.; Yang, H. Electroactive 4922 organic anion-doped polypyrrole as a low cost and renewable cathode 4923 for sodium-ion batteries. J. Polym. Sci., Part B: Polym. Phys. 2013, 51, $4924114-118$.

4925 (306) Zhu, L.; Niu, Y.; Cao, Y.; Lei, A.; Ai, X.; Yang, H. n-Type 4926 redox behaviors of polybithiophene and its implications for anodic $\mathrm{Li}$ 4927 and Na storage materials. Electrochim. Acta 2012, 78, 27-31.

4928 (307) Deng, W.; Liang, X.; Wu, X.; Qian, J.; Cao, Y.; Ai, X.; Feng, J.; 4929 Yang, H. A low cost, all-organic Na-ion Battery Based on Polymeric 4930 Cathode and Anode. Sci. Rep. 2013, 3, 2671.

4931 (308) Obrezkov, F. A.; Shestakov, A. F.; Traven, V. F.; Stevenson, K. $4932 \mathrm{~J}$.; Troshin, P. A. An ultrafast charging polyphenylamine-based 4933 cathode material for high rate lithium, sodium and potassium 4934 batteries. J. Mater. Chem. A 2019, 7, 11430-11437.

4935 (309) Huang, Y.; Fang, C.; Zeng, R.; Liu, Y.; Zhang, W.; Wang, Y.; 4936 Liu, Q.; Huang, Y. In Situ-Formed Hierarchical Metal-Organic 4937 Flexible Cathode for High-Energy Sodium-Ion Batteries. ChemSu4938 sChem 2017, 10, 4704-4708.

4939 (310) Fang, C.; Huang, Y.; Yuan, L.; Liu, Y.; Chen, W.; Huang, Y.; 4940 Chen, K.; Han, J.; Liu, Q.; Huang, Y. A Metal-Organic Compound as 4941 Cathode Material with Superhigh Capacity Achieved by Reversible 4942 Cationic and Anionic Redox Chemistry for High-Energy Sodium-Ion 4943 Batteries. Angew. Chem., Int. Ed. 2017, 56, 6793-6797.

4944 (311) Deng, W.; Qian, J.; Cao, Y.; Ai, X.; Yang, H. Graphene4945 Wrapped $\mathrm{Na}_{2} \mathrm{C}_{12} \mathrm{H}_{6} \mathrm{O}_{4}$ Nanoflowers as High Performance Anodes for 4946 Sodium-Ion Batteries. Small 2016, 12, 583-587.

4947 (312) Padhy, H.; Chen, Y.; Lüder, J.; Gajella, S. R.; Manzhos, S.; 4948 Balaya, P. Charge and Discharge Processes and Sodium Storage in 4949 Disodium Pyridine-2,5-Dicarboxylate Anode-Insights from Experi4950 ments and Theory. Adv. Energy Mater. 2018, 8, 1701572.

4951 (313) Choi, A.; Kim, Y. K.; Kim, T. K.; Kwon, M.-S.; Lee, K. T.; 4952 Moon, H. R. 4,4'-Biphenyldicarboxylate sodium coordination 4953 compounds as anodes for Na-ion batteries. J. Mater. Chem. A 2014, 4954 2, 14986-14993.

4955 (314) López-Herraiz, M.; Castillo-Martínez, E.; Carretero-González, 4956 J.; Carrasco, J.; Rojo, T.; Armand, M. Oligomeric-Schiff bases as 4957 negative electrodes for sodium ion batteries: unveiling the nature of 4958 their active redox centers. Energy Environ. Sci. 2015, 8, 3233-3241. 4959 (315) Fernández, N.; Sánchez-Fontecoba, P.; Castillo-Martínez, E.; 4960 Carretero-González, J.; Rojo, T.; Armand, M. Polymeric Redox-Active 4961 Electrodes for Sodium-Ion Batteries. ChemSusChem 2018, 11, 3114962319.

4963 (316) Castillo-Martínez, E.; Carretero-González, J.; Armand, M. 4964 Polymeric Schiff Bases as Low-Voltage Redox Centers for Sodium-Ion 4965 Batteries. Angew. Chem. 2014, 126, 5445-5449.

4966 (317) Zhang, Y.; Yang, S.; Chang, X.; Guo, H.; Li, Y.; Wang, M.; Li, 4967 W.; Jiao, L.; Wang, Y. MOF based on a longer linear ligand: 4968 electrochemical performance, reaction kinetics, and use as a novel 4969 anode material for sodium-ion batteries. Chem. Commun. 2018, 54, $497011793-11796$.

4971 (318) Yabuuchi, N.; Kubota, K.; Dahbi, M.; Komaba, S. Research 4972 Development on Sodium-Ion Batteries. Chem. Rev. 2014, 114, 4973 11636-11682.
(319) Cui, J.; Yao, S.; Kim, J.-K. Recent progress in rational design 4974 of anode materials for high-performance Na-ion batteries. Energy 4975 Storage Mater. 2017, 7, 64-114.

(320) Zhao, C.; Lu, Y.; Li, Y.; Jiang, L.; Rong, X.; Hu, Y.-S.; Li, H.; 4977 Chen, L. Novel Methods for Sodium-Ion Battery Materials. Small 4978 Methods 2017, 1, 1600063.

(321) Sun, Y.; Guo, S.; Zhou, H. Exploration of Advanced Electrode 4980 Materials for Rechargeable Sodium-Ion Batteries. Adv. Energy Mater. 4981 2019, 9, 1800212.

(322) Li, F.; Wei, Z.; Manthiram, A.; Feng, Y.; Ma, J.; Mai, L. 4983 Sodium-based batteries: from critical materials to battery systems. J. 4984 Mater. Chem. A 2019, 7, 9406-9431.

(323) Wu, X.; Jin, S.; Zhang, Z.; Jiang, L.; Mu, L.; Hu, Y.-S.; Li, H.; 4986 Chen, X.; Armand, M.; Chen, L.; et al. Unraveling the storage 4987 mechanism in organic carbonyl electrodes for sodium-ion batteries. 4988 Sci. Adv. 2015, 1, e1500330.

(324) Medabalmi, V.; Kuanr, N.; Ramanujam, K. Sodium 4990 Naphthalene Dicarboxylate Anode Material for Inorganic-Organic 4991 Hybrid Rechargeable Sodium-Ion Batteries. J. Electrochem. Soc. 2018, 4992 165, A175-A180.

4993

(325) Chen, L.; Li, W.; Wang, Y.; Wang, C.; Xia, Y. Polyimide as 4994 anode electrode material for rechargeable sodium batteries. RSC Adv. 4995 2014, 4, 25369-25373.

(326) Chihara, K.; Chujo, N.; Kitajou, A.; Okada, S. Cathode 4997 properties of $\mathrm{Na}_{2} \mathrm{C}_{6} \mathrm{O}_{6}$ for sodium-ion batteries. Electrochim. Acta 4998 2013, 110, 240-246.

4999

(327) Lee, M.; Hong, J.; Lopez, J.; Sun, Y.; Feng, D.; Lim, K.; 5000 Chueh, W. C.; Toney, M. F.; Cui, Y.; Bao, Z. High-performance 5001 sodium-organic battery by realizing four-sodium storage in disodium 5002 rhodizonate. Nat. Energy 2017, 2, 861-868.

5003

(328) Banda, H.; Damien, D.; Nagarajan, K.; Hariharan, M.; 5004 Shaijumon, M. M. A polyimide based all-organic sodium ion battery. J. 5005 Mater. Chem. A 2015, 3, 10453-10458.

5006

(329) Wang, S.; Wang, L.; Zhu, Z.; Hu, Z.; Zhao, Q.; Chen, J. All 5007 Organic Sodium-Ion Batteries with $\mathrm{Na}_{4} \mathrm{C}_{8} \mathrm{H}_{2} \mathrm{O}_{6}$. Angew. Chem., Int. 5008 Ed. 2014, 53, 5892-5896.

5009

(330) Sun, T.; Li, Z.; Wang, H.; Bao, D.; Meng, F.; Zhang, X. A 5010 Biodegradable Polydopamine-Derived Electrode Material for High- 5011 Capacity and Long-Life Lithium-Ion and Sodium-Ion Batteries. 5012 Angew. Chem., Int. Ed. 2016, 55, 10662-10666. 5013

(331) Wu, S.; Wang, W.; Li, M.; Cao, L.; Lyu, F.; Yang, M.; Wang, 5014 Z.; Shi, Y.; Nan, B.; Yu, S.; et al. Highly durable organic electrode for 5015 sodium-ion batteries via a stabilized $\alpha$-C radical intermediate. Nat. 5016 Commun. 2016, 7, 13318.

5017

(332) Gu, S.; Wu, S.; Cao, L.; Li, M.; Qin, N.; Zhu, J.; Wang, Z.; Li, 5018 Y.; Li, Z.; Chen, J.; et al. Tunable Redox Chemistry and Stability of 5019 Radical Intermediates in 2D Covalent Organic Frameworks for High 5020 Performance Sodium Ion Batteries. J. Am. Chem. Soc. 2019, 141, 5021 9623-9628. 5022

(333) Zhao, H.; Wang, J.; Zheng, Y.; Li, J.; Han, X.; He, G.; Du, Y. 5023 Organic Thiocarboxylate Electrodes for a Room-Temperature 5024 Sodium-Ion Battery Delivering an Ultrahigh Capacity. Angew. 5025 Chem., Int. Ed. 2017, 56, 15334-15338.

5026

(334) Tang, M.; Zhu, S.; Liu, Z.; Jiang, C.; Wu, Y.; Li, H.; Wang, B.; 5027 Wang, E.; Ma, J.; Wang, C. Tailoring $\pi$-Conjugated Systems: From $\pi$ - 5028 $\pi$ Stacking to High-Rate-Performance Organic Cathodes. Chem. 2018, 5029 4, 2600-2614. 5030

(335) Luo, C.; Xu, G.-L.; Ji, X.; Hou, S.; Chen, L.; Wang, F.; Jiang, 5031 J.; Chen, Z.; Ren, Y.; Amine, K.; et al. Reversible Redox Chemistry of 5032 Azo Compounds for Sodium-Ion Batteries. Angew. Chem., Int. Ed. 5033 2018, 57, 2879-2883.

5034

(336) Tripathi, A.; Chen, Y.; Padhy, H.; Manzhos, S.; Balaya, P. 5035 Experimental and Theoretical Studies of Trisodium-1,3,5-Benzene 5036 Tricarboxylate as a Low-Voltage Anode Material for Sodium-Ion 5037 Batteries. Energy Technol. 2019, 7, 1801030.

(337) Sakaushi, K.; Hosono, E.; Nickerl, G.; Gemming, T.; Zhou, 5039 H.; Kaskel, S.; Eckert, J. Aromatic porous-honeycomb electrodes for a 5040 sodium-organic energy storage device. Nat. Commun. 2013, 4, 1485. 5041 
5042 (338) Zhang, Y.; An, Y.; Dong, S.; Jiang, J.; Dou, H.; Zhang, X. 5043 Enhanced Cycle Performance of Polyimide Cathode Using a Quasi5044 Solid-State Electrolyte. J. Phys. Chem. C 2018, 122, 22294-22300. 5045 (339) Wang, H.; Yuan, S.; Ma, D.; Huang, X.; Meng, F.; Zhang, X. 5046 Tailored Aromatic Carbonyl Derivative Polyimides for High-Power 5047 and Long-Cycle Sodium-Organic Batteries. Adv. Energy Mater. 2014, 5048 4, 1301651.

5049 (340) Wu, D.; Zhang, G.; Lu, D.; Ma, L.; Xu, Z.; Xi, X.; Liu, R.; Liu, 5050 P.; Su, Y. Perylene diimide-diamine/carbon black composites as high 5051 performance lithium/sodium ion battery cathodes. J. Mater. Chem. A 5052 2018, 6, 13613-13618.

5053 (341) Zhang, Y.; Huang, Y.; Yang, G.; Bu, F.; Li, K.; Shakir, I.; Xu, Y. 5054 Dispersion-Assembly Approach to Synthesize Three-Dimensional 5055 Graphene/Polymer Composite Aerogel as a Powerful Organic 5056 Cathode for Rechargeable Li and Na Batteries. ACS Appl. Mater. 5057 Interfaces 2017, 9, 15549-15556.

5058 (342) Tang, W.; Liang, R.; Li, D.; Yu, Q.; Hu, J.; Cao, B.; Fan, C. 5059 Highly Stable and High Rate-Performance Na-Ion Batteries Using 5060 Polyanionic Anthraquinone as the Organic Cathode. ChemSusChem $50612019,12,2181-2185$.

5062 (343) Li, Z.; Zhou, J.; Xu, R.; Liu, S.; Wang, Y.; Li, P.; Wu, W.; Wu, $5063 \mathrm{M}$. Synthesis of three dimensional extended conjugated polyimide and 5064 application as sodium-ion battery anode. Chem. Eng. J. 2016, 287, $5065516-522$.

5066 (344) Li, H.; Tang, M.; Wu, Y.; Chen, Y.; Zhu, S.; Wang, B.; Jiang, 5067 C.; Wang, E.; Wang, C. Large $\pi$-Conjugated Porous Frameworks as 5068 Cathodes for Sodium-Ion Batteries. J. Phys. Chem. Lett. 2018, 9, $50693205-3211$.

5070 (345) Xu, Y.-S.; Duan, S.-Y.; Sun, Y.-G.; Bin, D.-S.; Tao, X.-S.; 5071 Zhang, D.; Liu, Y.; Cao, A.-M.; Wan, L.-J. Recent developments in 5072 electrode materials for potassium-ion batteries. J. Mater. Chem. A $50732019,7,4334-4352$.

5074 (346) Lei, K.; Li, F.; Mu, C.; Wang, J.; Zhao, Q.; Chen, C.; Chen, J. 5075 High K-storage performance based on the synergy of dipotassium 5076 terephthalate and ether-based electrolytes. Energy Environ. Sci. 2017, 5077 10, 552-557.

5078 (347) Tang, M.; Wu, Y.; Chen, Y.; Jiang, C.; Zhu, S.; Zhuo, S.; 5079 Wang, C. An organic cathode with high capacities for fast-charge 5080 potassium-ion batteries. J. Mater. Chem. A 2019, 7, 486-492.

5081 (348) Zhao, Q.; Wang, J.; Lu, Y.; Li, Y.; Liang, G.; Chen, J. 5082 Oxocarbon Salts for Fast Rechargeable Batteries. Angew. Chem., Int. 5083 Ed. 2016, 55, 12528-12532.

5084 (349) Li, C.; Xue, J.; Huang, A.; Ma, J.; Qing, F.; Zhou, A.; Wang, 5085 Z.; Wang, Y.; Li, J. Poly(N-vinylcarbazole) as an advanced organic 5086 cathode for potassium-ion-based dual-ion battery. Electrochim. Acta $50872019,297,850-855$.

5088 (350) Gao, H.; Xue, L.; Xin, S.; Goodenough, J. B. A High-Energy5089 Density Potassium Battery with a Polymer-Gel Electrolyte and a 5090 Polyaniline Cathode. Angew. Chem., Int. Ed. 2018, 57, 5449-5453.

5091 (351) Wang, C.; Tang, W.; Yao, Z.; Cao, B.; Fan, C. Potassium 5092 perylene-tetracarboxylate with two-electron redox behaviors as a 5093 highly stable organic anode for K-ion batteries. Chem. Commun. 2019, 5094 55, 1801-1804.

5095 (352) Li, C.; Deng, Q.; Tan, H.; Wang, C.; Fan, C.; Pei, J.; Cao, B.; 5096 Wang, Z.; Li, J. Para-Conjugated Dicarboxylates with Extended 5097 Aromatic Skeletons as the Highly Advanced Organic Anodes for K5098 Ion Battery. ACS Appl. Mater. Interfaces 2017, 9, 27414-27420.

5099 (353) Liang, Y.; Luo, C.; Wang, F.; Hou, S.; Liou, S.-C.; Qing, T.; Li, 5100 Q.; Zheng, J.; Cui, C.; Wang, C. An Organic Anode for High 5101 Temperature Potassium-Ion Batteries. Adv. Energy Mater. 2019, 9, 51021802986.

5103 (354) Fan, L.; Ma, R.; Wang, J.; Yang, H.; Lu, B. An Ultrafast and 5104 Highly Stable Potassium-Organic Battery. Adv. Mater. 2018, 30, 51051805486.

5106 (355) Chen, L.; Liu, S.; Wang, Y.; Liu, W.; Dong, Y.; Kuang, Q.; 5107 Zhao, Y. Ortho-di-sodium salts of tetrahydroxyquinone as a novel 5108 electrode for lithium-ion and potassium-ion batteries. Electrochim. 5109 Acta 2019, 294, 46-52.
(356) Tian, B.; Zheng, J.; Zhao, C.; Liu, C.; Su, C.; Tang, W.; Li, X.; 5110 Ning, G.-H. Carbonyl-based polyimide and polyquinoneimide for 5111 potassium-ion batteries. J. Mater. Chem. A 2019, 7, 9997-10003. 5112

(357) Canepa, P.; Sai Gautam, G.; Hannah, D. C.; Malik, R.; Liu, 5113 M.; Gallagher, K. G.; Persson, K. A.; Ceder, G. Odyssey of 5114 Multivalent Cathode Materials: Open Questions and Future 5115 Challenges. Chem. Rev. 2017, 117, 4287-4341.

(358) Ponrouch, A.; Bitenc, J.; Dominko, R.; Lindahl, N.; Johansson, 5117 P.; Palacin, M. R. Multivalent rechargeable batteries. Energy Storage 5118 Mater. 2019, 20, 253-262.

5119

(359) Aurbach, D.; Lu, Z.; Schechter, A.; Gofer, Y.; Gizbar, H.; 5120 Turgeman, R.; Cohen, Y.; Moshkovich, M.; Levi, E. Prototype 5121 systems for rechargeable magnesium batteries. Nature 2000, 407, 5122 $724-727$.

5123

(360) Liao, C.; Guo, B.; Jiang, D.; Custelcean, R.; Mahurin, S. M.; 5124 Sun, X.-G.; Dai, S. Highly soluble alkoxide magnesium salts for 5125 rechargeable magnesium batteries. J. Mater. Chem. A 2014, 2, 581- 5126 584.

5127

(361) Sun, X.; Bonnick, P.; Duffort, V.; Liu, M.; Rong, Z.; Persson, 5128 K. A.; Ceder, G.; Nazar, L. F. A high capacity thiospinel cathode for 5129 Mg batteries. Energy Environ. Sci. 2016, 9, 2273-2277.

5130

(362) Du, A.; Zhang, Z.; Qu, H.; Cui, Z.; Qiao, L.; Wang, L.; Chai, 5131 J.; Lu, T.; Dong, S.; Dong, T.; et al. An efficient organic magnesium 5132 borate-based electrolyte with non-nucleophilic characteristics for 5133 magnesium-sulfur battery. Energy Environ. Sci. 2017, 10, 2616-2625. 5134

(363) McAllister, B. T.; Kyne, L. T.; Schon, T. B.; Seferos, D. S. 5135 Potential for Disruption with Organic Magnesium-Ion Batteries. Joule 5136 2019, 3, 620-624.

5137

(364) Attias, R.; Salama, M.; Hirsch, B.; Gofer, Y.; Aurbach, D. 5138 Solvent Effects on the Reversible Intercalation of Magnesium-Ions 5139 into $\mathrm{V}_{2} \mathrm{O}_{5}$ Electrodes. ChemElectroChem 2018, 5, 3514-3524. 5140

(365) Salama, M.; Shterenberg, I.; Gizbar, H.; Eliaz, N. N.; Kosa, M.; 5141 Keinan-Adamsky, K.; Afri, M.; Shimon, L. J. W.; Gottlieb, H. E.; 5142 Major, D. T.; et al. Unique Behavior of Dimethoxyethane (DME)/ 5143 $\mathrm{Mg}\left(\mathrm{N}\left(\mathrm{SO}_{2} \mathrm{CF}_{3}\right)_{2}\right)_{2}$ Solutions. J. Phys. Chem. C 2016, 120, 19586- 5144 19594.

(366) Dong, H.; Liang, Y.; Tutusaus, O.; Mohtadi, R.; Zhang, Y.; 5146 Hao, F.; Yao, Y. Directing Mg-Storage Chemistry in Organic 5147 Polymers toward High-Energy Mg Batteries. Joule 2019, 3, 782-793. 5148

(367) Ju, Q.; Shi, Y.; Kan, J. Performance study of magnesium- 5149 polyaniline rechargeable battery in 1-ethyl-3-methylimidazolium ethyl 5150 sulfate electrolyte. Synth. Met. 2013, 178, 27-33.

$$
5151
$$

(368) Lu, D.; Liu, H.; Huang, T.; Xu, Z.; Ma, L.; Yang, P.; Qiang, P.; 5152 Zhang, F.; Wu, D. Magnesium ion based organic secondary batteries. 5153 J. Mater. Chem. A 2018, 6, 17297-17302.

5154

(369) Ha, S.-Y.; Lee, Y.-W.; Woo, S. W.; Koo, B.; Kim, J.-S.; Cho, J.; 5155 Lee, K. T.; Choi, N.-S. Magnesium(II) Bis(trifluoromethane sulfonyl) 5156 Imide-Based Electrolytes with Wide Electrochemical Windows for 5157 Rechargeable Magnesium Batteries. ACS Appl. Mater. Interfaces 2014, 5158 6, 4063-4073.

(370) Pan, B.; Zhou, D.; Huang, J.; Zhang, L.; Burrell, A. K.; 5160 Vaughey, J. T.; Zhang, Z.; Liao, C. 2,5-Dimethoxy-1,4-Benzoquinone 5161 (DMBQ) as Organic Cathode for Rechargeable Magnesium-Ion 5162 Batteries. J. Electrochem. Soc. 2016, 163, A580-A583. 5163

(371) Bitenc, J.; Pirnat, K.; Mali, G.; Novosel, B.; Randon Vitanova, 5164 A.; Dominko, R. Poly(hydroquinoyl-benzoquinonyl sulfide) as an 5165 active material in $\mathrm{Mg}$ and $\mathrm{Li}$ organic batteries. Electrochem. Commun. 5166 2016, 69, 1-5.

(372) Bitenc, J.; Pirnat, K.; Bančič, T.; Gaberšček, M.; Genorio, B.; 5168 Randon-Vitanova, A.; Dominko, R. Anthraquinone-Based Polymer as 5169 Cathode in Rechargeable Magnesium Batteries. ChemSusChem 2015, 5170 $8,4128-4132$.

(373) NuLi, Y.; Chen, Q.; Wang, W.; Wang, Y.; Yang, J.; Wang, J. 5172 Carbyne Polysulfide as a Novel Cathode Material for Rechargeable 5173 Magnesium Batteries. Sci. World J. 2014, 2014, 1-7.

(374) Sano, H.; Senoh, H.; Yao, M.; Sakaebe, H.; Kiyobayashi, T. 5175 $\mathrm{Mg} 2+$ Storage in Organic Positive-electrode Active Material Based on 5176 2,5-Dimethoxy-1,4-benzoquinone. Chem. Lett. 2012, 41, 1594-1596. 5177 
5178 (375) Hudak, N. S. Chloroaluminate-Doped Conducting Polymers 5179 as Positive Electrodes in Rechargeable Aluminum Batteries. J. Phys. 5180 Chem. C 2014, 118, 5203-5215.

5181 (376) Guerfi, A.; Trottier, J.; Boyano, I.; De Meatza, I.; Blazquez, J. 5182 A.; Brewer, S.; Ryder, K. S.; Vijh, A.; Zaghib, K. High cycling stability 5183 of zinc-anode/conducting polymer rechargeable battery with non5184 aqueous electrolyte. J. Power Sources 2014, 248, 1099-1104.

5185 (377) Walter, M.; Kravchyk, K. V.; Böfer, C.; Widmer, R.; 5186 Kovalenko, M. V. Polypyrenes as High-Performance Cathode 5187 Materials for Aluminum Batteries. Adv. Mater. 2018, 30, 1705644.

5188 (378) Lin, M.-C.; Gong, M.; Lu, B.; Wu, Y.; Wang, D.-Y.; Guan, M.; 5189 Angell, M.; Chen, C.; Yang, J.; Hwang, B.-J.; et al. An ultrafast 5190 rechargeable aluminium-ion battery. Nature 2015, 520, 324-328.

5191 (379) Yang, H.; Li, H.; Li, J.; Sun, Z.; He, K.; Cheng, H.-M.; Li, F. 5192 The Rechargeable Aluminum Battery: Opportunities and Challenges. 5193 Angew. Chem., Int. Ed. 2019, 58, 11978

5194 (380) Kim, D. J.; Yoo, D.-J.; Otley, M. T.; Prokofjevs, A.; Pezzato, 5195 C.; Owczarek, M.; Lee, S. J.; Choi, J. W.; Stoddart, J. F. Rechargeable 5196 aluminium organic batteries. Nat. Energy 2019, 4, 51-59.

5197 (381) Han, X.; Qing, G.; Sun, J.; Sun, T. How Many Lithium Ions 5198 Can Be Inserted onto Fused C6 Aromatic Ring Systems? Angew. 5199 Chem., Int. Ed. 2012, 51, 5147-5151.

5200 (382) Luo, W.; Allen, M.; Raju, V.; Ji, X. An Organic Pigment as a 5201 High-Performance Cathode for Sodium-Ion Batteries. Adv. Energy 5202 Mater. 2014, 4, 1400554.

5203 (383) Chen, Y.; Luo, W.; Carter, M.; Zhou, L.; Dai, J.; Fu, K.; Lacey, 5204 S.; Li, T.; Wan, J.; Han, X.; et al. Organic electrode for non-aqueous 5205 potassium-ion batteries. Nano Energy 2015, 18, 205-211.

5206 (384) Wang, Y.; Deng, Y.; Qu, Q.; Zheng, X.; Zhang, J.; Liu, G.; 5207 Battaglia, V. S.; Zheng, H. Ultrahigh-Capacity Organic Anode with 5208 High-Rate Capability and Long Cycle Life for Lithium-Ion Batteries. 5209 ACS Energy Lett. 2017, 2, 2140-2148.

5210 (385) Tian, N.; Gao, Y.; Li, Y.; Wang, Z.; Song, X.; Chen, L. $\mathrm{Li}_{2} \mathrm{C}_{2}$, a 5211 High-Capacity Cathode Material for Lithium Ion Batteries. Angew. 5212 Chem., Int. Ed. 2016, 55, 644-648.

5213 (386) Li, Y.; Song, X.; Tang, F.; Hou, C.; He, J.; Wang, H.; Liu, X. In 5214 situ study on the charge/discharge of nanocrystalline $\mathrm{Li}_{2} \mathrm{C}_{2}$ as a new 5215 cathode material. RSC Adv. 2016, 6, 54256-54262.

5216 (387) Kang, H.; Liu, H.; Li, C.; Sun, L.; Zhang, C.; Gao, H.; Yin, J.; 5217 Yang, B.; You, Y.; Jiang, K.-C.; et al. Polyanthraquinone-Triazine-A 5218 Promising Anode Material for High-Energy Lithium-Ion Batteries. 5219 ACS Appl. Mater. Interfaces 2018, 10, 37023-37030.

5220 (388) Schon, T. B.; An, S. Y.; Tilley, A. J.; Seferos, D. S. Unusual 5221 Capacity Increases with Cycling for Ladder-Type Microporous 5222 Polymers. ACS Appl. Mater. Interfaces 2019, 11, 1739-1747.

5223 (389) Wu, J.; Rui, X.; Wang, C.; Pei, W.-B.; Lau, R.; Yan, Q.; Zhang, 5224 Q. Nanostructured Conjugated Ladder Polymers for Stable and Fast 5225 Lithium Storage Anodes with High-Capacity. Adv. Energy Mater. 5226 2015, 5, 1402189.

5227 (390) Wu, J.; Rui, X.; Long, G.; Chen, W.; Yan, Q.; Zhang, Q. 5228 Pushing Up Lithium Storage through Nanostructured Polyazaacene 5229 Analogues as Anode. Angew. Chem., Int. Ed. 2015, 54, 7354-7358. 5230 (391) Li, W.; Dahn, J. R.; Wainwright, D. S. Rechargeable Lithium 5231 Batteries with Aqueous Electrolytes. Science 1994, 264, 1115-1118. 5232 (392) Alt, H.; Binder, H.; Klempert, G.; Köhling, A.; Sandstede, G. 5233 Evaluation of organic battery electrodes: Voltammetric study of the 5234 redox behaviour of solid quinones. J. Appl. Electrochem. 1972, 2, 1935235200.

5236 (393) Sun, D.; Tang, Y.; He, K.; Ren, Y.; Liu, S.; Wang, H. Long5237 lived Aqueous Rechargeable Lithium Batteries Using Mesoporous $5238 \mathrm{LiTi}_{2}\left(\mathrm{PO}_{4}\right)_{3} @ \mathrm{C}$ Anode. Sci. Rep. 2015, 5, 17452.

5239 (394) Zhao, B.; Lin, B.; Zhang, S.; Deng, C. A frogspawn-inspired 5240 hierarchical porous $\mathrm{NaTi}_{2}\left(\mathrm{PO}_{4}\right)_{3}-\mathrm{C}$ array for high-rate and long-life 5241 aqueous rechargeable sodium batteries. Nanoscale 2015, 7, 18552524218560 .

5243 (395) Liang, Y.; Jing, Y.; Gheytani, S.; Lee, K.-Y.; Liu, P.; Facchetti, 5244 A.; Yao, Y. Universal quinone electrodes for long cycle life aqueous 5245 rechargeable batteries. Nat. Mater. 2017, 16, 841-848.
(396) Li, Z.; Young, D.; Xiang, K.; Carter, W. C.; Chiang, Y.-M. 5246 Towards High Power High Energy Aqueous Sodium-Ion Batteries: 5247 The $\mathrm{NaTi}_{2}\left(\mathrm{PO}_{4}\right)_{3} / \mathrm{Na}_{0.44} \mathrm{MnO}_{2}$ System. Adv. Energy Mater. 2013, 3, 5248 290-294.

5249

(397) Whitacre, J. F.; Shanbhag, S.; Mohamed, A.; Polonsky, A.; 5250 Carlisle, K.; Gulakowski, J.; Wu, W.; Smith, C.; Cooney, L.; 5251 Blackwood, D.; et al. A Polyionic, Large-Format Energy Storage 5252 Device Using an Aqueous Electrolyte and Thick-Format Composite 5253 $\mathrm{NaTi}_{2}\left(\mathrm{PO}_{4}\right)_{3} /$ Activated Carbon Negative Electrodes. Energy Technol. 5254 2015, 3, 20-31.

(398) Hatakeyama-Sato, K.; Wakamatsu, H.; Katagiri, R.; Oyaizu, 5256 K.; Nishide, H. An Ultrahigh Output Rechargeable Electrode of a 5257 Hydrophilic Radical Polymer/Nanocarbon Hybrid with an Excep- 5258 tionally Large Current Density beyond $1 \mathrm{~A} \mathrm{~cm}^{-2}$. Adv. Mater. 2018, 5259 30,1800900 .

5260

(399) Suo, L.; Borodin, O.; Gao, T.; Olguin, M.; Ho, J.; Fan, X.; 5261 Luo, C.; Wang, C.; Xu, K. Water-in-salt” electrolyte enables high- 5262 voltage aqueous lithium-ion chemistries. Science 2015, 350, 938-943. 5263

(400) Yamada, Y.; Usui, K.; Sodeyama, K.; Ko, S.; Tateyama, Y.; 5264 Yamada, A. Hydrate-melt electrolytes for high-energy-density aqueous 5265 batteries. Nat. Energy 2016, 1, 16129.

5266

(401) Yamada, Y.; Wang, J.; Ko, S.; Watanabe, E.; Yamada, A. 5267 Advances and issues in developing salt-concentrated battery electro- 5268 lytes. Nat. Energy 2019, DOI: 10.1038/s41560-019-0336-z 5269

(402) Yang, C.; Chen, J.; Qing, T.; Fan, X.; Sun, W.; von Cresce, A.; 5270 Ding, M. S.; Borodin, O.; Vatamanu, J.; Schroeder, M. A.; et al. 4.0 V 5271 Aqueous Li-Ion Batteries. Joule 2017, 1, 122-132. 5272

(403) Ko, S.; Yamada, Y.; Miyazaki, K.; Shimada, T.; Watanabe, E.; 5273 Tateyama, Y.; Kamiya, T.; Honda, T.; Akikusa, J.; Yamada, A. 5274 Lithium-salt monohydrate melt: A stable electrolyte for aqueous 5275 lithium-ion batteries. Electrochem. Commun. 2019, 104, 106488. 5276

(404) Qin, H.; Song, Z. P.; Zhan, H.; Zhou, Y. H. Aqueous 5277 rechargeable alkali-ion batteries with polyimide anode. J. Power 5278 Sources 2014, 249, 367-372.

(405) Viehbeck, A. Electrochemical Properties of Polyimides and 5280 Related Imide Compounds. J. Electrochem. Soc. 1990, 137, 1460.

(406) Dong, X.; Chen, L.; Liu, J.; Haller, S.; Wang, Y.; Xia, Y. 5282 Environmentally-friendly aqueous $\mathrm{Li}$ (or $\mathrm{Na}$ )-ion battery with fast 5283 electrode kinetics and super-long life. Sci. Adv. 2016, 2, e1501038. 5284

(407) Fernández-Ropero, A. J.; Saurel, D.; Acebedo, B.; Rojo, T.; 5285 Casas-Cabanas, M. Electrochemical characterization of $\mathrm{NaFePO}_{4}$ as 5286 positive electrode in aqueous sodium-ion batteries. J. Power Sources 5287 2015, 291, 40-45.

(408) Pasta, M.; Wessells, C. D.; Liu, N.; Nelson, J.; McDowell, M. 5289 T.; Huggins, R. A.; Toney, M. F.; Cui, Y. Full open-framework 5290 batteries for stationary energy storage. Nat. Commun. 2014, 5, 3007. 5291

(409) Gao, H.; Goodenough, J. B. An Aqueous Symmetric Sodium- 5292 Ion Battery with NASICON-Structured $\mathrm{Na}_{3} \mathrm{MnTi}\left(\mathrm{PO}_{4}\right)_{3}$. Angew. 5293 Chem., Int. Ed. 2016, 55, 12768-12772.

5294

(410) Wang, Y.; Liu, J.; Lee, B.; Qiao, R.; Yang, Z.; Xu, S.; Yu, X.; 5295 $\mathrm{Gu}$, L.; Hu, Y.-S.; Yang, W.; et al. Ti-substituted tunnel-type 5296 $\mathrm{Na} 0.44 \mathrm{MnO} 2$ oxide as a negative electrode for aqueous sodium-ion 5297 batteries. Nat. Commun. 2015, 6, 6401.

(411) Jiang, L.; Lu, Y.; Zhao, C.; Liu, L.; Zhang, J.; Zhang, Q.; Shen, 5299 X.; Zhao, J.; Yu, X.; Li, H.; et al. Building aqueous K-ion batteries for 5300 energy storage. Nat. Energy 2019, 4, 495.

5301

(412) Zhao, Q.; Huang, W.; Luo, Z.; Liu, L.; Lu, Y.; Li, Y.; Li, L.; 5302 $\mathrm{Hu}, \mathrm{J}$.; Ma, H.; Chen, J. High-capacity aqueous zinc batteries using 5303 sustainable quinone electrodes. Sci. Adv. 2018, 4, eaao1761. 5304

(413) Chen, L.; Bao, J. L.; Dong, X.; Truhlar, D. G.; Wang, Y.; 5305 Wang, C.; Xia, Y. Aqueous Mg-Ion Battery Based on Polyimide 5306 Anode and Prussian Blue Cathode. ACS Energy Lett. 2017, 2, 1115- 5307 1121. 5308

(414) Wang, F.; Fan, X.; Gao, T.; Sun, W.; Ma, Z.; Yang, C.; Han, 5309 F.; Xu, K.; Wang, C. High-Voltage Aqueous Magnesium Ion Batteries. 5310 ACS Cent. Sci. 2017, 3, 1121-1128.

5311

(415) Gheytani, S.; Liang, Y.; Wu, F.; Jing, Y.; Dong, H.; Rao, K. K.; 5312 Chi, X.; Fang, F.; Yao, Y. An Aqueous Ca-Ion Battery. Adv. Sci. 2017, 5313 4, 1700465 . 
5315 (416) Wu, X.; Qi, Y.; Hong, J. J.; Li, Z.; Hernandez, A. S.; Ji, X. 5316 Rocking-Chair Ammonium-Ion Battery: A Highly Reversible Aqueous 5317 Energy Storage System. Angew. Chem., Int. Ed. 2017, 56, 13026531813030.

5319 (417) Poizot, P.; Dolhem, F.; Gaubicher, J. Progress in all-organic 5320 rechargeable batteries using cationic and anionic configurations: 5321 Toward low-cost and greener storage solutions? Curr. Opin. 5322 Electrochem. 2018, 9, 70-80.

5323 (418) Sano, N.; Tomita, W.; Hara, S.; Min, C.-M.; Lee, J.-S.; Oyaizu, 5324 K.; Nishide, H. Polyviologen Hydrogel with High-Rate Capability for 5325 Anodes toward an Aqueous Electrolyte-Type and Organic-Based 5326 Rechargeable Device. ACS Appl. Mater. Interfaces 2013, 5, 135553271361.

5328 (419) Chikushi, N.; Yamada, H.; Oyaizu, K.; Nishide, H. TEMPO5329 substituted polyacrylamide for an aqueous electrolyte-typed and 5330 organic-based rechargeable device. Sci. China: Chem. 2012, 55, 8225331829.

5332 (420) Dong, X.; Yu, H.; Ma, Y.; Bao, J. L.; Truhlar, D. G.; Wang, Y.; 5333 Xia, Y. All-Organic Rechargeable Battery with Reversibility Supported 5334 by "Water-in-Salt" Electrolyte. Chem. - Eur. J. 2017, 23, 2560-2565. 5335 (421) https://blue-storage.com/bollore-assets/uploads/2019/05/ 5336 presentation-bluesolutions.pdf and https://blue-storage.com/bollore5337 assets/uploads/2019/05/flyer-bluestorage.pdf, last accessed June 53382019.

5339 (422) Liu, W.; Lu, W.; Zhang, H.; Li, X. Aqueous Flow Batteries: 5340 Research and Development. Chem. - Eur. J. 2019, 25, 1649-1664.

5341 (423) Ye, R.; Henkensmeier, D.; Yoon, S. J.; Huang, Z.; Kim, D. K.; 5342 Chang, Z.; Kim, S.; Chen, R. Redox Flow Batteries for Energy 5343 Storage: A Technology Review. J. Electrochem. Energy Convers. Storage 5344 2018, 15, 010801 .

5345 (424) Xu, Q.; Ji, Y. N.; Qin, L. Y.; Leung, P. K.; Qiao, F.; Li, Y. S.; $5346 \mathrm{Su}, \mathrm{H}$. N. Evaluation of redox flow batteries goes beyond round-trip 5347 efficiency: A technical review. J. Energy Storage 2018, 16, 108-115. 5348 (425) Khor, A.; Leung, P.; Mohamed, M. R.; Flox, C.; Xu, Q.; An, 5349 L.; Wills, R. G. A.; Morante, J. R.; Shah, A. A. Review of zinc-based 5350 hybrid flow batteries: From fundamentals to applications. Mater. 5351 Today Energy 2018, 8, 80-108.

5352 (426) Duduta, M.; Ho, B.; Wood, V. C.; Limthongkul, P.; Brunini, 5353 V. E.; Carter, W. C.; Chiang, Y.-M. Semi-Solid Lithium Rechargeable 5354 Flow Battery. Adv. Energy Mater. 2011, 1, 511-516.

5355 (427) Wang, X.; Xing, X.; Huo, Y.; Zhao, Y.; Li, Y. A systematic 5356 study of the co-solvent effect for an all-organic redox flow battery. 5357 RSC Adv. 2018, 8, 24422-24427.

5358 (428) Ding, Y.; Zhang, C.; Zhang, L.; Wei, H.; Li, Y.; Yu, G. Insights 5359 into Hydrotropic Solubilization for Hybrid Ion Redox Flow Batteries. 5360 ACS Energy Lett. 2018, 3, 2641-2648.

5361 (429) Zhang, C.; Zhang, L.; Ding, Y.; Guo, X.; Yu, G. Eutectic 5362 Electrolytes for High-Energy-Density Redox Flow Batteries. ACS 5363 Energy Lett. 2018, 3, 2875-2883.

5364 (430) Gerhardt, M. R.; Tong, L.; Gómez-Bombarelli, R.; Chen, Q.; 5365 Marshak, M. P.; Galvin, C. J.; Aspuru-Guzik, A.; Gordon, R. G.; Aziz, 5366 M. J. Anthraquinone Derivatives in Aqueous Flow Batteries. Adv. 5367 Energy Mater. 2017, 7, 1601488.

5368 (431) Ji, Y.; Goulet, M.; Pollack, D. A.; Kwabi, D. G.; Jin, S.; 5369 Porcellinis, D.; Kerr, E. F.; Gordon, R. G.; Aziz, M. J. A Phosphonate5370 Functionalized Quinone Redox Flow Battery at Near-Neutral pH with 5371 Record Capacity Retention Rate. Adv. Energy Mater. 2019, 9, 53721900039.

5373 (432) Wang, C.; Yang, Z.; Wang, Y.; Zhao, P.; Yan, W.; Zhu, G.; Ma, 5374 L.; Yu, B.; Wang, L.; Li, G.; et al. High-Performance Alkaline Organic 5375 Redox Flow Batteries Based on 2-Hydroxy-3-carboxy-1,4-naphtho5376 quinone. ACS Energy Lett. 2018, 3, 2404-2409.

5377 (433) Beh, E. S.; De Porcellinis, D.; Gracia, R. L.; Xia, K. T.; 5378 Gordon, R. G.; Aziz, M. J. A Neutral pH Aqueous Organic5379 Organometallic Redox Flow Battery with Extremely High Capacity 5380 Retention. ACS Energy Lett. 2017, 2, 639-644.

5381 (434) Lin, K.; Chen, Q.; Gerhardt, M. R.; Tong, L.; Kim, S. B.; 5382 Eisenach, L.; Valle, A. W.; Hardee, D.; Gordon, R. G.; Aziz, M. J.; 5383 et al. Alkaline quinone flow battery. Science 2015, 349, 1529-1532.
(435) Hoober-Burkhardt, L.; Krishnamoorthy, S.; Yang, B.; Murali, 5384 A.; Nirmalchandar, A.; Prakash, G. K. S.; Narayanan, S. R. A New 5385 Michael-Reaction-Resistant Benzoquinone for Aqueous Organic 5386 Redox Flow Batteries. J. Electrochem. Soc. 2017, 164, A600-A607. 5387

(436) Carney, T. J.; Collins, S. J.; Moore, J. S.; Brushett, F. R. 5388 Concentration-Dependent Dimerization of Anthraquinone Disulfonic 5389 Acid and Its Impact on Charge Storage. Chem. Mater. 2017, 29, 5390 $4801-4810$

5391

(437) DeBruler, C.; Hu, B.; Moss, J.; Liu, X.; Luo, J.; Sun, Y.; Liu, T. 5392 L. Designer Two-Electron Storage Viologen Anolyte Materials for 5393 Neutral Aqueous Organic Redox Flow Batteries. Chem. 2017, 3, 961- 5394 978.

5395

(438) Orita, A.; Verde, M. G.; Sakai, M.; Meng, Y. S. The impact of 5396 $\mathrm{pH}$ on side reactions for aqueous redox flow batteries based on 5397 nitroxyl radical compounds. J. Power Sources 2016, 321, 126-134. 5398

(439) Wedege, K.; Dražević, E.; Konya, D.; Bentien, A. Organic 5399 Redox Species in Aqueous Flow Batteries: Redox Potentials, Chemical 5400 Stability and Solubility. Sci. Rep. 2016, 6, DOI: 10.1038/srep39101 5401

(440) Chen, Q.; Gerhardt, M. R.; Hartle, L.; Aziz, M. J. A Quinone- 5402 Bromide Flow Battery with $1 \mathrm{~W} / \mathrm{cm} 2$ Power Density. J. Electrochem. 5403 Soc. 2016, 163, A5010-A5013.

(441) Janoschka, T.; Martin, N.; Hager, M. D.; Schubert, U. S. An 5405 Aqueous Redox-Flow Battery with High Capacity and Power: The 5406 TEMPTMA/MV System. Angew. Chem., Int. Ed. 2016, 55, 14427- 5407 14430. 5408

(442) Janoschka, T.; Martin, N.; Martin, U.; Friebe, C.; 5409 Morgenstern, S.; Hiller, H.; Hager, M. D.; Schubert, U. S. An 5410 aqueous, polymer-based redox-flow battery using non-corrosive, safe, 5411 and low-cost materials. Nature 2015, 527, 78-81.

5412

(443) Luo, J.; Wu, W.; Debruler, C.; Hu, B.; Hu, M.; Liu, T. L. A 5413 $1.51 \mathrm{~V} \mathrm{pH}$ neutral redox flow battery towards scalable energy storage. 5414 J. Mater. Chem. A 2019, 7, 9130-9136.

5415

(444) Hu, B.; DeBruler, C.; Rhodes, Z.; Liu, T. L. Long-Cycling 5416 Aqueous Organic Redox Flow Battery (AORFB) toward Sustainable 5417 and Safe Energy Storage. J. Am. Chem. Soc. 2017, 139, 1207-1214. 5418

(445) Yang, B.; Hoober-Burkhardt, L.; Krishnamoorthy, S.; Murali, 5419 A.; Prakash, G. K. S.; Narayanan, S. R. High-Performance Aqueous 5420 Organic Flow Battery with Quinone-Based Redox Couples at Both 5421 Electrodes. J. Electrochem. Soc. 2016, 163, A1442-A1449. 5422

(446) Yang, B.; Hoober-Burkhardt, L.; Wang, F.; Surya Prakash, G. 5423 K.; Narayanan, S. R. An Inexpensive Aqueous Flow Battery for Large- 5424 Scale Electrical Energy Storage Based on Water-Soluble Organic 5425 Redox Couples. J. Electrochem. Soc. 2014, 161, A1371-A1380. 5426

(447) Wang, W.; Xu, W.; Cosimbescu, L.; Choi, D.; Li, L.; Yang, Z. 5427 Anthraquinone with tailored structure for a nonaqueous metal- 5428 organic redox flow battery. Chem. Commun. 2012, 48, 6669 . 5429

(448) Wei, X.; Xu, W.; Vijayakumar, M.; Cosimbescu, L.; Liu, T.; 5430 Sprenkle, V.; Wang, W. TEMPO-Based Catholyte for High-Energy 5431 Density Nonaqueous Redox Flow Batteries. Adv. Mater. 2014, 26, 5432 $7649-7653$

5433

(449) Wei, X.; Cosimbescu, L.; Xu, W.; Hu, J. Z.; Vijayakumar, M.; 5434 Feng, J.; Hu, M. Y.; Deng, X.; Xiao, J.; Liu, J.; et al. Towards High- 5435 Performance Nonaqueous Redox Flow Electrolyte Via Ionic 5436 Modification of Active Species. Adv. Energy Mater. 2015, 5, 1400678. 5437

(450) Chen, H.; Zhou, Y.; Lu, Y.-C. Lithium-Organic Nano- 5438 composite Suspension for High-Energy-Density Redox Flow Batteries. 5439 ACS Energy Lett. 2018, 3, 1991-1997.

(451) Huang, J.; Cheng, L.; Assary, R. S.; Wang, P.; Xue, Z.; Burrell, 5441 A. K.; Curtiss, L. A.; Zhang, L. Liquid Catholyte Molecules for 5442 Nonaqueous Redox Flow Batteries. Adv. Energy Mater. 2015, 5, 5443 1401782. 5444

(452) Wei, X.; Duan, W.; Huang, J.; Zhang, L.; Li, B.; Reed, D.; Xu, 5445 W.; Sprenkle, V.; Wang, W. A High-Current, Stable Nonaqueous 5446 Organic Redox Flow Battery. ACS Energy Lett. 2016, 1, 705-711. 5447

(453) Duan, W.; Huang, J.; Kowalski, J. A.; Shkrob, I. A.; 5448 Vijayakumar, M.; Walter, E.; Pan, B.; Yang, Z.; Milshtein, J. D.; Li, 5449 B.; et al. Wine-Dark Sea" in an Organic Flow Battery: Storing 5450 Negative Charge in 2,1,3-Benzothiadiazole Radicals Leads to 5451 Improved Cyclability. ACS Energy Lett. 2017, 2, 1156-1161. 5452 
5453 (454) Milshtein, J. D.; Kaur, A. P.; Casselman, M. D.; Kowalski, J. 5454 A.; Modekrutti, S.; Zhang, P. L.; Harsha Attanayake, N.; Elliott, C. F.; 5455 Parkin, S. R.; Risko, C.; et al. High current density, long duration 5456 cycling of soluble organic active species for non-aqueous redox flow 5457 batteries. Energy Environ. Sci. 2016, 9, 3531-3543.

5458 (455) Milton, M.; Cheng, Q.; Yang, Y.; Nuckolls, C.; Hernández 5459 Sánchez, R.; Sisto, T. J. Molecular Materials for Nonaqueous Flow 5460 Batteries with a High Coulombic Efficiency and Stable Cycling. Nano 5461 Lett. 2017, 17, 7859-7863.

5462 (456) Zhang, J.; Huang, J.; Robertson, L. A.; Shkrob, I. A.; Zhang, L. 5463 Comparing calendar and cycle life stability of redox active organic 5464 molecules for nonaqueous redox flow batteries. J. Power Sources 2018, $5465397,214-222$.

5466 (457) Goulet, M.-A.; Tong, L.; Pollack, D. A.; Tabor, D. P.; Odom, 5467 S. A.; Aspuru-Guzik, A.; Kwan, E. E.; Gordon, R. G.; Aziz, M. J. 5468 Extending the Lifetime of Organic Flow Batteries via Redox State 5469 Management. J. Am. Chem. Soc. 2019, DOI: 10.1021/jacs.8b13295

5470 (458) Fongy, C.; Gaillot, A.-C.; Jouanneau, S.; Guyomard, D.; 5471 Lestriez, B. Ionic vs Electronic Power Limitations and Analysis of the 5472 Fraction of Wired Grains in $\mathrm{LiFePO}_{4}$ Composite Electrodes. J. 5473 Electrochem. Soc. 2010, 157, A885.

5474 (459) Lestriez, B.; Bahri, S.; Sandu, I.; Roue, L.; Guyomard, D. On 5475 the binding mechanism of CMC in Si negative electrodes for Li-ion 5476 batteries. Electrochem. Commun. 2007, 9, 2801-2806.

5477 (460) Guy, D.; Lestriez, B.; Bouchet, R.; Guyomard, D. Critical Role 5478 of Polymeric Binders on the Electronic Transport Properties of 5479 Composites Electrode. J. Electrochem. Soc. 2006, 153, A679.

5480 (461) Wang, Y.; Xia, Y. Hybrid Aqueous Energy Storage Cells Using 5481 Activated Carbon and Lithium-Intercalated Compounds. J. Electro5482 chem. Soc. 2006, 153, A450.

5483 (462) Park, K.-S.; Schougaard, S. B.; Goodenough, J. B. Conducting5484 Polymer/Iron-Redox- Couple Composite Cathodes for Lithium 5485 Secondary Batteries. Adv. Mater. 2007, 19, 848-851.

5486 (463) Huang, Y.-H.; Goodenough, J. B. High-Rate $\mathrm{LiFePO}_{4}$ Lithium 5487 Rechargeable Battery Promoted by Electrochemically Active Poly5488 mers. Chem. Mater. 2008, 20, 7237-7241.

5489 (464) Wang, Q.; Evans, N.; Zakeeruddin, S. M.; Exnar, I.; Grätzel, 5490 M. Molecular Wiring of Insulators: Charging and Discharging 5491 Electrode Materials for High-Energy Lithium-Ion Batteries by 5492 Molecular Charge Transport Layers. J. Am. Chem. Soc. 2007, 129, 5493 3163-3167.

5494 (465) Hatakeyama-Sato, K.; Masui, T.; Serikawa, T.; Sasaki, Y.; 5495 Choi, W.; Doo, S.-G.; Nishide, H.; Oyaizu, K. Nonconjugated Redox5496 Active Polymer Mediators for Rapid Electrocatalytic Charging of 5497 Lithium Metal Oxides. ACS Appl. Energy Mater. 2019, 2, 6375-6382. 5498 (466) Lepage, D.; Michot, C.; Liang, G.; Gauthier, M.; Schougaard, 5499 S. A Soft Chemistry Approach to Coating of $\mathrm{LiFePO}_{4}$ with a 5500 Conducting Polymer. Angew. Chem. Int. Ed. 2011, 123, 70167019.

5501 (467) Yassin, Y.; Jiménez, P.; Lestriez, B.; Moreau, P.; Leriche, P.; 5502 Roncali, J.; Blanchard, P.; Terrisse, H.; Guyomard, D.; Gaubicher, J. 5503 Engineered Electronic Contacts for Composite Electrodes in $\mathrm{Li}$ 5504 Batteries Using Thiophene-based Molecular Junctions. Chem. Mater. 5505 2015, 27, 40574065. 